\title{
CULTIVO DA RÚCULA E DO RABANETE SOB TÚNEIS BAIXOS COBERTOS COM PLÁSTICO COM DIFERENTES NÍVEIS DE PERFURAÇÃO
}

\section{EDILAINE REGINA PEREIRA}

\author{
Dissertação apresentada à Escola Superior \\ de Agricultura "Luiz de Queiroz", \\ Universidade de São Paulo, para \\ obtenção do título de Mestre em \\ Agronomia. Área de concentração: \\ Irrigação e Drenagem
}

\author{
PIRACICABA \\ Estado de São Paulo - Brasil \\ Fevereiro - 2002
}




\title{
CULTIVO DA RÚCULA E DO RABANETE SOB TÚNEIS BAIXOS COBERTOS COM PLÁSTICO COM DIFERENTES NÍVEIS DE PERFURAÇÃO
}

\section{EDILAINE REGINA PEREIRA}

Engenheira Agrícola

Orientador: Prof. Dr. Iran José Oliveira da Silva

\author{
Dissertação apresentada à Escola Superior \\ de Agricultura "Luiz de Queiroz" , \\ Universidade de São Paulo, para \\ obtenção do título de Mestre em \\ Agronomia. Área de concentração: \\ Irrigação e Drenagem
}

\section{PIRACICABA}

Estado de São Paulo - Brasil

Fevereiro - 2002 


\section{Dados Internacionais de Catalogação na Publicação (CIP) DIVSÃO DE BIBLIOTECA E DOCUMENTAÇÃO - ESALQ/USP}

\section{Pereira, Edila ine Regina}

Cultivo da rúcula e do rabanete sob túneis baixos cobertos com plástico com diferentes níveis de perfuração / Edila ine Regina Pereira. - -

Piracicaba, 2002.

113 p. : il.

Dissertação (mestra do) - - Escola Superior de Agricultura Luiz de Queiroz, 2002

Bibliografia.

1. Estufas 2. Interação biosfera-atmosfera 3. Plasticultura 4. Rabanete 5. Rúcula I. Título

CDD 635.5

"Permitida a cópia total ou parcial deste documento, desde que citada a fonte - O autor" 
Aos meus pais, Pedro Luiz e Nadir, exemplos

de vida e luta, cujo amor e dedicação eleva-me

a cada instante.

\section{MINHA HOMENAGEM}

Ao meu tio Marcos que nos deixou tão cedo e que sempre foi exemplo de caráter $e$ humildade:

Aos meus avós Pedro e Durvalina que sempre estiveram presentes em minha vida; Aos meus sobrinhos Marina e Marcelo.

À minha irmã Elaine OFEREÇO E DEDICO 


\section{AGRADECIMENTOS}

À Deus, que me iluminou e me deu forças nos momentos em que mais precisei para vencer os obstáculos surgidos durante o percurso.

Aos amigos do Núcleo de Pesquisa em Ambiência - NUPEA, que tanto me auxiliaram no desenvolvimento deste trabalho.

Ao Departamento de Engenharia Rural da Escola Superior de Agricultura "Luiz de Queiroz”, pela oportunidade oferecida.

Ao Prof. Dr. Iran José Oliveira da Silva, pela orientação e estímulo no desenvolvimento deste trabalho.

À Prof a Sonia Maria Piedade e ao amigo José Luis Martins, pelo auxílio na definição e execução das análises estatísticas.

Aos professores Paulo Cesar Sentelhas, Rubens Duarte Coelho e João Tessarioli Neto, pelas sugestões para a melhoria e engrandecimento deste trabalho.

Aos amigos adquiridos no decorrer deste período, pelo companheirismo divididos nos momentos difíceis e também nos momentos de alegria.

Aos funcionários do Departamento de Engenharia Rural da ESALQ/USP, pela colaboração e serviços prestados, em especial ao Sr. Antonio que tanto me auxiliou na instalação e execução do experimento em campo.

À Fundação de Amparo à Pesquisa - FAPESP, pelo financiamento para a realização desta pesquisa.

A todos àqueles que, de uma forma ou de outra, contribuíram para a realização deste trabalho. 


\section{SUMÁRIO}

LISTA DE FIGURAS

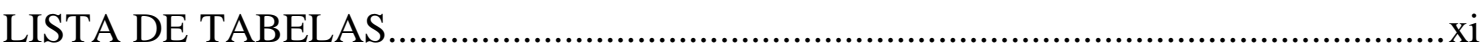

LISTA DE APÊNDICES............................................................................

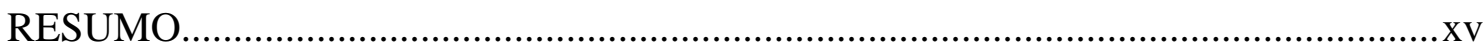

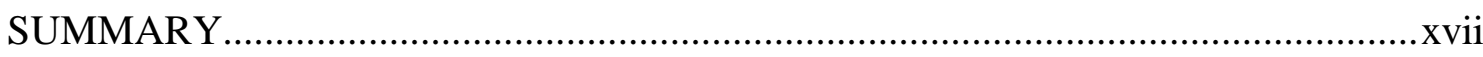

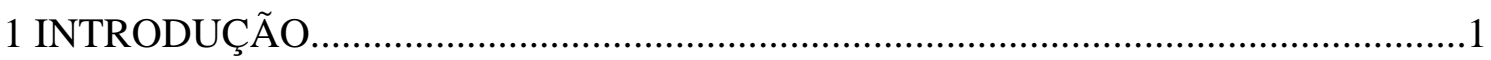

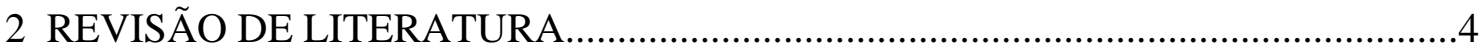

2.1 Influência dos elementos meteorológicos em cultivo protegido................................4

2.2 Ventilação Natural em estufas............................................................................

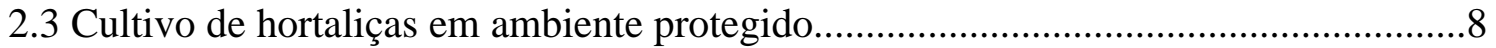

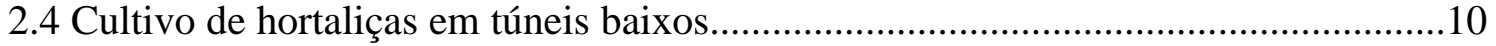

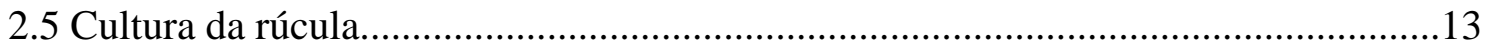

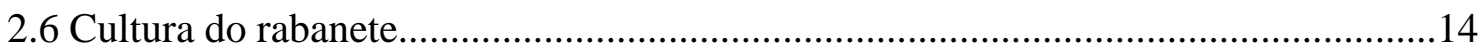

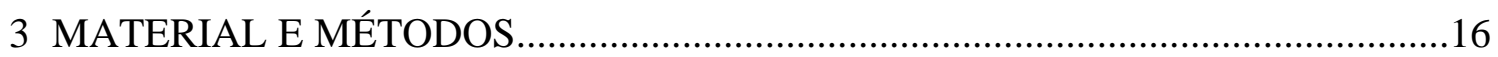

3.1 Localização e caracterização da área experimental..................................................16

3.2 Descrição da instalação do experimento.........................................................17

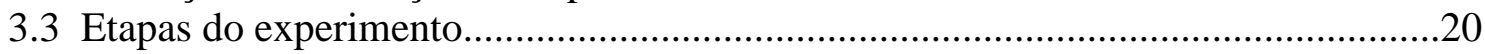

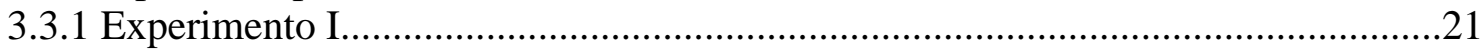

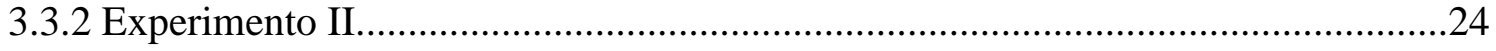

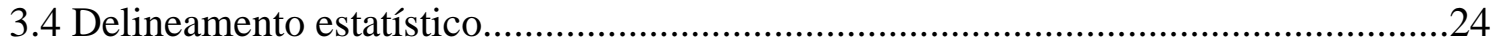

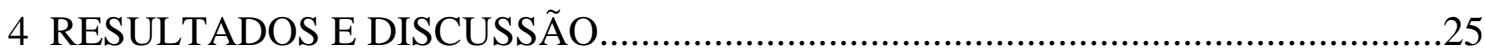

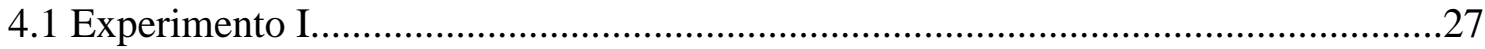

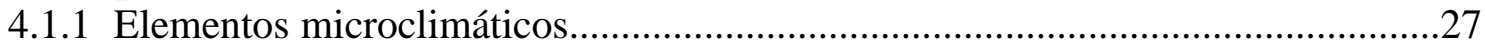

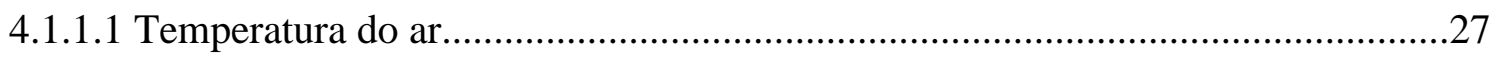

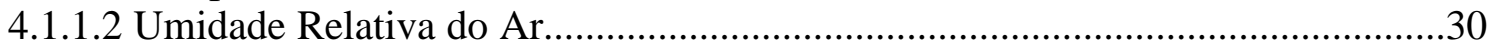

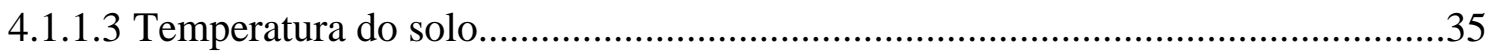

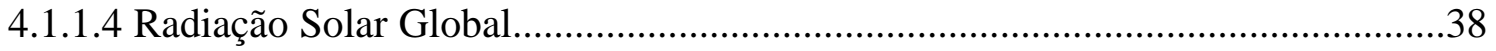

4.1.2 Avaliação do desenvolvimento das plantas..........................................................40

4.1.2.1 Massa seca (MS) e Massa verde (MV) em época de verão....................................40

4.1.2.2 Massa seca (MS) e Massa verde (MV) em época de outono...............................42 


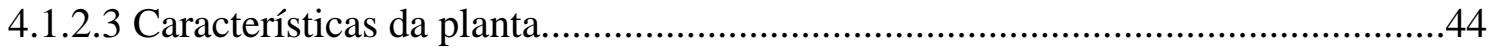

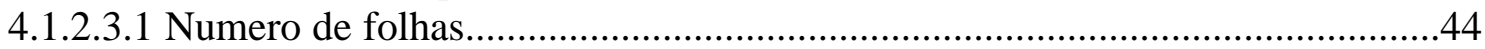

4.1.2.3.2 Tamanho, peso e largura das folhas......................................................45

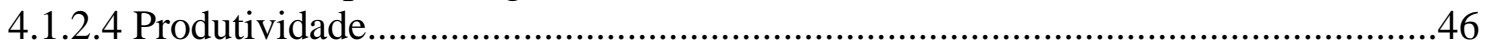

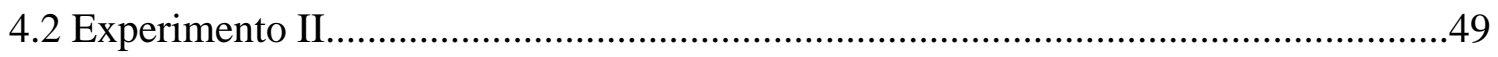

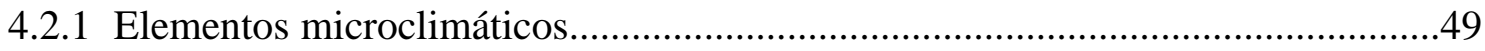

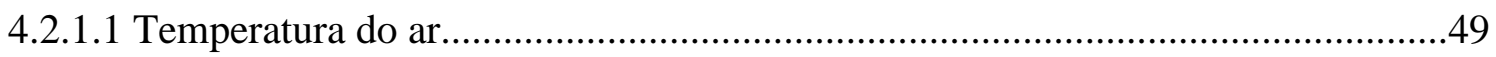

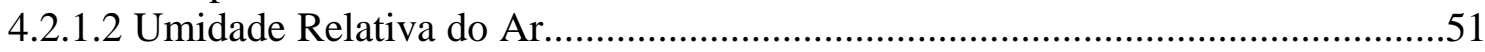

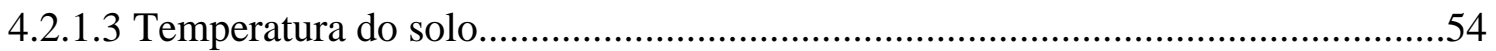

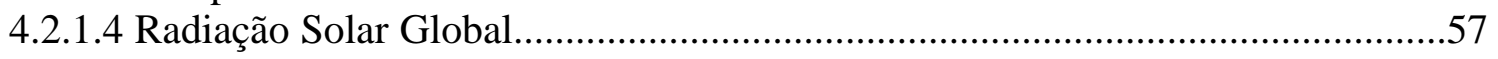

4.2.2 Avaliação do desenvolvimento das plantas.....................................................60

4.2.2.1 Massa seca (MS) e Massa verde (MV) em época de inverno.............................60

4.2.2.2 Massa seca (MS) e Massa verde (MV) em época de primavera.........................62

4.2.2.3 Características do tubérculo........................................................................64

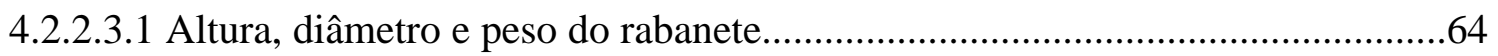

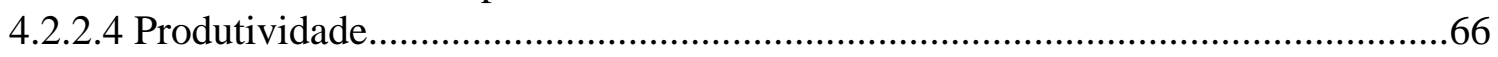

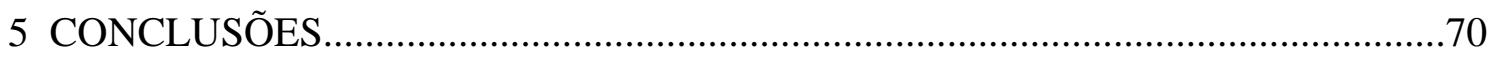

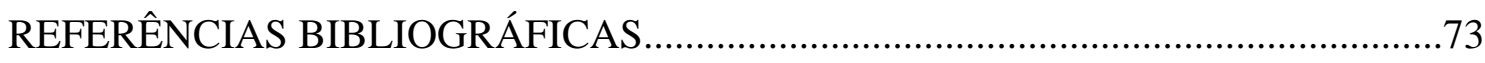

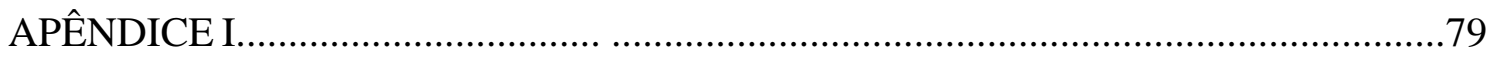

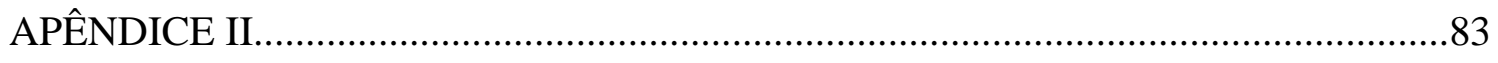

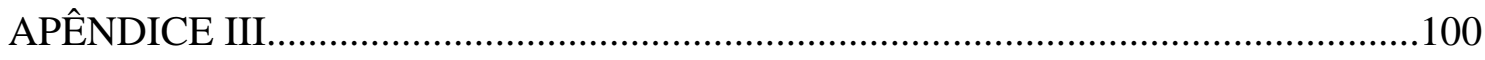

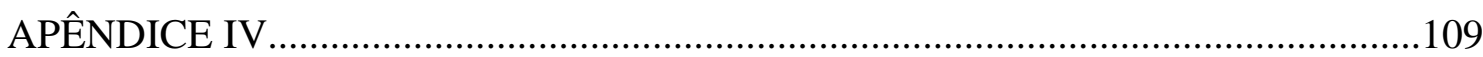




\section{LISTA DE FIGURAS}

Página

1 Vista geral da área experimental, no NUPEA/DER/ESALQ/USP, em Piracicaba, SP

2 Densidade de perfuração avaliada na cobertura plástica utilizada no presente trabalho, na área experimental do NUPEA/DER/ESALQ/USP, em Piracicaba, SP

3 Sistema de irrigação por gotejamento utilizado no presente trabalho, na área experimental do NUPEA/DER/ESALQ/USP, em Piracicaba, SP.

4 Instrumento utilizado (vazador) para perfurar o filme plástico, utilizado como cobertura nos túneis baixos

5 Sistema de aquisição de dados instalado na área experimental do NUPEA/DER/ESALQ/USP, a partir da fase II.........................................22

6 Temperatura média diária do ar no período de coleta de dados de verão, de 30/01/01 a 06/03/01, em Piracicaba, SP. .25

7 Temperatura média diária do ar no período de coleta de dados de outono, de 17/04/01 a 17/05/01, em Piracicaba, SP.

8 Temperatura média horária do ar no período de coleta de dados de verão, de 30/01/01 a 06/03/01, em Piracicaba, SP. 
9 Temperatura média horária do ar no período de coleta de dados

de outono, de 17/04/01 a 17/05/01, em Piracicaba, SP.

10 Umidade relativa média diária do ar no período de coleta de dados de verão, de 30/01/01 a 06/03/01, em Piracicaba, SP.

11 Umidade relativa média diária do ar no período de coleta de dados de outono, de 17/04/01 a 17/05/01, em Piracicaba, SP.

12 Umidade relativa média horária do ar no período de coleta de dados de verão, de 30/01/01 a 06/03/01, em Piracicaba, SP.

13 Umidade relativa do ar média horária no período de coleta de dados de outono, de 17/04/01 a 17/05/01, em Piracicaba, SP.

14 Temperatura do solo média horária no período de coleta de dados de outono, de 17/04/01 a 17/05/01, em Piracicaba, SP

15 Temperatura do solo média diária no período de coleta de dados de outono, de 17/04/01 a 17/05/01, em Piracicaba, SP.

16 Radiação solar global incidente média horária no período de coleta de dados de outono, de 17/04/01 a 17/05/01, em Piracicaba, SP.

17 Produção de massa seca média por planta de rúcula no período de coleta de dados de verão, de 30/01/01 a 06/03/01 em Piracicaba, SP

18 Produção de massa verde média por planta de rúcula no período de coleta de dados de verão, de 30/01/01 a 06/03/01 em Piracicaba, SP........42

19 Produção de massa seca média por planta de rúcula no período de coleta de dados de outono, de 17/04/01 a 17/05/01, em Piracicaba, SP.... 43

20 Produção de massa verde média por planta no período de coleta de dados de verão, de 30/01/01 a 06/03/01, em Piracicaba, SP.......43

21 Produtividade relativa (\%) obtidos no final do ciclo da cultura de rúcula em época de verão, de 30/01/01 a 06/03/01,em Piracicaba, SP 
22 Produtividade relativa (\%) obtidos no final do ciclo da cultura de rúcula em época de outono, de 17/04/01 a 17/05/01, em Piracicaba, SP. .48

23 Temperatura média horária do ar no período de coleta de dados de inverno, de 22/08/01 a 05/09/01, em Piracicaba, SP.

24 Temperatura média horária do ar no período de coleta de dados de primavera, de 22/11/01 a 03/12/01, em Piracicaba, SP.............................50

25 Umidade relativa média horária do ar no período de coleta de dados de inverno, de 22/08/01 a 05/09/01, em Piracicaba, SP

26 Umidade relativa média horária do ar no período de coleta de dados de primavera, de 22/11/01 a 03/12/01, em Piracicaba, SP.

27 Temperatura do solo média horária no período de coleta de dados de inverno, de 22/08/01 a 05/09/01, em Piracicaba, SP .55

28 Temperatura do solo média diária no período de coleta de dados de primavera, de 22/11/01 a 03/12/01, em Piracicaba, SP. .55

29 Radiação solar global média horária no período de coleta de dados de inverno, de 22/08/01 a 05/09/01, em Piracicaba, SP .58

30 Radiação solar global média horária no período de coleta de dados de primavera, de 22/11/01 a 03/12/01, em Piracicaba, SP. .58

31 Produção de massa seca média por planta de rabanete no período de coleta de dados de inverno, de 22/08/01 a 05/09/01, em Piracicaba, SP....60

32 Produção de massa verde média por planta de rabanete no período de coleta de dados de inverno, de 22/08/01 a 05/09/01, em Piracicaba, SP... 61

33 Produção de massa seca média por planta de rabanete no período de coleta de dados de primavera, de 22/11/01 a 03/12/01, em Piracicaba, SP .62

34 Produção de massa verde média por planta de rabanete no período de coleta de dados de primavera, de 22/11/01 a 03/12/01, em Piracicaba, SP. 
35 Produtividade relativa (\%) do rabanete no período de coleta de dados de inverno, de 22/08/01 a 05/09/01, em Piracicaba, SP .66

36 Produção final do rabanete no tratamento com túnel baixo a 5\% de perfuração, e no tratamento de cultivo a céu aberto, durante o inverno, em Piracicaba,SP. .67

37 Produtividade relativa (\%) do rabanete no período de coleta de dados de primavera, de 22/11/01 a 03/12/01, em Piracicaba, SP. .68

38 Produção final do rabanete no tratamento com túnel baixo a 15\% de perfuração, e no tratamento de cultivo a céu aberto, durante a primavera, em Piracicaba, SP 


\section{LISTA DE TABELAS}

Página

1 Resultados da análise química do solo no início do período experimental

2 Resultado do teste de Tukey para as médias horárias de temperatura do ar durante coleta de dados de verão, no intervalo das 11:00 às 15:00 horas, em Piracicaba, SP.

3 Resultado do teste de Tukey para as médias horárias de temperatura do ar durante coleta de dados de outono, no intervalo das 11:00 às 15:00 horas, em Piracicaba, SP.

$4 \quad$ Resultado do teste de Tukey para as médias horárias de umidade relativa do ar durante coleta de dados de verão, no intervalo das 11:00 às 15:00 horas, em Piracicaba, SP .34

5 Resultado do teste de Tukey para as médias horárias de umidade relativa do ar durante coleta de dados de outono, no intervalo das 11:00 às 15:00 horas, em Piracicaba, SP. .35

6 Resultado do teste de Tukey para as médias horárias de temperatura do solo a $10 \mathrm{~cm}$ de profundidade durante coleta de dados de outono, no intervalo das 11:00 às 15:00 horas, em Piracicaba, SP.

7 Resultado do teste de Tukey para as médias horárias de radiação solar global incidente durante coleta de dados de outono, no intervalo das 11:00 às 14:00 horas,em Piracicaba, SP. 
8 Resultado do teste de Tukey para as médias do número de folhas no final do ciclo da rúcula em época de verão e de outono, em Piracicaba, SP.....................45

9 Resultado do teste de Tukey para altura, largura e peso das folhas no final do ciclo da rúcula em época de verão, em Piracicaba, SP. 46

10 Valores de produtividade média $\left(\mathrm{g} / \mathrm{m}^{2}\right)$ e relativa $(\%)$ da rúcula obtidos no final do ciclo em época de verão e de outono, em Piracicaba, SP......47

11 Resultado do teste de Tukey para as médias horárias de temperatura do ar durante coleta de dados de inverno, no intervalo das 11:00 às 15:00 horas, em Piracicaba, SP

12 Resultado do teste de Tukey para as médias horárias de temperatura do ar durante coleta de dados de primavera, no intervalo das 11:00 às 15:00 horas, em Piracicaba, SP

13 Resultado do teste de Tukey para as médias horárias de umidade relativa do ar durante coleta de dados de inverno, no intervalo das 11:00 às 15:00 horas em Piracicaba, SP.

14 Resultado do teste de Tukey para as médias horárias de umidade relativa do ar durante coleta de dados de primavera, no intervalo das 11:00 às 15:00 horas em Piracicaba, SP.

15 Resultado do teste de Tukey para as médias horárias de temperatura do solo à $10 \mathrm{~cm}$ de profundidade, durante coleta de dados de inverno, no intervalo das 11:00 às 15:00 horas, em Piracicaba, SP 
16 Resultado do teste de Tukey para as médias horárias de temperatura do solo durante coleta de dados de primavera, no intervalo das 11:00 às 15:00 horas, em Piracicaba, SP

17 Resultado do teste de Tukey para as médias horárias de radiação solar durante coleta de dados de inverno, no intervalo das 11:00 às 15:00 horas, em Piracicaba, SP 59

18 Resultado do teste de Tukey para as médias horárias de radiação solar global durante coleta de dados de primavera, no intervalo das 11:00 às 15:00 horas em Piracicaba, SP.

19 Resultado do teste de Tukey para as médias de produção de massa seca e massa verde de rabanete durante a coleta de dados de inverno, em Piracicaba, SP 61

20 Resultado do teste de Tukey para as médias de produção de massa seca e massa verde de rabanete durante a coleta de dados de primavera, em Piracicaba, SP .64

21 Resultado do teste de Tukey para as médias de características do tubérculo quanto à altura, diâmetro e peso do rabanete durante coleta de dados de inverno, em Piracicaba, SP. .65

22 Resultado do teste de Tukey para as médias de características do tubérculo quanto à altura, diâmetro e peso do rabanete durante coleta de dados de primavera, em Piracicaba, SP .65

23 Resultado do teste de Tukey para as médias de produtividade do rabanete durante coleta de dados de inverno e de primavera, em Piracicaba, SP .66 


\section{LISTA DE APÊNDICES}

\section{Página}

1 Dados obtidos no experimento I - cultivo da rúcula no verão........................79

2 Dados obtidos no experimento I - cultivo da rúcula no outono.....................83

3 Dados obtidos no experimento II - cultivo do rabanete no inverno...............100

4 Dados obtidos no experimento II - cultivo do rabanete na primavera...........109 


\title{
CULTIVO DA RÚCULA E DO RABANETE SOB TÚNEIS BAIXOS COBERTOS COM PLÁSTICO COM DIFERENTES NÍVEIS DE PERFURAÇÃO
}

\author{
Autora: EDILAINE REGINA PEREIRA \\ Orientador: Prof. Dr. IRAN JOSÉ OLIVEIRA DA SILVA
}

\section{RESUMO}

Este trabalho objetivou determinar as modificações ambientais causadas pelo uso de filme de polietileno de baixa densidade (PEBD), em túneis baixos com perfurações de $0 \%$, $5 \%, 10 \%, 15 \%$ e $20 \%$ no desempenho da cultura da rúcula (Eruca vesicaria sativa (Mill) Thell) durante o verão e o outono e da cultura do rabanete (Raphanus sativus L.) durante o inverno e a primavera. Como variáveis resposta analisaram-se a umidade relativa do ar, a temperatura ambiente, a temperatura do solo, a radiação solar, além das características morfológicas da cultura: a massa seca, a massa verde, número de folhas (altura, peso, largura da planta), além da produtividade por área em cada tratamento. Os resultados mostraram que as variáveis climáticas envolvidas não apresentaram resultados significativamente diferentes entre os diversos níveis de perfuração pesquisados $(5 \%, 10 \%, 15 \%$ e $20 \%)$. 
No entanto, as alterações microclimáticas ocorridas pela influência das perfurações no filme plástico tornaram o microclima no interior dos túneis baixos propício ao melhor desenvolvimento da cultura da rúcula (Eruca vesicaria sativa (Mill)Thell), e do rabanete (Raphanus sativus L.), resultando em maior produtividade. 


\title{
ROCKET PRESS AND RADISH CULTIVE IN LOW TUNNEL WITH DIFFERENT PERFORATED FILM AREA
}

\author{
Author: EDILAINE REGINA PEREIRA \\ Adviser: Prof. Dr. IRAN JOSÉ OLIVEIRA DA SILVA
}

\section{SUMMARY}

The purpose of this research was to determine the environmental changes that the low density polythylene with different perforated film area $(5,10,15,20 \%)$ may cause on the rocket press culture (Eruca vesicaria sativa (Mill) Thell) during summer and fall time and radish culture (Raphanus sativus L.) during winter and spring time in low tunnel conditions. The climate variables analyzed were the humidity and air temperature, soil temperature and solar radiation. The culture parameters used to compare the treatments were dry matter, green matter, morphologicals characteristics of the plants (number, height, width and weight of leaves) and productivity. The results showed that find any significative differences between the climate variables inside the low tunnel with different perforated film area $(5,10,15,20 \%)$. However, the modification caused by the low tunnel with perforated plastic did provide performance of rocket press culture (Eruca vesicaria sativa (Mill) Thell) development in summer and fall time, and radish culture (Raphanus sativus L.) development in winter and spring, had better productivity and marketable characteristics. 


\section{INTRODUÇÃO}

Frente a um mercado em constante modificação, mais aberto, "globalizado" e cada vez mais competitivo, os agricultores se deparam com a necessidade de produzir mais, com melhor qualidade e ocupando o mínimo espaço, para que, dessa forma, possam permanecer praticando uma produção economicamente viável e compensadora.

Os produtores de hortaliças sempre desejaram produzir fora dos períodos normais ou antecipar suas produções com o objetivo de obterem melhores preços na venda de seus produtos. Para conseguir isso exploravam os microclimas, ou utilizavam uma série de recursos para a proteção das plantas. Com o surgimento do plástico e o aperfeiçoamento de sua utilização, foi possível obter os resultados esperados.

Uma de suas utilizações é a cobertura fazendo parte de estruturas de proteção semicirculares ao longo dos canteiros cultivados, denominados túneis de cultivo forçado. Segundo Sganzerla (1995), trata-se de uma técnica simples e econômica, que pode ser adotada por agricultores de todos os níveis, com baixo investimento e retorno seguro em pouco tempo .

De acordo com Oliveira (1997), o cultivo em ambientes protegidos consiste numa tecnologia amplamente consolidada em países como: Espanha, Itália, Holanda, França, Japão e Estados Unidos.

No Brasil, apesar de sua crescente utilização (aproximadamente 1000 hectares cobertos com ambiente protegido), essa tecnologia ainda carece de informações relativas 
ao efeito da proteção ambiental, principalmente em se tratando de estufas plásticas, sobre as variáveis meteorológicas e a sua conseqüente influência no crescimento e desenvolvimento das culturas.

Ainda, as condições continentais do território nacional com regiões climaticamente bem distintas, exigem a realização de estudos regionais visando determinar as potencialidades e limitações dessa tecnologia (Schneider et al. 1993).

O emprego de estufas plásticas é responsável por alterações em diversos elementos meteorológicos, tornando viável a produção de vegetais em épocas ou lugares cujas condições climáticas são críticas.

Os resultados e trabalhos científicos realizados no Brasil, desde 1988, com diversas espécies olerícolas cultivadas em estufa plástica, são bastante animadores, pois indicam, com esta técnica de cultivo, rendimentos bastante superiores aos normalmente obtidos em campo e compatíveis com os rendimentos obtidos em estufa plástica em países do chamado primeiro mundo (Martins et al. 1995).

No entanto, a falta de conhecimento sobre os aspectos estruturais, geometria e forma que determinam a dinâmica dos elementos ambientais como, por exemplo, a temperatura, a umidade, a concentração de $\mathrm{CO}_{2}$ e a luminosidade no interior dos túneis, faz com que técnicos da área questionem os princípios básicos da construção. Uma das características importantes e que não apresenta informações consistentes relacionadas à ambiência dos túneis, é a necessidade de se manejarem as aberturas laterais ao longo do dia, em função da variação desses elementos.

Para Sganzerla (1995), a utilização dos plásticos perfurados em túneis de cultivo forçado é um processo que dispensa o manejo das laterais para o arejamento das plantas durante o seu ciclo vegetativo, oferecendo vantagens adicionais.

Com a perfuração do plástico (filme de polietileno), de acordo com Buriol et al. (1993), devido ao pequeno volume de ar contido no túnel, a temperatura do ar pode ser elevada em dias de intensa radiação solar. As perfurações contidas no plástico proporcionam a convecção e advecção do ar quente evitando que as temperaturas diurnas do ar se tornem 
prejudiciais ao cultivo. Além disso, a ventilação no interior do túnel diminui o excesso de umidade do ar, dificultando, dessa forma, o desenvolvimento de doenças fúngicas.

Baseando-se nisso, este trabalho tem como objetivo geral a análise de diferentes níveis de perfuração $(5 \%, 10 \%, 15 \%$ e $20 \%)$ na cobertura do filme plástico em túneis baixos e sua influência sobre o microclima e como objetivos específicos a análise dos elementos microclimáticos (temperatura do ar, temperatura do solo, umidade relativa do ar, radiação solar) e suas influências sobre as características morfológicas (produção de matéria seca, matéria verde, número de folhas, altura, largura e peso das folhas) e produtivas da cultura da rúcula (Eruca vesicaria sativa (Mill) Thell) e da cultura do rabanete (Raphanus sativus L.). 


\section{REVISÃO DE LITERATURA}

\subsection{Influência dos elementos meteorológicos em cultivo protegido}

A radiação solar é a principal fonte de energia para as plantas e a maior parte dessa energia é convertida em calor, impulsionando o processo de transpiração e alterando a temperatura do tecidos vegetais com consequiências para os processos metabólicos (Jones, 1992).

O uso de técnicas para atenuar a densidade de fluxo da radiação solar incidente, com o objetivo de aumentar o crescimento, e melhorar a qualidade dos produtos agrícolas no período do ano em que a temperatura do ar alcança valores elevados, tem-se mostrado vantajoso.

A radiação solar global incidente no interior de uma estufa coberta com plástico é sempre menor do que a que incide sobre uma superfície livre. A redução da densidade de fluxo de radiação solar no interior da estufa é devida aos processos de reflexão e de absorção pela cobertura plástica. Durante o dia, devido à radiação líquida positiva, a superfície aquece a parcela de ar próxima a ela, desencadeando um processo convectivo. Dentro de ambientes protegidos, este processo é interrompido pela cobertura plástica que impede a ascensão do ar quente, provocando a elevação das temperaturas durante o período diurno (Pezzopane, 1994). Com isso, as temperaturas máximas atingem valores bem mais elevados do que no exterior .

A radiação solar no ambiente protegido é parcialmente absorvida pelo solo, plantas e objetos, sendo parte convertida em energia térmica (radiação de onda longa). Esta radiação térmica é irradiada para o espaço e, ao atingir algum material opaco, fica 
retida nesse ambiente, propiciando uma elevação da temperatura (efeito estufa) (Tapia, 1981).

Além das perdas de radiação térmica, o ambiente protegido também perde energia por processos de condução-convecção através da cobertura, pelas aberturas existentes. A céu aberto, também há grande perda de radiação térmica, porém, os movimentos horizontais e verticais de massa de ar podem transportar calor, aquecendo o ambiente externo por mistura de camadas de ar, o que não ocorre no interior do ambiente protegido, que quando fechados impede a ascensão dos ventos. Desta forma, é possível a ocorrência de temperatura interna inferior as verificadas externamente (Farias et al., 1993).

A temperatura do ar no interior de estufas plásticas está intimamente ligada ao balanço de energia, que irá depender de fatores como: tamanho da estufa, propriedades óticas da cobertura e das condições meteorológicas locais (Buriol et al. 1993).

De acordo com Alpi \& Tognoni (1991), as variações de temperatura, verificadas no interior de estufas, notadamente no sentido vertical, são a causa direta dos fenômenos de transmissão de calor por irradiação, condução e, principalmente, convecção. Sendo assim, ocorre um gradiente de temperatura, no interior da estufa, variando de um mínimo, próximo ao solo, até um máximo, contíguo ao teto.

Segundo Seeman (1979), a absorção da radiação solar incidente depende da composição química e da espessura do material plástico, as quais, além de reduzir a densidade de fluxo da radiação solar, possuem efeito seletivo, isto é, permitem a passagem de certas faixas espectrais e reduzem a transmitância de outras faixas de comprimento de onda. Já a reflexão é condicionada pelas características da superfície da cobertura e pelo ângulo de incidência da radiação solar.

Gimenes et al. (1994) estudaram o efeito da cobertura com tela plástica preta para atenuação da densidade de fluxo de radiação solar incidente sobre o crescimento da alface, nas condições de verão em Santa Maria, RS, e observaram valores mais elevados de massa seca das folhas e do caule sob os túneis quando comparados ao tratamento sem a utilização 
da tela, com o nível de $30 \%$ de atenuação da radiação solar incidente, apresentando melhores resultados.

A temperatura do ar no interior das estufas difere da externa e depende da densidade de fluxo de radiação solar incidente no interior destas e do seu manejo. A variação de temperatura depende também do tamanho da estufa e do volume de ar a ser aquecido (Seeman, 1979).

Em seus estudos, Tanaka \& Genta (1982), observam que o efeito da cobertura plástica é maior sobre as temperaturas máximas e atribuem este fato à intima relação da temperatura com a radiação solar e, ao menor volume de ar a ser aquecido e ao efeito eficiente das estufas, impedindo o resfriamento do ambiente causado pela ação dos ventos.

Buriol et al. (1993) em pesquisa sobre as alterações micrometeorológicas causadas por túneis baixos de tela plástica preta com 18, 30 e 50\% de atenuação da radiação solar incidente, durante os meses de verão, na região de Santa Maria, RS, para o cultivo da alface, concluíram que a atenuação da densidade de fluxo de radiação solar incidente diminui a temperatura do solo e do ar e as perdas de água do solo, mas não influencia de forma significativa a temperatura mínima e a umidade relativa do ar.

O menor volume de ar no interior das estufas a ser aquecido e a redução da influência dos ventos no resfriamento do ambiente, fazem com que durante o dia, a radiação solar incidente compense as perdas de calor que ocorrem através da cobertura, permitindo atingir temperaturas mais elevadas do que no ambiente externo (Martinez Garcia, 1986).

A reação das plantas às alterações da temperatura é marcante. Altas oscilações de temperatura durante o desenvolvimento das plantas podem resultar na sua morte total ou parcial. Devido ao processo fotossintético da maioria das plantas cultivadas, a temperatura ótima para o desenvolvimento vegetativo está em torno de $25^{\circ}$ C. À medida que a temperatura oscila para pontos afastados desse nível ótimo, o crescimento da planta é prejudicado (Scarpare Filho, 1995). 
Com relação à influência da temperatura sobre a produtividade vegetal, Sentelhas et al. (1998) relataram que a temperatura está relacionada ao crescimento, devido ao seu efeito na velocidade das reações químicas e dos processos internos de transporte de seiva, e ao desenvolvimento normal das plantas. Estes processos só se sucedem de forma adequada entre certos limites térmicos, sendo que diferentes espécies toleram distintos limites de temperatura.

De acordo com Sganzerla (1995), quanto maior a relação volume/área de uma estufa, maior será o contraste sobre a umidade relativa e temperatura.

\subsection{Ventilação Natural em estufas}

A ventilação natural no interior das instalações ocorre pelo aquecimento diferencial do ar ou devido à ação dos ventos. Este aquecimento diferencial do ar que ocasiona a ventilação é conhecido como efeito "termo-sifão".

Burn \& Lagier (1985) desenvolvendo um novo modelo de estufa que se adaptasse às condições climáticas do mediterrâneo, concluíram que a estufa que se utilizava do efeito "termo-sifão" foi a que apresentou melhor rendimento da cultura e melhor índice de controle de temperatura.

Feuilloley et al. (1990) e Rault (1990) compararam diferentes modelos de estufas para determinar qual a mais eficiente em regiões de clima quente, e concluíram que as estufas com abertura no teto e nas paredes são as mais eficientes, pois geram uma excelente circulação de ar.

Buriol et al. (1997), avaliando as modificações micrometeorológicas causadas por túneis baixos utilizando diferentes manejos de abertura de laterais visando à ventilação em estufas cultivadas com alface, encontraram resultados que comprovam serem as temperaturas médias e máximas diárias e a umidade relativa do ar, mais elevadas no interior dos túneis do que no exterior. Nos meses mais frios, os túneis apresentaram maior rendimento e precocidade na cultura e nos meses de primavera, ocorrendo vários dias com a temperatura 
do ar elevada, o crescimento sob os túneis foi prejudicado, necessitando de maior rigor em seu manejo.

De acordo com Rault (1990), é necessário o desenvolvimento de estufas que possuam um efeito "termo-sifão" eficiente, pois em regiões de clima quente a temperatura do ar no interior de estufas durante o dia, pode ser prejudicial para o desenvolvimento das plantas. Outra grande vantagem de se utilizar estufas com sistemas de ventilação natural é que o custo de instalação e de manutenção deste tipo de sistema é bem inferior ao dos sistemas mecânicos.

A ventilação das estruturas de proteção deve ser realizada nas horas em que a temperatura se eleva acima das ótimas de que necessitam as culturas. Portanto, as instalações devem possuir suficiente superfície de ventilação e, seu mecanismo de abertura e fechamento deve ser rápido e cômodo (Cermeño, 1994).

De acordo com Martins \& Gonzales, (1995) ventilação natural é um fator extremamente importante, pois controla a umidade relativa, evita o calor excessivo durante o dia e assegura a taxa mínima de $\mathrm{CO}_{2}$.

\subsection{Cultivo de hortaliças em ambiente protegido}

Para aumentar o rendimento das hortaliças, os órgãos de extensão rural tem fomentado a técnica do cultivo em estufa plástica, o que vem despertando o interesse cada vez maior, por parte dos agricultores, pelo conhecimento e adoção desta tecnologia, e pela necessidade de respostas às inúmeras questões sobre a mesma por parte da pesquisa agrícola.

Estimativas da área de produção de hortaliças em ambiente protegido no Brasil, para o ano de 1998, não corroboram com as expectativas de crescimento do início da década. De acordo com um levantamento efetuado em 1999, cerca de 1390 há foram cultivados com hortaliças nesse sistema, no Brasil, no ano de 1998. São Paulo, Paraná e Rio Grande do Sul foram os estados com maior área de produção (Vecchia et al. 1999). 
Com este sistema de produção é possível obter aumento nos rendimentos, bem como ter produto de melhor qualidade para comercialização, principalmente fora da épocas tradicionais de cultivo. O plantio de hortaliças em ambiente protegido, isto é, o cultivo em estufas e túneis de cultivo forçado iniciou-se há pouco tempo no Brasil, apresentando, contudo, expressiva expansão nos últimos anos.

Os ambientes protegidos podem ser vistos como uma estratégia para superar limitações climáticas, especialmente considerando a sua eficiência na captação da energia radiante e melhor aproveitamento pelas plantas da temperatura, água disponível e nutrientes, proporcionando maiores rendimentos que no campo (Slater, 1983)

Os resultados dos experimentos realizados na Universidade Federal de Pelotas, desde 1988, com diversas espécies olerícolas cultivadas em estufa plástica, são bastante animadoras, pois indicam com esta técnica de cultivo, rendimentos bastante superiores aos normalmente obtidos a campo e compatíveis com os rendimentos obtidos em estufa plástica em países do primeiro mundo (Martins et al, 1995).

Segundo Faria Jr. et al. (1993), a resposta de cultivares de alface no cultivo protegido, bem como o ambiente formado por modelos distintos de estufas plásticas (Arco e Capela), em Ilha Solteira (SP), apresentou valores de temperatura máxima mais elevados nas estufas do que na testemunha sem proteção plástica (entre 3 e $5^{\circ} \mathrm{C}$ ), ocorrendo o mesmo com a umidade relativa, às $13 \mathrm{~h}$. Em relação às temperaturas mínimas, as diferenças foram muito pequenas $\left(0,3^{\circ} \mathrm{C}\right)$, entre as estufas e a testemunha a campo aberto.

Estudando a resposta de híbridos de pepino às condições ambientais nos modelos de estufa arco e capela, comparadas àquelas de campo aberto, em Ilha Solteira, SP, Faria Jr. (1994) verificou valores mais elevados de temperatura máxima, umidade absoluta e déficit de saturação de vapor do que aqueles obtidos em campo aberto.

Ainda, na busca de informações sobre as condições de microclima proporcionadas por dois modelos de estufa (Arco e Capela), Faria Jr. (1997) avaliou a eficiência de diferentes materiais plásticos como cobertura do solo, associados ao cultivo em estufas, para a cultura 
do pimentão; e estudou dois híbridos de pimentão (Capsicum annuum L.) no cultivo protegido, em Jaboticabal, SP. Concluiu que as estufas promoveram alterações ambientais sensíveis, em relação à área descoberta, reduzindo a quantidade de radiação disponível, possibilitando médias de temperaturas máximas mais elevadas, e permitindo maiores valores de umidade absoluta e de déficit de saturação de vapor d'água do ar, no período da tarde.

Manzini (1994), avaliando o emprego do túnel de cultivo forçado e da cobertura do solo na produção de abobrinha italiana (Cucurbita pepo var. melopepo), em Jaboticabal, SP, em condições de outono-inverno, concluiu que esta técnica de cultivo foi eficiente na proteção das plantas de abobrinha a baixas temperaturas do ar, inclusive às geadas, independente da cultivar estudada. Obteve, ainda, um incremento na produção de abobrinha, mesmo quando semeada fora da época tradicional, mostrando desta forma, ser uma alternativa para o seu cultivo em inverno. A ocorrência de uma geada no decorrer do experimento provocou a morte das plantas nas parcelas sem túnel, enquanto que nas parcelas de cultivo forçado sob túnel, as plantas não apresentaram danos significativos.

Pesquisando a produtividade de diferentes cultivares de pepino, cultivados em estufa plástica, Buriol et al. (1999) observaram que os elementos meteorológicos que mais interferiram no rendimento foram a radiação solar e a temperatura do ar. Valores baixos de radiação solar global ocasionaram abortamento de frutos não ocorrendo tal fato em dias com valores de radiação global mais elevados. Já a influência da temperatura interfere com mais intensidade no crescimento do frutos.

\subsection{Cultivo de hortaliças em túneis baixos}

Os túneis baixos são utilizados, principalmente, em cultivo de espécies de pequeno porte, como a alface e o morango. Em comparação às estufas, são estruturas de mais fácil construção, de menor custo e exigem um manejo mais intenso. 
Nos dias ensolarados costuma-se abrir as laterais dos túneis pela manhã e abaixá-las à tarde, com a finalidade de não permitir a elevação excessiva da temperatura do ar no seu interior durante o dia e a temperatura mínima não atinja valores prejudiciais às plantas durante a noite. Nos dias mais quentes, as laterais são abertas mais cedo e fechadas mais tarde, e em dias com temperaturas baixas e/ou com chuva os túneis permanecem fechados ou somente com pequenas aberturas.

É de fundamental importância arejar os cultivos nos dias quentes. Com o arejamento do túnel, busca-se não somente baixar a temperatura, como também diminuir o excesso de umidade do ar, que conjugado com o calor excessivo, cria condições favoráveis para o desenvolvimento de doenças fúngicas. A ventilação também é importante para evitar a condensação no interior do túnel (Sganzerla, 1995).

No caso do solo apresentar-se excessivamente quente, recomenda-se a abertura lateral do túnel. Muito embora as condições de aquecimento do ambiente sejam por vezes superiores às ideais, os túneis são também utilizados no verão, especialmente nas condições de chuva excessiva. Nessa época, o túnel permanece semi-aberto dia e noite, funcionando como um telhado. Na ocorrência de ventos intensos e aquecidos, o túnel deve ser aberto apenas na face contrária à direção dos ventos predominantes (Lemos, 1986).

Uma técnica utilizada para diminuir o manejo e mão-de-obra, é a perfuração do filme de polietileno, pois devido ao pequeno volume de ar contido no túnel, a temperatura do ar pode se elevar muito em dias de intensa radiação solar, necessitando, dessa forma, de muito rigor em seu manejo. O princípio da técnica supõe que a ventilação proporcionada pelas perfurações seja suficiente para evitar temperaturas diurnas do ar, prejudiciais ao cultivo e, durante o período noturno mantenha a temperatura mais elevada do que no ambiente externo (Buriol et al., 1993).

Avaliando a temperatura do ar no interior de túneis baixos com diferentes tipos de cobertura (guarda chuva, perfurado, testemunha e convencional) Cunha et al. (1999) comprovaram que o uso de túneis perfurados ou com aberturas laterais como o túnel guarda 
chuva, proporcionaram temperaturas mínimas do ar superiores ao ambiente externo e boa aeração durante o período diurno, reduzindo a condensação do vapor d'água no seu interior e a precipitação indesejável sobre as plantas, além de requerer menor manejo do que o túnel convencional.

Em seus estudos sobre a modificação ambiental causada por túneis baixos de polietileno transparente perfurado cultivados com alface, com 0,78\%, 1,57\%, 2,35\% e 3,14\% de área perfurada, Buriol et al. (1993), concluíram que a perfuração não afetou significativamente a disponibilidade de energia solar. À medida que se aumentou a densidade de perfuração ocorreu um decréscimo no valor médio diurno da temperatura do ar, aspecto que demonstra a viabilidade de se ventilar o túnel baixo através da perfuração do plástico. Também foi constatado que nos túneis perfurados, os valores médios da temperatura do solo, mínima e média diurna do ar e umidade relativa do ar foram maiores do que no ambiente externo.

Streck et al. (1994), determinando o efeito do filme de polietileno perfurado sob diferentes porcentagens de perfuração ( $0,78 \%, 1,57 \%, 2,35 \%$ e 3,14\% ), em túneis baixos, sobre o crescimento da alface no Brasil (região de Santa Maria, RS) concluíram que o crescimento da alface é favorecido no ambiente sob os túneis baixos de polietileno perfurado em relação ao ambiente externo, uma vez que obteve maior número de folhas, área foliar e massa seca nos cultivos sob túneis.

Monteiro et al. (2000), comparando o microclima gerado em um canteiro aberto e no interior de um túnel baixo coberto com polietileno transparente sem perfuração e com porcentagens de perfuração de 5\%, 10\%, $15 \%$ e 20\%, na região de Piracicaba, SP, concluíram que à medida que se aumentou a densidade de área perfurada, a temperatura média diurna foi menor, em função da maior ventilação proporcionada pelas perfurações na cobertura, atingindo um máximo no túnel sem perfuração e um mínimo no canteiro sem túnel. Constataram, também, que houve aumento da temperatura no período mais crítico do dia, das 11 às 15 horas, tanto no inverno como no verão. Além disso, no inverno, ao final do dia, 
ocorreu um rápido abaixamento da temperatura em todos os tratamentos, à medida que se diminuiu a densidade de radiação solar.

Monteiro et al. (2000) analisaram o microclima em túneis baixos com diferentes níveis de perfuração $(0 \%, 5 \%, 10 \%, 15 \%$ e $20 \%$ ) no cultivo de alface e concluíram que os resultados dos parâmetros de crescimento: produção de matéria verde, seca e altura das plantas, foram mais elevados no interior dos túneis, com exceção do teor de matéria seca que foi maior na área sem cobertura. Porém, não foram identificados diferenças significativas nas produções de massa verde e seca de alface entre os túneis perfurados e o não perfurado.

Na região de Piracicaba e mesmo nas demais regiões do Estado de São Paulo, o uso de túneis perfurados é, ainda, incipiente e dependente de informações sobre as modificações causadas no ambiente e sobre o crescimento e desenvolvimento dos cultivos.

Dessa forma, a análise detalhada das modificações ambientais causadas no interior dos túneis baixos, assim como um estudo comparativo feito nos túneis de material plástico com diferentes níveis de perfuração, tornam-se uma boa opção para se determinarem as alterações encontradas no microclima procurando, dessa forma, obter o ambiente mais adequado para o melhor desenvolvimento dos produtos vegetais

\subsection{Cultura da rúcula}

A rúcula (ou pinchão) é uma hortaliça herbácea anual, baixa, possuindo normalmente altura de 15 a $20 \mathrm{~cm}$. Apresenta folhas relativamente espessas e divididas, de cor verde clara e as nervuras verde arroxeadas claras. Essa cultura se desenvolve melhor em condições de temperatura amena. Por isso, é mais cultivada no período que se estende de março a setembro. No calor cresce e floresce rapidamente, tornando-se imprópria para a comercialização, pois, as folhas se tornam pequenas e duras. Nas regiões de altitude elevada, ela pode ser cultivada o ano inteiro. Em condições de estufa climatizada também é possível cultivá-la durante o ano todo (Minami \& Tessarioli Neto, 1998). 
Quanto à irrigação é preferível, em pequenas áreas, fazer a rega diária na base de 3 a 5 litros de água por metro quadrado, procurando-se evitar encharcamento, que a rúcula não suporta. Em áreas maiores, faz-se a irrigação por aspersão.

O excesso de água, causado por uma chuva torrencial ou irrigação excessiva, reduz o crescimento das plantas, podendo provocar o amarelecimento das folhas em fase inicial de crescimento, o que compromete o valor comercial da rúcula. Além disso, muita água no solo pode ser propícia para o aparecimento do tombamento, doença provocada por certos fungos do solo, na fase inicial da cultura.

Segundo Minami \& Tessarioli Neto (1998), a colheita da rúcula é feita de 30 a 40 dias após a semeadura . Nesta fase, as folhas deverão estar com 15 a $20 \mathrm{~cm}$ de comprimento, bem desenvolvidas, verdes e frescas. A colheita é feita arrancando-se as plantas com raízes, ou cortando-as rentes ao solo. Neste caso, deixa-se o restante no solo para a rebrota, originando-se um segundo corte.

\subsection{Cultura do rabanete}

Por se caracterizar como uma das culturas de ciclo mais curto dentre as hortaliças, o rabanete (Raphanus sativus L.) se torna uma opção interessante ao produtor rural.

O rabanete é uma das plantas hortícolas mais antigas de que se tem notícia, havendo registros de que ele seja cultivado há mais de três mil anos. Segundo Sonnemberg (1981), há alguma divergência sobre a região exata de origem do rabanete, considerando-se o Oeste da Ásia e o Sul da Europa como as mais prováveis. Na China e em alguns países, essa hortaliça tem significativo consumo pela população.

Cientificamente, o rabanete é classificado como pertencente à família Brassicácea, gênero Raphanus, espécie R. sativus. Apresenta um ciclo dividido em fase vegetativa e fase reprodutiva. $\mathrm{Na}$ fase vegetativa a planta emite um tufo de folhas, dispostas em roseta, e forma 
uma raiz tuberosa. Na fase reprodutiva ocorre o pendoamento, florescimento e frutificação (Minami e Tessarioli Neto, 1997),

O desenvolvimento e a produtividade do rabanete depende, em grande parte, do clima que irá afetar a cultura já a partir da germinação. Pesquisas comprovam que a temperatura mínima para germinação é de $4,5{ }^{\circ} \mathrm{C}$, que a faixa ideal vai de 7,2 a $32,2{ }^{0} \mathrm{C}$, sendo $29,4{ }^{0} \mathrm{C}$ a temperatura ótima e a máxima tolerável $35{ }^{\circ} \mathrm{C}$.

Para a produção do rabanete, o solo deve absorver água rapidamente, drenar o excesso com relativa rapidez, conservar umidade suficiente para as plantas crescerem, apresentar espaços entre partículas para a circulação de ar e para que as raízes se desenvolvam livremente.

É fundamental salientar que a irrigação é fundamental para o bom desenvolvimento desta cultura. A frequiência de irrigação depende do suprimento de água disponível no solo e do consumo de água pela cultura. Ambos estão afetados pelo tipo de solo, profundidade e dispersão do sistema radicular, clima e idade da planta. Aconselha-se, segundo Dematte e Payão (1987) proceder às irrigações quando 75\% da água disponível na região das raízes tiver sido evapotranspirada. Restam $25 \%$ de reserva, impedindo dessa forma que a planta atinja o ponto de murchamento.

O suprimento de água precisa ser abundante e uniforme. Irregularidades no fornecimento de água provocam a rachadura da raiz tuberosa. Se a falta de água coincidir com altas temperaturas haverá um estímulo ao pendoamento precoce. Em condições de ensaio, pesquisadores verificaram que o consumo máximo de água na cultura do rabanete ocorreu entre o $15^{0}$ e o $18^{0}$ dia após a germinação, com uma média de 5,6 $\mathrm{mm}$ por dia (Minami e Tessarioli Neto, 1997). 


\section{MATERIAL E MÉTODOS}

\subsection{Localização e caracterização da área experimental}

O experimento foi conduzido no período de 30/01/2001 a 06/03/2001 no primeiro ciclo de plantio da rúcula e de 17/04/01 a 17/05/01 no segundo ciclo de plantio da rúcula na fase experimental I e no período de 03/07/01 a 05/08/01 no primeiro ciclo de plantio do rabanete na fase experimental II - em andamento, períodos estes que se iniciaram logo após a semeadura. O experimento foi conduzido na área experimental do Núcleo de Pesquisa em Ambiência (NUPEA) junto ao Departamento de Engenharia Rural da Escola Superior de Agricultura "Luiz de Queiroz" da Universidade de São Paulo (ESALQ-USP), no município de

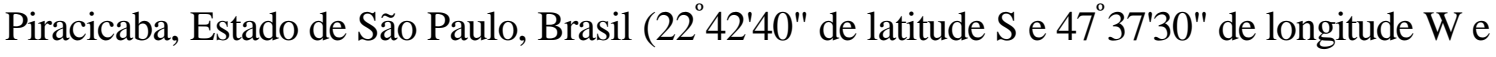
altitude entre 500 e 600 metros).

O clima da região, segundo a classificação de Koopen é do tipo Cwa, ou seja, subtropical úmido, com estiagem no inverno.

\subsection{Descrição da instalação do experimento}

Nesse experimento foram utilizados 6 canteiros, sendo que 5 deles cobertos com polietileno transparente de baixa densidade (PEBD) em forma de túneis baixos semicirculares e um sem nenhum tipo de cobertura, como testemunha. Os canteiros foram construídos nas dimensões de $1,2 \mathrm{~m}$ de largura e 6,0m de comprimento, com 1,6m de perímetro do semicírculo e 0,6m de altura e raio, apoiados sobre arcos de

aço galvanizado de aproximadamente $7 \mathrm{~mm}$ de diâmetro e separados entre si de $2 \mathrm{~m}$, e dispostos no sentido Leste - Oeste. A Figura 1, mostra uma vista geral da área experimental. 


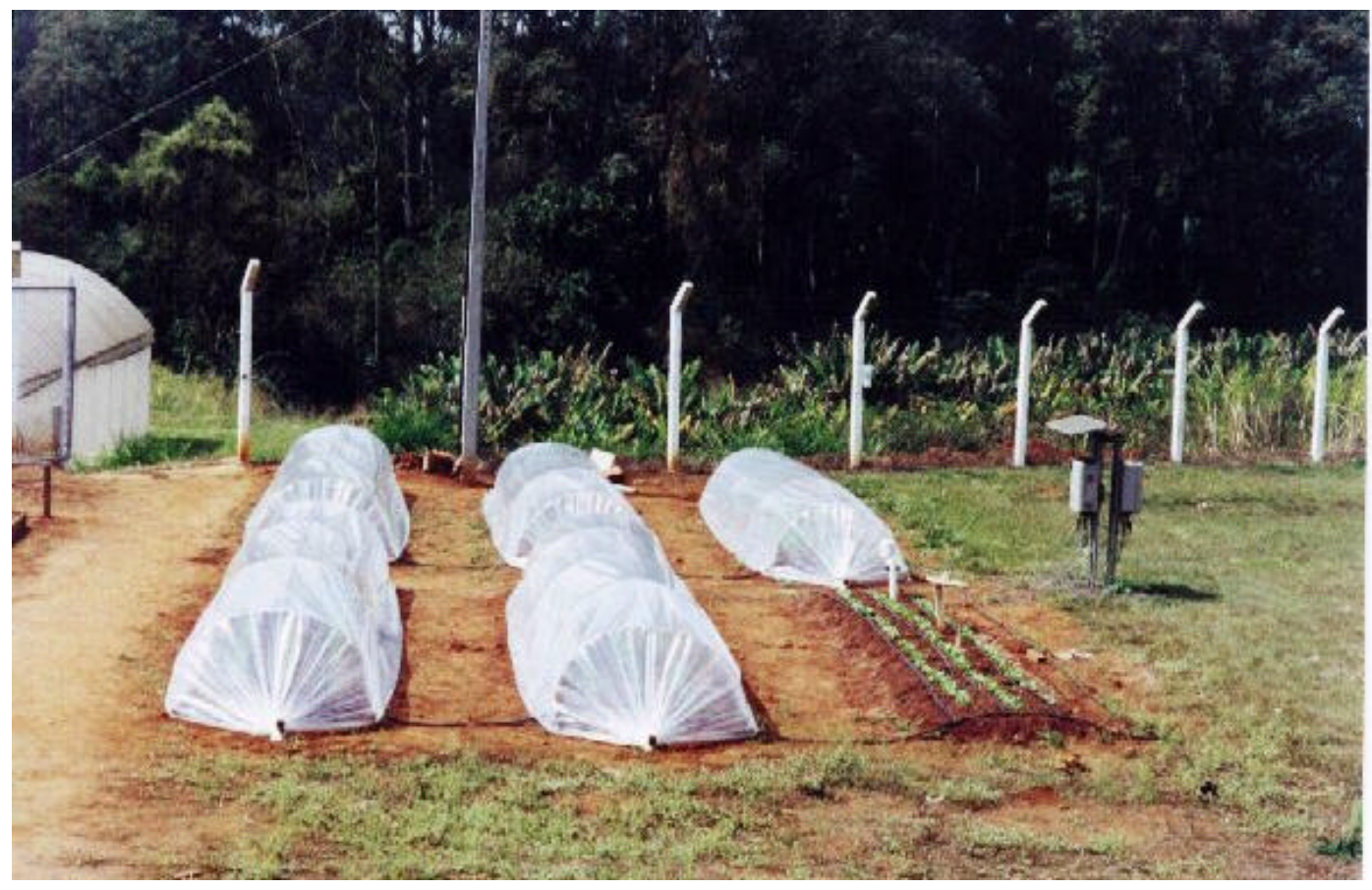

Figura 1 - Vista geral da área experimental, no NUPEA/DER/ESALQ/USP, em Piracicaba, SP.

Os tratamentos avaliados nesse trabalho, foram instalados nos canteiros descritos da seguinte forma:

Tratamento 1: Testemunha, sem cobertura;

Tratamento 2: PEBD com 0\% de perfuração;

Tratamento 3: PEBD com 5\% de perfuração;

Tratamento 4: PEBD com 10\% de perfuração;

Tratamento 5: PEBD com 15\% de perfuração;

Tratamento 6: PEBD com 20\% de perfuração; 
$5 \%$

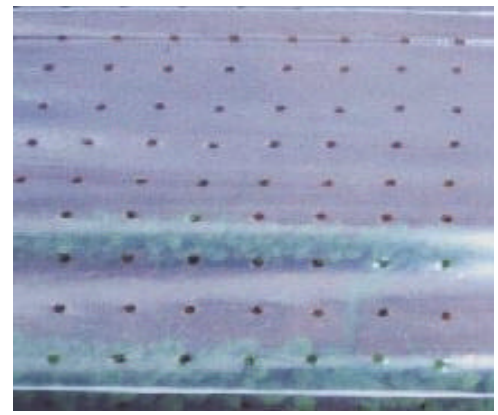

$15 \%$

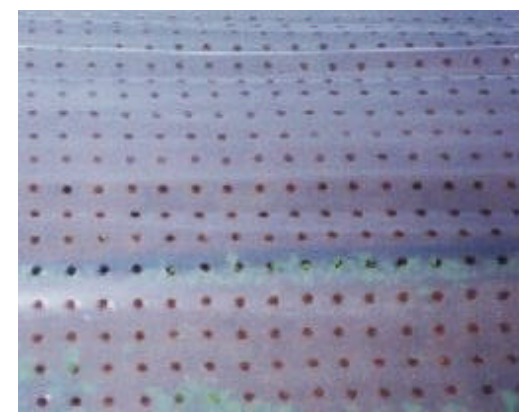

$10 \%$

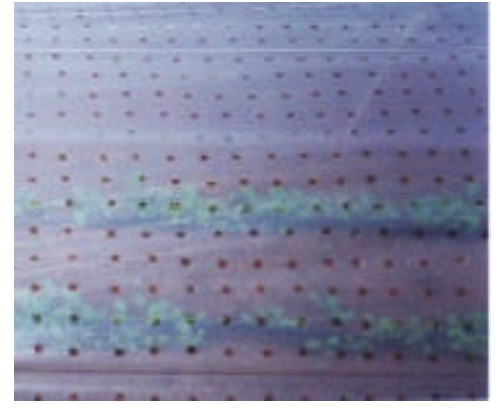

$20 \%$

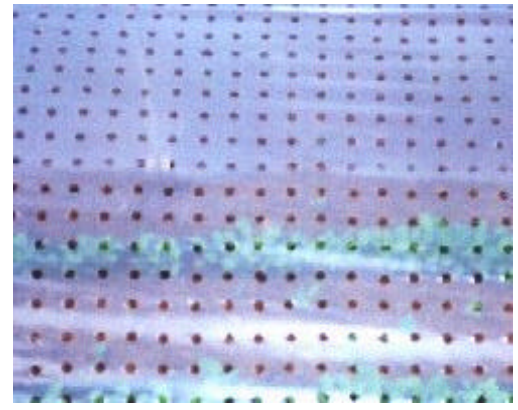

Figura 2 - Densidades de perfuração avaliada na cobertura plástica utilizadas no presente trabalho, na área experimental do NUPEA/DER/ESALQ/USP, em Piracicaba, SP.

O preparo do solo nos canteiros foi realizado com aração e passagem da enxada rotativa com encanteiramento, visando a uma maior aproximação das características reais encontradas nos cultivos convencionais

Foram retiradas amostras de solo em cada parcela e levadas ao laboratório para análise química (Tabela1). Foram adicionados, de acordo com recomendação, sulfato de amônio, cloreto de potássio e nitrato de amônia. Na Tabela 1 pode-se verificar o resultado final da análise química do solo. 
Tabela 1 - Resultados da análise química do solo no início do período experimental

\begin{tabular}{|c|c|c|c|c|c|c|c|c|c|c|c|c|c|c|c|}
\hline Amostra & & $\mathrm{PH}$ & & $\begin{array}{c}\mathrm{MO} \\
\text { (g.Kg-1) }\end{array}$ & $\begin{array}{c}\mathrm{P} \\
(\mathrm{mg} \cdot \mathrm{Kg}-1)\end{array}$ & $\mathrm{Na}$ & $\mathrm{K}$ & $\mathrm{Ca}$ & $\mathrm{Mg}$ & $\begin{array}{c}\mathrm{Al} \\
\left(\mathrm{mm} \cdot \mathrm{Kg}^{-1}\right.\end{array}$ & $\begin{array}{c}\mathrm{H}+\mathrm{A} \\
1\end{array}$ & SB & $\mathrm{T}$ & $\mathrm{V}$ & $\mathrm{m}$ \\
\hline & $\mathrm{H} 2 \mathrm{O}$ & $\mathrm{KCl}$ & $\mathrm{CaCl} 2$ & & & & & & & & & & & & \\
\hline 1 & 6,5 & 5,5 & 6,3 & 31 & 51 & - & 7,1 & 49 & 17 & 0 & 19 & 73,1 & 92,1 & 79 & 0 \\
\hline
\end{tabular}

Preparados os canteiros, foi instalado na área, o sistema de irrigação por gotejamento, contendo 3 fitas de gotejo da marca Chapin de 8 milésimos de polegada de espessura em cada canteiro, espaçamento entre gotejadores de $20 \mathrm{~cm}$ e vazão do sistema de 3,73 litros/hora (Figura 2). Foram aplicados, segundo Miname \& Tessarioli Netto (1998), turnos de rega diários obedecendo-se as recomendações de aplicação de 3 litros $/ \mathrm{m}^{2}$. Na Figura 3, pode-se observar o sistema de irrigação por gotejamento.

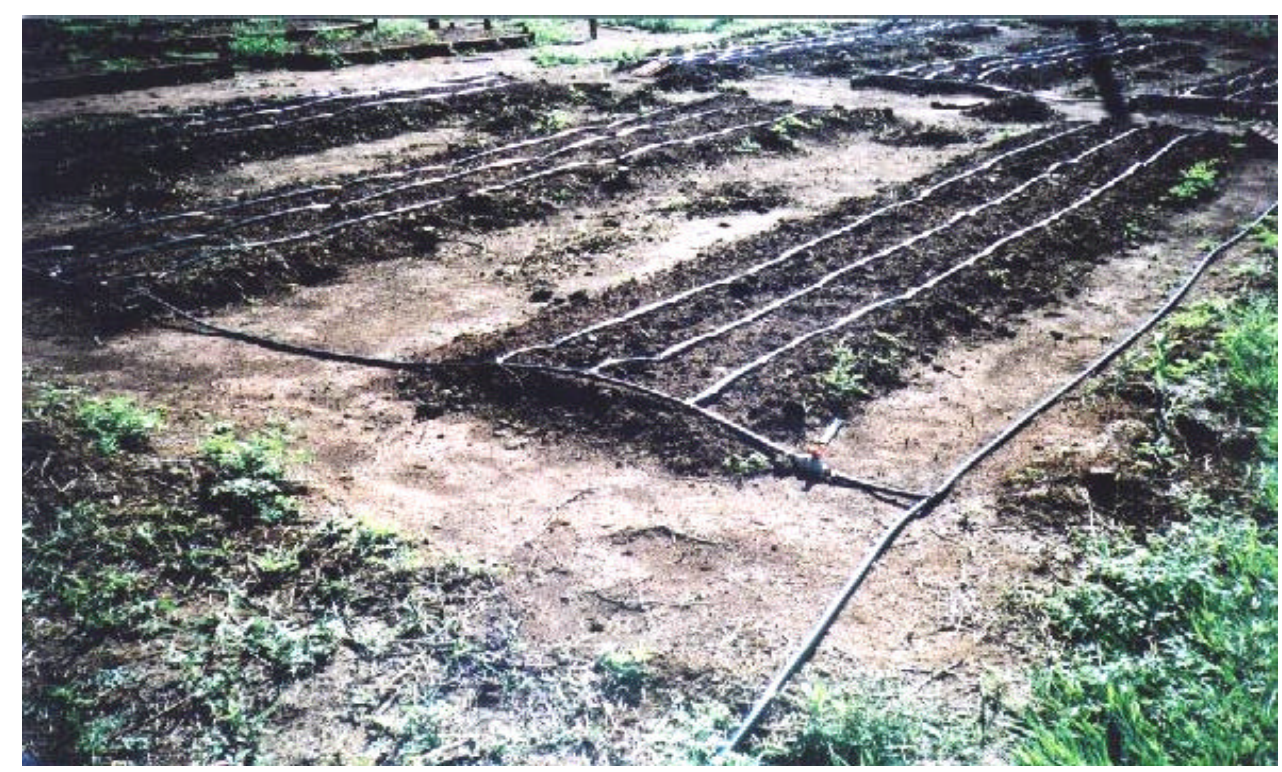

Figura 3 - Sistema de irrigação por gotejamento utilizado no presente trabalho, na área experimental do NUPEA/DER/ESALQ/USP, em Piracicaba .

As perfurações de cada filme plástico, para cada tratamento, foram realizadas manualmente com a utilização de um vazador de $10 \mathrm{~mm}$ de diâmetro. Foi utilizada uma placa de madeira como modelo contendo perfurações equidistantes entre si, em disposição quadrática, uniformemente distribuídas por toda sua extensão. Dessa forma foi possível obter 
diferentes percentuais de perfuração utilizados no experimento, que correspondeu a $5 \%, 10 \%$ , $15 \%$ e $20 \%$ de área perfurada. Na Figura 4, verifica-se o tipo de instrumento (vazador) utilizado para fazer a perfuração do plástico.

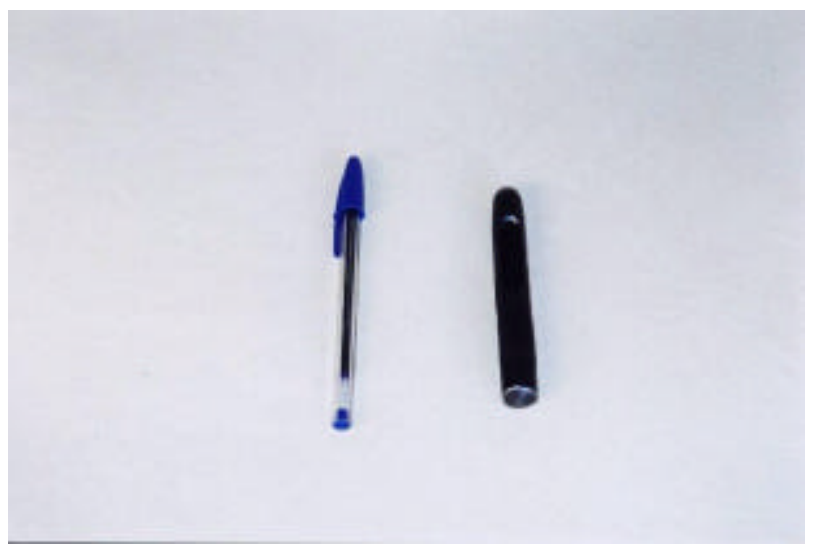

Figura 4 - Instrumento utilizado (vazador) para perfurar o filme plástico, utilizado como cobertura nos túneis baixos.

\subsection{Etapas do experimento}

O experimento foi conduzido em duas fases distintas de acordo com o esquema:

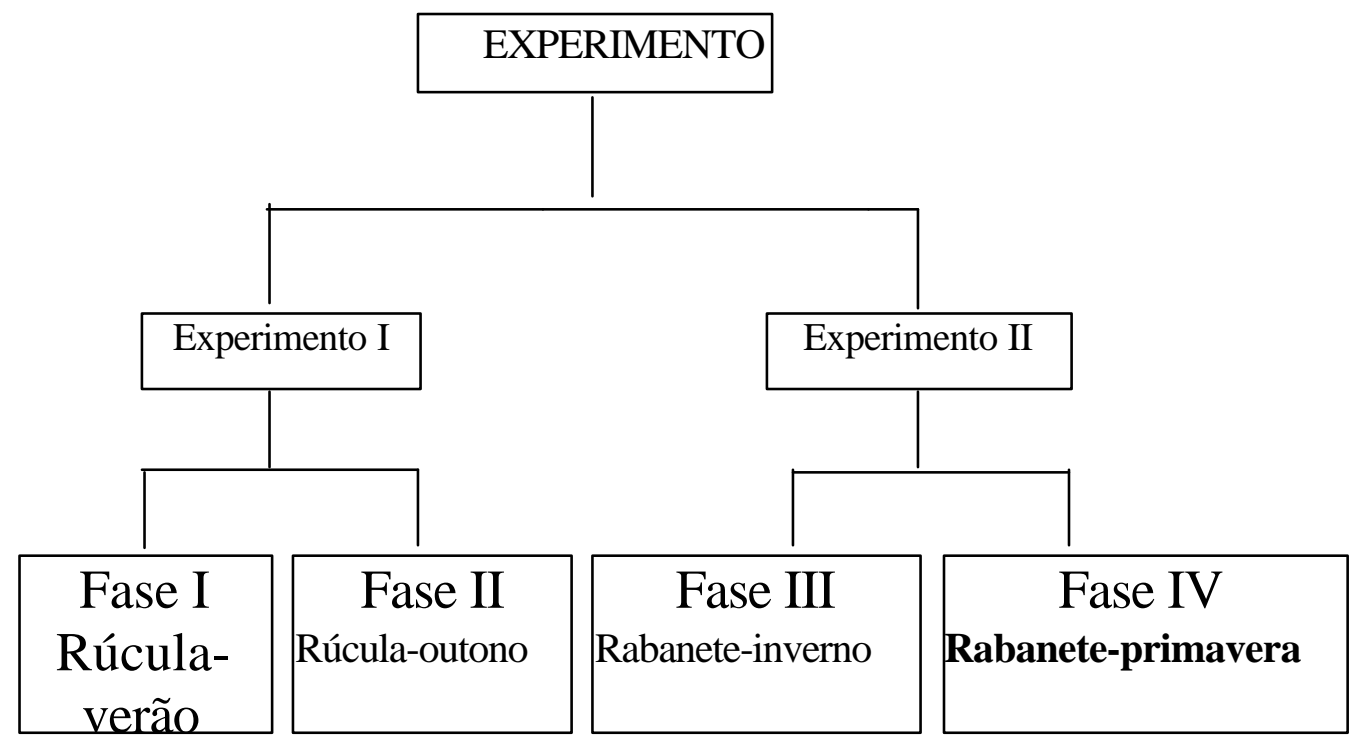




\subsubsection{Experimento I}

\subsubsection{Cultura da Rúcula}

Foi implantada na área a cultura da rúcula (Eruca vesicaria (Mill) Thell.) em duas

épocas: de verão (fase I) e de outono (fase II). A cultura foi semeada, segundo Minami \& Tessarioli Neto (1998), diretamente em sulcos com espaçamento entre linhas de $30 \mathrm{~cm}$ e a quantidade de sementes de $0,3 \mathrm{~g}$ por metro linear numa profundidade de $0,5 \mathrm{~cm}$.

\subsubsection{Equipamentos utilizados durante a fase experimental I}

Foram utilizados em cada tratamento termohigrômetros de leitura digital que forneceram dados de temperatura e umidade relativa do ar. Todos os equipamentos foram calibrados e aferidos inicialmente.

Para abrigar os instrumentos de medição utilizados na primeira fase do experimento I, foi utilizado um anteparo de madeira de 2,0 cm de espessura, pintado de branco, que serviu de apoio e proteção contra a incidência direta da radiação solar.

\subsubsection{Equipamentos utilizados durante a fase experimental II}

A partir do segundo ciclo de plantio da cultura da rúcula foi utilizado um sistema automático de aquisição de dados (Datalogger) modelo A1000 da marca Squitter, com canais de recepção para os sensores de: temperatura e umidade relativa do ar (modelo S2095), temperatura do solo (modelo S2029), e radiação solar global (modelo S2022). Na Figura 5 verifica-se o sistema utilizado para a aquisição dos dados microclimáticos. 


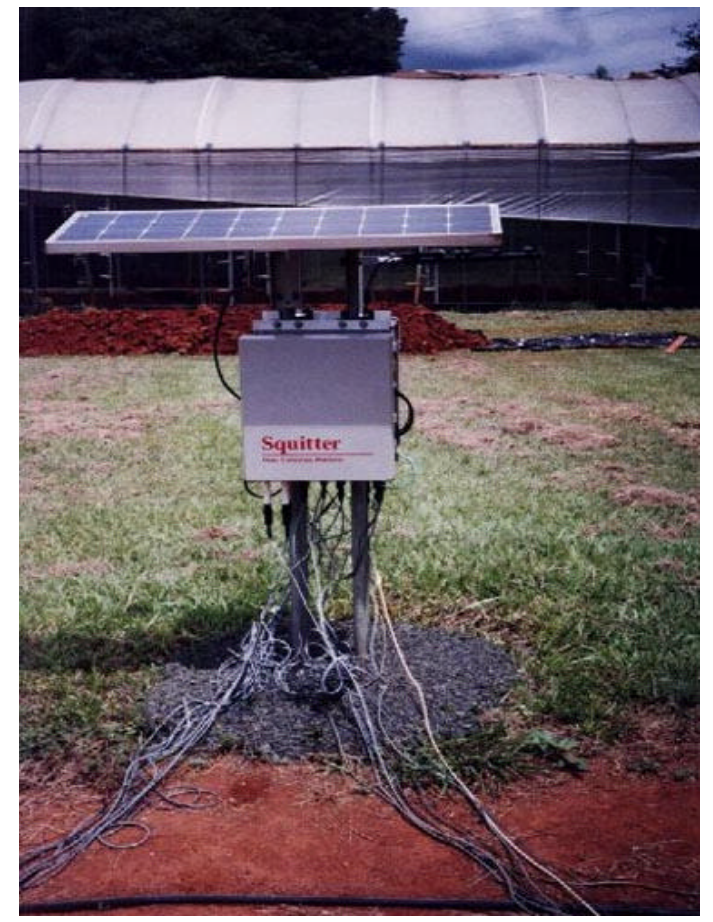

Figura 5 - Sistema de aquisição de dados instalado na área experimental do NUPEA/DER/ESALQ/USP, a partir da fase II.

\subsubsection{Coleta e análise dos resultados}

\section{a) Dados micrometeorológicos}

Durante a primeira fase do experimento foram selecionados, aleatoriamente, 9 dias de coleta de dados distribuídos ao longo do ciclo da cultura para análise dos valores obtidos para cada variável estudada. Os dados foram coletados durante o verão no período das 8:00 às 18:00 horas com frequiência de hora em hora e as variáveis respostas do experimento (temperatura ambiente e umidade relativa do ar) foram utilizadas para a comparação dos diferentes tratamentos e respectivas áreas de perfuração.

A partir da segunda fase do experimento, foram obtidos dados meteorológicos de temperatura e umidade relativa do ar, temperatura do solo a $10 \mathrm{~cm}$ de profundidade e radiação 
solar durante 30 dias a partir do $15^{0}$ dia após a semeadura. Tais dados foram coletados pelo sistema de aquisição de dados em intervalos de 15 minutos, porém, foram analisados os períodos horários da 8:00 às 18:00 horas.

b) Dados da cultura

As variáveis utilizadas para avaliação da influência dos tratamentos no desenvolvimento das culturas foram: produção de massa seca, produção de massa verde e características da planta (número de folhas, altura, largura e peso das folhas), para ambas as fases do experimento.

\section{b.1) Massa Verde}

Plantas de cada tratamento numa amostragem em 10 pontos equidistantes foram colhidas e pesadas imediatamente após, para a verificação da produção de massa verde, segundo metodologia adotada por Monteiro et al. (2000).

\section{b.2) Massa Seca}

Seguindo metodologia adotado por Monteiro et al. (2000) foram amostradas plantas em 10 pontos equidistantes ao longo de cada canteiro ao final do ciclo. Para a verificação da massa seca, as plantas, após pesadas, foram acondicionadas em sacos de papel permeável e mantidas em estufa de ventilação forçada a $65^{\circ} \mathrm{C}$ por 72 horas ou até massa constante, sendo novamente pesadas ao fim deste período.

\section{b.3) Características da planta}

Foram coletadas, aleatoriamente, 10 plantas por tratamento e realizadas a contagem do número de folhas por planta e as medições da largura, peso e altura das folhas (Monteiro et al. (2000)).

\section{b.4) Produtividade}

Plantas, numa área de $2 \mathrm{~m}$, em cada tratamento, foram coletadas e pesadas imediatamente após, a fim de se obter a produtividade por área de cada canteiro $\left(\mathrm{g} / \mathrm{m}^{2}\right)$. 


\subsubsection{Experimento II}

As variáveis medidas no experimento II foram as mesmas descritas anteriormente na fase II do experimento I, assim como as variáveis respostas analisadas.

\subsubsection{Cultura do rabanete}

Foi implantada nessa área a cultura do rabanete (Raphanus sativus L.) em época de inverno (fase III) e primavera (fase IV). A cultura, com ciclo de 30 a 40 dias, foi semeada, segundo Minami e Tessarioli Neto (1998), diretamente em sulcos com espaçamento entre linhas de $30 \mathrm{~cm}$ e com uma quantidade de sementes $15 \mathrm{Kg}$ por hectare, numa profundidade de $1,5 \mathrm{~cm}$.

A coleta e análise dos resultados foram os mesmos adotados na fase II do experimento I.

\subsection{Delineamento Estatístico}

O delineamento estatístico adotado foi o de blocos ao acaso, com os dados sendo estudados estatisticamente através do teste de Tukey a $1 \%$ de probabilidade da análise de variância e posteriormente foram comparados entre si utilizando-se o programa Statistics Analisys System (SAS).

Os canteiros foram considerados como blocos e os diferentes níveis de perfuração da cobertura plástica dos túneis baixos foram analisados como tratamentos. Porém, não foi possível efetuar repetições deste experimento numa mesma época do ano. 


\section{RESULTADOS E DISCUSSÃO}

\subsection{Experimento I}

Na primeira fase do experimento, foram analisados alguns elementos microclimáticos como a temperatura do ar, a umidade relativa do ar, a radiação solar global e a temperatura do solo, além de algumas características morfológicas e produtivas da cultura da rúcula (Eruca sativa (Mill) Thell.) como massa seca, massa verde, características da folha (altura, largura e peso), em época de verão e outono.

\subsubsection{Elementos microclimáticos}

\subsubsection{Temperatura do ar}

Observa-se nas Figuras 6 e 7, que todos os canteiros protegidos pelos túneis apresentam valores superiores de temperatura do ar quando comparados ao canteiro sem cobertura, tanto no verão como no outono.

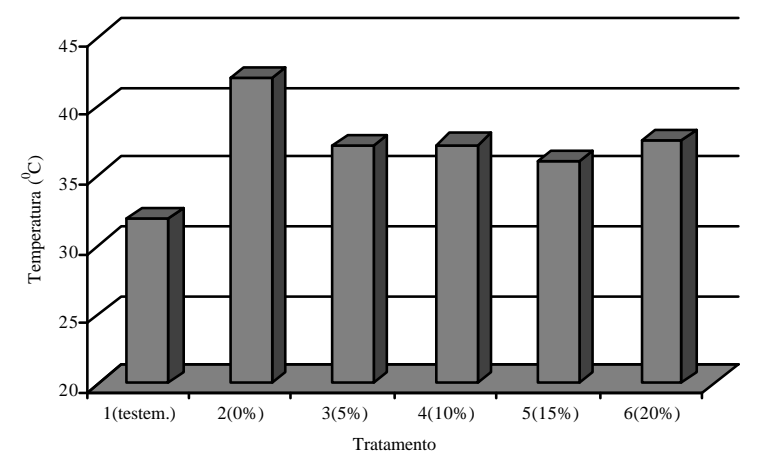

Figura 6 - Temperatura média diária do ar no período de coleta de dados de verão, de 30/01/01 a 06/03/01, em Piracicaba, SP. 


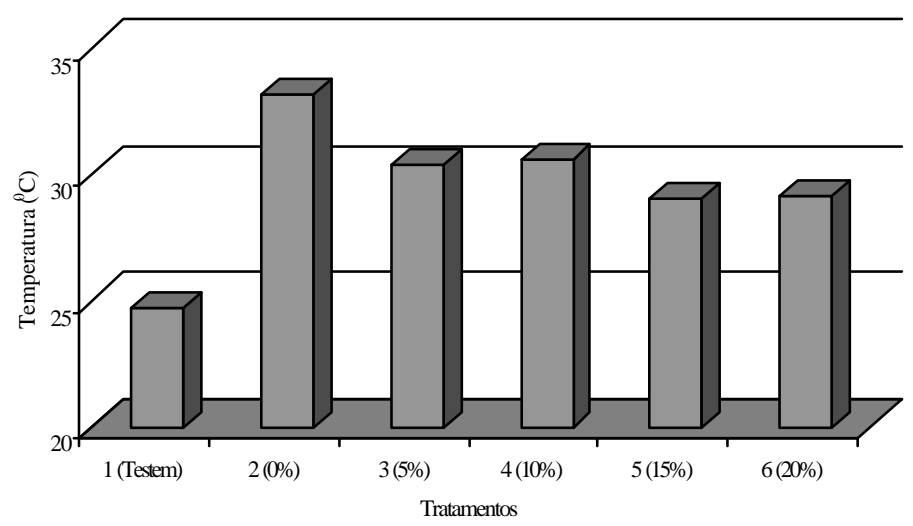

Figura 7 - Temperatura média diária do ar no período de coleta de dados de outono, de 17/04/01 a 17/05/01, em Piracicaba, SP.

Isso se deve, principalmente, ao fato de que o pequeno volume de ar contido no interior dos túneis está menos sujeito à renovação do ar, ao contrário do que ocorreu no ambiente externo. A perfuração no filme plástico minimiza a transferência de energia na forma de calor latente e sensível, além de conter as movimentações convectivas e advectivas do ar. Resultados semelhantes foram encontrados por Monteiro et al. (2000) em estudo sobre o microclima no interior de túneis baixos com plástico perfurado no cultivo da alface na primavera em Piracicaba, SP.

Analisando os valores de temperatura do ar para cada tratamento de hora em hora, pode-se dizer que, durante o dia, devido à radiação líquida positiva, há um aquecimento do ar e da superfície terrestre, que por sua vez, também aquece a parcela de ar próxima a ela, desencadeando um processo convectivo. Dentro do ambiente protegido este processo é interrompido pela cobertura plástica que impede a ascensão do ar quente, provocando a elevação da temperatura durante o período diurno (Pezzopane, 1994).

Assim, como mostram as Figuras 8 e 9, as temperaturas máximas internas atingem valores bem mais elevados do que no exterior. 


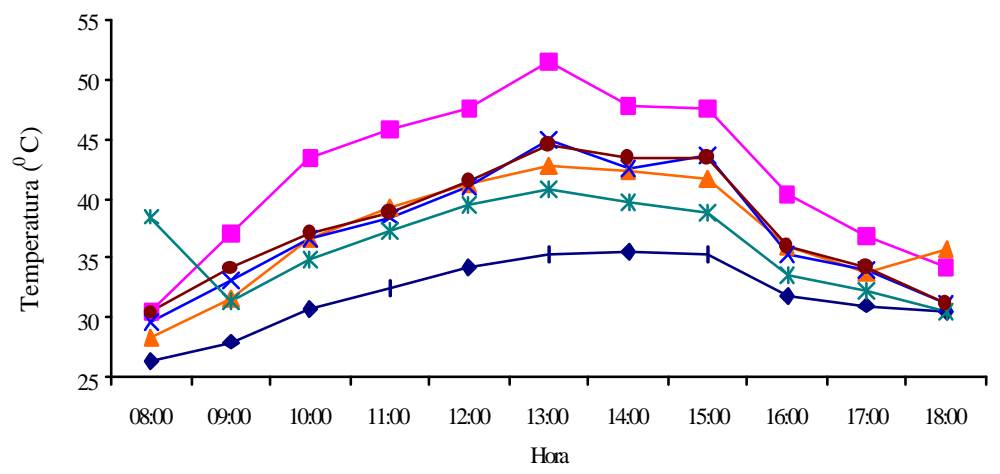

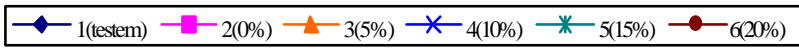

Figura 8 - Temperatura média horária do ar no período de coleta de dados de verão, de 30/01/01 à 06/03/01, em Piracicaba, SP.

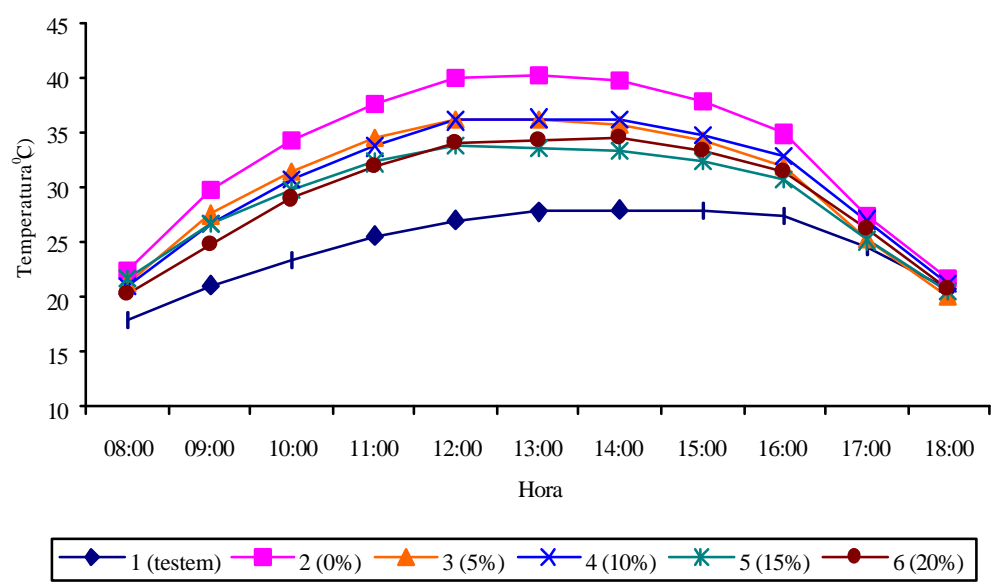

Figura 9 - Temperatura média horária do ar no período de coleta de dados de outono, de 17/04/01 a 17/05/01, em Piracicaba, SP.

Tanto o experimento de verão como o de outono foram marcados por um extenso período seco. Assim, a variação da temperatura ao longo do dia foi sempre uniforme, havendo poucas diferenças. As curvas de variação da temperatura do ar em cada tratamento ao longo 
do dia na época de outono são bem características, com tendência bem definida. Algumas oscilações observadas no período de verão (Figura 8), revelam provavelmente as possíveis diferenças de leitura cometidas pelo uso do termohigrômetro, instrumento menos sensível e preciso se comparados ao sistema de aquisição de dados automático utilizado no outono.

Por meio da análise estatística realizada para a variável temperatura do ar e analisando-se os dados obtidos no ensaio de verão (Tabela 2), pode-se afirmar que nos horários mais críticos do dia houve diferença significativa entre o tratamento sem túnel e os demais tratamentos com plástico perfurado. Todas as densidades de perfuração estudadas proporcionaram valores significativamente superiores, variando de 4,6 a 7,6 ${ }^{0} \mathrm{C}$ em relação ao ambiente externo, concordando com Farias et al. (1993) que encontraram médias superiores no interior de estufas convencionais tipo túnel, em relação ao cultivo a céu aberto que variaram de 1,2 a $4,4{ }^{0} \mathrm{C}$.

O túnel com $0 \%$ de perfuração no plástico chegou a atingir, em média nos horários mais críticos do dia, $13,4{ }^{0} \mathrm{C}$ a mais que a testemunha o que comprova que as perfurações proporcionaram um ambiente com melhor circulação de ar durante o período diurno, diminuindo a temperatura do ar e reduzindo a condensação do vapor d'água no seu interior. De acordo com a Tabela 2, os maiores valores observados nos túneis com $0 \%$ de perfuração, evidenciaram que a elevação na temperatura do ar em túneis perfurados é menor do que em estufas plásticas sem perfuração, concordando com a pesquisa realizada por Buriol et al. (1993). Estes autores, trabalhando com túneis baixos e diferentes níveis de perfuração na cobertura plástica para o cultivo da alface, concluíram que os ganhos térmicos foram maiores em ambientes com menor área perfurada. 
Tabela 2 - Resultado do teste de Tukey para as médias horárias de temperatura do ar durante a coleta de dados de verão, no intervalo das 11:00 às 15:00 horas, em Piracicaba, SP.

\begin{tabular}{cccccc}
\hline Tratamento & & \multicolumn{4}{c}{ Temperatura do ar } \\
& 11 horas & 12 horas & 13 horas & 14 horas & 15 horas \\
\hline 1 (testemunha) & $32,5 \mathrm{c}$ & $34,2 \mathrm{c}$ & $35,3 \mathrm{c}$ & $35,6 \mathrm{~d}$ & $35,3 \mathrm{c}$ \\
$2(0 \%)$ & $45,7 \mathrm{a}$ & $47,5 \mathrm{a}$ & $51,5 \mathrm{a}$ & $47,6 \mathrm{a}$ & $47.4 \mathrm{a}$ \\
$3(5 \%)$ & $39,1 \mathrm{~b}$ & $41,2 \mathrm{~b}$ & $42,8 \mathrm{~b}$ & $42,8 \mathrm{bc}$ & $41,6 \mathrm{~b}$ \\
$4(10 \%)$ & $38,5 \mathrm{~b}$ & $41,02 \mathrm{~b}$ & $44,9 \mathrm{~b}$ & $42,5 \mathrm{bc}$ & $43,6 \mathrm{ab}$ \\
$5(15 \%)$ & $37,2 \mathrm{~b}$ & $39,4 \mathrm{~b}$ & $40,7 \mathrm{~b}$ & $39,8 \mathrm{~b}$ & $38,7 \mathrm{bc}$ \\
$6(20 \%)$ & $38,7 \mathrm{~b}$ & $41,3 \mathrm{~b}$ & $44,4 \mathrm{~b}$ & $43,4 \mathrm{~b}$ & $43,2 \mathrm{ab}$ \\
\hline
\end{tabular}

*médias seguidas pela mesma letra nas colunas não diferem estatisticamente entre si pelo teste de Tukey a nível de $1 \%$ de probabilidade

Para os dados coletados no período de outono, além da diferença significativa observada entre a testemunha e os demais tratamentos (Tabela 3) houve diferença significativa entre os diferentes níveis de perfuração e o tratamento com túnel sem perfuração. Em função dos resultados obtidos, observou-se valores médios de temperatura do ar no ambiente protegido com perfurações no filme plástico em torno de ${ }^{-0} \mathrm{C}$ inferior ao túnel com $0 \%$ de perfuração. Isso concorda com pesquisas realizadas por Buriol et al. (1993). Estes autores observaram que, a medida que aumentou-se a densidade de perfuração, houve um decréscimo no valor médio diurno da temperatura do ar, demonstrando a viabilidade de ventilar o túnel baixo através da perfuração do plástico.

Pode-se notar ainda, pela Tabela 3, que houve diferenças significativas entre os tratamentos com plástico perfurado no período do outono. Durante esta época do ano o fato das temperaturas médias do ar apresentarem-se mais amenas que no verão, pode ter evidenciado tais diferenças. E ainda, os tratamentos com diferenças superiores a 5\%, foram os que possuíram maiores diferenças nos valores de temperatura do ar (tratamento a 5\% e 15\% de perfuração, ou então, $5 \%$ e $20 \%$ de perfuração). Isso demonstra que, em época de 
outono, o nível de perfuração necessário para afetar significativamente a redução da temperatura do ar no interior dos túneis baixos, deve ultrapassar o valor de $5 \%$ de diferença entre as áreas de perfuração.

Tabela 3 - Resultado do teste de Tukey para as médias horárias de temperatura do ar durante a coleta de dados de outono, no intervalo das 11:00 às 15:00 horas, em Piracicaba, SP.

\begin{tabular}{cccccc}
\hline Tratamento & \multicolumn{5}{c}{ Temperatura do ar } \\
& 11 horas & 12 horas & 13 horas & 14 horas & 15 horas \\
\hline 1 (testemunha) & $25,58 \mathrm{~d}$ & $26,98 \mathrm{~d}$ & $27,74 \mathrm{~d}$ & $27,97 \mathrm{e}$ & $27,86 \mathrm{e}$ \\
$2(0 \%)$ & $37,54 \mathrm{a}$ & $39,93 \mathrm{a}$ & $40,19 \mathrm{a}$ & $39,72 \mathrm{a}$ & $37,72 \mathrm{a}$ \\
$3(5 \%)$ & $34,54 \mathrm{~b}$ & $36,15 \mathrm{~b}$ & $36,13 \mathrm{~b}$ & $35,68 \mathrm{~b}$ & $34,20 \mathrm{bc}$ \\
$4(10 \%)$ & $33,69 \mathrm{~b}$ & $36,03 \mathrm{~b}$ & $36,26 \mathrm{~b}$ & $36,78 \mathrm{~b}$ & $34,82 \mathrm{~b}$ \\
$5(15 \%)$ & $32,28 \mathrm{c}$ & $33,74 \mathrm{c}$ & $33,57 \mathrm{c}$ & $33,21 \mathrm{~d}$ & $32,32 \mathrm{~d}$ \\
$6(20 \%)$ & $31,84 \mathrm{c}$ & $34,01 \mathrm{c}$ & $34,33 \mathrm{c}$ & $34,54 \mathrm{c}$ & $33,36 \mathrm{c}$ \\
\hline *médias seguidas pela mesma letra nas colunas não diferem estatisticamente \\
entre si pelo teste de Tukey a nível de 1\% de probabilidade
\end{tabular}

\subsubsection{Umidade Relativa do Ar}

Verifica-se que no verão, de acordo com a Figura 10 e 11, os tratamentos que apresentaram maior valor de umidade relativa média diária foram os túneis com grau de perfuração $0 \%, 5 \%, 10 \%, 15 \%$ e $20 \%$, respectivamente. Assim como comprovado por Robledo e Martin (1981); Buriol et al. (1993), a menor evapotranspiração em uma atmosfera com pouca ventilação do ar é a causa da maior umidade relativa dos túneis. Quanto menor a área perfurada, maior a resistência ao fluxo turbulento de vapor d'água e maior a dificuldade de trocas com o meio externo, o que contribui para uma maior retenção de vapor de água no interior dos túneis e um aumento da umidade relativa do ar. 


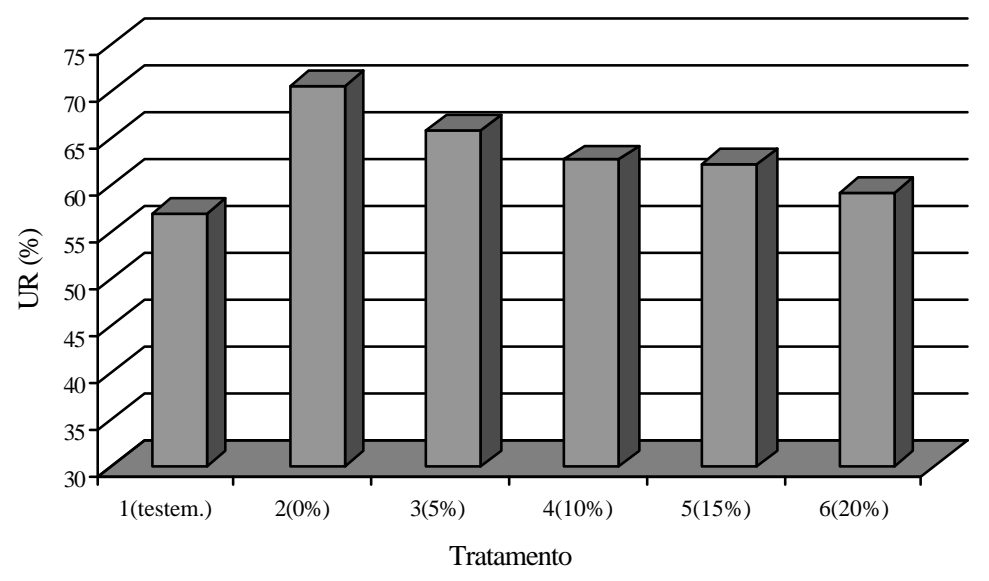

Figura 10 - Umidade Relativa média diária do ar no período de coleta de dados de verão, de 31/01/01 a 06/03/01, em Piracicaba, SP.

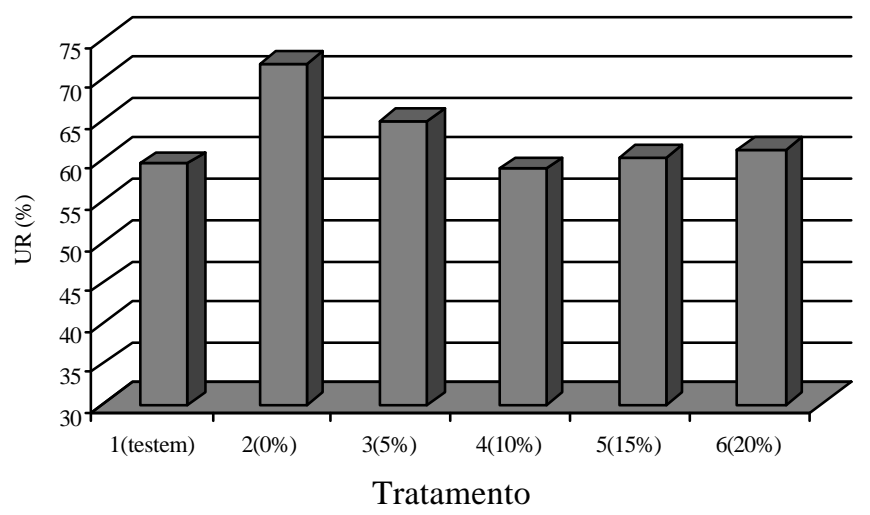

Figura 11 - Umidade Relativa média diária do ar no período de coleta de dados de outono, de 17/04/01 à 17/05/01, em Piracicaba, SP.

Como se pode notar nas Figuras 12 e 13, a umidade relativa média horária é sempre superior no interior do ambiente protegido, principalmente nos horários mais críticos do dia. Observou - se que a rúcula perde água facilmente para o ambiente por meio da transpiração e dependendo da demanda evaporativa da atmosfera no ambiente. Neste caso, provavelmente, 
a taxa de perda de água pela planta pode ter sido maior que a taxa de reposição, mesmo em condições de plena disponibilidade de água no solo. Associado à incidência de ventos, as movimentações advectivas do ar provocadas contribuem para a renovação do ar junto ao solo e à planta, tornando o ambiente com maior área perfurada menos úmido. Resultados semelhantes foram constatados por Monteiro et al (2000) para cultivo da alface em túneis baixos.

Outro fator que pode influenciar os valores médios da umidade relativa do ar a serem mais elevados no interior dos túneis é o alto valor da pressão parcial de vapor d'água. A pouca renovação do ar no interior do ambiente a $0 \%$ de perfuração aliada a uma umidade do solo geralmente mais elevada do que no exterior faz com que o valor da pressão atual de vapor permaneça mais elevado no interior dos túneis.

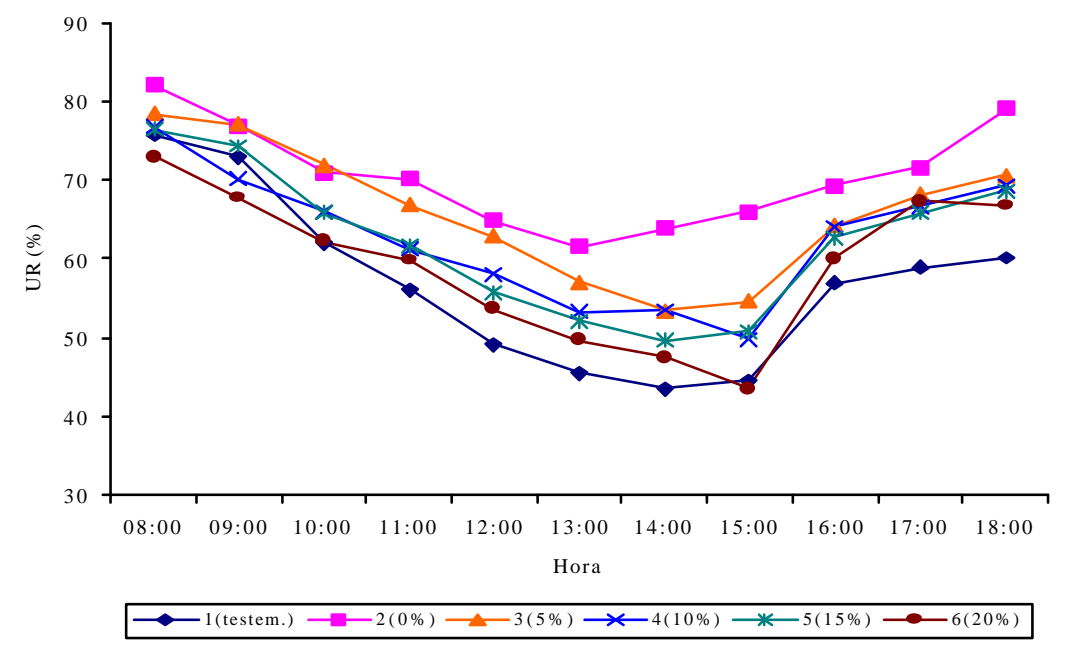

Figura 12 - Umidade relativa média horária do ar no período de coleta de dados de verão, de 31/01/01 à 06/03/01, em Piracicaba, SP. 


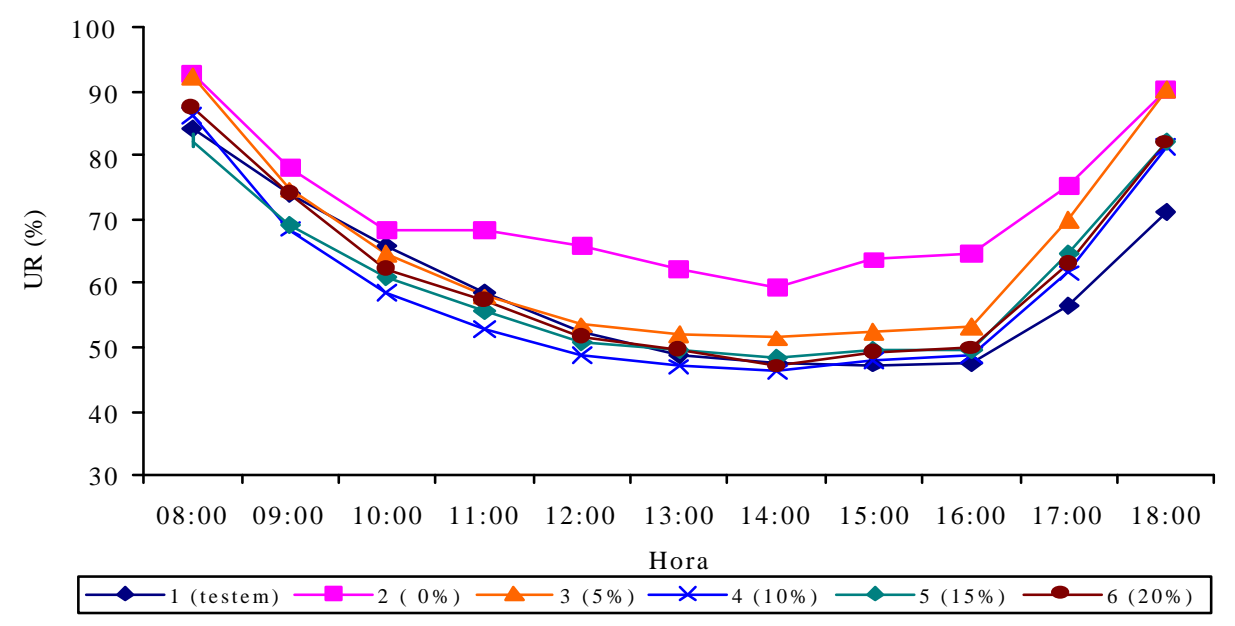

Figura 13 - Umidade relativa do ar média horária no período de coleta de dados de outono, de 17/04/01 à 17/05/01, em Piracicaba, SP.

Baseando-se na análise estatística com teste de Tukey a 1\% de significância, com os dados observados na época de verão, os tratamentos que apresentaram maior valor de umidade relativa do ar foram os túneis com grau de perfuração $0 \%, 5 \%, 10 \%, 15 \%$ e $20 \%$, respectivamente. Pode ser notada uma diferença significativa entre os tratamentos testemunha e o túnel sem perfuração (Tabela 4), evidenciando o fato do ambiente com menor renovação de ar apresentar-se com elevada umidade relativa do ar.

Outra diferença significativa ocorreu com o tratamento sem túnel e o tratamento com $20 \%$ de área perfurada. Ao longo do período mais crítico do dia, ou seja, com temperatura mais elevada, verificou-se que as maiores diferenças dos valores médios diários de umidade relativa do ar ocorreram com o tratamento a $20 \%$ de perfuração que apresentou valores superiores em 14,4 \% com relação ao ambiente externo, seguidos do tratamento a 15\%, 10\% e $5 \%$ que apresentaram valores superiores em $11,22 \%, 10,02 \%, 6,32 \%$, respectivamente. 
Tabela 4 - Resultado do teste de Tukey para as médias horárias de umidade relativa do ar durante a coleta de dados de verão, no intervalo das 11:00 às 15:00 horas, em Piracicaba, SP.

\begin{tabular}{cccccc}
\hline Tratamento & \multicolumn{5}{c}{ Umidade Relativa do ar } \\
& 11 horas & 12 horas & 13 horas & 14 horas & 15 horas \\
\hline 1 (testemunha) & $56,1 \mathrm{c}$ & $49,1 \mathrm{~d}$ & $45,4 \mathrm{c}$ & $43,5 \mathrm{c}$ & $44,5 \mathrm{c}$ \\
$2(0 \%)$ & $70,1 \mathrm{a}$ & $64,7 \mathrm{a}$ & $61,4 \mathrm{a}$ & $63,8 \mathrm{a}$ & $65,9 \mathrm{a}$ \\
$3(5 \%)$ & $66,7 \mathrm{ab}$ & $62,7 \mathrm{ab}$ & $57,0 \mathrm{ab}$ & $53,4 \mathrm{~b}$ & $54,5 \mathrm{~b}$ \\
$4(10 \%)$ & $61,3 \mathrm{bc}$ & $58,0 \mathrm{abc}$ & $53,3 \mathrm{~b}$ & $53,5 \mathrm{~b}$ & $49,7 \mathrm{bc}$ \\
$5(15 \%)$ & $61,6 \mathrm{abc}$ & $55,7 \mathrm{bcd}$ & $52,1 \mathrm{bc}$ & $49,6 \mathrm{bc}$ & $50,8 \mathrm{bc}$ \\
$6(20 \%)$ & $59,8 \mathrm{bc}$ & $53,5 \mathrm{~cd}$ & $49,6 \mathrm{bc}$ & $47,5 \mathrm{bc}$ & $43,5 \mathrm{c}$ \\
\hline * médias seguidas pela mesma letra nas colunas não diferem estatisticamente entre si pelo teste de Tukey \\
ao nível de 1\% de probabilidade
\end{tabular}

Em se tratando da análise da umidade relativa do ar em época de outono (Tabela 5), algumas diferenças podem ser notadas. A variação média dos valores de umidade relativa no outono são bem menores que no verão, devido à menor variação da temperatura do ar no período analisado, fazendo com que não haja mais diferença significativa entre os tratamentos com túnel perfurado a $20 \%$ e o ambiente externo. A diferença significativa ainda permanece entre a testemunha e o tratamento com túnel sem perfuração num valor médio de umidade relativa que não ultrapassa $13 \%$.

Assim, como comprovado por Santos et al. (2001), o efeito da cobertura plástica sobre a temperatura e a umidade relativa do ar, está diretamente relacionado às condições atmosféricas do ambiente externo. Sendo assim, no período de outono, em que a temperatura é mais acentuada, há uma redução na amplitude de variação da umidade relativa do ar, da temperatura do ar, do déficit de saturação e da tensão de vapor d'água no ar. 
Tabela 5 - Resultado do teste de Tukey para as médias horárias de umidade relativa do ar durante a coleta de dados de outono, no intervalo das 11:00 às 15:00 horas, em Piracicaba, SP.

\begin{tabular}{cccccc}
\hline Tratamento & \multicolumn{4}{c}{ Umidade Relativa do ar } \\
& 11 horas & 12 horas & 13 horas & 14 horas & 15 horas \\
\hline 1 (testemunha) & $58,5 \mathrm{~b}$ & $52,3 \mathrm{bc}$ & $48,9 \mathrm{bc}$ & $47,4 \mathrm{bc}$ & $47,3 \mathrm{c}$ \\
$2(0 \%)$ & $68,4 \mathrm{a}$ & $66,1 \mathrm{a}$ & $62,2 \mathrm{a}$ & $59,5 \mathrm{a}$ & $63,6 \mathrm{a}$ \\
$3(5 \%)$ & $58,0 \mathrm{~b}$ & $53,4 \mathrm{~b}$ & $52,1 \mathrm{~b}$ & $51,4 \mathrm{~b}$ & $52,4 \mathrm{~b}$ \\
$4(10 \%)$ & $53,0 \mathrm{c}$ & $48,8 \mathrm{c}$ & $47,0 \mathrm{c}$ & $46,1 \mathrm{c}$ & $48,0 \mathrm{c}$ \\
$5(15 \%)$ & $55,6 \mathrm{bc}$ & $50,6 \mathrm{bc}$ & $49,7 \mathrm{bc}$ & $48,5 \mathrm{bc}$ & $49,4 \mathrm{bc}$ \\
$6(20 \%)$ & $57,3 \mathrm{bc}$ & $51,7 \mathrm{bc}$ & $49,4 \mathrm{bc}$ & $46,9 \mathrm{bc}$ & $49,1 \mathrm{bc}$ \\
\hline
\end{tabular}

* médias seguidas pela mesma letra nas colunas não diferem estatisticamente entre si pelo teste de Tukey ao níve de $1 \%$ de probabilidade

\subsubsection{Temperatura do solo}

A variável temperatura do solo somente foi possível ser avaliada durante o cultivo da rúcula em época de outono. A temperatura do solo média horária observada no interior do ambiente protegido apresentou-se superior à temperatura no canteiro sem a cobertura do túnel, como mostrado na Figura 14.

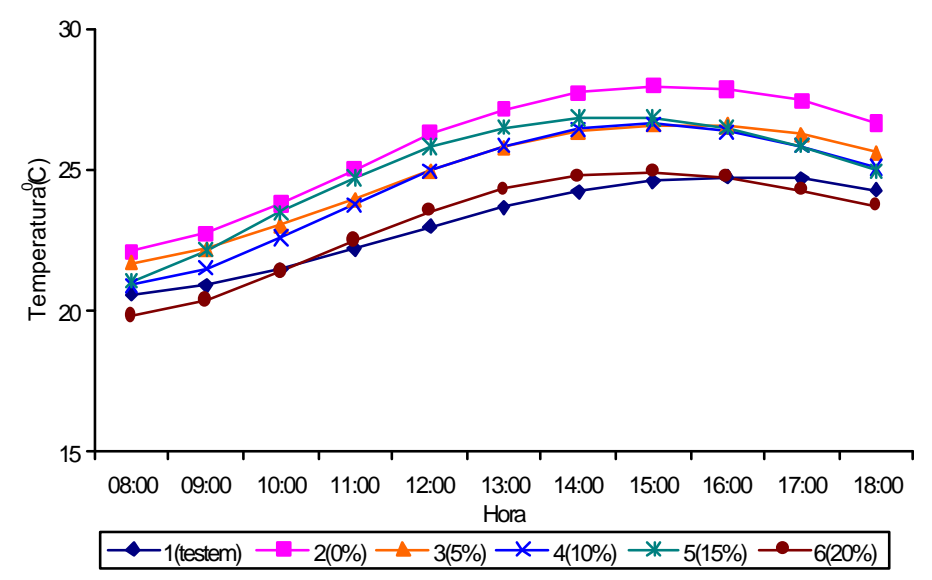

Figura 14 - Temperatura do solo média horária no período de coleta de dados de outono, de 17/04/01 a 17/05/01, em Piracicaba, SP. 
A temperatura do solo é função da densidade de fluxo de radiação solar global incidente e das propriedades térmicas do solo. A princípio a temperatura do solo no interior dos túneis baixos deveria ser menor do que no ambiente externo, visto que a energia solar disponível é, em média, menor no interior dos túneis e que, como o solo normalmente é mais úmido, a condutividade térmica e o calor específico são maiores, o que determinaria uma menor elevação da temperatura. Como existe no interior do túnel um menor volume de ar e normalmente uma menor velocidade de renovação de ar junto à superfície, a transferência de energia na forma de calor latente e sensível é menor, comparativamente ao ambiente externo, e com isso certamente haverá um maior fluxo de calor para o solo, acentuando o maior aquecimento deste no interior dos túneis.

$\mathrm{Na}$ análise da temperatura do solo em média horária (Figura 14), pôde-se notar que houve horários do dia em que a temperatura do solo no interior do túnel com $20 \%$ de área perfurada foi inferior ao ambiente externo. Isso ocorreu devido à redução da camada de vapor d'água sob o filme de polietileno. A maior incidência de vento no interior deste ambiente intensificou a perda radiativa de energia que, juntamente com a menor disponibilidade de energia solar e o maior teor de umidade do solo, foram as causas para que a temperatura do solo no túnel com densidade de perfuração a $20 \%$ não se elevasse tanto quanto no ambiente externo.

Constatou-se, ainda, a relação entre o desenvolvimento da cultura e a variação da temperatura do solo em média diária (Figura 15). O aumento do sombreamento do solo pelo dossel da cultura e a diminuição da incidência de radiação solar direta sobre o solo, proporcionou uma redução da incidência da radiação solar disponível na linha de plantio, concordando com as pesquisas desenvolvidas por Aguiar e Silva et al (2001) sobre a variação da temperatura do solo em ambiente protegido para a cultura do pimentão. De acordo com esses autores, a temperatura do solo apresentou-se inversamente proporcional ao índice de área foliar da cultura. 


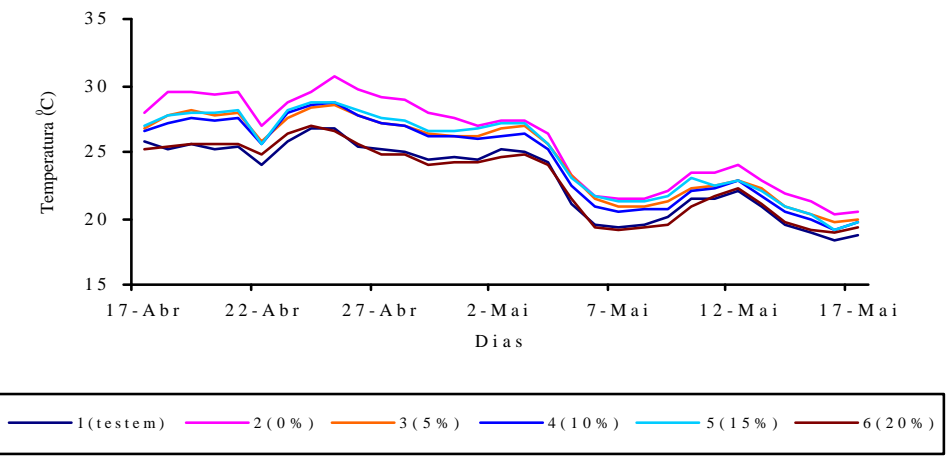

Figura 15 - Temperatura do solo média diária no período de coleta de dados de outono, de 17/04/01 a 17/05/01, em Piracicaba, SP.

De acordo com os resultados da análise estatística obtidos pelo teste de Tukey a $1 \%$ de significância para temperatura do solo em média horária, pode-se comprovar que houve uma diferença significativa nos períodos mais críticos do dia entre o canteiro sem a cobertura do túnel e os demais tratamentos (Tabela 6).

Estes resultados vêm concordar com os encontrados por Schneider et al. (1993) em estudo realizado sobre as modificações da temperatura do solo causado por estufas de polietileno onde observaram valores de temperatura média interna do solo a 10 e $20 \mathrm{~cm}$ de profundidade sempre superiores àqueles obtidos em condições externas.

Tabela 6 - Resultado do teste de Tukey para as médias horárias de temperatura do solo à 10 $\mathrm{cm}$ de profundidade, durante a coleta de dados de outono, no intervalo das 11:00 às 15:00 horas, em Piracicaba, SP.

\begin{tabular}{|c|c|c|c|c|c|}
\hline \multirow[t]{2}{*}{ Tratamento } & & Temperatura & do solo & & \\
\hline & 11:00 & 12:00 & 13:00 & 14:00 & 15:00 \\
\hline 1(testemunha) & $22,20 \mathrm{c}$ & $22,98 \mathrm{e}$ & $23,65 \mathrm{e}$ & $24,18 \mathrm{e}$ & $24,56 \mathrm{c}$ \\
\hline $2(0 \%)$ & 24,99 a & $26,28 \mathrm{a}$ & $27,13 \mathrm{a}$ & $27,70 \mathrm{a}$ & $27,93 \mathrm{a}$ \\
\hline $3(5 \%)$ & $23,92 \mathrm{~b}$ & $24,94 \mathrm{c}$ & $25,78 \mathrm{c}$ & $26,32 \mathrm{c}$ & $26,57 b$ \\
\hline $4(10 \%)$ & $23,75 \mathrm{~b}$ & $24,94 \mathrm{c}$ & $25,82 \mathrm{c}$ & $26,42 \mathrm{bc}$ & $26,60 \mathrm{~b}$ \\
\hline $5(15 \%)$ & $24,70 \mathrm{a}$ & $25,79 \mathrm{~b}$ & $26,49 \mathrm{~b}$ & $26,83 \mathrm{~b}$ & $26,82 \mathrm{~b}$ \\
\hline $6(20 \%)$ & $22,46 c$ & $23,52 \mathrm{~d}$ & $24,28 \mathrm{~d}$ & $24,74 \mathrm{~d}$ & $24,89 \mathrm{c}$ \\
\hline
\end{tabular}

*médias seguidas pela mesma letra nas colunas não diferem estatisticamente entre si pelo teste de Tukey ao nível de $1 \%$ de probabilidade. 
Como pôde-se notar, os valores de temperatura do solo são sempre superiores à testemunha. Tal fato pode ter sido causado pela cobertura de PEBD, através da reflexão da radiação de ondas curtas, e pela baixa renovação de ar no interior do ambiente protegido, fazendo com que as camadas mais superficiais do solo tenham mais energia disponível que em condições de campo.

A temperatura média do solo, na profundidade estudada de $10 \mathrm{~cm}$, no interior dos túneis foi em média $2,0{ }^{0} \mathrm{C}$ superior que a temperatura do solo no ambiente externo. Apesar de ter ocorrido diferença significativa entre as densidades de 5\%, $15 \%$ e $20 \%$ nos horários mais críticos do dia (Tabela 6), as diferenças entre os valores médios dos tratamentos com plástico perfurado não ultrapassaram $1,76{ }^{0} \mathrm{C}$ se comparados à testemunha, podendo-se assumir que os valores médios de temperatura do solo são similares. Resultados como estes foram também comprovados por Buriol et al. (1993) analisando a temperatura do solo no interior de túneis baixos no cultivo da alface onde observaram valores superiores de $2,1{ }^{0} \mathrm{C}$ na profundidade de $5 \mathrm{~cm}$ no interior dos túneis perfurados se comparados ao ambiente externo.

\subsubsection{Radiação Solar Global}

Na figura 16 são mostrados valores médios horários de radiação solar global incidente. Em relação ao ambiente externo, no interior dos túneis baixos ocorreu uma menor disponibilidade de radiação solar. A redução média no interior do ambiente protegido foi de $26 \%$, considerando-se a média dos tratamentos. Este valor supera os resultados obtidos por Buriol et al. (1993), em túneis baixos com plástico perfurado cultivados com alface que encontraram uma redução média de 21,4\%. Considerando que estes autores realizaram tal pesquisa na região sul e em época de inverno e primavera, pode-se atribuir que os resultados atingiram uma mesma faixa de redução de radiação solar média. 


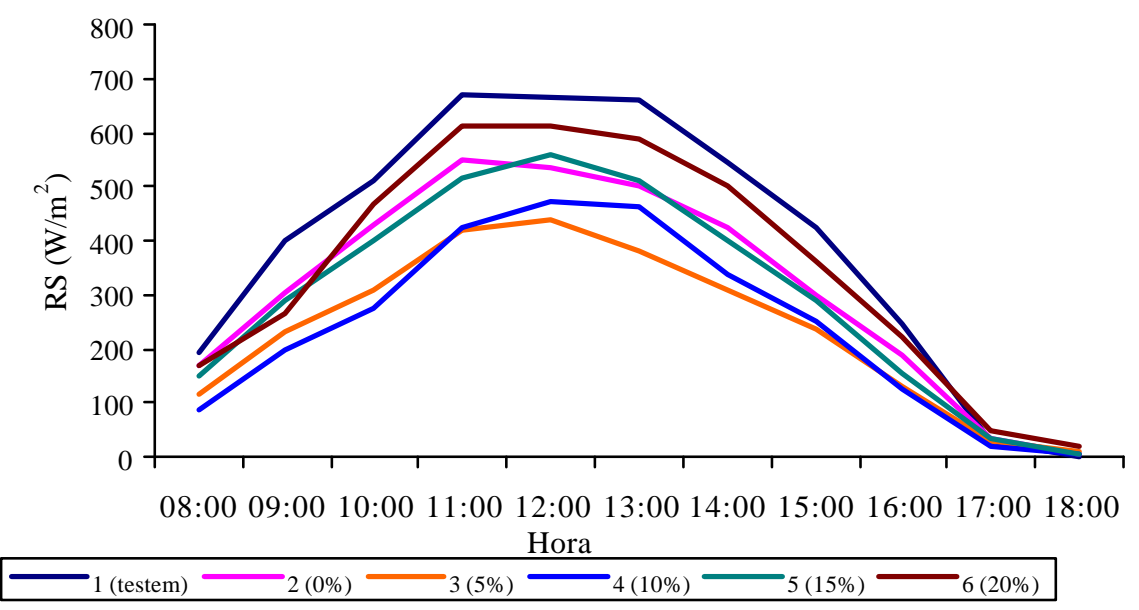

Figura 16 - Radiação solar global incidente média horária, no período de coleta de dados de outono, de 17/04/01 à 17/05/01, em Piracicaba, SP.

A atenuação média ao longo do dia foi um pouco superior no período da manhã. Tal fato ocorreu, principalmente, devido à permanência da camada de condensação de vapor d'água na parte interna da cobertura plástica. Notou-se ainda, que nos tratamentos com maior perfuração, a quantidade de água condensada foi menor do que nos demais, o que mostra que o menor fluxo de radiação solar global no interior dos túneis ocorreu nos tratamentos com $20 \%, 15 \%, 10 \%, 5 \%$ de área perfurada, respectivamente.

$\mathrm{Na}$ análise estatística da variável radiação solar global incidente houve diferença significativa entre a testemunha e os tratamentos com densidade a $0 \%, 5 \%, 10 \%$ e 15\%, porém, não houve diferença significativa entre a testemunha e o tratamento com $20 \%$ de perfuração nos horários mais críticos do dia (Tabela 7). No interior do túnel com maior densidade de perfuração houve maior incidência de vento o que provocou a remoção mais rápida da camada de água condensada sob o plástico, permitindo dessa maneira menores diferenças entre a quantidade interna de fluxo radiante incidente em ambos os tratamentos. 
Tabela 7 - Resultado do teste de Tukey para as médias horárias de radiação solar global incidente durante a coleta de dados de outono, no período das 11:00 às 14:00 horas, em Piracicaba, SP.

\begin{tabular}{ccccc}
\hline Tratamento & \multicolumn{4}{c}{ Radiação solar Global $\left(\mathrm{W} / \mathrm{m}^{2}\right)$} \\
& $11: 00$ & $12: 00$ & $13: 00$ & $14: 00$ \\
\hline 1 (testemunha) & $669,65 \mathrm{a}$ & $665,17 \mathrm{a}$ & $658,79 \mathrm{a}$ & $547,25 \mathrm{a}$ \\
$2(0 \%)$ & $420,33 \mathrm{c}$ & $439,01 \mathrm{e}$ & $383,26 \mathrm{c}$ & $306,84 \mathrm{~d}$ \\
$3(5 \%)$ & $427,04 \mathrm{c}$ & $475,07 \mathrm{de}$ & $462,99 \mathrm{~b}$ & $338,37 \mathrm{~cd}$ \\
$4(10 \%)$ & $516,64 \mathrm{~b}$ & $560,24 \mathrm{bc}$ & $510,16 \mathrm{~b}$ & $397,96 \mathrm{bc}$ \\
$5(15 \%)$ & $549,85 \mathrm{~b}$ & $535,7 \mathrm{~cd}$ & $502,84 \mathrm{~b}$ & $423,94 \mathrm{~b}$ \\
$6(20 \%)$ & $612,02 \mathrm{a}$ & $612,06 \mathrm{ab}$ & $590,66 \mathrm{a}$ & $502,65 \mathrm{a}$ \\
\hline
\end{tabular}

* médias seguidas pela mesma letra nas colunas não diferem estatisticamente entre si pelo teste de Tukey a $1 \%$ de probabilidade

O maior valor de radiação solar global incidente no tratamento com túnel sem perfuração comprova a relação do efeito dos altos valores de radiação solar no interior de um ambiente com a elevada demanda evaporativa da atmosfera (Gimenes et al. (1994)). A aderência das gotas de água sob o filme plástico reduz a transmissividade deste material e, portanto, aumenta a interceptação de radiação solar de onda longa, obtendo-se um ambiente com maior conservação de calor.

\subsubsection{Avaliação do desenvolvimento das plantas}

\subsubsection{Massa seca (MS) e massa verde (MV) em época de verão}

No período de verão, os resultados das variáveis de produção, massa seca e massa verde, foram mais elevados fora do ambiente protegido (Figuras 17 e 18). A produção de massa verde foi, em média, 55\% superior no ambiente externo. Já a produção de matéria seca foi $45 \%$ maior no canteiro testemunha. Estes resultados contrariam os apresentados por Monteiro et al. (2000) que observaram, no período de primavera, maior produção de massa verde da alface no interior do túnel, na ordem de $62 \%$, e uma produção de massa seca $14 \%$ maior nos túneis. No entanto, confirma os resultados apresentados por Streck et al. (1994), que avaliaram o efeito do crescimento da alface em túneis baixos em época de primavera e 
inverno, apresentando resultados superiores em massa seca e verde nos tratamentos sem túnel em época de primavera se comparado à produção sob o túnel baixo de manejo convencional, ou seja, com abertura das laterais.

Era esperado que as plantas de rúcula sob os túneis apresentassem maior desenvolvimento do que aquelas cultivadas em ambiente natural. Entretanto, os resultados obtidos neste experimento, não foram coerentes com o que ocorre normalmente. Este fato pode ser explicado em função das elevadas temperaturas máximas ocorridas durante o período experimental de verão, onde a média de temperatura ao longo do dia atingiu valores de $48{ }^{0} \mathrm{C}$ no interior do túnel com $0 \%$ de perfuração, em contrapartida aos valores médios encontrados por Monteiro et al. (2000) de $31^{\circ} \mathrm{C}$ em época de primavera.

Os resultados também indicam que o manejo com abertura das laterais no tratamento com túnel baixo sem perfuração na cobertura plástica, é recomendado para proporcionar maiores chances de melhor desenvolvimento da cultura.

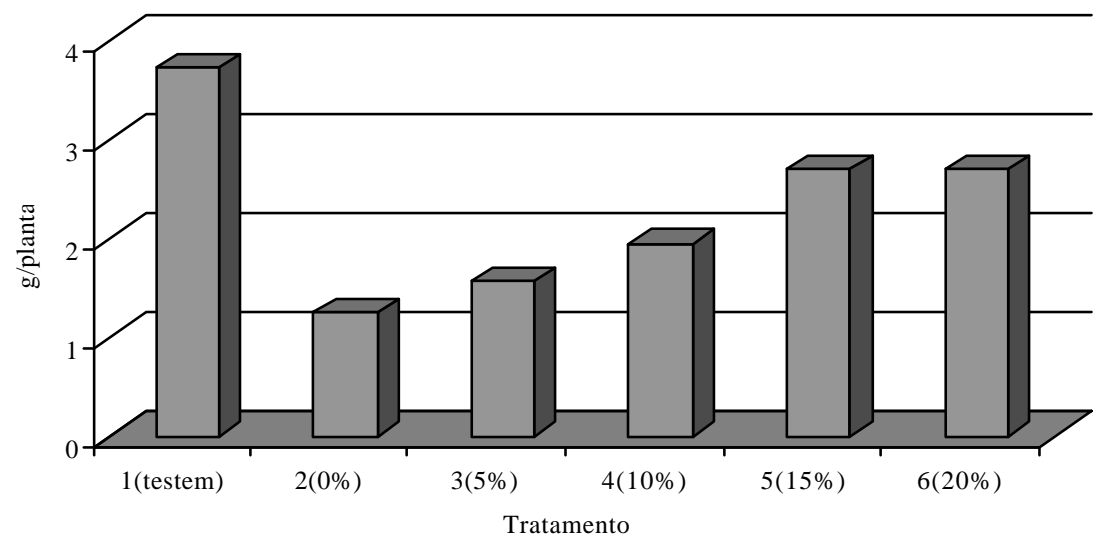

Figura 17 - Produção de massa seca média por planta de rúcula, no período de coleta de dados de verão, de 31/01/01 a 06/03/01, em Piracicaba, SP. 


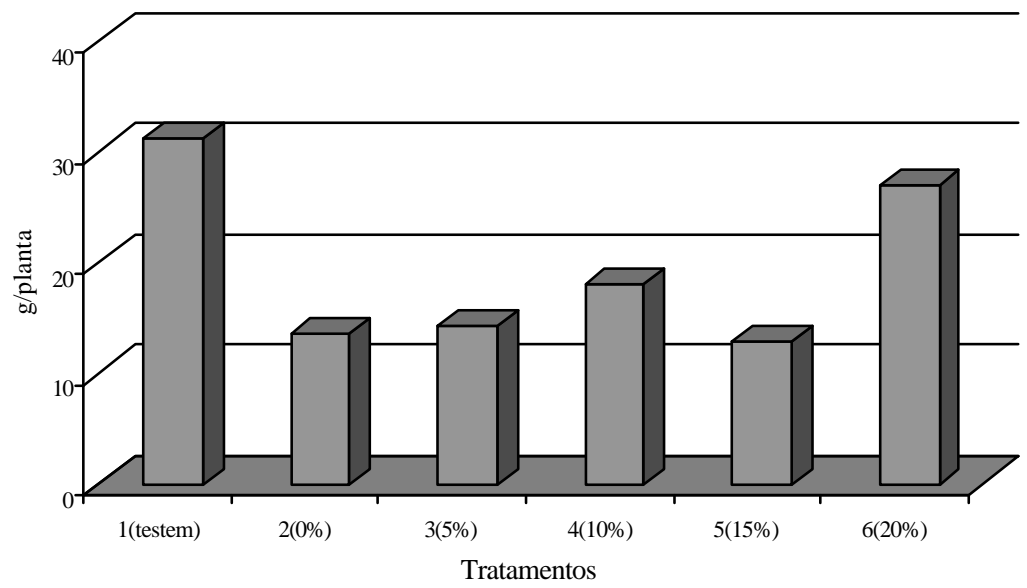

Figura 18 - Produção de massa verde média por planta de rúcula, durante o período de coleta de dados de verão, de 31/01/01 a 06/03/01, em Piracicaba, SP.

4.1.2.2 Massa seca (MS) e massa verde (MV) em época de outono

No período de outono, as variáveis massa verde e massa seca apresentaram valores superiores no interior dos túneis (Figuras 19 e 20). A produção de massa verde foi no interior dos túneis, em média, 65\% superior à do canteiro descoberto. Já a produção de massa seca foi $68 \%$ maior nos tratamentos cobertos com túnel baixo. Tais resultados concordam com Streck et al. (1994); Buriol et al. (1997); e Monteiro et al. (2000) que observaram o crescimento da alface sendo favorecido no ambiente sob os túneis baixos de polietileno transparente perfurado em relação ao ambiente externo. 


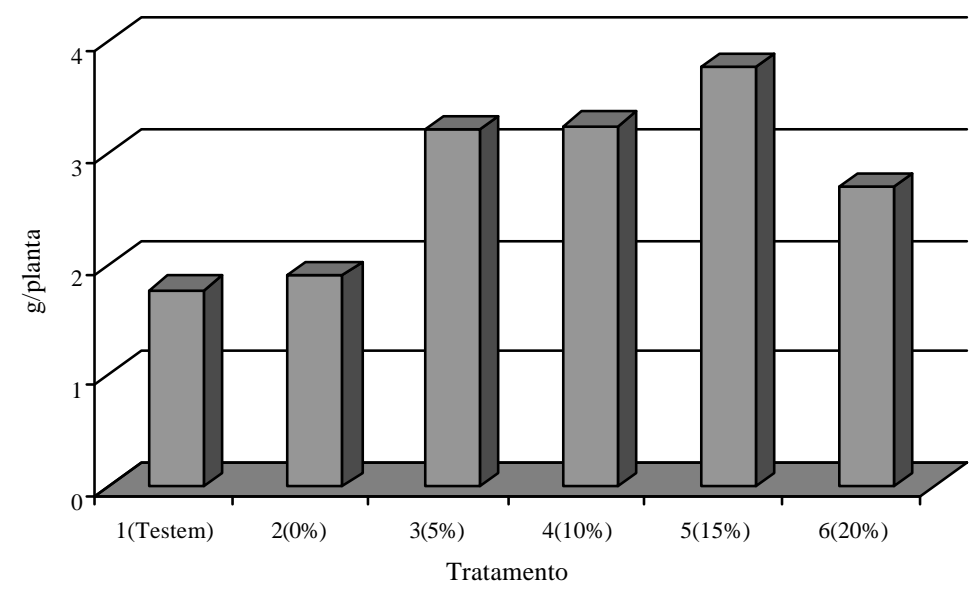

Figura 19 - Produção de massa seca média por planta de rúcula, no período de coleta de dados de outono, de 17/04/01 a 17/05/01, em Piracicaba, SP.

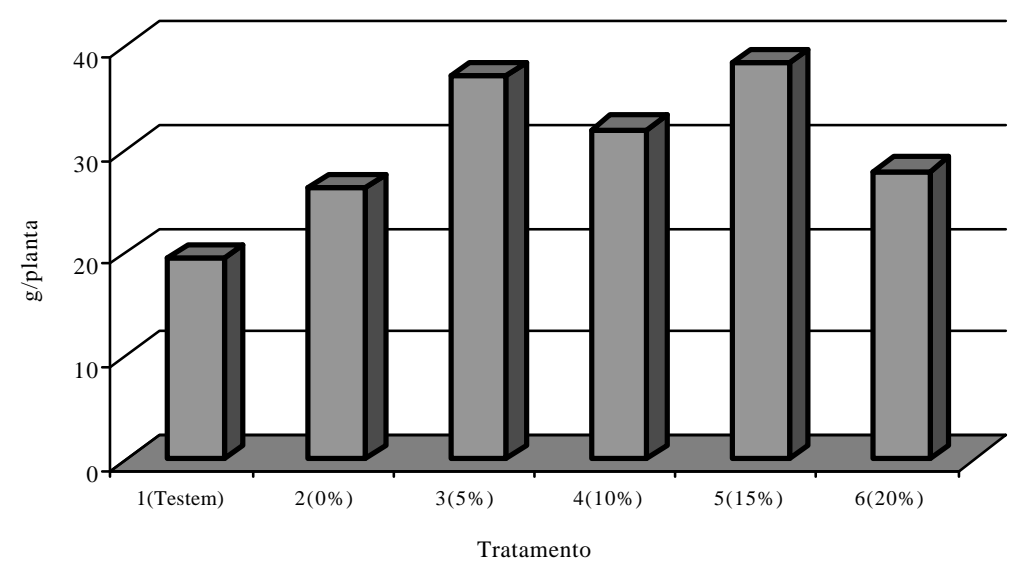

Figura 20 - Produção de massa verde média por planta de rúcula, durante o período de coleta de dados de outono, de 17/04/01 a 17/05/01, em Piracicaba, SP.

A produção de massa verde durante o outono foi superior à produção no verão. Devido ao excesso de calor, a rúcula emite rapidamente seu pendão floral, diminuindo, com isso, o tamanho da planta e apresentando, consequentemente, um florescimento precoce. $\mathrm{E}$, 
além disso, a rúcula necessita de temperaturas médias mais amenas $\left(15\right.$ à $\left.18^{0} \mathrm{C}\right)$ para seu bom desenvolvimento, de acordo com Sonnenberg (1980).

Essa resposta diferenciada sugere que, em diferentes épocas do ano, há a necessidade de mudanças de manejo do ambiente protegido ou ainda, uma taxa diferenciada dá área de perfuração.

\subsubsection{Características da planta}

\subsection{Número de folhas}

Analisando-se as características da planta com relação ao número de folhas produzidas, concluiu-se que não houve diferença significativa entre o tratamento sem cobertura e os demais tratamentos (Tabela 8).

$\mathrm{Na}$ época de verão, houve diferença significativa entre o túnel com $20 \%$ de perfuração e o túnel com plástico sem perfuração, mostrando valores inferiores no canteiro a $0 \%$ de perfuração. No interior do túnel sem perfuração as temperaturas máximas atingiram com frequiência valores muito elevados, em torno de $48{ }^{0} \mathrm{C}$ nos horários mais críticos do dia, tornando o ambiente prejudicial ao crescimento das plantas e provocando uma queda no número de folhas e em seu desenvolvimento.

Já no outono, o número de folhas não apresentou diferença significativa entre os diversos tratamentos com túnel. Tal resultado pode ser decorrência do fato de que a temperatura ambiente apresentou-se de forma mais amena, variando de $33,6{ }^{\circ} \mathrm{C}$ e $39,0{ }^{\circ} \mathrm{C}$ nos tratamentos a $20 \%$ e $0 \%$ de área perfurada, respectivamente, tornando-se menos prejudicial ao desenvolvimento da planta devido à menor temperatura interna e menor umidade relativa, $\mathrm{o}$ que proporcionou um microclima menos favorável à manifestação de doenças. 
Tabela 8 - Resultados do teste de Tukey para as médias do número de folhas no final do ciclo da rúcula, cultivado em túneis baixos com diferentes níveis de perfuração, em época de verão e de outono, em Piracicaba, SP.

\begin{tabular}{ccc}
\hline Tratamentos & \multicolumn{2}{c}{ Numero de folhas/planta } \\
& verão & outono \\
\hline 1 (testemunha) & $6,6 \mathrm{ab}$ & $5,8 \mathrm{a}$ \\
$2(0 \%)$ & $5,3 \mathrm{~b}$ & $7,1 \mathrm{a}$ \\
$3(5 \%)$ & $7,5 \mathrm{ab}$ & $7,3 \mathrm{a}$ \\
$4(10 \%)$ & $6,7 \mathrm{ab}$ & $6,3 \mathrm{a}$ \\
$5(15 \%)$ & $7,1 \mathrm{ab}$ & $5,6 \mathrm{a}$ \\
$6(20 \%)$ & $8,4 \mathrm{a}$ & $6,2 \mathrm{a}$ \\
\hline guidas pela mesma letra nas colunas não diferem estatisticamente entre si pelo teste de Tukey
\end{tabular}

\subsection{Tamanho, peso e largura das folhas}

No verão, por meio da análise das características das folhas como altura, peso e largura, o tratamento com plantas sob o túnel sem perfuração foi o que apresentou diferença significativa com relação à testemunha, tanto para a altura quanto para a largura e o peso das folhas, demonstrando valores médios inferiores de até $6,5 \mathrm{~cm}$ de altura, quando comparados às plantas produzidas em ambiente externo.

O maior crescimento das plantas foi apresentado no tratamento com $15 \%$ de perfuração, seguido dos tratamentos com 5\%; 20\%; $10 \%$ e a testemunha, o que comprova uma interação mais favorável entre as temperaturas e trocas gasosas no ambiente a $15 \%$ (Tabela 9).

No entanto, comparando-se o crescimento da planta (altura e peso) nos túneis perfurados e no tratamento sem cobertura observou-se não haver diferença significativa. Tais resultados comprovam a pesquisa realizada por Monteiro et al. (2000), que também não encontraram diferenças significativas quanto à altura da planta em túneis baixos com diferentes porcentagens de perfuração. Porém, tais resultados contrariam pesquisa realizada por Streck et al. (1994) que trabalharam com plástico perfurado a $0,78 \% ; 1,57 \% ; 2,35 \%$ e 3,14\% na cobertura de túneis baixos e observaram o crescimento significativo da alface favorecido no 
ambiente sob os túneis baixos de polietileno transparente perfurado em relação ao ambiente externo. Esse resultado deve-se ao fato do trabalho ter sido realizado no período de inverno e primavera, épocas nos quais a temperatura é mais amena, além da diferença existente entre as áreas de perfuração do filme plástico em questão.

Apesar de não ter ocorrido diferenças significativas entre os diversos tratamentos, no ambiente sob o túnel em época de outono as características das folhas da planta foram visivelmente de melhor qualidade, apresentando-se mais tenras e com aspecto sensivelmente superior, concordando com Monteiro et al. (2000) no cultivo da alface sob túneis baixos em época de primavera.

Tabela 9 - Resultados do teste de Tukey para altura, largura e peso das folhas no final do ciclo da rúcula, em época de verão, em Piracicaba, SP.

\begin{tabular}{cccc}
\hline Tratamentos & \multicolumn{3}{c}{ Características da folha } \\
& Altura $(\mathrm{cm})$ & Largura $(\mathrm{cm})$ & Peso $(\mathrm{g})$ \\
\hline 1 (testemunha) & $24,50 \mathrm{a}$ & $6,90 \mathrm{a}$ & $3,40 \mathrm{ab}$ \\
$2(0 \%)$ & $18,00 \mathrm{~b}$ & $4,20 \mathrm{c}$ & $1,30 \mathrm{c}$ \\
$3(5 \%)$ & $26,80 \mathrm{a}$ & $6,80 \mathrm{ab}$ & $3,60 \mathrm{ab}$ \\
$4(10 \%)$ & $25,50 \mathrm{a}$ & $5,60 \mathrm{~b}$ & $3,70 \mathrm{ab}$ \\
$5(15 \%)$ & $27,00 \mathrm{a}$ & $6,70 \mathrm{~b}$ & $4,10 \mathrm{a}$ \\
$6(20 \%)$ & $25,80 \mathrm{a}$ & $5,70 \mathrm{~b}$ & $2,70 \mathrm{~b}$ \\
\hline
\end{tabular}

\subsubsection{Produtividade}

Quanto à produtividade pode-se notar pelos resultados apresentados na Tabela 10 que houve variação entre os diversos níveis de perfuração dos túneis baixos e o cultivo sem cobertura . 
Tabela 10 - Valores de produtividade média $\left(\mathrm{g} / \mathrm{m}^{2}\right)$ e relativa $(\%)$ da rúcula obtidos no final do ciclo, em época de verão e de outono, em Piracicaba, SP.

\begin{tabular}{ccccc}
\hline Tratamento & \multicolumn{2}{c}{$\begin{array}{c}\text { Produtividade média }\left(\mathrm{g} / \mathrm{m}^{2}\right) \\
\text { ourão }\end{array}$} & outono & \multicolumn{2}{c}{ Produtividade relativa (\%) } \\
& verão & outono \\
\hline 1 (testemunha) & 2385 & 2955 & 100 & 100 \\
$2(0 \%)$ & 1213 & 4118 & 52 & 139 \\
$3(5 \%)$ & 3821 & 4268 & 127 & 144 \\
$4(10 \%)$ & 3247 & 3193 & 116 & 108 \\
$5(15 \%)$ & 4793 & 4431 & 157 & 150 \\
$6(20 \%)$ & 2901 & 3295 & 122 & 112 \\
\hline
\end{tabular}

* médias seguidas pela mesma letra nas colunas não diferem estatisticamente entre si pelo teste de Tukey ao nível de $1 \%$ de probabilidade

O túnel coberto com plástico a 15\% de área perfurada apresentou uma produção 57\% maior do que a testemunha em época de verão. Já o túnel coberto com plástico sem perfuração produziu um número de plantas $48 \%$ menor do que a testemunha, o que acarretou uma baixa produtividade. Esta menor produtividade comprova que um ambiente com plástico sem perfuração, em época de verão, apresenta uma maior camada de gotículas de água sob o plástico devido à elevada temperatura e umidade relativa do ar, afetando diretamente o crescimento e desenvolvimento da cultura (Figura 21).

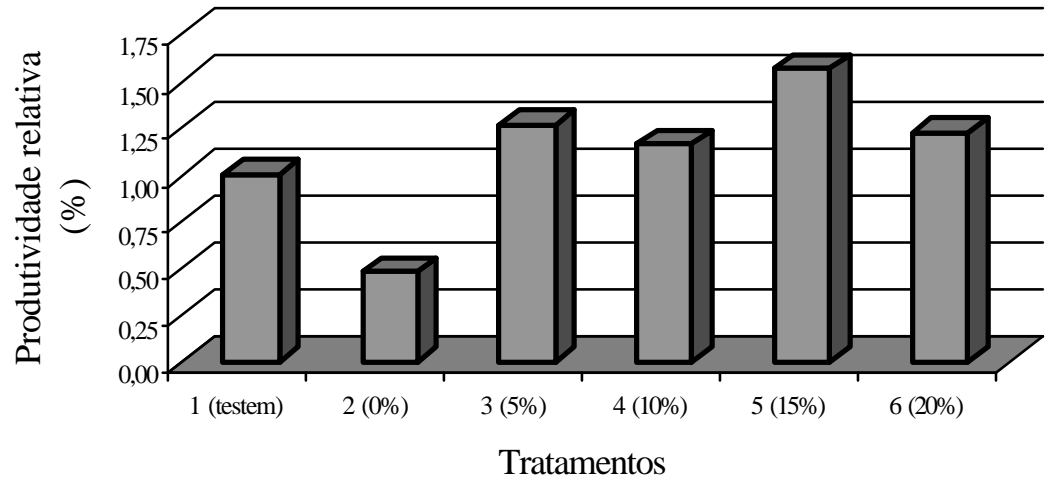

Figura 21 - Produtividade relativa (\%) obtida no final do ciclo da rúcula em época de verão, de 31/01/01 a 06/03/01, em Piracicaba, SP. 
A maior produtividade em época de outono (Figura 22) pode ser observada também no tratamento a 15\%, obtendo-se uma produção $50 \%$ maior do que a da testemunha, o que vem comprovar resultados obtidos por Monteiro et al. (2000) que encontraram valores superiores de produção da alface no tratamento a $15 \%$ durante a primavera.

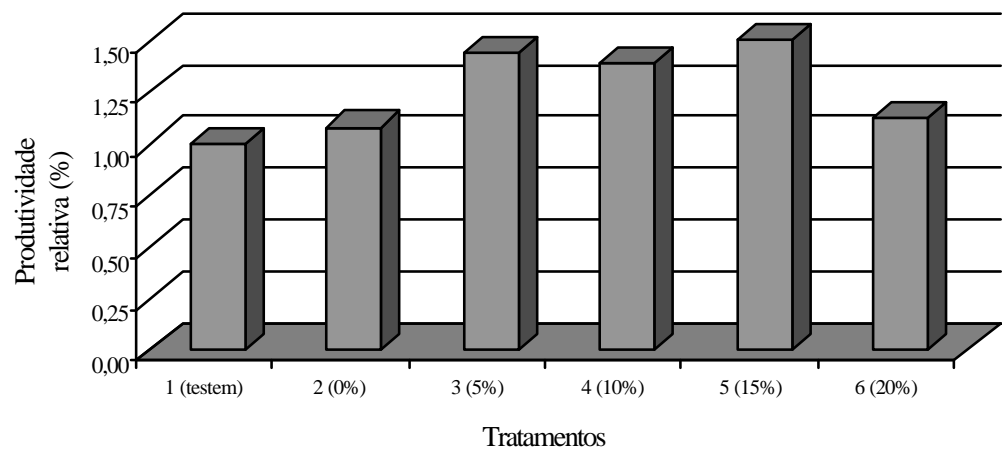

Figura 22 - Produtividade relativa (\%) obtida no final do ciclo da rúcula em época de outono, de 17/04/01 a 17/05/01, em Piracicaba, SP.

A perfuração do filme plástico de túneis baixos favorece a movimentação interna do ar, um dos fatores mais importantes no desenvolvimento de um ambiente adequado para o cultivo. No entanto, a área perfurada mais adequada ao crescimento da rúcula depende da época do cultivo. Recomenda-se a utilização de um manejo diferenciado dos túneis baixos para as diferentes estações do ano.

Analisando-se as variáveis temperatura do ar, características da planta, além da produção de massa verde, pôde-se concluir que, o manejo convencional com a utilização da abertura das laterais deve estar associado, principalmente, aos túneis com menor ou nenhuma densidade de perfuração durante o verão. Já no outono, os resultados obtidos no interior dos túneis dispensam a utilização do manejo convencional, sendo as perfurações no filme plástico suficientes para proporcionar uma movimentação do ar que proporcione um ambiente adequado ao cultivo desta hortaliça. 


\subsection{Experimento II}

$\mathrm{Na}$ Segunda fase do experimento, foram analisados alguns elementos microclimáticos como a temperatura do ar, a umidade relativa do ar, a radiação solar global e a temperatura do solo, além de algumas características morfológicas e produtivas da cultura do rabanete (Raphanus sativus L.) como massa seca, massa verde, características do tubérculo (altura, diâmetro e peso), em época de inverno e de primavera.

\subsubsection{Elementos microclimáticos}

\subsubsection{Temperatura do ar}

Observa-se nas Figuras 23 e 24, que tanto no inverno como na primavera, todos os tratamentos com túnel baixo apresentaram temperatura ambiente superior ao tratamento sem túnel devido, principalmente, ao fato de que o pequeno volume de ar presente no interior dos túneis baixos está menos sujeito à renovação de ar que no ambiente externo apresentando dessa forma temperaturas mais elevadas no interior dos túneis. Resultados semelhantes foram encontrados por Monteiro et al. (2001) para o cultivo da alface em túneis baixos.

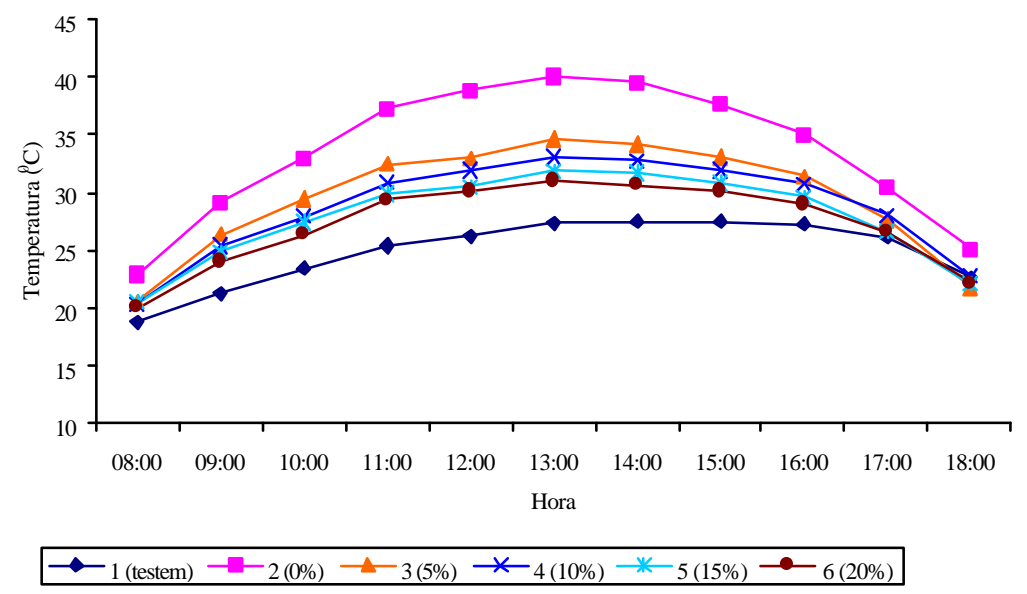

Figura 23 - Temperatura média horária do ar no período de coleta de dados de inverno, de 22/08/01 a 05/09/01, em Piracicaba, SP. 


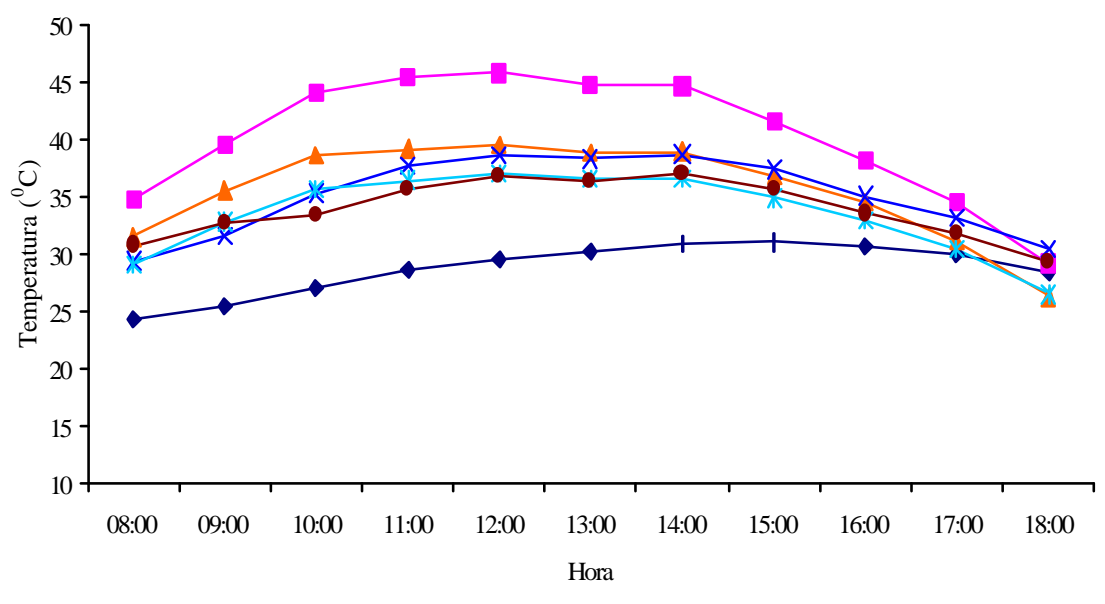

$\rightarrow-1$ (testem) $-2(0 \%) \rightarrow-3(5 \%) \rightarrow 4(10 \%) \rightarrow-5(15 \%) \rightarrow 6(20 \%)$

Figura 24 - Temperatura média horária do ar no período de coleta de dados de primavera, de 22/11/01 a 03/12/01, em Piracicaba, SP.

De acordo com as Tabelas 11 e 12, por meio da análise estatística realizada para a variável temperatura do ar pôde-se notar que, nos horários mais críticos do dia durante os períodos estudados, houve diferença significativa entre o tratamento sem túnel e os demais tratamentos. No período de inverno a diferença estatística pôde ser observada também entre os tratamentos a $0 \%$ de perfuração e os demais tratamentos com área perfurada, assim como no tratamento a $5 \%$ e $20 \%$ de perfuração. O mesmo pôde ser observado na primavera. Os ganhos térmicos foram maiores nos ambientes com menor área de perfuração o que comprova resultados encontrados por Buriol et al. (1993) em estudo sobre diferentes níveis de perfuração em cobertura de túneis baixos sobre o cultivo da alface, discutidos anteriormente. 
Tabela 11 - Resultado do teste de Tukey para as médias horárias de temperatura do ar, durante coleta de dados de inverno, no intervalo das 11:00 às 15:00 horas, em Piracicaba, SP.

\begin{tabular}{cccccc}
\hline \multicolumn{5}{c}{ Temperatura do $\operatorname{ar}\left({ }^{\circ} \mathrm{C}\right)$} \\
Tratamento & 11 horas & 12 horas & 13 horas & 14 horas & 15 horas \\
\hline 1 (testem) & $25,34 \mathrm{~d}$ & $26,26 \mathrm{~d}$ & $27,30 \mathrm{~d}$ & $27,50 \mathrm{~d}$ & $27,48 \mathrm{~d}$ \\
$2(0 \%)$ & $37,28 \mathrm{a}$ & $38,84 \mathrm{a}$ & $40,01 \mathrm{a}$ & $39,49 \mathrm{a}$ & $37,66 \mathrm{a}$ \\
$3(5 \%)$ & $32,46 \mathrm{~b}$ & $32,98 \mathrm{~b}$ & $34,63 \mathrm{~b}$ & $34,21 \mathrm{~b}$ & $33,04 \mathrm{~b}$ \\
$4(10 \%)$ & $30,89 \mathrm{bc}$ & $31,95 \mathrm{bc}$ & $33,05 \mathrm{bc}$ & $32,73 \mathrm{bc}$ & $31,93 \mathrm{bc}$ \\
$5(15 \%)$ & $29,89 \mathrm{c}$ & $30,52 \mathrm{bc}$ & $31,86 \mathrm{c}$ & $31,68 \mathrm{c}$ & $30,85 \mathrm{c}$ \\
$6(20 \%)$ & $29,32 \mathrm{c}$ & $30,11 \mathrm{c}$ & $31,01 \mathrm{c}$ & $30,66 \mathrm{c}$ & $30,12 \mathrm{c}$ \\
\hline
\end{tabular}

*médias seguidas pela mesma letra nas colunas não diferem estatisticamente entre si pelo teste de Tukey a nível de $1 \%$ de probabilidade

Tabela 12 - Resultado do teste de Tukey para as médias horárias de temperatura do ar, durante coleta de dados de primavera, no intervalo das 11:00 às 15:00 horas, em Piracicaba, SP.

\begin{tabular}{cccccc}
\hline & \multicolumn{5}{c}{ Temperatura do ar $\left({ }^{\circ} \mathrm{C}\right)$} \\
Tratamento & 11 horas & 12 horas & 13 horas & 14 horas & 15 horas \\
\hline 1 (testem) & $28,59 \mathrm{~d}$ & $29,50 \mathrm{~d}$ & $30,26 \mathrm{c}$ & $31,01 \mathrm{c}$ & $31,09 \mathrm{c}$ \\
$2(0 \%)$ & $45,52 \mathrm{a}$ & $45,87 \mathrm{a}$ & $44,87 \mathrm{a}$ & $44,68 \mathrm{a}$ & $41,68 \mathrm{a}$ \\
$3(5 \%)$ & $39,22 \mathrm{~b}$ & $39,60 \mathrm{~b}$ & $38,87 \mathrm{~b}$ & $38,96 \mathrm{~b}$ & $36,93 \mathrm{~b}$ \\
$4(10 \%)$ & $37,72 \mathrm{bc}$ & $38,64 \mathrm{bc}$ & $38,32 \mathrm{~b}$ & $38,79 \mathrm{~b}$ & $37,44 \mathrm{~b}$ \\
$5(15 \%)$ & $36,49 \mathrm{bc}$ & $37,09 \mathrm{bc}$ & $36,62 \mathrm{~b}$ & $36,61 \mathrm{~b}$ & $34,90 \mathrm{~b}$ \\
$6(20 \%)$ & $35,77 \mathrm{c}$ & $36,82 \mathrm{c}$ & $36,32 \mathrm{~b}$ & $37,01 \mathrm{~b}$ & $35,77 \mathrm{~b}$ \\
\hline
\end{tabular}

*médias seguidas pela mesma letra nas colunas não diferem estatisticamente entre si pelo teste de Tukey a nível de $1 \%$ de probabilidade

\subsubsection{Umidade Relativa do Ar}

Verifica-se através da Figura 25, que todos os valores de umidade relativa do ar no interior dos túneis baixos no inverno apresentaram-se superiores ao tratamento testemunha, variando de $6,82 \%$ a $25,24 \%$ superior nos tratamentos a $20 \%$ e $0 \%$, respectivamente. A pouca renovação do ar no interior do ambiente a $0 \%$ de perfuração aliada a elevada umidade do solo no interior do túnel faz com que o valor da pressão atual de vapor também 
permaneça mais elevado. Quanto maior o nível de perfuração, menor o valor de umidade relativa do ar, visto que, quanto maior a área perfurada, menor a resistência ao fluxo turbulento de vapor d'água no interior dos túneis, reduzindo a umidade relativa do ar. Tal fato comprova estudos realizados por Monteiro et al. (2001), que observaram ser inversamente proporcional, a umidade relativa do ar e a densidade de perfuração da cobertura plástica nos túneis baixos.

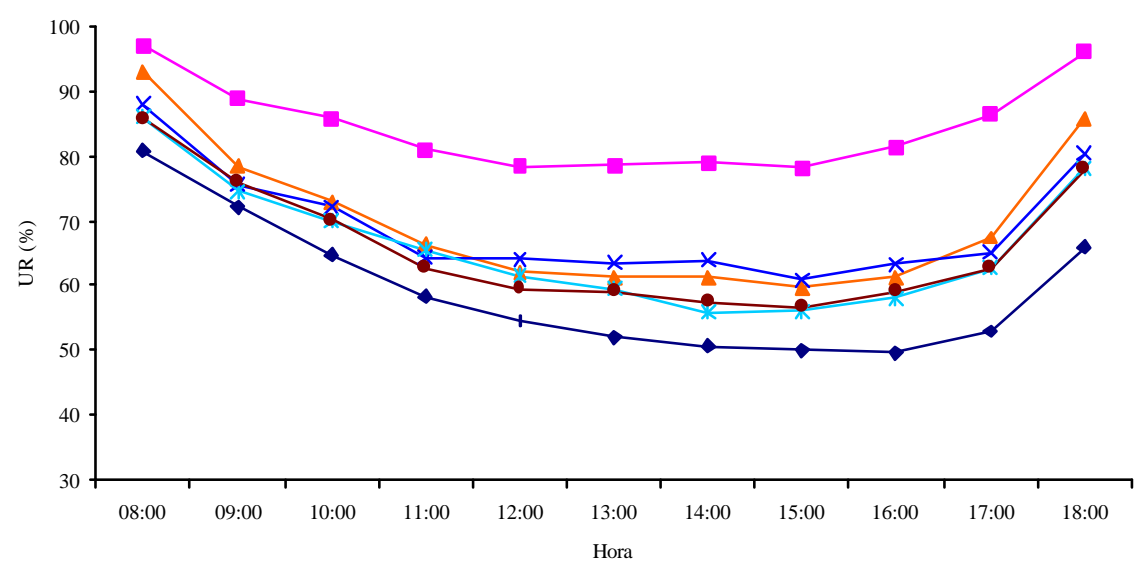

$\rightarrow-1$ (testem) $\rightarrow-2(0 \%) \multimap-3(5 \%) \rightarrow 4(10 \%) \rightarrow-6(15 \%) \rightarrow-6(20 \%)$

Figura 25 - Umidade Relativa média horária do ar no período de coleta de dados de inverno, de 22/08/01 a 05/09/01, em Piracicaba, SP.

Na primavera os valores de umidade relativa do ar em média horária apresentou valores muito próximos entre os túneis com plástico perfurado variando em média 4\%. Com relação à testemunha a variação foi de 5,35\% a 9,14\% nos tratamentos a $20 \%$ e $0 \%$, respectivamente. A amplitude de variação foi bastante inferior à observada no verão e a relação de quanto maior a área perfurada menor o valor de umidade relativa não pôde ser observada entre os tratamentos a 5\%,10\% e 15\% devido aos valores muito próximos nessa época do ano (Figura 26). 


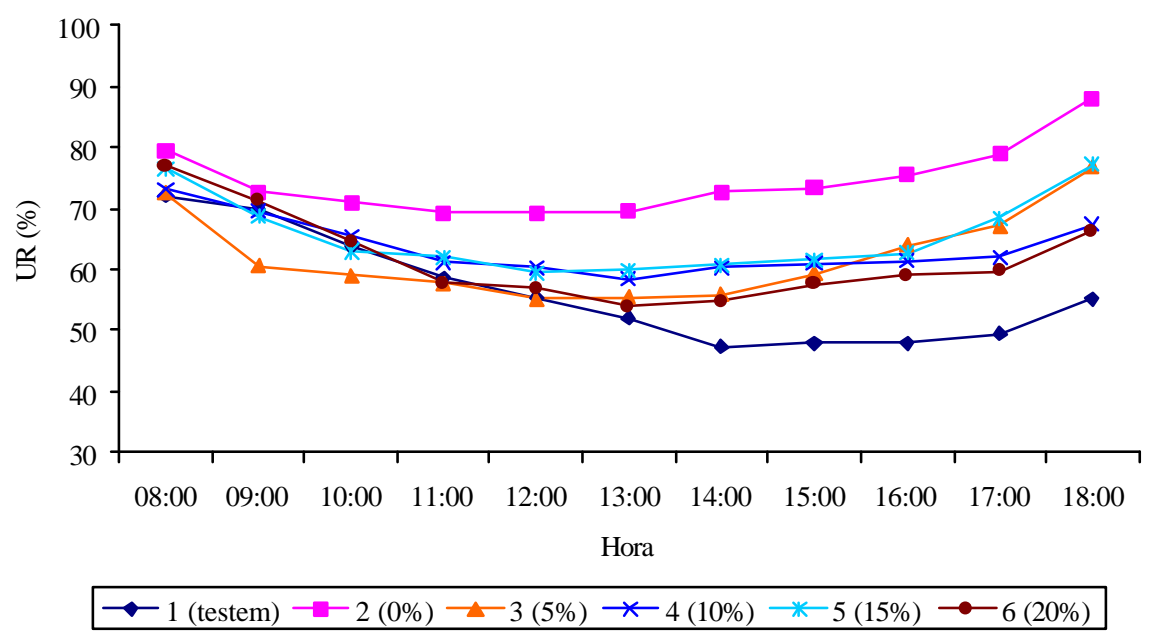

Figura 26 - Umidade relativa média horária do ar no período de coleta de dados de primavera, de 22/11/01 a 03/12/01, em Piracicaba, SP.

De acordo com os resultados da análise estatística, adotando o teste de Tukey a $1 \%$ de significância, observou-se que no inverno (Tabela 13), houve diferença significativa entre os tratamentos a céu aberto, $0 \%$ e 5\% de área perfurada, não havendo diferença significativa entre os níveis de perfuração $5 \%, 10 \%, 15 \%$ e $20 \%$ entre si. No período da primavera (Tabela 14), não houve diferença significativa entre os tratamentos no período mais crítico do dia, o que pode comprovar a pequena influência da variação de umidade relativa nessa época do ano. A temperatura mais acentuada no período da primavera reduz a amplitude de variação da umidade relativa, do déficit de saturação e da tensão de vapor do ar. 
Tabela 13 - Resultado do teste de Tukey para as médias horárias de umidade relativa do ar, durante coleta de dados de inverno, no intervalo das 11:00 às 15:00 horas, em Piracicaba, SP.

\begin{tabular}{cccccc}
\hline & \multicolumn{5}{c}{ Umidade relativa do ar (\%) } \\
Tratamento & 11 horas & 12 horas & 13 horas & 14 horas & 15 horas \\
\hline 1 (testem) & $58,36 \mathrm{c}$ & $54,56 \mathrm{c}$ & $51,93 \mathrm{c}$ & $50,60 \mathrm{c}$ & $50,09 \mathrm{c}$ \\
$2(0 \%)$ & $80,93 \mathrm{a}$ & $78,21 \mathrm{a}$ & $78,41 \mathrm{a}$ & $78,89 \mathrm{a}$ & $78,16 \mathrm{a}$ \\
$3(5 \%)$ & $66,27 \mathrm{~b}$ & $61,98 \mathrm{~b}$ & $61,33 \mathrm{~b}$ & $61,20 \mathrm{~b}$ & $59,75 \mathrm{~b}$ \\
$4(10 \%)$ & $64,16 \mathrm{bc}$ & $64,06 \mathrm{~b}$ & $63,36 \mathrm{~b}$ & $63,93 \mathrm{~b}$ & $60,88 \mathrm{~b}$ \\
$5(15 \%)$ & $65,44 \mathrm{~b}$ & $61,37 \mathrm{bc}$ & $59,49 \mathrm{~b}$ & $55,99 \mathrm{bc}$ & $56,18 \mathrm{bc}$ \\
$6(20 \%)$ & $62,70 \mathrm{bc}$ & $59,48 \mathrm{bc}$ & $59,13 \mathrm{bc}$ & $57,46 \mathrm{bc}$ & $56,66 \mathrm{bc}$ \\
\hline
\end{tabular}

*médias seguidas pela mesma letra nas colunas não diferem estatisticamente entre si pelo teste de Tukey a nível de $1 \%$ de probabilidade

Tabela 14 - Resultado do teste de Tukey para as médias horárias de umidade relativa do ar, durante coleta de dados de primavera, no intervalo das 11:00 às 15:00 horas, em Piracicaba, SP.

\begin{tabular}{cccccc}
\hline & \multicolumn{5}{c}{ Umidade relativa do ar (\%) } \\
Tratamento & 11 horas & 12 horas & 13 horas & 14 horas & 15 horas \\
\hline 1 (testem) & $58,65 \mathrm{ab}$ & $55,51 \mathrm{~b}$ & $51,98 \mathrm{~b}$ & $47,27 \mathrm{c}$ & $47,89 \mathrm{c}$ \\
$2(0 \%)$ & $69,26 \mathrm{a}$ & $69,36 \mathrm{a}$ & $69,18 \mathrm{a}$ & $72,69 \mathrm{a}$ & $73,42 \mathrm{a}$ \\
$3(5 \%)$ & $59,19 \mathrm{ab}$ & $55,16 \mathrm{~b}$ & $55,47 \mathrm{~b}$ & $55,83 \mathrm{bc}$ & $59,25 \mathrm{~b}$ \\
$4(10 \%)$ & $61,30 \mathrm{ab}$ & $61,31 \mathrm{ab}$ & $61,53 \mathrm{ab}$ & $58,50 \mathrm{~b}$ & $61,53 \mathrm{~b}$ \\
$5(15 \%)$ & $63,03 \mathrm{ab}$ & $59,51 \mathrm{ab}$ & $57,48 \mathrm{ab}$ & $60,79 \mathrm{~b}$ & $59,66 \mathrm{~b}$ \\
$6(20 \%)$ & $56,88 \mathrm{~b}$ & $57,90 \mathrm{~b}$ & $54,81 \mathrm{~b}$ & $53,86 \mathrm{bc}$ & $59,11 \mathrm{~b}$ \\
\hline
\end{tabular}

*médias seguidas pela mesma letra nas colunas não diferem estatisticamente entre si pelo teste de Tukey a nível de $1 \%$ de probabilidade

\subsubsection{Temperatura do solo}

Como pode ser observado na Figura 27, a temperatura do solo em média horária no interior do túnel baixos no inverno apresentou valores superiores à testemunha que variam de $1,4{ }^{0} \mathrm{C}$ a $4,3{ }^{0} \mathrm{C}$ nos tratamentos a $20 \%$ e $0 \%$, respectivamente. $\mathrm{O}$ mesmo aconteceu no período de primavera, porém com variação de $1,7{ }^{0} \mathrm{C}$ a $5,1{ }^{0} \mathrm{C}$ (Figura 28). O túnel a $0 \%$ de 
área perfurada apresentou uma menor capacidade de renovação de ar junto à superfície o que aumenta o fluxo de calor para o solo, acentuando seu aquecimento, fazendo com que apresentasse maior valor em ${ }^{0} \mathrm{C}$.

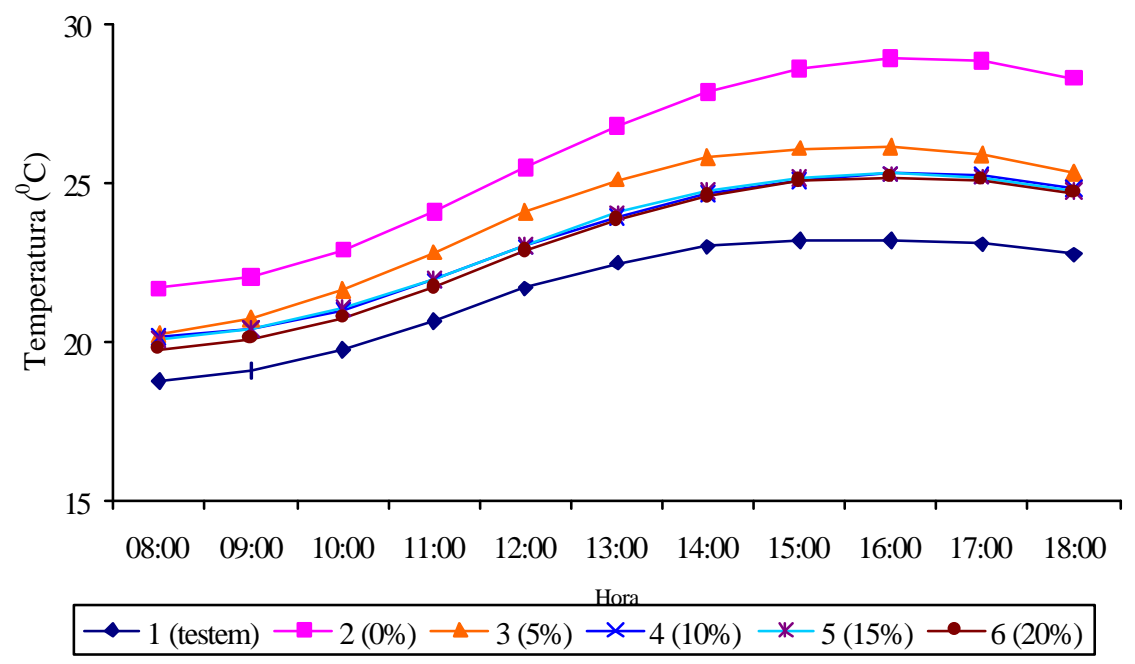

Figura 27 - Temperatura do solo média horária no período de coleta de dados de inverno, de 22/08/01 a 05/09/01, em Piracicaba, SP.

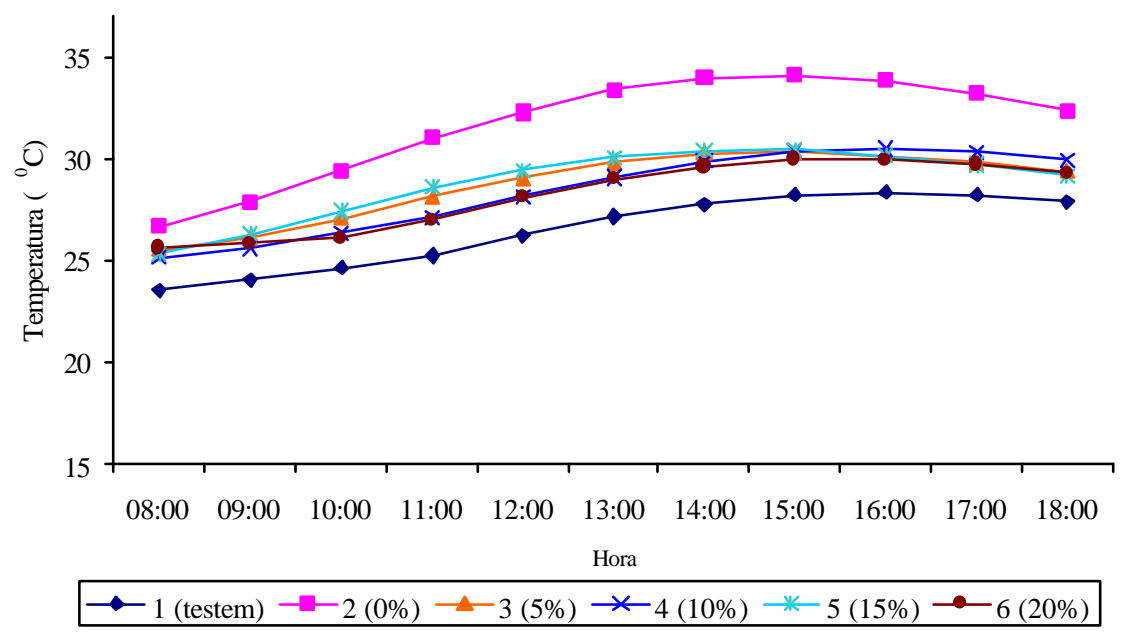

Figura 28 - Temperatura do solo média horária no período de coleta de dados de primavera, de 22/11/01 a 03/12/01, em Piracicaba, SP. 
De acordo com os resultados da análise estatística obtidos em período de inverno (Tabela 15) nota-se diferença significativa entre a testemunha e os demais tratamentos. Entre os tratamentos com plástico perfurado observou-se haver diferença significativa entre o tratamento a 5\% com relação aos demais. A maior temperatura do ar ocasionada pelo menor grau de perfuração produz uma menor renovação de ar com o meio, contribuindo para o aumento da temperatura do solo.

Tabela 15 - Resultado do teste de Tukey para as médias horárias de temperatura do solo, à $10 \mathrm{~cm}$ de profundidade, durante coleta de dados de inverno, no intervalo das 11:00 às 15:00 horas, em Piracicaba, SP.

\begin{tabular}{cccccc}
\hline & \multicolumn{5}{c}{ Temperatura do solo $\left({ }^{0} \mathrm{C}\right)$} \\
Tratamento & 11 horas & 12 horas & 13 horas & 14 horas & 15 horas \\
\hline 1 (testem) & $20,65 \mathrm{~d}$ & $21,66 \mathrm{~d}$ & $22,46 \mathrm{~d}$ & $22,98 \mathrm{~d}$ & $23,19 \mathrm{~d}$ \\
$2(0 \%)$ & $24,06 \mathrm{a}$ & $25,46 \mathrm{a}$ & $26,80 \mathrm{a}$ & $27,87 \mathrm{a}$ & $28,60 \mathrm{a}$ \\
$3(5 \%)$ & $22,81 \mathrm{~b}$ & $24,07 \mathrm{~b}$ & $25,10 \mathrm{~b}$ & $25,80 \mathrm{~b}$ & $26,09 \mathrm{~b}$ \\
$4(10 \%)$ & $21,94 \mathrm{c}$ & $22,98 \mathrm{c}$ & $23,91 \mathrm{c}$ & $24,64 \mathrm{c}$ & $25,07 \mathrm{c}$ \\
$5(15 \%)$ & $21,96 \mathrm{c}$ & $23,04 \mathrm{c}$ & $24,04 \mathrm{c}$ & $24,76 \mathrm{c}$ & $25,14 \mathrm{c}$ \\
$6(20 \%)$ & $21,71 \mathrm{c}$ & $22,84 \mathrm{c}$ & $23,84 \mathrm{c}$ & $24,60 \mathrm{c}$ & $25,04 \mathrm{c}$ \\
\hline *médias seguidas pela mesma letra nas colunas não diferem estatisticamente entre si pelo teste de Tukey a \\
nível de 1\% de probabilidade
\end{tabular}

Em época de primavera, a menor variação na temperatura do ar provoca também uma menor variação na temperatura do solo. Sendo assim, não houve diferença significativa entre os túneis com níveis de perfuração. A diferença significativa pôde ser observada nos tratamentos com túnel se comparados à testemunha e a $0 \%$ de perfuração (Tabela 16). 
Tabela 16 - Resultado do teste de Tukey para as médias horárias de temperatura do solo, à $10 \mathrm{~cm}$ de profundidade, durante coleta de dados de primavera, no intervalo das 11:00 às 15:00 horas, em Piracicaba, SP.

\begin{tabular}{cccccc}
\hline & \multicolumn{5}{c}{ Temperatura do solo $\left({ }^{\circ} \mathrm{C}\right)$} \\
Tratamento & 11 horas & 12 horas & 13 horas & 14 horas & 15 horas \\
\hline 1 (testem) & $25,25 \mathrm{~d}$ & $26,21 \mathrm{~d}$ & $27,16 \mathrm{~d}$ & $27,78 \mathrm{c}$ & $28,22 \mathrm{c}$ \\
$2(0 \%)$ & $31,05 \mathrm{a}$ & $32,30 \mathrm{a}$ & $33,41 \mathrm{a}$ & $34,00 \mathrm{a}$ & $34,12 \mathrm{a}$ \\
$3(5 \%)$ & $28,16 \mathrm{~b}$ & $29,08 \mathrm{bc}$ & $29,85 \mathrm{bc}$ & $30,25 \mathrm{~b}$ & $30,32 \mathrm{~b}$ \\
$4(10 \%)$ & $27,12 \mathrm{c}$ & $28,14 \mathrm{c}$ & $29,08 \mathrm{c}$ & $29,89 \mathrm{~b}$ & $30,40 \mathrm{~b}$ \\
$5(15 \%)$ & $28,62 \mathrm{~b}$ & $29,43 \mathrm{~b}$ & $30,06 \mathrm{~b}$ & $30,43 \mathrm{~b}$ & $30,45 \mathrm{~b}$ \\
$6(20 \%)$ & $27,00 \mathrm{c}$ & $28,13 \mathrm{c}$ & $28,98 \mathrm{c}$ & $29,60 \mathrm{~b}$ & $29,97 \mathrm{~b}$ \\
\hline *médias seguidas pela mesma letra nas colunas não diferem estatisticamente entre si pelo teste de Tukey a \\
nível de 1\% de probabilidade
\end{tabular}

\subsubsection{Radiação Solar Global}

No inverno, a variação da radiação solar apresentou-se mais uniforme, com uma menor disponibilidade de radiação solar no interior dos túneis baixos (Figura 29). A redução média no interior do ambiente protegido se comparado à testemunha foi de $25 \%$ considerando a média dos tratamentos, tendo atingido um maior valor de radiação solar de $583 \mathrm{~W} / \mathrm{m}^{2}$ no ambiente com $20 \%$ de área perfurada. Buriol et al (1993) encontraram resultados semelhantes para o cultivo da alface em túneis baixos, na região sul em época de inverno e primavera, porém, com redução de $21,4 \%$. Essa menor redução da radiação solar global encontrada por estes autores, está diretamente relacionada às diferenças ambientais da região e à utilização de densidade de perfurações inferiores a 5\% entre os tratamentos 


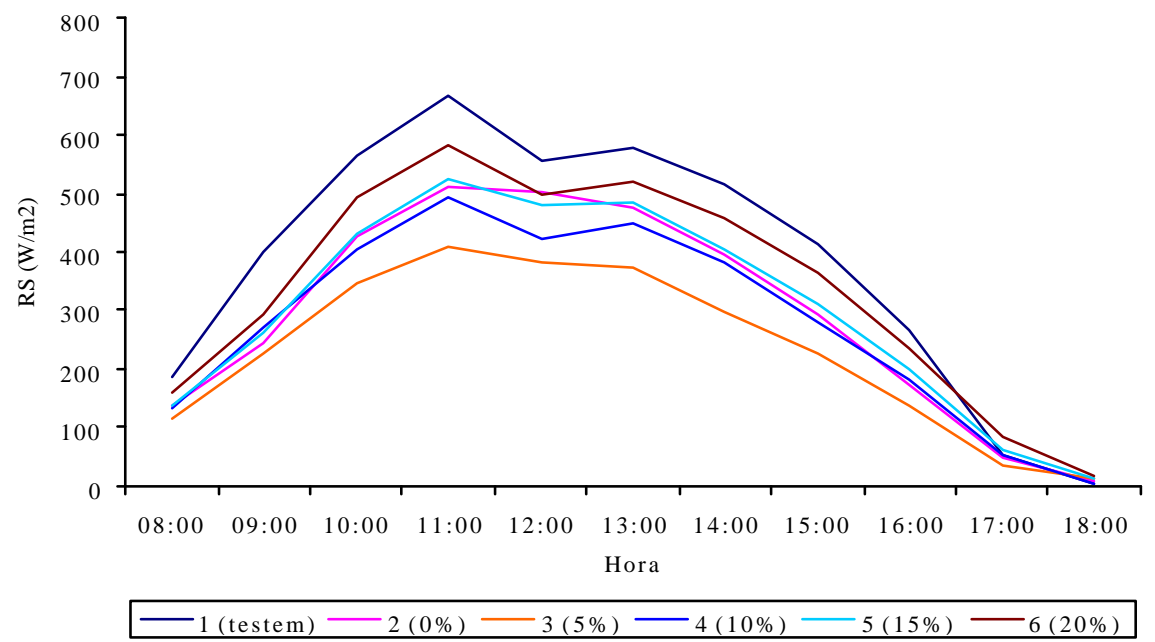

Figura 29 - Radiação solar global média horária no período de coleta de dados de inverno, de 22/08/01 a 05/09/01, em Piracicaba, SP.

Durante a primavera, os valores de atenuação da radiação solar foram, em média dos tratamentos $23,1 \%$ inferior à testemunha, sendo o maior valor de radiação solar global de $739,2 \mathrm{~W} / \mathrm{m}^{2}$ atingido pelo ambiente a $20 \%$ de perfuração (Figura 30 ).

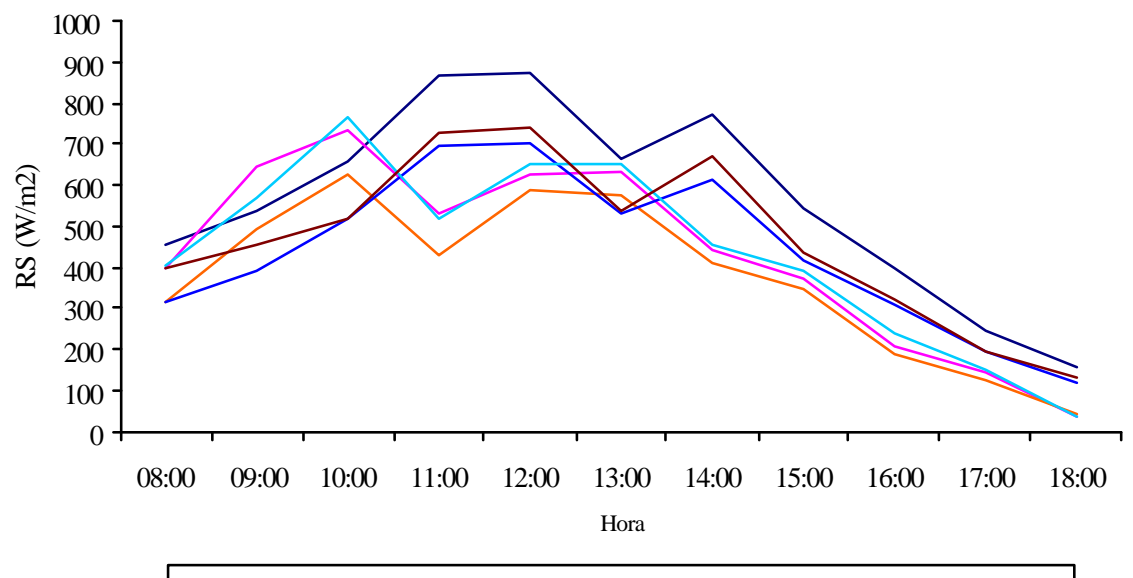

Figura 30 - Radiação solar global média horária no período de coleta de dados de primavera, de 22/11/01 a 03/12/01, em Piracicaba, SP. 
O resultado da análise estatística pode ser observada pelas Tabelas 17 e 18, onde tanto em época de inverno como primavera, não há diferença significativa entre os diversos tratamentos comprovando que, para essas épocas do ano, a variável radiação solar no interior dos túneis não é influenciada pelos níveis de perfuração do plástico de cobertura.

Tabela 17 - Resultado do teste de Tukey para as médias horárias de radiação solar global durante coleta de dados de inverno, no intervalo das 11:00 às 15:00 horas, em Piracicaba, SP.

\begin{tabular}{cccccc}
\hline & \multicolumn{5}{c}{ Radiação solar global $\left(\mathrm{W} / \mathrm{m}^{2}\right)$} \\
Tratamento & 11 horas & 12 horas & 13 horas & 14 horas & 15 horas \\
\hline 1 (testem) & $667,18 \mathrm{a}$ & $554,10 \mathrm{a}$ & $579,90 \mathrm{a}$ & $515,77 \mathrm{a}$ & $415,50 \mathrm{a}$ \\
$2(0 \%)$ & $512,40 \mathrm{~b}$ & $502,35 \mathrm{ab}$ & $478,55 \mathrm{bc}$ & $394,13 \mathrm{~b}$ & $293,94 \mathrm{bcd}$ \\
$3(5 \%)$ & $410,55 \mathrm{c}$ & $384,40 \mathrm{c}$ & $375,21 \mathrm{~d}$ & $297,60 \mathrm{c}$ & $226,99 \mathrm{~d}$ \\
$4(10 \%)$ & $495,44 \mathrm{bc}$ & $424,04 \mathrm{bc}$ & $449,43 \mathrm{c}$ & $382,04 \mathrm{bc}$ & $278,65 \mathrm{~cd}$ \\
$5(15 \%)$ & $525,16 \mathrm{~b}$ & $480,35 \mathrm{abc}$ & $483,97 \mathrm{bc}$ & $403,30 \mathrm{~b}$ & $313,10 \mathrm{bc}$ \\
$6(20 \%)$ & $583,02 \mathrm{ab}$ & $498,69 \mathrm{ab}$ & $520,80 \mathrm{~b}$ & $458,45 \mathrm{ab}$ & $365,97 \mathrm{ab}$ \\
\hline *médias seguidas pela mesma letra nas colunas não diferem estatisticamente \\
entre si pelo teste de Tukey a nível de 1\% de probabilidade
\end{tabular}

Tabela 18 - Resultado do teste de Tukey para as médias horárias de radiação solar global durante coleta de dados de primavera, no intervalo das 11:00 às 15:00 horas, em Piracicaba, SP.

\begin{tabular}{cccccc}
\hline & \multicolumn{5}{c}{ Radiação solar global } \\
Tratamento & 11 horas & 12 horas & 13 horas & 14 horas & 15 horas \\
\hline $1($ testem$)$ & $866,06 \mathrm{a}$ & $874,08 \mathrm{a}$ & $661,11 \mathrm{a}$ & $773,71 \mathrm{a}$ & $544,25 \mathrm{a}$ \\
$2(0 \%)$ & $533,63 \mathrm{~b}$ & $628,47 \mathrm{a}$ & $629,50 \mathrm{a}$ & $444,73 \mathrm{ab}$ & $370,49 \mathrm{a}$ \\
$3(5 \%)$ & $432,33 \mathrm{~b}$ & $590,50 \mathrm{a}$ & $577,77 \mathrm{a}$ & $408,04 \mathrm{~b}$ & $347,34 \mathrm{a}$ \\
$4(10 \%)$ & $694,38 \mathrm{ab}$ & $702,05 \mathrm{a}$ & $532,49 \mathrm{a}$ & $615,92 \mathrm{ab}$ & $417,79 \mathrm{a}$ \\
$5(15 \%)$ & $518,95 \mathrm{~b}$ & $653,44 \mathrm{a}$ & $652,21 \mathrm{a}$ & $456,76 \mathrm{ab}$ & $389,30 \mathrm{a}$ \\
$6(20 \%)$ & $730,36 \mathrm{ab}$ & $739,18 \mathrm{a}$ & $537,06 \mathrm{a}$ & $667,77 \mathrm{ab}$ & $439,12 \mathrm{a}$ \\
\hline
\end{tabular}

*médias seguidas pela mesma letra nas colunas não diferem estatisticamente entre si pelo teste de Tukey a nível de $1 \%$ de probabilidade 


\subsubsection{Avaliação do desenvolvimento das plantas}

4.2.2.1 Massa seca (MS) e massa verde (MV) em época de inverno

No período de inverno, os resultados das variáveis produção de massa seca e massa verde foram superiores no interior dos túneis com plástico perfurado. A produção de massa seca nos tratamentos com túnel perfurado foi em média $44 \%$ superior que no tratamento testemunha, sendo que o tratamento a 5\% apresentou o maior valor de massa seca em gramas/planta (Figura 31).

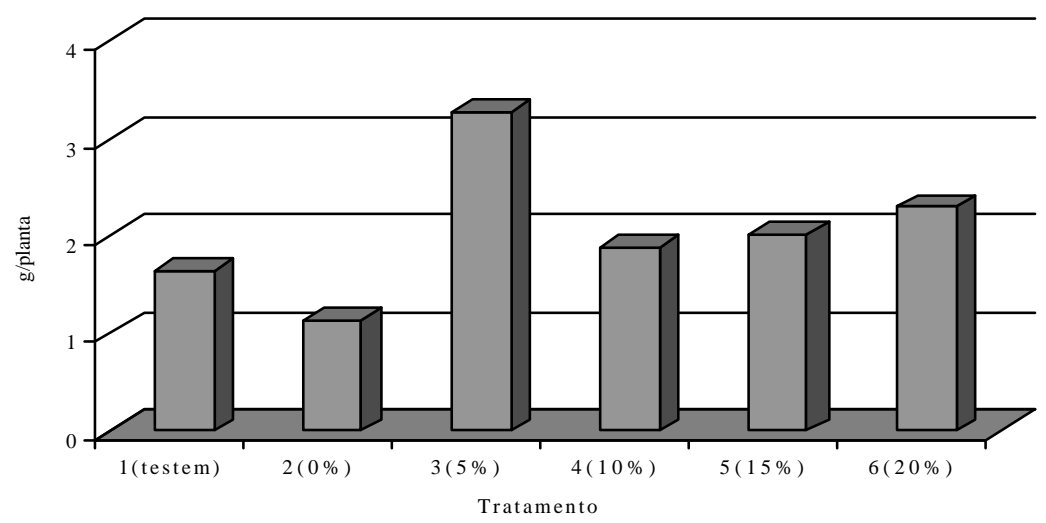

Figura 31 - Produção de massa seca média por planta de rabanete no período de coleta de dados de inverno, de 22/08/01 a 05/09/01, em Piracicaba, SP.

Já a produção de massa verde apresentou no interior dos túneis perfurados uma média de $47 \%$ superior se comparado à testemunha, com o tratamento a $5 \%$ de área perfurada apresentando o maior valor de massa verde em gramas/planta (Figura 32). Tais resultados confirmam os apresentados por Monteiro et al. (2000) que observaram no período de primavera maior produção de massa verde da alface nos túneis com $15 \%$ de perfuração. Pode-se concluir, portanto, a viabilidade de se utilizar perfurações na cobertura plástica dos túneis baixos, a fim de obter ambientes adequados e que promovam uma melhor qualidade final à cultura. 


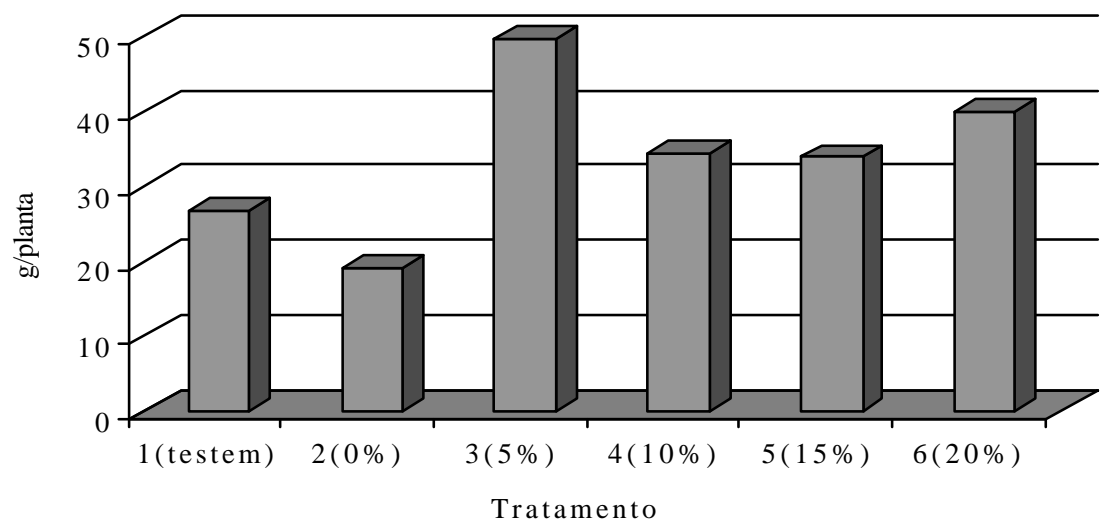

Figura 32 - Produção de massa verde média por planta de rabanete no período de coleta de dados de inverno, de 22/08/01 a 05/09/01, em Piracicaba, SP.

De acordo com a análise estatística, pode-se notar, através da Tabela 19, que há diferença significativa entre o tratamento testemunha e o tratamento com $5 \%$ de área perfurada, para a variável produção de massa verde e massa seca. Nesta época do ano, um ambiente mais fechado, que promova circulação de ar suficiente para o bom desenvolvimento das plantas, é mais indicado do que um ambiente com muita renovação de ar, como o que é promovido pelos tratamentos com maior densidade de perfuração.

Tabela 19 - Resultado do teste de Tukey para as médias de produção de massa seca e massa verde de rabanete, durante período de coleta de dados de inverno, em Piracicaba, SP.

\begin{tabular}{ccc}
\hline Tratamento & MS(g/planta) & MV(g/planta) \\
\hline 1 (testem) & $1,64 \mathrm{~b}$ & $26,69 \mathrm{bc}$ \\
$2(0 \%)$ & $1,13 \mathrm{~b}$ & $19,14 \mathrm{c}$ \\
$3(5 \%)$ & $3,27 \mathrm{a}$ & $49,78 \mathrm{a}$ \\
$4(10 \%)$ & $1,88 \mathrm{~b}$ & $34,42 \mathrm{abc}$ \\
$5(15 \%)$ & $2,02 \mathrm{~b}$ & $33,95 \mathrm{abc}$ \\
$6(20 \%)$ & $2,30 \mathrm{ab}$ & $39,96 \mathrm{ab}$ \\
\hline
\end{tabular}

*médias seguidas pela mesma letra nas colunas não diferem estatisticamente entre si pelo teste de Tukey a nível de $1 \%$ de probabilidade 
4.2.2.1 Massa seca (MS) e massa verde (MV) em época de primavera

Nas figuras 33 e 34 observa-se que a variável produção de massa seca e verde apresenta valores superiores nos tratamentos com plástico perfurado se comparados à testemunha. Isso se deve à diferença de umidade entre as plantas dentro e fora dos túneis, fato este que interfere diretamente sobre a qualidade de produção. A massa seca apresenta uma variação superior em 33\% se comparado à testemunha, enquanto que a produção de massa verde apresenta valor médio entre os tratamentos com túnel perfurado de $58 \%$ superior à testemunha, sendo que o tratamento que apresentou valor mais elevado em gramas por planta de massa seca foi o tratamento a $15 \%$ de área perfurada e o de massa verde foi o tratamento a $10 \%$ de área perfurada.

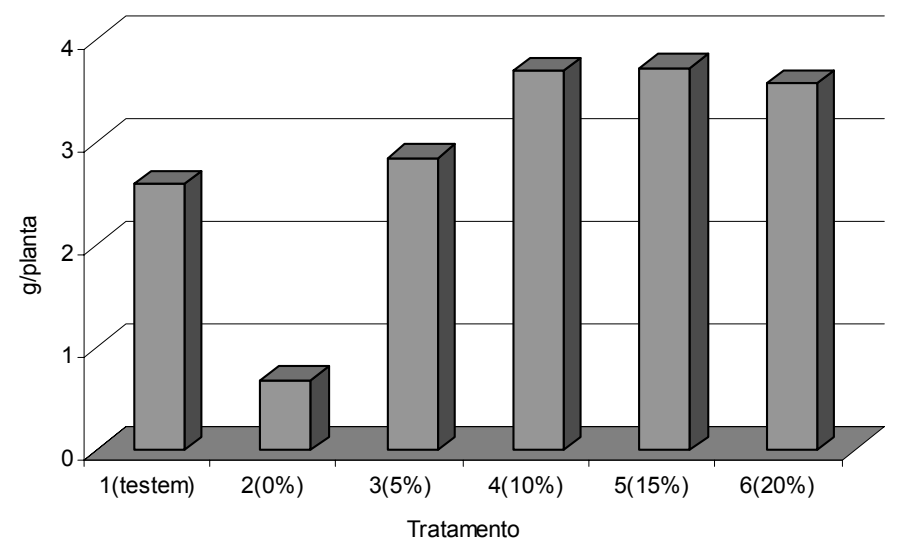

Figura 33 - Produção de massa seca média por planta de rabanete no período de coleta de dados de primavera, de 22/11/01 a 03/12/01, em Piracicaba, SP. 


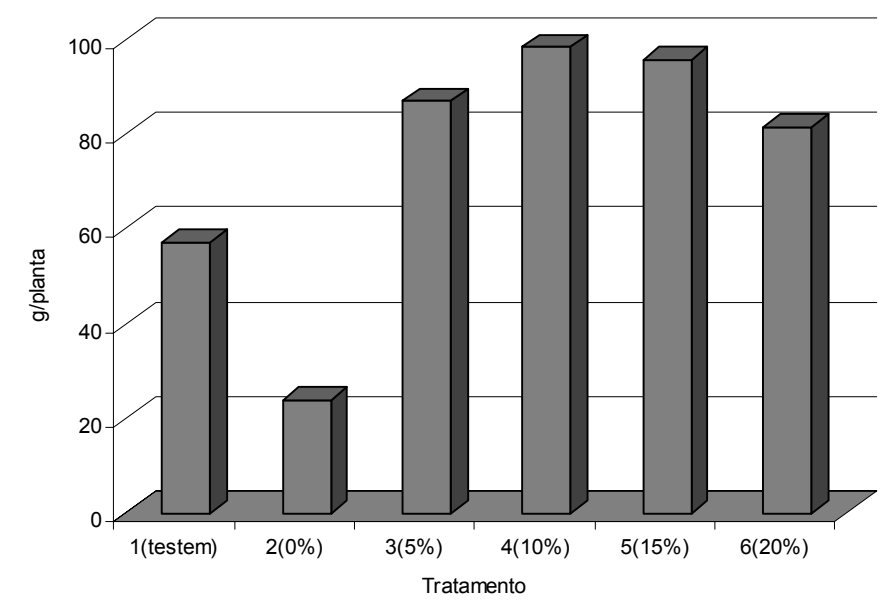

Figura 34 - Produção de massa verde média por planta de rabanete no período de coleta de dados de primavera, de 22/11/01 a 03/12/01, em Piracicaba, SP.

$\mathrm{Na}$ Tabela 20 pode-se notar que, durante a primavera, os dados de massa seca e massa verde não apresentaram diferenças significativas entre os tratamentos com plástico perfurado e a testemunha, concordando com Monteiro et al.(2001) que observou que o teor de massa seca em alface cultivado sob túnel baixo na primavera foi aproximadamente o mesmo.

Os resultados de produção de massa verde da cultura do rabanete desenvolvida na primavera foram superiores aos encontrados no inverno, visto que, a temperatura do solo apresentou valores mais próximos às necessárias para o crescimento adequado da planta (em torno de $29^{\circ} \mathrm{C}$, segundo Sonnenberg, 1980). Durante o inverno, essas temperaturas foram inferiores, ao recomendado, o que provavelmente pôde influenciar no desenvolvimento da cultura. 
Tabela 20 - Resultado do teste de Tukey para as médias de produção de massa seca e massa verde de rabanete durante coleta de dados de primavera, em Piracicaba, SP.

\begin{tabular}{ccc}
\hline Tratamento & MS (g/planta) & MV (g/planta) \\
\hline 1 (testem) & $2,59 \mathrm{a}$ & $57,14 \mathrm{ab}$ \\
$2(0 \%)$ & $0,68 \mathrm{~b}$ & $23,85 \mathrm{~b}$ \\
$3(5 \%)$ & $2,84 \mathrm{a}$ & $86,93 \mathrm{a}$ \\
$4(10 \%)$ & $3,70 \mathrm{a}$ & $98,22 \mathrm{a}$ \\
$5(15 \%)$ & $3,73 \mathrm{a}$ & $95,55 \mathrm{a}$ \\
$6(20 \%)$ & $3,57 \mathrm{a}$ & $81,34 \mathrm{a}$ \\
\hline
\end{tabular}

*médias seguidas pela mesma letra nas colunas não diferem estatisticamente entre si pelo teste de Tukey a nível de $1 \%$ de probabilidade

\subsubsection{Características do Tubérculo}

\subsection{Altura, diâmetro e peso do rabanete}

Analisando-se as características do tubérculo conclui-se que no inverno não houve diferença significativa entre os túneis com plástico perfurado e a testemunha quanto a altura, diâmetro e peso do rabanete (Tabela 21). Como nessa época do ano, a temperatura é mais amena, o desenvolvimento do rabanete foi favorecido no ambiente sob os túneis baixos de polietileno transparente perfurado em relação ao ambiente externo, não havendo porém, diferença significativa entre os tratamentos. 
Tabela 21 - Resultado do teste de Tukey para a média das características do rabanete (altura, diâmetro e peso do tubérculo), durante coleta de dados de inverno, em Piracicaba, SP.

\begin{tabular}{cccc}
\hline & \multicolumn{2}{c}{ Características do tubérculo } & \\
Tratamento & Altura $(\mathrm{cm})$ & Diâmetro $(\mathrm{cm})$ & Peso $(\mathrm{g})$ \\
\hline 1 (testem) & $3,88 \mathrm{a}$ & $3,43 \mathrm{bc}$ & $26,69 \mathrm{bc}$ \\
$2(0 \%)$ & $3,34 \mathrm{a}$ & $3,14 \mathrm{c}$ & $19,14 \mathrm{c}$ \\
$3(5 \%)$ & $4,78 \mathrm{a}$ & $4,10 \mathrm{a}$ & $49,78 \mathrm{a}$ \\
$4(10 \%)$ & $4,10 \mathrm{a}$ & $3,84 \mathrm{ab}$ & $34,41 \mathrm{abc}$ \\
$5(15 \%)$ & $4,08 \mathrm{a}$ & $3,64 \mathrm{abc}$ & $33,94 \mathrm{abc}$ \\
$6(20 \%)$ & $4,28 \mathrm{a}$ & $3,86 \mathrm{ab}$ & $39,95 \mathrm{ab}$ \\
\hline
\end{tabular}

*médias seguidas pela mesma letra nas colunas não diferem estatisticamente entre si pelo teste de Tukey a nível de $1 \%$ de probabilidade.

Durante a primavera, o rabanete também apresentou melhores resultados nos tratamentos com perfurações na cobertura plástica, sem haver diferenças significativas entre estes tratamentos quanto à altura, diâmetro e peso do tubérculo (Tabela 22). O cultivo do rabanete na primavera apresentou um produto mais desenvolvido, com resultados de características superiores ao cultivo no inverno. Isso comprova que a época do ano influencia diretamente no desenvolvimento de uma mesma cultura.

Tabela 22 - Resultado do teste de Tukey para as médias das características do rabanete (altura, diâmetro e peso do tubérculo), durante coleta de dados de primavera, em Piracicaba, SP.

\begin{tabular}{cccc}
\hline & \multicolumn{2}{c}{ Características do tubérculo } \\
Tratamento & Altura $(\mathrm{cm})$ & Diâmetro $(\mathrm{cm})$ & Peso $(\mathrm{g})$ \\
\hline 1 (testem) & $4,84 \mathrm{a}$ & $3,56 \mathrm{ab}$ & $37,99 \mathrm{a}$ \\
$2(0 \%)$ & $3,00 \mathrm{~b}$ & $2,54 \mathrm{~b}$ & $9,54 \mathrm{~b}$ \\
$3(5 \%)$ & $5,9 \mathrm{a}$ & $3,72 \mathrm{a}$ & $51,95 \mathrm{a}$ \\
$4(10 \%)$ & $5,4 \mathrm{a}$ & $3,74 \mathrm{a}$ & $51,82 \mathrm{a}$ \\
$5(15 \%)$ & $6,2 \mathrm{a}$ & $4,20 \mathrm{a}$ & $61,60 \mathrm{a}$ \\
$6(20 \%)$ & $5,38 \mathrm{a}$ & $4,04 \mathrm{a}$ & $57,40 \mathrm{a}$ \\
\hline
\end{tabular}

*médias seguidas pela mesma letra nas colunas não diferem estatisticamente entre si pelo teste de Tukey a nível de $1 \%$ de probabilidade 


\subsubsection{Produtividade}

Quanto à produtividade pode-se notar pelos resultados apresentados na Tabela $23 \mathrm{e}$ Figura 35, que no inverno, o ambiente com plástico perfurado foi o que apresentou maior produção por metro quadrado. O tratamento a 5\% de área perfurada apresentou uma produção três vezes superior à testemunha no período do inverno, em torno de $816 \mathrm{~g} / \mathrm{m}^{2}$ superior à testemunha. Durante a primavera o tratamento que apresentou maior valor em gramas por metro quadrado foi o tratamento com $15 \%$ de área perfurada, em torno de 789 $\mathrm{g} / \mathrm{m}^{2}$ superior à testemunha.

Tabela 23 - Resultado do teste de Tukey para as médias de produtividade do rabanete durante o inverno, de 22/08/01 à 05/09/01, e durante a primavera, de 22/11/01 à 03/06/01, em Piracicaba, SP.

\begin{tabular}{ccccc}
\hline & \multicolumn{2}{c}{ Produtividade $\left(\mathrm{g} / \mathrm{m}^{2}\right)$} & \multicolumn{2}{c}{ Produtividade $(\%)$} \\
Tratamento & Inverno & Primavera & Inverno & Primavera \\
\hline $1($ testem $)$ & 297 & 272 & 1,00 & 1,00 \\
$2(0 \%)$ & 458 & 166 & 1,54 & 0,61 \\
$3(5 \%)$ & 1113 & 988 & 3,74 & 3,63 \\
$4(10 \%)$ & 524 & 673 & 1,76 & 2,47 \\
$5(15 \%)$ & 939 & 1061 & 3,16 & 3,90 \\
$6(20 \%)$ & 664 & 837 & 2,23 & 3,07 \\
\hline
\end{tabular}

*médias seguidas pela mesma letra nas colunas não diferem estatisticamente entre si pelo teste de Tukey a nível de $1 \%$ de probabilidade

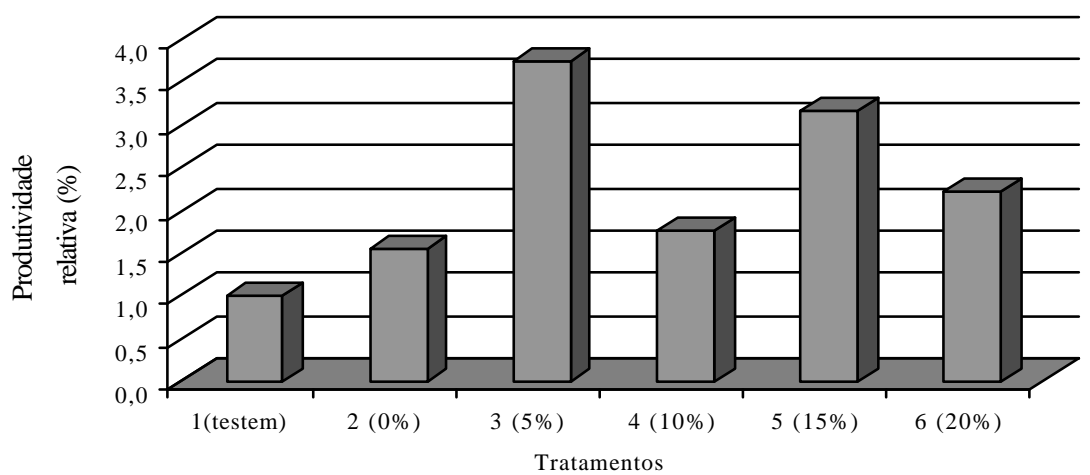

Figura 35 - Valores de produtividade relativa (\%) no período de coleta de dados de rabanete durante o inverno, de 22/11/01 à 03/12/01, em Piracicaba, SP. 
A produtividade superior no interior do túnel baixo com plástico perfurado a 5\% também pode ser comprovado pela figura 36 , onde demonstra a produção do rabanete cultivado a 5\% e a céu aberto.

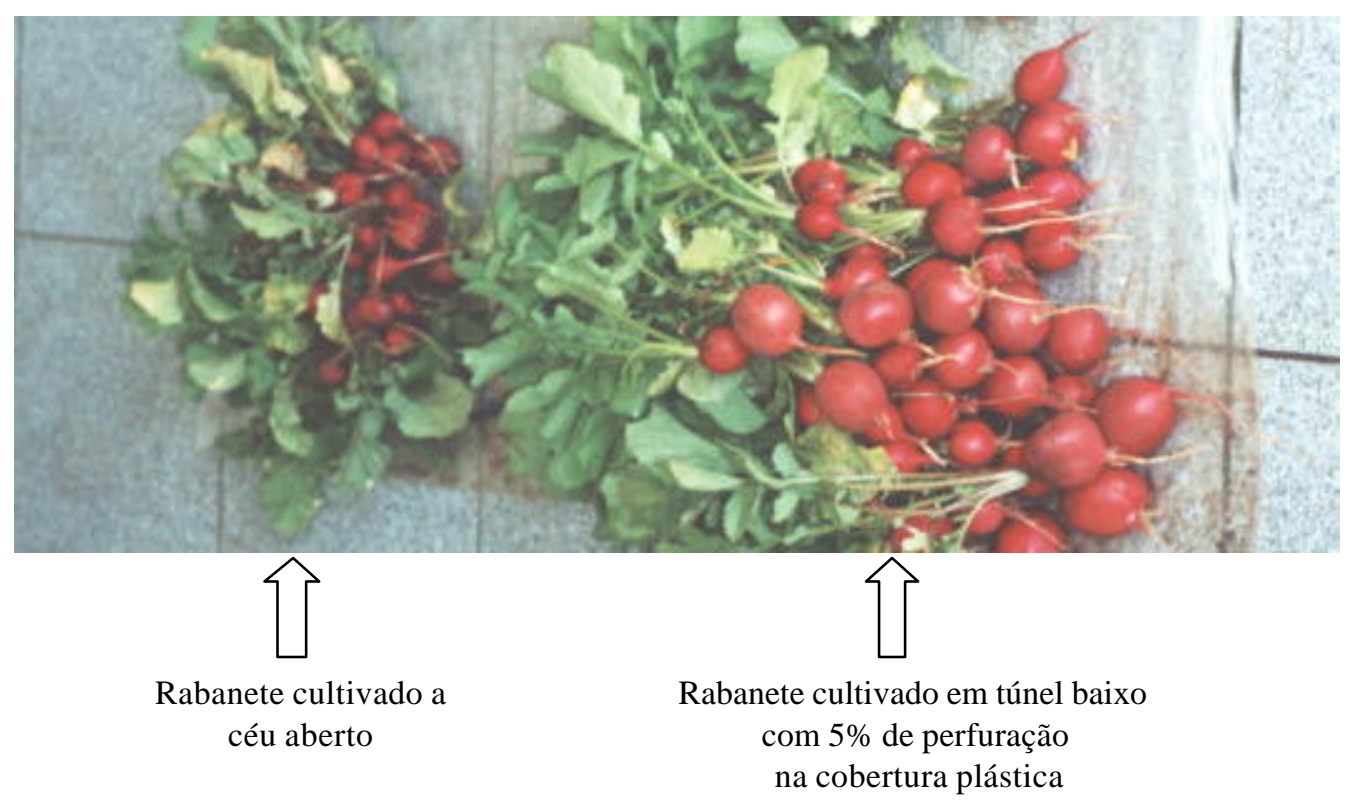

Figura 36 - Produção final do rabanete no tratamento com túnel baixo a 5\% de perfuração e no tratamento de cultivo a céu aberto, durante o inverno, em Piracicaba, SP.

Observou-se que, na primavera, o tratamento a $0 \%$ de perfuração apresentou valores inferiores à testemunha quanto à produtividade relativa do rabanete num valor de $39 \%$ (Figura 37). Essa menor produtividade comprova que um ambiente com plástico sem perfuração, em época de primavera, apresenta uma temperatura do ar mais elevada, o que estimula a permanência de camada de gotículas de água sob o plástico, aumentando a umidade relativa do ar e afetando diretamente no crescimento e desenvolvimento da cultura.

A maior produtividade de rabanete durante a primavera pode ser observado no tratamento com túnel a 15\% de perfuração, com valores 4 vezes maior que à testemunha. Isso 
concorda com trabalho realizado por Monteiro et al. (2000) onde encontraram valores superiores de produção da alface no tratamento a $15 \%$ durante a primavera.

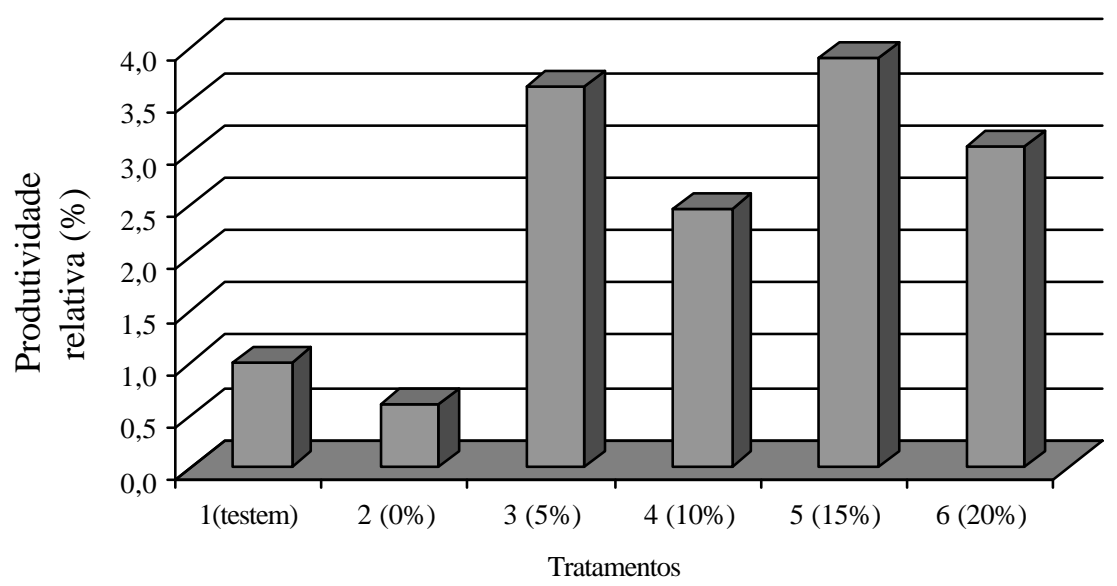

Figura 37- Produtividade relativa (\%) do rabanete obtidos no período de coleta de dados de primavera, de 22/11/01 a 03/12/01 , em Piracicaba, SP.

A produtividade superior no interior do túnel baixo com plástico perfurado a $15 \%$ também pode ser comprovado pela figura 38, onde mostra a produtividade do rabanete no tratamento a 15 e o tratamento de cultivo a céu aberto. 


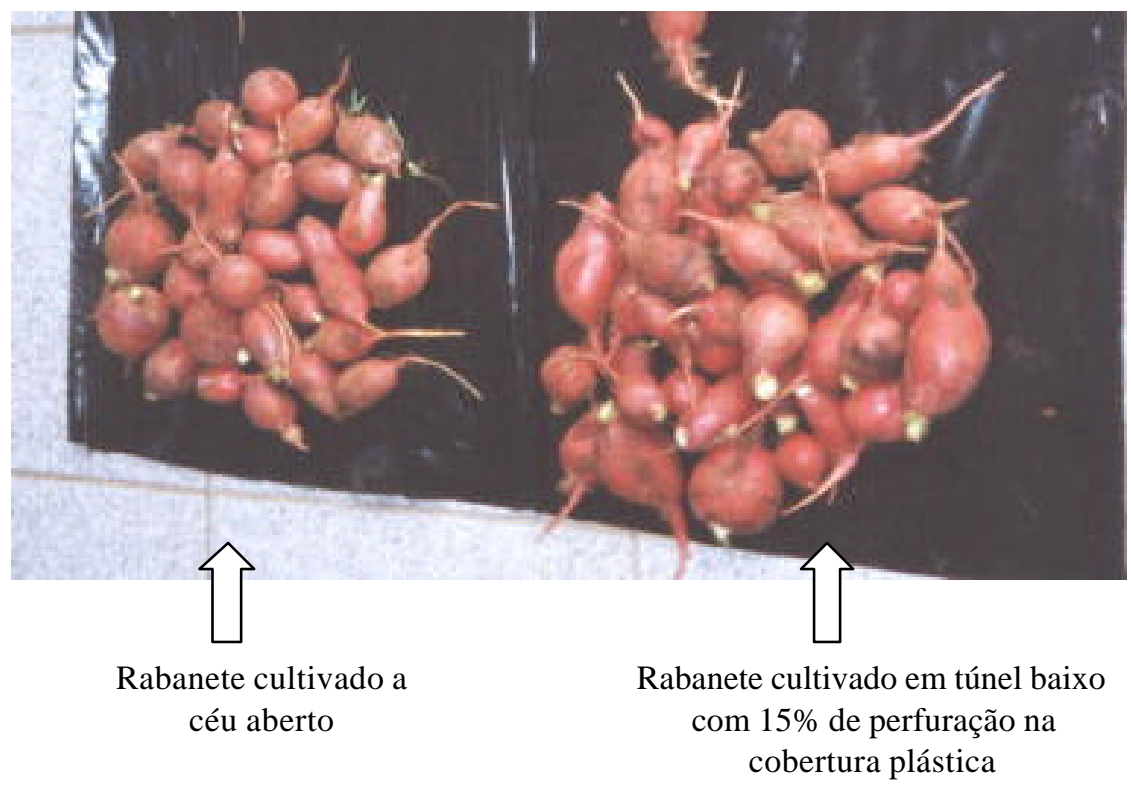

Figura 38 - Produção final do rabanete no tratamento com túnel baixo a $15 \%$ de perfuração e no tratamento de cultivo a céu aberto, durante a primavera, em Piracicaba, SP. 


\section{CONCLUSÕES}

De acordo com os resultados analisados nesta pesquisa, pode-se concluir que:

\section{A) Cultura da Rúcula (Eruca vesicaria sativus (Mill) Thell), cultivados no verão e no outono:}

- A temperatura do ar no interior dos túneis baixos apresentaram valores superiores à temperatura do ambiente externo tanto no verão quanto no outono. Todas as densidades de perfuração do filme de polietileno apresentaram diferença estatística com relação à testemunha, valores estes que variaram em torno de 4,58 a 7,62 ${ }^{0} \mathrm{C}$ superiores ao tratamento sem a utilização do túnel.

- No verão, os tratamentos que apresentaram maior umidade relativa média diária foram os tratamentos a $0 \%, 5 \%, 10 \%, 15 \%$ e $20 \%$, respectivamente. As maiores diferenças significativas nos meses de verão foram encontradas no tratamento a $20 \%$ de perfuração apresentando valores inferiores aos da testemunha em 14,4\% de umidade relativa do ar.

- A temperatura do solo, média horária, observada no interior do ambiente protegido em época de outono apresentou-se superior à temperatura do canteiro sem a cobertura do túnel, em média $2,0{ }^{\circ} \mathrm{C}$.

- Para a radiação solar global houve uma redução média de $26 \%$ no interior do ambiente protegido. Houve diferença significativa entre a testemunha e os tratamentos a 5\%,10\%, $15 \%$, o mesmo não acontecendo no tratamento a $20 \%$.

- Em época de verão a produção de massa seca e massa verde foram em média, $45 \%$ e $55 \%$, respectivamente, superiores no tratamento sem a utilização dos túneis baixos. Já em 
época de outono a produção no interior do túnel superou a testemunha em média dos tratamentos em $65 \%$ de massa verde e $68 \%$ de massa seca.

- Tanto no verão como no outono a maior produtividade pôde ser observada no interior do ambiente com $15 \%$ de densidade de perfuração no filme plástico, apresentando uma produção maior em $57 \%$ no verão e $34 \%$ no outono se comparado à produção da cultura em ambiente externo.

\section{B) Cultura do rabanete (Raphanus sativus $L$.), cultivados no verão e no outono:}

- Tanto no inverno como na primavera, todos os tratamentos com túnel baixo apresentaram temperatura ambiente superior ao tratamento sem túnel, apresentando diferenças significativas entre os tratamentos a $5 \%$ e $20 \%$ de área perfurada.

- Os valores de umidade relativa do ar no interior dos túneis baixos no inverno apresentaram-se superiores ao tratamento testemunha, variando de 6,82 \% a 25,24\% superior nos tratamentos a $20 \%$ e $0 \%$, respectivamente. Na primavera, os valores de umidade relativa do ar em média horária apresentou valores muito próximos entre os túneis com plástico perfurado variando em média $4 \%$.

- A temperatura do solo em média horária no interior do túnel baixos, no inverno, apresentou valores superiores à testemunha que variaram de $1,4{ }^{0} \mathrm{C}$ a $4,3{ }^{0} \mathrm{C}$ nos tratamentos a $20 \%$ e $0 \%$, respectivamente. O mesmo aconteceu no período de primavera, porém com variação de $1,7{ }^{0} \mathrm{C}$ a $5,1{ }^{0} \mathrm{C}$.

- No inverno, a variação da radiação solar apresentou-se mais uniforme, com uma menor disponibilidade no interior dos túneis baixos, apresentando redução média 25\%. Durante a primavera, os valores de atenuação da radiação solar foram, em média dos tratamentos $23,1 \%$ inferior à testemunha.

- No inverno, os resultados das variáveis morfológicas produção de massa seca e massa verde foram superiores no interior dos túneis com plástico perfurado. A produção de 
massa seca e massa verde nos tratamentos com túnel perfurado foi, em média, $44 \%$ e $47 \%$ superior que no tratamento testemunha, respectivamente, sendo o tratamento a $5 \%$ o que apresentou melhores resultados. Já na primavera, os valores de massa seca e massa verde foram, respectivamente, superiores no tratamento a $15 \%$ em $33 \%$ e $58 \%$.

- Analisando-se as características do tubérculo concluiu-se que no inverno e na primavera não apresentaram diferenças significativas entre os túneis com plástico perfurado e a testemunha quanto a altura, diâmetro e peso do rabanete, porém o

- desenvolvimento da cultura foi visivelmente notada, superior no interior dos túneis baixos.

- Quanto à produtividade, o tratamento a 5\% de área perfurada apresentou uma produção três vezes superior à testemunha no período do inverno, em torno de $816 \mathrm{~g} / \mathrm{m}^{2}$ superior à testemunha. Durante a primavera, o tratamento que apresentou maior produtividade foi o tratamento com $15 \%$ de área perfurada, em torno de $789 \mathrm{~g} / \mathrm{m}^{2}$, o que representou uma produção quatro vezes maior do que a testemunha.

- Sugere-se para continuidade desta pesquisa, a avaliação da resistência do material plástico de cobertura, assim como sua vida útil e provável relação custo/benefício, para a utilização dos túneis baixos com plástico perfurado no desenvolvimento de hortaliças. 


\section{REFERÊNCIAS BIBLIOGRÁFICAS}

AGUIAR E SILVA, M.A.; ESCOBEDO, J.F.; GALVANI, E. et al. Variação da temperatura do solo e do índice de área foliar em ambiente protegido e campo com cultura de pimentão. In: Congresso Brasileiro de Agrometeorologia, 12. Fortaleza, 2001. Anais. Fortaleza, 2001. p.819-820.

ALFONSO O.U.; ELICIO M.O.; RECAREDO O.C. Efectos de siembra sobre el comportamiento productivo de três cultivares de pepino de ensalada (Cucumis sativus L.) bajo condiciones de invernadero y riego por goteo. Idesia, v.8, ene. p. 55-62, dec. 1984.

ALPI, A., TOGNONI, F. Cultivo en invernadero. 3.ed. Madri: Mundi-Prensa, 1991. $347 \mathrm{p}$.

AL-RIAHI, M.; AL-KARAGHOULI, A.; HASSON, A.M. et al. Relations between radiation fluxes of a greenhouse in semi-arid conditions. Agricultural and Forest Meteorology, v.44, p.329-338, 1989.

BURIOL, G.A.; ANDRIOLO, J.L.; ESTEFANEL,V. et al. Modificação na temperatura mínima diária do ar causada por estufas de polietileno transparente de baixa densidade em Santa Maria, RS. In: Congresso Brasileiro de Agrometeorologia, 7, Viçosa, 1991 Resumos. Viçosa: SBA/UFV, 1991, p.36-37.

BURIOL, G.A.; SCHNEIDER, M.; HELDWEIN, A.B. et al. Efeito da ventilação sobre a temperatura e umidade do ar em túneis baixos de polietileno transparente e o crescimento da alface. Revista Brasileira de Agrometeorologia. v.5, n.1, p.17-24, 1997. 
BURIOL, G.A.; SCHNEIDER, F.M.; STRECK, N.A. et al. Modificação da temperatura mínima do ar causada por estufas de polietileno transparente de baixa densidade. Revista Brasileira de Agrometeorologia, v. 1, p. 43-49, 1994.

BURIOL, G.A.; SCHNEIDER, F.M.; STRECK, N.A. et al. Modificação ambiental causada por túneis baixos de polietileno transparente perfurado cultivados com alface. Ciência Rural, v.23, n.3, p.261-266, 1993.

BURN, R.; LAGIER, I. A new greenhouse structure adapted to mediterranean growing. Acta Horticulturae, n.170, p.37-46, 1985.

CESAR, H.P. Hortas e hortaliças. São Paulo. Edições Melhoramentos, 1951.320p.

CUNHA, N.S.; CELLA, W.L.; MANFRON, P.A. et al. Avaliação da temperatura do ar no interior de túneis baixos com diferentes tipos de coberturas. In: Congresso Brasileiro de Engenharia Agrícola, 10, 1997. Anais. Piracicaba: ESALQ, 1997. p.468-470.

DEMATTE, J.B.I.; PAYAO, M.E.S. Determinação do consumo de água e frequênica de irrigação em cultura de rabanete (Raphanus sativus L.). Horticultura Brasileira, v.5, n.1, p.84. 1987.

FARIA Jr., M.J.A. Avaliação de diferentes arquiteturas de estufas, coberturas do solo com filme plástico, em híbridos de Pimentão (Capsicum annuum L.). Jaboticabal, 1997. 102p. Tese (Doutorado) - Faculdade de Ciências Agrárias e Veterinárias, Campus de Jaboticabal, Universidade Estadual Paulista "Júlio de Mesquita Filho".

FARIA Jr., M.J.A. Avaliação de Híbridos de pepino para cultivo protegido e do microclima formada por dois modelos de estufa. Jaboticabal, 1994. 102p. Dissertação (Mestrado) - Faculdade de Ciências Agrárias e Veterinárias, Campus de Jaboticabal, Universidade Estadual Paulista “Júlio de Mesquita Filho”.

FARIA JR., M.J.A. et al., Avaliação de cultivares de alface (Lactuca sativa) e de dois modelos de estufa com cobertura plástica, durante o verão, em Ilha Solteira, SP. Cultura Agronômica, v.2, p. 119-128, 1993. 
FARIAS, J.R.B.; BERGAMASCHI, S.R.; MARTINS, S.R. et al. Alterações na temperatura e umidade relativa do ar provocadas pelo uso de estufa plástica. Revista Brasileira de Agrometeorologia, v.1, n.1, p. 51-62, 1993.

FARIAS, J.R.B. ; BERGAMASCHI, H. ; MARTINS, M.A .B. et al. Efeito da cobertura plástica de estufa sobre a radiação solar. Revista Brasileira de Agrometeorologia, v.1 n.1, p.31-36, 1993 b.

FEUILLOLEY, P.; MEKIKDJIAN, C.; SEVILA, F. Static aeration in greenhouses. Acta Horticulturae, n. 281, p.175-182, 1990.

FILGUEIRA, F.A.R. Manual de olericultura: cultura e comercialização de hortaliças. São Paulo: Agronômica Ceres, 1981. 451p.

GIMENES, E.S.; STRECK, N.A.; BURIOL, G.A. et al. Efeito da atenuação da densidade de fluxo de radiação solar incidente no crescimento da alface. Ciencia Rural, v. 24, n.2, p. 241-246, 1994.

JONES, H.G. Plants and microclimate: a quantitative approach to environmental plant physiology. 2.ed. Cambridge: Cambridge University Press, 1992. 429 p.

LEMOS, O. Os avanços na agricultura. Agricultura de Hoje, n.117, p. 24-30, jun. 1986.

MANZINI, J. P. Emprego do túnel de cultivo forçado e da cobertura de solo na produção de abobrinha italiana (Cucurbita pepo var. melopepo), em condições de outono-inverno. Jaboticabal, 1994. 54p. Dissertação (Iniciação Científica) Faculdade de Ciências Agrárias e Veterinárias de Jaboticabal, Universidade Estadual Paulista "Júlio de Mesquita Filho".

MARTINEZ GARCIA, P.F. La regulación de las condiciones del ambiente en los cultivos protegidos. In: Feria Tecnica Internacional de la Maquinaria Agrícola, Zaragoza, Anais. Zaragoza, Associación de Ingenieros Agronomos, 1986. p.135-147. 
MARTINS, S.R. ; FERNANDES, H.S. ; FARIAS Jr. et al. Respuestas agronómicas y fisiológicas de hortalizas cultivadas en invernadero de bajo costo en la región de Pelotas (RS-Brasil). In: I Simpósio Iberoamericano de Aplicación de los Plásticos en las Tecnologías Agrárias, Almeria, 1995. Anales. Almeria: FIAPA, 1995.

MARTINS, S.R.; GONZALES, J.F. Avaliação do resfriamento em estufa plástica mediante sistema de ventilação e nebulização. Revista Brasileira de Agrometeorologia, v.3, p.13-18, 1995.

MINAMI, K. Instruções práticas das principais hortaliças. Piracicaba: ESALQ.1983. 89p.

MINAMI, K.; TESSARIOLI NETO, J. A cultura da rúcula. Piracicaba: ESALQ, 1998. $19 \mathrm{p}$.

MINAMI, K.; TESSARIOLI NETO, J. Rabanete: cultura rápida para temperaturas amenas e solos areno-argilosos. Piracicaba: ESALQ, 1997. 27p.

MONTEIRO, J.E.B.; SILVA, I.J.O.da; PIEDADE, S.M.S. Uso de plásticos perfurados na modificação de ambiência de túneis baixos. Piracicaba, 1999. 58p. Dissertação (Iniciação Científica) - Escola Superior de Agricultura "Luiz de Queiroz", Universidade de São Paulo.

MONTEIRO, J.E.B.; SILVA, I.J.O.da; PIEDADE, S.M.S. Modificação da ambiência de túneis baixos com o uso de filmes plásticos perfurados. Revista Horticultura Brasileira , v.18, 236-237, jul. 2000.

MONTEIRO, J.E.B.; SILVA, I.J.O.da; PIEDADE, S.M.S. Uso de filme plástico perfurado em túneis baixos (II) cultivados com alface (Lactuca sativa L.). In: Congresso Brasileiro de Agrometeorologia, 12. Fortaleza, 2001. Anais. Fortaleza, 2001. p.777-778. 
MURAYAMA, S. Horticultura. Campinas: Instituto Campineiro de Ensino Agrícola, 1983. 321p.

OLIVEIRA,C.R. Cultivo em ambiente protegido. Campinas: Coordenadoria de Assistência Técnica Integral. 1997. 31 p. (Boletim Técnico, 232).

PEZZOPANE, J.E.M. O uso de estufa com cobertura plástica e de quebra-ventos na produção de porta-enxertos de seringueira, na região de Campinas, SP. Piracicaba, 1994. 87p. Dissertação (Mestrado) - Escola Superior de Agricultura "Luiz de Queiroz”. Universidade de São Paulo.

RAULT, P.A. A tunnel greenhouse adapted to the tropical lowland climate. Acta Horticulturae, n.281, p. 95-103, 1990.

ROBLEDO, F.de P.; MARTIN, L.V. Aplicacion de los plasticos en la agricultura. Madrid: Mundial-Prensa, 1981. 553p.

SANTOS, M.M. Espaçamento e densidades de semeadura em pepino para indústria em Pelotas. Pelotas: EMBRAPA, CNFT, 1980. 2p (Comunicado Técnico, 6).

SCARPARE FILHO, J. A. Viveiros para formação de mudas. In: MINAMI, K. Produção de mudas de alta qualidade em horticultura. São Paulo: T.A. Queiroz, 1995. cap. 7 , p.47 - 51.

SCHNEIDER, F. M., STRECK, N. A., BURIOL, G. A. Modificação na temperatura do solo causada por estufa de polietileno transparente de baixa densidade em Santa Maria - RS. Revista Brasileira de Agrometeorologia, v.1, n.1, p.37-42, 1993.

SEEMAN, J. Greenhouse cimate. In: Seeman, J. et al. Agrometeorology. Berlin Heidelberg, Germany: Springer-Verlarg, p. 165-178, 1979. 
SENTELHAS, P.C.; PEREIRA, A.R.; ANGELOCCI, L.R. Meteorologia Agrícola. (Apostila). Departamento de Física e Meteorologia - Escola Superior de Agricultura “Luiz de Queiroz”- Universidade de São Paulo, Piracicaba, 1998. 131p.

SERRANO CERMEÑO, Z. Construcción de invernaderos. Madri: Mundi - Prensa, 1994. 445p.

SGANZERLA, E. Nova agricultura: a fascinante arte de cultivar com os plásticos. 6.ed. Porto Alegre: Petroquímica Triunfo, 1995. 341p.

SONNENBERG, P.E. Olericultura especial. Goiania: UFG, 1980. 143p.

STANGHELLINI,C. Evapotranspiration in greenhouses with especial reference to mediterranean conditions. Acta Horticulturae, n.335, p. 295-304, 1993.

STRECK, N. A.; BURIOL, G. A.; ANDRIOLO, J. L. Crescimento da alface em túneis baixos com filme de polietileno perfurado. Ciência Rural, v. 24, n. 2, p. 235-240, 1994.

TANAKA, M.; GENTA, H. Control del medio ambiente baho invernadero y tunel plastico. Salto: Estación Experimental de Citricultura, 1982. 61p.

TAPIA, G.J. Filmes térmicos para invernadeiros. Revista de los plásticos modernos, v.295, p. 75-82, 1981.

VECCHIA, P.T.D.; KOCH, P.S. História e perspectivas da produção de hortaliças em ambiente protegido no Brasil. Informe Agropecuário, v.20, n.200/201, p.5-10, set./dez. 1999. 


\section{APÊNDICE I}

Dados obtidos no Experimento I - cultivo da rúcula no verão 
DIA DE COLETA DE DADOS: 20/02

\begin{tabular}{|c|c|c|c|c|c|c|c|c|c|c|c|c|}
\hline \multirow[b]{2}{*}{ HORA } & \multicolumn{2}{|c|}{ TESTE MUNHA } & \multicolumn{2}{|c|}{$0 \%$} & \multicolumn{2}{|c|}{$5 \%$} & \multicolumn{2}{|c|}{$10 \%$} & \multicolumn{2}{|c|}{$15 \%$} & \multicolumn{2}{|c|}{$20 \%$} \\
\hline & $\mathrm{T}(\mathrm{C})$ & $\mathrm{UR}(\%)$ & $\mathrm{T}(\mathrm{C})$ & $\mathrm{UR}(\%)$ & $\mathrm{T}(\mathrm{C})$ & $\mathrm{UR}(\%)$ & $\mathrm{T}(\mathrm{C})$ & $\mathrm{UR}(\%)$ & $\mathrm{T}(\mathrm{C})$ & $\mathrm{UR}(\%)$ & $\mathrm{T}(\mathrm{C})$ & $\mathrm{UR}(\%)$ \\
\hline 08:00 & 26,5 & 80,0 & 28,8 & 92,0 & 29,3 & 95,0 & 28,2 & 85,0 & 28,5 & 84,0 & 28,5 & 81,0 \\
\hline 09:00 & 29,2 & 75,0 & 35,5 & 87,0 & 34,6 & 83,0 & 32,6 & 77,0 & 32,1 & 80,0 & 33,0 & 74,0 \\
\hline $10: 00$ & 31,4 & 69,0 & 40,9 & 80,0 & 37,7 & 78,0 & 36,4 & 72,0 & 34,9 & 74,0 & 37,5 & 69,0 \\
\hline $11: 00$ & 33,5 & 60,0 & 43,4 & 73,0 & 40,2 & 72,0 & 38,7 & 62,0 & 37,5 & 69,0 & 39,6 & 61,0 \\
\hline $12: 00$ & 35,8 & 50,0 & 43,0 & 77,0 & 43,7 & 69,0 & 39,1 & 59,0 & 40,6 & 53,0 & 43,0 & 54,0 \\
\hline $13: 00$ & 36,4 & 45,0 & 46,7 & 70,0 & 43,5 & 60,0 & 42,1 & 56,0 & 40,9 & 55,0 & 41,8 & 49,0 \\
\hline $14: 00$ & 39,0 & 43,0 & 45,8 & 76,2 & 45,8 & 58,0 & 40,3 & 51,0 & 42,4 & 56,0 & 44,8 & 46,0 \\
\hline $15: 00$ & 38,0 & 40,0 & 46,5 & 71,0 & 44,0 & 52,0 & 41,9 & 50,0 & 41,4 & 49,0 & 42,7 & 45,0 \\
\hline $16: 00$ & 28,4 & 67,0 & 31,2 & 89,0 & 29,8 & 78,0 & 29,1 & 75,0 & 28,9 & 72,0 & 29,4 & 68,0 \\
\hline $17: 00$ & 31,2 & 66,0 & 31,7 & 72,0 & 32,8 & 83,0 & 32,0 & 80,0 & 31,2 & 77,0 & 33,2 & 94,0 \\
\hline $18: 00$ & 34,8 & 57,0 & 34,5 & 90,0 & 34,4 & 77,0 & 33,4 & 74,0 & 33,4 & 71,0 & 33,3 & 67,0 \\
\hline
\end{tabular}

DIA DE COLETA DE DADOS:

$21 / 02$

\begin{tabular}{|c|c|c|c|c|c|c|c|c|c|c|c|c|}
\hline \multirow[b]{2}{*}{ HORA } & \multicolumn{2}{|c|}{ TESTE MUNHA } & \multicolumn{2}{|c|}{$0 \%$} & \multicolumn{2}{|c|}{$5 \%$} & \multicolumn{2}{|c|}{$10 \%$} & \multicolumn{2}{|c|}{$15 \%$} & \multicolumn{2}{|c|}{$20 \%$} \\
\hline & $\mathrm{T}(\mathrm{C})$ & $\mathrm{UR}(\%)$ & $\mathrm{T}(\mathrm{C})$ & $\mathrm{UR}(\%)$ & $\mathrm{T}(\mathrm{C})$ & $\mathrm{UR}(\%)$ & $\mathrm{T}(\mathrm{C})$ & $\mathrm{UR}(\%)$ & $\mathrm{T}(\mathrm{C})$ & $\mathrm{UR}(\%)$ & $\mathrm{T}(\mathrm{C})$ & $\mathrm{UR}(\%)$ \\
\hline 08:00 & 27,3 & 70,0 & 30,3 & 86,0 & 28,3 & 73,0 & 28,2 & 80,0 & 29,6 & 80,0 & 29,5 & 74,0 \\
\hline 09:00 & 29,0 & 69,0 & 34,7 & 94,0 & 31,6 & 74,0 & 32,3 & 70,0 & 33,4 & 84,0 & 33,9 & 75,0 \\
\hline $10: 00$ & 32,4 & 59,0 & 41,9 & 87,0 & 39,4 & 71,0 & 36,8 & 66,0 & 36,5 & 66,0 & 38,2 & 58,0 \\
\hline $11: 00$ & 33,5 & 55,0 & 44,4 & 78,0 & 40,3 & 70,0 & 39,2 & 65,0 & 37,8 & 61,0 & 40,5 & 57,0 \\
\hline $12: 00$ & 35,4 & 48,0 & 46,7 & 84,0 & 42,0 & 65,0 & 41,6 & 57,0 & 40,0 & 60,0 & 42,5 & 49,0 \\
\hline $13: 00$ & 36,7 & 44,0 & 47,4 & 76,0 & 43,7 & 57,0 & 42,2 & 46,0 & 41,3 & 52,0 & 44,6 & 46,0 \\
\hline $14: 00$ & 37,1 & 46,0 & 46,5 & 61,0 & 44,2 & 55,0 & 40,9 & 52,0 & 41,8 & 50,0 & 45,0 & 41,0 \\
\hline $15: 00$ & 37,2 & 40,0 & 50,8 & 65,0 & 36,0 & 57,0 & 47,0 & 44,0 & 40,0 & 44,0 & 49,0 & 35,0 \\
\hline $16: 00$ & 37,4 & 33,0 & 49,7 & 66,0 & 42,0 & 51,0 & 41,0 & 57,0 & 39,5 & 53,0 & 43,0 & 45,0 \\
\hline $17: 00$ & 36,4 & 33,0 & 46,2 & 74,0 & 38,0 & 65,0 & 36,0 & 60,0 & 38,0 & 64,0 & 38,0 & 60,0 \\
\hline $18: 00$ & 35,1 & 32,0 & 44,0 & 73,0 & 37,0 & 74,0 & 32,0 & 64,0 & 36,0 & 62,0 & 33,5 & 58,0 \\
\hline
\end{tabular}

DIA DE COLETA DE DADOS:

$22 / 02$

\begin{tabular}{|c|c|c|c|c|c|c|c|c|c|c|c|c|}
\hline \multirow[b]{2}{*}{ HORA } & \multicolumn{2}{|c|}{ TESTE MUNHA } & \multicolumn{2}{|c|}{$0 \%$} & \multicolumn{2}{|c|}{$5 \%$} & \multicolumn{2}{|c|}{$10 \%$} & \multicolumn{2}{|c|}{$15 \%$} & \multicolumn{2}{|c|}{$20 \%$} \\
\hline & $\mathrm{T}(\mathrm{C})$ & $\mathrm{UR}(\%)$ & $\mathrm{T}(\mathrm{C})$ & $\mathrm{UR}(\%)$ & $\mathrm{T}(\mathrm{C})$ & $\mathrm{UR}(\%)$ & $\mathrm{T}(\mathrm{C})$ & $\mathrm{UR}(\%)$ & $\mathrm{T}(\mathrm{C})$ & $\mathrm{UR}(\%)$ & $\mathrm{T}(\mathrm{C})$ & $\mathrm{UR}(\%)$ \\
\hline 08:00 & 26,3 & 80,0 & 27,5 & 84,0 & 28,1 & 84,0 & 27,8 & 88,0 & 27,8 & 77,0 & 27,8 & 75,0 \\
\hline 09:00 & 26,5 & 84,0 & 29,5 & 87,0 & 29,7 & 85,0 & 28,7 & 89,0 & 28,4 & 80,0 & 28,5 & 77,0 \\
\hline 10:00 & 30,4 & 66,0 & 35,7 & 80,0 & 35,7 & 73,0 & 34,3 & 78,0 & 33,1 & 70,0 & 34,0 & 65,0 \\
\hline $11: 00$ & 31,9 & 64,0 & 41,0 & 78,0 & 38,1 & 71,0 & 36,1 & 72,0 & 35,7 & 66,0 & 36,5 & 63,0 \\
\hline $12: 00$ & 34,9 & 51,0 & 46,0 & 53,0 & 41,9 & 61,0 & 40,9 & 62,0 & 39,4 & 59,0 & 41,1 & 52,0 \\
\hline $13: 00$ & 37,2 & 44,0 & 56,4 & 47,4 & 44,0 & 55,0 & 52,7 & 40,8 & 45,0 & 52,0 & 42,9 & 48,0 \\
\hline $14: 00$ & 37,2 & 43,0 & 46,6 & 65,0 & 43,3 & 53,0 & 43,1 & 56,7 & 41,8 & 49,0 & 45,0 & 45,1 \\
\hline $15: 00$ & 36,3 & 42,0 & 52,3 & 56,0 & 42,0 & 52,0 & 53,5 & 34,4 & 40,8 & 45,0 & 52,6 & 32,7 \\
\hline $16: 00$ & 33,7 & 51,0 & 43,4 & 61,0 & 37,8 & 63,0 & 42,3 & 49,0 & 36,6 & 56,0 & 41,4 & 49,8 \\
\hline $17: 00$ & 31,6 & 56,0 & 37,0 & 74,9 & 33,5 & 67,0 & 34,2 & 62,0 & 32,9 & 60,0 & 34,9 & 59,0 \\
\hline 18:00 & 33,7 & 54,0 & 34,3 & 73,0 & 33,7 & 69,0 & 36,2 & 60,0 & 34,5 & 60,0 & 34,6 & 54,2 \\
\hline
\end{tabular}


DIA DE COLETA DE DADOS:

$23 / 02$

\begin{tabular}{|c|c|c|c|c|c|c|c|c|c|c|c|c|}
\hline \multirow[b]{2}{*}{ HORA } & \multicolumn{2}{|c|}{ TESTE MUNHA } & \multicolumn{2}{|c|}{$0 \%$} & \multicolumn{2}{|c|}{$5 \%$} & \multicolumn{2}{|c|}{$10 \%$} & \multicolumn{2}{|c|}{$15 \%$} & \multicolumn{2}{|c|}{$20 \%$} \\
\hline & $\mathrm{T}(\mathrm{C})$ & $\mathrm{UR}(\%)$ & $\mathrm{T}(\mathrm{C})$ & $\mathrm{UR}(\%)$ & $\mathrm{T}(\mathrm{C})$ & $\mathrm{UR}(\%)$ & $\mathrm{T}(\mathrm{C})$ & $\mathrm{UR}(\%)$ & $\mathrm{T}(\mathrm{C})$ & $\mathrm{UR}(\%)$ & $\mathrm{T}(\mathrm{C})$ & $\mathrm{UR}(\%)$ \\
\hline $08: 00$ & 29,2 & 75,0 & 35,0 & 71,9 & 31,2 & 76,0 & 35,8 & 61,8 & 30,0 & 72,0 & 36,2 & 64,0 \\
\hline 09:00 & 30,3 & 76,0 & 43,3 & 65,8 & 35,2 & 73,0 & 38,9 & 60,4 & 32,6 & 68,0 & 42,2 & 56,0 \\
\hline $10: 00$ & 32,9 & 61,0 & 50,7 & 58,3 & 39,2 & 69,0 & 39,3 & 60,0 & 36,2 & 66,0 & 44,1 & 50,4 \\
\hline 11:00 & 34,8 & 51,0 & 52,0 & 61,9 & 41,8 & 66,0 & 40,5 & 60,4 & 38,4 & 58,0 & 43,3 & 54,1 \\
\hline $12: 00$ & 37,4 & 43,0 & 53,1 & 66,5 & 45,4 & 60,0 & 45,6 & 50,6 & 42,3 & 51,0 & 47,1 & 46,5 \\
\hline $13: 00$ & 37,0 & 40,0 & 52,4 & 59,1 & 46,9 & 56,0 & 44,8 & 51,8 & 41,7 & 43,0 & 48,2 & 46,0 \\
\hline $14: 00$ & 37,3 & 41,0 & 50,8 & 64,0 & 43,8 & 55,0 & 51,6 & 44,5 & 40,8 & 41,0 & 48,0 & 45,7 \\
\hline $15: 00$ & 38,3 & 35,0 & 55,9 & 54,0 & 53,7 & 50,0 & 55,7 & 37,3 & 42,3 & 42,0 & 52,0 & 30,0 \\
\hline $16: 00$ & 24,9 & 99,0 & 35,4 & 76,0 & 29,2 & 76,0 & 29,2 & 80,0 & 26,5 & 87,0 & 28,0 & 94,0 \\
\hline $17: 00$ & 27,1 & 96,0 & 33,0 & 88,0 & 30,1 & 85,0 & 30,8 & 83,0 & 28,2 & 90,0 & 31,7 & 99,0 \\
\hline $18: 00$ & 27,2 & 92,0 & 32,0 & 92,1 & 29,7 & 88,0 & 29,3 & 86,0 & 27,8 & 88,0 & 29,0 & 97,0 \\
\hline
\end{tabular}

DIA DE COLETA DE DADOS:

$25 / 02$

\begin{tabular}{|c|c|c|c|c|c|c|c|c|c|c|c|c|}
\hline \multirow[b]{2}{*}{ HORA } & \multicolumn{2}{|c|}{ TESTE MUNHA } & \multicolumn{2}{|c|}{$0 \%$} & \multicolumn{2}{|c|}{$5 \%$} & \multicolumn{2}{|c|}{$10 \%$} & \multicolumn{2}{|c|}{$15 \%$} & \multicolumn{2}{|c|}{$20 \%$} \\
\hline & $\mathrm{T}(\mathrm{C})$ & $\mathrm{UR}(\%)$ & $\mathrm{T}(\mathrm{C})$ & $\mathrm{UR}(\%)$ & $\mathrm{T}(\mathrm{C})$ & $\mathrm{UR}(\%)$ & $\mathrm{T}(\mathrm{C})$ & $\operatorname{UR}(\%)$ & $\mathrm{T}(\mathrm{C})$ & $\mathrm{UR}(\%)$ & $\mathrm{T}(\mathrm{C})$ & $\mathrm{UR}(\%)$ \\
\hline 08:00 & 27,9 & 74,0 & 30,3 & 73,4 & 29,1 & 76,0 & 31,6 & 71,5 & 28,4 & 76,0 & 31,7 & 69,4 \\
\hline 09:00 & 28,5 & 72,0 & 38,1 & 72,2 & 33,3 & 75,0 & 35,8 & 66,8 & 31,0 & 75,0 & 36,9 & 64,0 \\
\hline $10: 00$ & 31,0 & 64,0 & 46,8 & 63,8 & 38,0 & 72,0 & 37,0 & 65,0 & 34,7 & 70,0 & 39,9 & 61,1 \\
\hline 11:00 & 32,7 & 56,0 & 47,0 & 64,7 & 39,5 & 66,0 & 38,0 & 66,0 & 36,2 & 62,0 & 38,8 & 70,0 \\
\hline $12: 00$ & 33,7 & 54,0 & 48,8 & 63,4 & 41,1 & 64,0 & 39,3 & 64,7 & 38,6 & 60,0 & 40,1 & 59,7 \\
\hline $13: 00$ & 35,4 & 50,0 & 51,4 & 64,7 & 43,8 & 60,0 & 41,0 & 61,0 & 39,8 & 56,0 & 43,2 & 57,7 \\
\hline $14: 00$ & 36,9 & 43,0 & 52,5 & 59,0 & 44,4 & 43,0 & 43,4 & 58,2 & 41,3 & 49,0 & 44,7 & 47,8 \\
\hline $15: 00$ & 34,6 & 46,0 & 48,0 & 64,0 & 41,4 & 56,0 & 39,4 & 54,0 & 38,0 & 47,0 & 40,4 & 46,5 \\
\hline $16: 00$ & 32,4 & 58,0 & 41,0 & 74,4 & 35,5 & 70,0 & 36,3 & 62,2 & 33,8 & 61,0 & 38,2 & 56,0 \\
\hline $17: 00$ & 32,1 & 59,0 & 36,8 & 72,8 & 34,8 & 72,0 & 35,9 & 65,6 & 33,4 & 65,0 & 36,4 & 56,8 \\
\hline 18:00 & 31,5 & 66,0 & 37,7 & 81,7 & 33,7 & 78,0 & 34,5 & 71,0 & 32,6 & 69,0 & 35,8 & 62,8 \\
\hline
\end{tabular}

DIA DE COLETA DE DADOS:

$26 / 02$

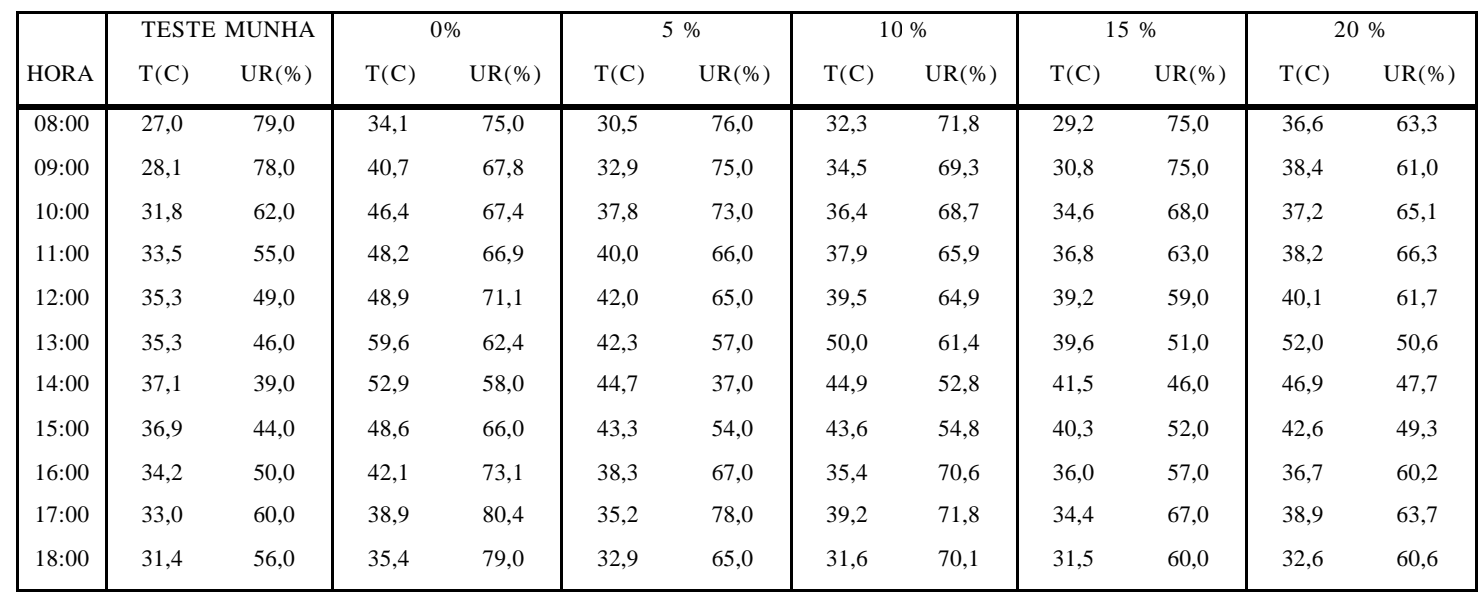


DIA DE COLETA DE DADOS:

$27 / 02$

\begin{tabular}{|c|c|c|c|c|c|c|c|c|c|c|c|c|}
\hline \multirow[b]{2}{*}{ HORA } & \multicolumn{2}{|c|}{ TESTE MUNHA } & \multicolumn{2}{|c|}{$0 \%$} & \multicolumn{2}{|c|}{$5 \%$} & \multicolumn{2}{|c|}{$10 \%$} & \multicolumn{2}{|c|}{$15 \%$} & \multicolumn{2}{|c|}{$20 \%$} \\
\hline & $\mathrm{T}(\mathrm{C})$ & $\mathrm{UR}(\%)$ & $\mathrm{T}(\mathrm{C})$ & $\mathrm{UR}(\%)$ & $\mathrm{T}(\mathrm{C})$ & $\mathrm{UR}(\%)$ & $\mathrm{T}(\mathrm{C})$ & $\mathrm{UR}(\%)$ & $\mathrm{T}(\mathrm{C})$ & $\mathrm{UR}(\%)$ & $\mathrm{T}(\mathrm{C})$ & $\mathrm{UR}(\%)$ \\
\hline 08:00 & 26,8 & 70,0 & 32,0 & 72,7 & 28,8 & 72,0 & 30,7 & 68,8 & 28,0 & 71,0 & 30,5 & 66,5 \\
\hline 09:00 & 28,5 & 68,0 & 41,3 & 64,6 & 33,1 & 73,0 & 33,4 & 68,2 & 30,7 & 69,0 & 34,7 & 68,7 \\
\hline $10: 00$ & 30,8 & 60,0 & 48,8 & 55,5 & 37,3 & 70,0 & 35,5 & 67,8 & 34,1 & 63,0 & 36,4 & 65,2 \\
\hline 11:00 & 33,1 & 54,0 & 48,8 & 58,3 & 40,9 & 67,0 & 38,2 & 64,6 & 36,8 & 61,0 & 38,6 & 61,0 \\
\hline $12: 00$ & 33,9 & 52,0 & 49,3 & 61,7 & 41,4 & 65,0 & 41,0 & 63,0 & 37,8 & 57,0 & 41,3 & 58,6 \\
\hline $13: 00$ & 35,9 & 44,0 & 51,4 & 61,8 & 43,9 & 57,0 & 44,5 & 57,0 & 39,3 & 54,0 & 45,6 & 47,6 \\
\hline $14: 00$ & 33,7 & 48,0 & 43,6 & 67,4 & 38,1 & 64,0 & 39,5 & 62,3 & 35,9 & 59,0 & 40,7 & 50,2 \\
\hline $15: 00$ & 33,8 & 56,0 & 40,5 & 68,8 & 36,0 & 62,0 & 37,7 & 60,6 & 36,0 & 62,0 & 37,7 & 55,1 \\
\hline $16: 00$ & 32,0 & 55,0 & 38,7 & 60,0 & 34,7 & 66,0 & 33,1 & 72,4 & 32,7 & 61,0 & 34,7 & 68,8 \\
\hline $17: 00$ & 26,8 & 63,0 & 33,5 & 48,0 & 30,2 & 58,0 & 29,2 & 62,0 & 28,7 & 60,0 & 28,4 & 70,0 \\
\hline $18: 00$ & 24,4 & 78,0 & 30,2 & 57,5 & 27,6 & 70,0 & 25,2 & 79,0 & 25,1 & 80,0 & 25,0 & 79,0 \\
\hline
\end{tabular}

DIA DE COLETA DE DADOS:

$02 / 03$

\begin{tabular}{|c|c|c|c|c|c|c|c|c|c|c|c|c|}
\hline \multirow[b]{2}{*}{ HORA } & \multicolumn{2}{|c|}{ TESTE MUNHA } & \multicolumn{2}{|c|}{$0 \%$} & \multicolumn{2}{|c|}{$5 \%$} & \multicolumn{2}{|c|}{$10 \%$} & \multicolumn{2}{|c|}{$15 \%$} & \multicolumn{2}{|c|}{$20 \%$} \\
\hline & $\mathrm{T}(\mathrm{C})$ & $\mathrm{UR}(\%)$ & $\mathrm{T}(\mathrm{C})$ & $\mathrm{UR}(\%)$ & $\mathrm{T}(\mathrm{C})$ & $\mathrm{UR}(\%)$ & $\mathrm{T}(\mathrm{C})$ & $\mathrm{UR}(\%)$ & $\mathrm{T}(\mathrm{C})$ & $\mathrm{UR}(\%)$ & $\mathrm{T}(\mathrm{C})$ & $\mathrm{UR}(\%)$ \\
\hline 08:00 & 23,0 & 79,8 & 27,9 & 87,4 & 26,5 & 81 & 26,4 & 78,7 & 26,9 & 76,2 & 25,7 & 80,0 \\
\hline 09:00 & 25,6 & 69,6 & 34,8 & 75,9 & 29,1 & 77,0 & 31,0 & 68,1 & 31,8 & 68,4 & 29,8 & 65,6 \\
\hline $10: 00$ & 28,1 & 61,5 & 39,2 & 68,2 & 33,3 & 72 & 35,3 & 65,3 & 35,3 & 52,1 & 33,5 & 69,8 \\
\hline 11:00 & 30,3 & 58,4 & 43,6 & 74,3 & 38,5 & 58 & 39,1 & 44,4 & 38,1 & 59,2 & 36,7 & 50,7 \\
\hline $12: 00$ & 31,2 & 48,6 & 45,9 & 54,2 & 40 & 62 & 41,3 & 50,0 & 38,9 & 55,5 & 38,6 & 52,0 \\
\hline 13:00 & 31,9 & 49,2 & 48,3 & 58,5 & 40,7 & 54,0 & 42,9 & 54,8 & 38,2 & 55,9 & 40,6 & 47,5 \\
\hline $14: 00$ & 31,9 & 40,0 & 48,7 & 48,5 & 39,9 & 50,0 & 42,6 & 47,5 & 38,9 & 41,3 & 40,9 & 51,4 \\
\hline $15: 00$ & 30,8 & 51,5 & 39,8 & 81,5 & 43,2 & 44,0 & 34,0 & 60,2 & 33,4 & 67,5 & 33,9 & 54,9 \\
\hline $16: 00$ & 30,4 & 54,4 & 36,7 & 75,4 & 44,3 & 43,0 & 33,5 & 58,4 & 32,0 & 63,7 & 33,1 & 56,8 \\
\hline $17: 00$ & 29,5 & 52,4 & 33,2 & 69,7 & 39,7 & 48 & 30,4 & 63,5 & 29,2 & 60,7 & 30,2 & 58,1 \\
\hline 18:00 & 27,7 & 57,0 & 29,7 & 86,2 & 39,0 & 45,0 & 28,4 & 62,7 & 26,3 & 68,6 & 27,9 & 64,3 \\
\hline
\end{tabular}

DIA DE COLETA DE DADOS:

03/03

\begin{tabular}{|c|c|c|c|c|c|c|c|c|c|c|c|c|}
\hline \multirow[b]{2}{*}{ HORA } & \multicolumn{2}{|c|}{ TESTE MUNHA } & \multicolumn{2}{|c|}{$0 \%$} & \multicolumn{2}{|c|}{$5 \%$} & \multicolumn{2}{|c|}{$10 \%$} & \multicolumn{2}{|c|}{$15 \%$} & \multicolumn{2}{|c|}{$20 \%$} \\
\hline & $\mathrm{T}(\mathrm{C})$ & $\mathrm{UR}(\%)$ & $\mathrm{T}(\mathrm{C})$ & $\mathrm{UR}(\%)$ & $\mathrm{T}(\mathrm{C})$ & $\mathrm{UR}(\%)$ & $\mathrm{T}(\mathrm{C})$ & $\mathrm{UR}(\%)$ & $\mathrm{T}(\mathrm{C})$ & $\mathrm{UR}(\%)$ & $\mathrm{T}(\mathrm{C})$ & $\operatorname{UR}(\%)$ \\
\hline 08:00 & 24,0 & 74,6 & 29,5 & 96,8 & 23,8 & 73 & 27,0 & 85,6 & 28,0 & 76,1 & 26,9 & 82,9 \\
\hline 09:00 & 26,5 & 64,5 & 34,6 & 77,3 & 24,9 & 79,0 & 30,9 & 62,5 & 31,4 & 69,2 & 29,8 & 67,9 \\
\hline 10:00 & 28,0 & 55,4 & 39,2 & 78,5 & 31,1 & 69 & 34,8 & 51,4 & 34,8 & 62,7 & 33,2 & 56,9 \\
\hline 11:00 & 29,9 & 52,0 & 43,6 & 76,4 & 33,1 & 65 & 38,9 & 51,4 & 37,5 & 55,5 & 36,4 & 55,2 \\
\hline $12: 00$ & 30,9 & 46,8 & 46,4 & 51,9 & 33,7 & 54 & 40,9 & 51,5 & 38,4 & 47,0 & 38,1 & 48,8 \\
\hline 13:00 & 32,1 & 47,2 & 50,6 & 53,5 & 36,4 & 57,0 & 44,0 & 50,9 & 40,7 & 50,3 & 40,9 & 54,8 \\
\hline $14: 00$ & 30,6 & 48,7 & 41,7 & 75,2 & 36,4 & 66,0 & 36,3 & 56,8 & 34,3 & 55,8 & 34,8 & 52,7 \\
\hline $15: 00$ & 32,3 & 46,1 & 45,0 & 66,8 & 35,0 & 64,0 & 40,0 & 52,5 & 36,5 & 48,7 & 38,6 & 43,5 \\
\hline $16: 00$ & 32,8 & 44,6 & 43,6 & 49,1 & 33,0 & 63,0 & 39,2 & 50,8 & 35,8 & 53,5 & 38,5 & 41,9 \\
\hline 17:00 & 31,9 & 43,9 & 40,7 & 63,8 & 30,2 & 58 & 37,5 & 50,9 & 33,4 & 48,5 & 36,4 & 44,7 \\
\hline 18:00 & 28,8 & 49,3 & 30,6 & 79,2 & 27,6 & 70,0 & 29,7 & 57,6 & 26,8 & 59,6 & 28,7 & 57,5 \\
\hline
\end{tabular}




\section{APÊNDICE II}

Dados obtidos no Experimento I - cultivo da rúcula no outono 
DIA DE COLETA DE DADOS:

$17 / \mathrm{Abr}$

\begin{tabular}{|c|c|c|c|c|c|c|c|c|c|c|c|c|c|c|c|c|c|c|c|c|c|c|c|c|}
\hline \multirow[b]{2}{*}{ HORA } & \multicolumn{4}{|c|}{ TESTEMUNHA } & \multicolumn{4}{|c|}{$0 \%$} & \multicolumn{4}{|c|}{$5 \%$} & \multicolumn{4}{|c|}{$10 \%$} & \multicolumn{4}{|c|}{$15 \%$} & \multicolumn{4}{|c|}{$20 \%$} \\
\hline & $\mathrm{T}(\mathrm{C})$ & UR(\%) & Tsolo & RS & $\mathrm{T}(\mathrm{C})$ & UR $(\%)$ & Tsolo & RS & $\mathrm{T}(\mathrm{C})$ & UR(\%) & Tsolo & RS & $\mathrm{T}(\mathrm{C})$ & UR $(\%)$ & Tsolo & RS & $\mathrm{T}(\mathrm{C})$ & UR(\%) & Tsolo & RS & $\mathrm{T}(\mathrm{C})$ & $\mathrm{UR}(\%)$ & Tsolo & RS \\
\hline 08:00 & 19,9 & 72,9 & 21,0 & 333,5 & 20,4 & 74,3 & 21,1 & 337,2 & 20,3 & 74,6 & 19,9 & $\overline{9,9}$ & 20,7 & (2, & 21,6 & 328,6 & 20,7 & , & 19,8 & 376,9 & 20,3 & 73,7 & 20,1 & 362,1 \\
\hline 09:00 & 22,3 & 66,3 & 21,0 & 508,1 & 30,7 & 65,8 & 21,9 & 409,6 & 29,7 & 63,7 & 21,4 & 335,3 & 28,5 & 55,3 & 21,3 & 286,0 & 28,4 & 56,3 & 22,3 & 422,9 & 26,9 & 58,5 & 21,4 & 428,3 \\
\hline $10: 00$ & 24,3 & 58,7 & 23,9 & 671,4 & 35,9 & 59,1 & 24,1 & 584,2 & 34,6 & 48,2 & 23,2 & 481,5 & 33,4 & 43,6 & 23,2 & 441,7 & 32,0 & 46,9 & 24,7 & 552,3 & 31,4 & 49,1 & 22,6 & 590,0 \\
\hline $11: 00$ & 25,9 & 56,3 & 26,1 & 780,4 & 40,2 & 60,5 & 26,6 & 660,0 & 38,4 & 48,6 & 25,4 & 531,7 & 37,4 & 41,3 & 25,6 & 641,9 & 34,6 & 40,8 & 27,1 & 647,7 & 35,3 & 43,0 & 24,1 & 811,6 \\
\hline $12: 00$ & 28,2 & 49,4 & 27,0 & 827,7 & 43,6 & 63,2 & 29,3 & 526,4 & 40,3 & 46,3 & 27,5 & 569,4 & 40,0 & 37,1 & 27,6 & 811,8 & 37,0 & 43,0 & 29,0 & 720,9 & 38,0 & 38,5 & 25,3 & 876,5 \\
\hline 13:00 & 29,5 & 44,6 & 27,7 & 804,4 & 45,1 & 48,3 & 30,8 & 712,7 & 41,9 & 41,9 & 29,3 & 448,5 & 41,4 & 33,8 & 29,1 & 645,3 & 38,1 & 37,4 & 30,4 & 663,2 & 39,6 & 38,6 & 26,3 & 763,5 \\
\hline $14: 00$ & 28,1 & 45,7 & 28,2 & 128,0 & 41,2 & 49,7 & 31,9 & 107,6 & 37,0 & 43,6 & 30,4 & 85,8 & 39,3 & 34,1 & 30,0 & 76,2 & 34,3 & 44,3 & 30,6 & 105,1 & 37,5 & 35,4 & 27,1 & 108,6 \\
\hline $15: 00$ & 27,6 & 47,6 & 27,8 & 539,6 & 35,9 & 69,7 & 31,7 & 122,6 & 33,1 & 52,6 & 30,2 & 98,2 & 33,5 & 50,0 & 29,7 & 318,4 & 31,8 & 50,8 & 29,6 & 119,2 & 32,4 & 49,2 & 27,5 & 490,1 \\
\hline $16: 00$ & 29,6 & 39,3 & 27,5 & 382,0 & 40,2 & 56,2 & 31,2 & 228,5 & 37,4 & 42,4 & 29,8 & 190,7 & 37,4 & 36,0 & 29,1 & 228,5 & 35,2 & 33,9 & 29,0 & 297,0 & 36,1 & 35,9 & 27,5 & 305,9 \\
\hline $17: 00$ & 27,6 & 45,2 & 27,2 & 57,4 & 33,5 & 55,9 & 30,8 & 57,3 & 30,9 & 52,5 & 29,5 & 40,8 & 32,6 & 44,7 & 28,8 & 44,9 & 29,6 & 47,0 & 28,3 & 55,2 & 31,9 & 41,4 & 27,6 & 79,3 \\
\hline 18:00 & 25,2 & 46,4 & 26,1 & 1,9 & 24,7 & 78,5 & 29,5 & 6,4 & 23,6 & 69,8 & 28,5 & 19,1 & 24,8 & 54,2 & 27,7 & 2,3 & 24,2 & 59,0 & 27,1 & 7,8 & 24,6 & 54,2 & 27,1 & 12,5 \\
\hline
\end{tabular}

DIA DE COLETA DE DADOS:

18/Abr

\begin{tabular}{|c|c|c|c|c|c|c|c|c|c|c|c|c|c|c|c|c|c|c|c|c|c|c|c|c|}
\hline \multirow[b]{2}{*}{ HORA } & \multicolumn{4}{|c|}{ TESTEMUNHA } & \multicolumn{4}{|c|}{$0 \%$} & \multicolumn{4}{|c|}{$5 \%$} & \multicolumn{4}{|c|}{$10 \%$} & \multicolumn{4}{|c|}{$15 \%$} & \multicolumn{3}{|c|}{$20 \%$} & \multirow[b]{2}{*}{ RS } \\
\hline & $\mathrm{T}(\mathrm{C})$ & $\mathrm{UR}(\%)$ & Tsolo & RS & $\mathrm{T}(\mathrm{C})$ & UR(\%) & Tsolo & RS & $\mathrm{T}(\mathrm{C})$ & UR(\%) & Tsolo & RS & $\mathrm{T}(\mathrm{C})$ & UR(\%) & Tsolo & RS & $\mathrm{T}(\mathrm{C})$ & UR(\%) & Tsolo & RS & $\mathrm{T}(\mathrm{C})$ & $\mathrm{UR}(\%)$ & Tsolo & \\
\hline 08:00 & 18,2 & 82,8 & 19,7 & 291,9 & 24,3 & 87,5 & 22,3 & 203,6 & 23,6 & 77,8 & 22,0 & 182,4 & 23,5 & 73,7 & 21,2 & 140,4 & 24,1 & 71,4 & 21,6 & 172,0 & 22,4 & 77,4 & 21,3 & 211,6 \\
\hline 09:00 & 22,0 & 69,6 & 20,9 & 510,6 & 32,8 & 65,9 & 23,9 & 345,3 & 30,3 & 65,1 & 23,1 & 309,5 & 28,6 & 62,3 & 22,4 & 305,9 & 28,8 & 62,7 & 23,5 & 446,7 & 26,7 & 66,9 & 22,0 & 353,4 \\
\hline 10:00 & 24,8 & 64,6 & 22,5 & 680,2 & 38,4 & 56,9 & 26,0 & 561,7 & 34,7 & 55,7 & 24,7 & 497,6 & 33,9 & 56,6 & 24,3 & 411,6 & 32,4 & 51,8 & 25,6 & 497,1 & 31,4 & 55,2 & 22,9 & 561,3 \\
\hline 11:00 & 25,9 & 57,5 & 24,2 & 793,6 & 41,1 & 56,2 & 28,5 & 727,7 & 37,6 & 43,1 & 26,6 & 470,2 & 36,4 & 43,0 & 26,1 & 572,5 & 35,2 & 46,3 & 27,6 & 656,0 & 35,0 & 49,2 & 24,1 & 799,7 \\
\hline 12:00 & 28,1 & 54,6 & 25,5 & 830,8 & 45,0 & 60,2 & 30,9 & 583,7 & 40,7 & 51,9 & 28,3 & 568,9 & 39,8 & 40,5 & 27,9 & 800,5 & 37,3 & 44,8 & 29,2 & 687,5 & 38,0 & 46,0 & 25,2 & 850,9 \\
\hline 13:00 & 28,7 & 47,5 & 26,7 & 798,7 & 46,8 & 60,5 & 32,1 & 569,2 & 41,4 & 43,3 & 29,8 & 449,0 & 40,8 & 38,6 & 29,3 & 618,6 & 38,0 & 41,6 & 30,4 & 650,6 & 39,1 & 44,7 & 26,2 & 726,1 \\
\hline 14:00 & 29,5 & 41,6 & 27,6 & 698,5 & 47,2 & 57,6 & 33,0 & 668,7 & 42,0 & 28,7 & 30,7 & 607,6 & 41,9 & 34,8 & 30,2 & 429,8 & 38,5 & 33,2 & 31,0 & 547,9 & 40,4 & 37,7 & 26,9 & 606,2 \\
\hline 15:00 & 30,2 & 38,7 & 28,1 & 533,9 & 44,8 & 56,2 & 33,3 & 301,4 & 40,9 & 40,3 & 31,1 & 362,2 & 40,8 & 27,3 & 30,7 & 287,7 & 38,0 & 36,3 & 31,0 & 515,5 & 40,0 & 29,5 & 27,6 & 450,8 \\
\hline 16:00 & 29,2 & 35,8 & 28,2 & 336,0 & 40,0 & 54,3 & 33,0 & 275,3 & 37,6 & 37,4 & 30,9 & 151,9 & 38,1 & 32,7 & 30,3 & 193,9 & 35,3 & 34,7 & 30,2 & 283,4 & 37,3 & 31,9 & 28,0 & 255,3 \\
\hline $17: 00$ & 28,1 & 45,8 & 27,5 & 22,7 & 33,9 & 72,9 & 32,1 & 28,9 & 30,6 & 58,4 & 30,3 & 18,6 & 33,5 & 46,3 & 29,4 & 24,4 & 29,8 & 54,6 & 29,0 & 32,0 & 32,3 & 49,8 & 27,9 & 42,5 \\
\hline 18:00 & 21,2 & 70,7 & 26,2 & 1,3 & 24,2 & 87,3 & 30,6 & 4,6 & 21,5 & 93,3 & 29,0 & 12,9 & 22,7 & 80,1 & 28,0 & 2,3 & 21,5 & 83,1 & 27,5 & 5,3 & 22,1 & 80,9 & 27,2 & 12,5 \\
\hline
\end{tabular}


DIA DE COLETA DE DADOS:

19/Abr

\begin{tabular}{|c|c|c|c|c|c|c|c|c|c|c|c|c|c|c|c|c|c|c|c|c|c|c|c|c|}
\hline \multirow[b]{2}{*}{ HORA } & \multicolumn{4}{|c|}{ TESTEMUNHA } & \multicolumn{4}{|c|}{$0 \%$} & \multicolumn{4}{|c|}{$5 \%$} & \multicolumn{4}{|c|}{$10 \%$} & \multicolumn{4}{|c|}{$15 \%$} & \multicolumn{4}{|c|}{$20 \%$} \\
\hline & $\mathrm{T}(\mathrm{C})$ & UR(\%) & Tsolo & RS & $\mathrm{T}(\mathrm{C})$ & UR(\%) & Tsolo & RS & $\mathrm{T}(\mathrm{C})$ & UR(\%) & Tsolo & RS & $\mathrm{T}(\mathrm{C})$ & UR(\%) & Tsolo & RS & $\mathrm{T}(\mathrm{C})$ & UR(\%) & Tsolo & RS & $\mathrm{T}(\mathrm{C})$ & UR(\%) & Tsolo & RS \\
\hline 08:00 & 16,4 & 92,0 & 20,0 & 262,9 & 23,7 & 91,8 & 23,0 & 189,7 & 22,4 & 83,1 & 22,4 & 167,4 & 22,3 & 75,8 & 21,6 & 133,6 & 22,9 & 74,2 & 21,8 & 165,2 & 21,4 & 77,4 & 21,6 & 189,8 \\
\hline 09:00 & 21,4 & 78,9 & 21,0 & 484,8 & 32,3 & 72,6 & 24,3 & 424,6 & 29,8 & 67,9 & 23,5 & 443,3 & 28,7 & 63,5 & 22,7 & 295,6 & 29,0 & 64,3 & 23,5 & 417,6 & 26,5 & 69,9 & 22,2 & 306,5 \\
\hline 10:00 & 23,6 & 69,8 & 22,6 & 650,5 & 38,0 & 63,0 & 26,3 & 559,4 & 34,8 & 54,1 & 24,8 & 373,6 & 33,5 & 53,6 & 24,5 & 325,2 & 33,2 & 56,6 & 25,6 & 489,8 & 31,5 & 61,2 & 23,1 & 514,4 \\
\hline 11:00 & 26,9 & 58,1 & 24,4 & 766,5 & 41,9 & 53,6 & 28,7 & 567,5 & 38,7 & 53,1 & 26,4 & 462,4 & 38,4 & 45,4 & 26,4 & 558,9 & 35,9 & 47,6 & 27,8 & 618,2 & 35,8 & 46,8 & 24,3 & 713,0 \\
\hline 12:00 & 28,4 & 51,5 & 27,3 & 796,8 & 43,3 & 63,0 & 30,6 & 481,3 & 40,1 & 42,7 & 28,5 & 476,9 & 40,3 & 38,7 & 28,5 & 687,3 & 37,4 & 38,9 & 29,2 & 642,9 & 38,2 & 41,9 & 25,5 & 796,0 \\
\hline 13:00 & 29,8 & 37,0 & 28,1 & 786,7 & 44,8 & 55,9 & 31,8 & 586,6 & 40,4 & 34,1 & 30,1 & 427,3 & 40,8 & 36,0 & 29,7 & 592,4 & 37,3 & 33,2 & 30,5 & 622,1 & 39,0 & 36,1 & 26,6 & 684,9 \\
\hline 14:00 & 30,3 & 38,7 & 28,1 & 685,2 & 44,7 & 48,5 & 32,5 & 606,8 & 40,8 & 39,6 & 30,9 & 507,4 & 40,8 & 35,9 & 30,4 & 452,5 & 37,3 & 35,6 & 31,0 & 525,6 & 39,3 & 38,1 & 27,3 & 581,9 \\
\hline 15:00 & 30,7 & 33,7 & 29,1 & 562,3 & 42,5 & 53,5 & 32,8 & 432,1 & 38,6 & 40,5 & 31,5 & 336,4 & 39,2 & 34,9 & 31,0 & 316,7 & 36,1 & 35,5 & 30,9 & 493,7 & 38,4 & 36,1 & 28,0 & 470,1 \\
\hline 16:00 & 29,9 & 35,5 & 28,0 & 318,3 & 39,2 & 61,4 & 32,3 & 243,5 & 36,1 & 44,6 & 31,2 & 148,8 & 36,4 & 37,1 & 30,5 & 149,5 & 34,0 & 35,9 & 30,2 & 220,4 & 35,4 & 36,4 & 28,2 & 248,5 \\
\hline $17: 00$ & 28,4 & 36,7 & 27,0 & 33,4 & 32,8 & 64,2 & 31,7 & 36,4 & 30,2 & 50,2 & 30,5 & 24,3 & 32,4 & 43,3 & 29,7 & 24,4 & 29,5 & 46,9 & 29,1 & 37,8 & 31,4 & 44,2 & 28,1 & 45,6 \\
\hline 18:00 & 21,8 & 67,6 & 26,1 & 1,3 & 24,3 & 92,4 & 30,4 & 6,4 & 22,4 & 93,4 & 29,4 & 16,0 & 23,5 & 78,9 & 28,4 & 2,8 & 22,5 & 82,2 & 27,7 & 5,8 & 22,9 & 80,3 & 27,4 & 13,1 \\
\hline
\end{tabular}

DIA DE COLETA DE DADOS:

20/Abr

\begin{tabular}{|c|c|c|c|c|c|c|c|c|c|c|c|c|c|c|c|c|c|c|c|c|c|c|c|c|}
\hline \multirow[b]{2}{*}{ HORA } & \multicolumn{4}{|c|}{ TESTEMUNHA } & \multicolumn{4}{|c|}{$0 \%$} & \multicolumn{4}{|c|}{$5 \%$} & \multicolumn{4}{|c|}{$10 \%$} & \multicolumn{4}{|c|}{$15 \%$} & \multicolumn{3}{|c|}{$20 \%$} & \multirow[b]{2}{*}{ RS } \\
\hline & $\mathrm{T}(\mathrm{C})$ & $\mathrm{UR}(\%)$ & Tsolo & RS & $\mathrm{T}(\mathrm{C})$ & $\mathrm{UR}(\%)$ & Tsolo & RS & $\mathrm{T}(\mathrm{C})$ & $\mathrm{UR}(\%)$ & Tsolo & RS & $\mathrm{T}(\mathrm{C})$ & $\mathrm{UR}(\%)$ & Tsolo & RS & $\mathrm{T}(\mathrm{C})$ & $\mathrm{UR}(\%)$ & Tsolo & RS & $\mathrm{T}(\mathrm{C})$ & $\mathrm{UR}(\%)$ & Tsolo & \\
\hline 08:00 & 18,2 & 84,7 & 19,8 & 286,8 & 24,9 & 86,8 & 23,1 & 197,8 & 23,4 & 86,8 & 22,6 & 162,8 & 23,1 & 73,7 & 21,6 & 125,6 & 24,0 & 74,5 & 22,1 & 156,0 & 22,0 & 77,8 & 21,6 & 203,5 \\
\hline 09:00 & 23,6 & 67,3 & 20,9 & 497,4 & 33,7 & 67,9 & 24,5 & 311,8 & 31,8 & 63,8 & 23,6 & 346,7 & 30,1 & 54,7 & 22,8 & 255,3 & 30,3 & 57,9 & 23,9 & 424,9 & 27,7 & 62,5 & 22,2 & 309,0 \\
\hline 10:00 & 25,8 & 55,9 & 22,6 & 658,7 & 38,4 & 60,7 & 26,4 & 548,4 & 36,5 & 55,2 & 25,1 & 395,3 & 35,0 & 45,9 & 24,6 & 361,6 & 34,3 & 46,8 & 26,1 & 507,7 & 33,0 & 50,9 & 23,2 & 538,8 \\
\hline $11: 00$ & 29,1 & 45,9 & 24,3 & 763,4 & 42,4 & 62,1 & 28,7 & 668,7 & 39,6 & 40,8 & 26,6 & 501,7 & 39,6 & 40,6 & 26,5 & 545,2 & 37,1 & 41,6 & 28,0 & 623,0 & 37,0 & 38,8 & 24,4 & 737,3 \\
\hline $12: 00$ & 30,3 & 38,9 & 25,6 & 804,4 & 44,2 & 66,5 & 30,8 & 668,1 & 41,5 & 36,9 & 28,3 & 510,5 & 41,1 & 29,5 & 28,1 & 687,3 & 38,4 & 37,1 & 29,4 & 640,0 & 39,2 & 31,7 & 25,5 & 789,7 \\
\hline 13:00 & 30,9 & 37,0 & 26,6 & 801,8 & 44,4 & 59,1 & 32,0 & 551,3 & 40,3 & 35,3 & 29,6 & 444,3 & 41,5 & 33,1 & 29,5 & 618,0 & 37,5 & 34,8 & 30,5 & 624,5 & 39,6 & 39,1 & 26,4 & 704,8 \\
\hline $14: 00$ & 31,3 & 37,5 & 27,6 & 691,5 & 44,4 & 50,9 & 32,5 & 592,9 & 40,4 & 32,2 & 30,4 & 442,8 & 40,7 & 34,4 & 30,4 & 468,5 & 37,3 & 32,6 & 30,9 & 533,4 & 39,1 & 37,1 & 27,1 & 598,7 \\
\hline $15: 00$ & 30,9 & 34,9 & 28,7 & 533,3 & 43,1 & 44,6 & 32,6 & 414,2 & 39,1 & 33,6 & 30,7 & 355,0 & 39,5 & 31,6 & 30,6 & 270,1 & 36,8 & 34,9 & 30,8 & 490,3 & 38,6 & 30,8 & 27,9 & 451,4 \\
\hline $16: 00$ & 30,7 & 33,3 & 28,2 & 339,8 & 39,1 & 53,6 & 32,2 & 255,1 & 35,7 & 35,5 & 30,6 & 143,1 & 36,8 & 33,4 & 30,3 & 159,8 & 34,1 & 32,5 & 30,2 & 175,9 & 35,7 & 37,0 & 28,2 & 292,8 \\
\hline $17: 00$ & 28,6 & 34,2 & 27,2 & 31,5 & 32,4 & 59,4 & 31,3 & 34,7 & 29,9 & 51,5 & 30,1 & 22,7 & 32,3 & 36,3 & 29,4 & 21,6 & 29,3 & 44,7 & 29,2 & 35,4 & 31,2 & 38,2 & 28,1 & 47,4 \\
\hline 18:00 & 22,3 & 63,7 & 26,2 & 1,3 & 24,0 & 90,7 & 30,0 & 5,2 & 22,5 & 92,3 & 29,1 & 23,3 & 23,7 & 74,2 & 28,3 & 2,8 & 22,6 & 77,5 & 27,8 & 3,9 & 23,0 & 76,4 & 27,5 & 15,0 \\
\hline
\end{tabular}


DIA DE COLETA DE DADOS:

21/Abr

\begin{tabular}{|c|c|c|c|c|c|c|c|c|c|c|c|c|c|c|c|c|c|c|c|c|c|c|c|c|}
\hline \multirow[b]{2}{*}{ HORA } & \multicolumn{4}{|c|}{ TESTEMUNHA } & \multicolumn{4}{|c|}{$0 \%$} & \multicolumn{4}{|c|}{$5 \%$} & \multicolumn{4}{|c|}{$10 \%$} & \multicolumn{4}{|c|}{$15 \%$} & \multicolumn{3}{|c|}{$20 \%$} & \multirow[b]{2}{*}{ RS } \\
\hline & $\mathrm{T}(\mathrm{C})$ & $\mathrm{UR}(\%)$ & Tsolo & RS & $\mathrm{T}(\mathrm{C})$ & $\mathrm{UR}(\%)$ & Tsolo & RS & $\mathrm{T}(\mathrm{C})$ & $\mathrm{UR}(\%)$ & Tsolo & RS & $\mathrm{T}(\mathrm{C})$ & UR(\%) & Tsolo & RS & $\mathrm{T}(\mathrm{C})$ & UR(\%) & Tsolo & RS & $\mathrm{T}(\mathrm{C})$ & $\mathrm{UR}(\%)$ & Tsolo & \\
\hline 08:00 & 19,3 & 76,8 & 20,5 & 271,7 & 25,4 & 71,9 & 23,6 & 203,0 & 24,2 & 72,5 & 23,1 & 161,7 & 22,9 & 71,8 & 22,0 & 124,5 & 24,2 & 66,0 & 22,4 & 186,0 & 22,4 & 75,2 & 21,9 & 211,0 \\
\hline 09:00 & 23,4 & 65,8 & 21,5 & 471,5 & 33,6 & 63,6 & 24,8 & 316,4 & 31,3 & 60,2 & 23,9 & 253,7 & 30,6 & 51,0 & 23,0 & 206,4 & 30,3 & 56,2 & 24,1 & 401,6 & 28,5 & 56,3 & 22,3 & 313,4 \\
\hline 10:00 & 27,1 & 55,2 & 22,9 & 643,6 & 39,3 & 48,7 & 26,4 & 512,5 & 37,4 & 53,5 & 25,2 & 458,3 & 36,2 & 43,5 & 24,7 & 379,8 & 34,7 & 50,4 & 26,0 & 532,9 & 34,2 & 50,3 & 23,3 & 570,6 \\
\hline 11:00 & 29,7 & 46,5 & 24,7 & 750,1 & 42,6 & 66,4 & 28,7 & 688,9 & 41,5 & 41,1 & 26,9 & 553,9 & 40,3 & 40,3 & 26,6 & 512,8 & 38,9 & 44,4 & 28,0 & 620,1 & 38,7 & 40,4 & 24,6 & 668,0 \\
\hline 12:00 & 32,3 & 38,8 & 26,1 & 715,5 & 45,4 & 46,3 & 30,6 & 777,4 & 43,5 & 40,8 & 28,5 & 599,3 & 42,9 & 29,3 & 28,5 & 511,1 & 40,7 & 41,4 & 29,6 & 751,9 & 41,4 & 33,1 & 25,7 & 633,0 \\
\hline 13:00 & 33,1 & 34,8 & 27,2 & 753,9 & 48,0 & 51,5 & 31,7 & 714,4 & 44,0 & 32,7 & 29,8 & 425,7 & 44,6 & 26,9 & 29,8 & 585,0 & 40,7 & 35,6 & 30,6 & 599,8 & 42,6 & 28,0 & 26,6 & 653,7 \\
\hline 14:00 & 32,6 & 34,5 & 28,1 & 712,3 & 46,9 & 56,4 & 32,7 & 592,9 & 43,0 & 38,3 & 30,6 & 372,0 & 43,3 & 32,1 & 30,8 & 484,4 & 40,1 & 34,9 & 31,2 & 526,6 & 41,4 & 32,1 & 27,4 & 611,8 \\
\hline $15: 00$ & 31,3 & 37,4 & 28,1 & 255,9 & 38,1 & 65,4 & 32,5 & 192,6 & 36,4 & 52,0 & 30,8 & 165,9 & 36,5 & 38,8 & 30,7 & 184,8 & 35,2 & 42,8 & 30,5 & 186,0 & 35,6 & 38,1 & 27,8 & 221,0 \\
\hline 16:00 & 30,8 & 40,0 & 27,8 & 246,5 & 37,8 & 55,3 & 32,0 & 155,0 & 35,8 & 40,5 & 30,4 & 112,6 & 36,3 & 42,7 & 30,2 & 145,0 & 34,5 & 37,0 & 29,8 & 131,3 & 35,1 & 40,9 & 27,9 & 223,5 \\
\hline 17:00 & 28,6 & 49,8 & 27,2 & 28,4 & 30,9 & 66,8 & 31,3 & 29,5 & 29,5 & 57,1 & 29,9 & 35,1 & 30,7 & 51,9 & 29,5 & 18,2 & 29,5 & 55,2 & 29,0 & 27,6 & 29,9 & 55,1 & 27,7 & 64,3 \\
\hline 18:00 & 26,5 & 57,1 & 26,5 & 1,9 & 26,5 & 82,4 & 30,0 & 8,7 & 25,9 & 72,8 & 29,0 & 28,4 & 26,7 & 65,8 & 28,4 & 3,4 & 26,3 & 67,1 & 27,8 & 7,3 & 26,3 & 64,2 & 27,3 & 25,6 \\
\hline
\end{tabular}

DIA DE COLETA DE DADOS:

22/Abr

\begin{tabular}{|c|c|c|c|c|c|c|c|c|c|c|c|c|c|c|c|c|c|c|c|c|c|c|c|c|}
\hline \multirow[b]{2}{*}{ HORA } & \multicolumn{4}{|c|}{ TESTEMUNHA } & \multicolumn{4}{|c|}{$0 \%$} & \multicolumn{4}{|c|}{$5 \%$} & \multicolumn{4}{|c|}{$10 \%$} & \multicolumn{4}{|c|}{$15 \%$} & \multicolumn{3}{|c|}{$20 \%$} & \multirow[b]{2}{*}{ RS } \\
\hline & $\mathrm{T}(\mathrm{C})$ & UR(\%) & Tsolo & RS & $\mathrm{T}(\mathrm{C})$ & $\mathrm{UR}(\%)$ & Tsolo & RS & $\mathrm{T}(\mathrm{C})$ & $\mathrm{UR}(\%)$ & Tsolo & RS & $\mathrm{T}(\mathrm{C})$ & UR(\%) & Tsolo & RS & $\mathrm{T}(\mathrm{C})$ & $\mathrm{UR}(\%)$ & Tsolo & RS & $\mathrm{T}(\mathrm{C})$ & UR(\%) & & \\
\hline 08:00 & 18,8 & 91,7 & 21,9 & 93,3 & 22,6 & 98,0 & 24,5 & 77,5 & 20,8 & 97,7 & 23,8 & 29,5 & 21,4 & 94,5 & 23,3 & 18,8 & 21,0 & 93,3 & 23,1 & 70,7 & 21,0 & 96,8 & 23,2 & 79,9 \\
\hline 09:00 & 20,3 & 85,9 & 22,2 & 172,1 & 26,5 & 86,3 & 24,9 & 149,8 & 24,0 & 81,2 & 24,1 & 93,5 & 24,3 & 81,8 & 23,7 & 120,5 & 23,7 & 81,8 & 23,7 & 137,6 & 23,7 & 81,2 & 23,4 & 114,9 \\
\hline 10:00 & 20,9 & 82,4 & 22,9 & 230,7 & 28,8 & 78,7 & 25,6 & 209,4 & 25,7 & 81,7 & 24,6 & 190,7 & 26,0 & 76,1 & 24,4 & 163,2 & 24,9 & 78,2 & 24,5 & 205,9 & 25,1 & 79,6 & 23,8 & 189,8 \\
\hline 11:00 & 23,0 & 75,0 & 23,4 & 824,5 & 34,0 & 76,8 & 26,4 & 536,8 & 31,0 & 62,9 & 25,2 & 461,4 & 29,8 & 66,0 & 25,1 & 483,8 & 29,8 & 63,2 & 25,4 & 603,6 & 28,5 & 69,0 & 24,2 & 696,7 \\
\hline 12:00 & 24,9 & 69,1 & 24,5 & 453,2 & 37,9 & 61,5 & 27,7 & 256,3 & 33,7 & 54,0 & 26,1 & 223,2 & 34,6 & 53,5 & 26,4 & 340,0 & 32,9 & 52,5 & 26,7 & 263,1 & 33,0 & 57,0 & 25,0 & 398,3 \\
\hline 13:00 & 22,7 & 79,0 & 24,9 & 156,3 & 29,6 & 80,4 & 27,9 & 152,7 & 26,3 & 79,7 & 26,5 & 136,9 & 27,6 & 76,4 & 26,6 & 112,0 & 26,3 & 78,9 & 26,6 & 154,1 & 26,3 & 78,7 & 25,4 & 149,8 \\
\hline $14: 00$ & 22,9 & 87,6 & 24,8 & 453,2 & 32,3 & 78,9 & 27,9 & 352,9 & 29,3 & 81,2 & 26,5 & 295,0 & 28,8 & 79,8 & 26,6 & 293,9 & 28,6 & 78,5 & 26,5 & 331,9 & 27,9 & 81,7 & 25,5 & 360,9 \\
\hline $15: 00$ & 23,1 & 81,5 & 25,1 & 216,2 & 30,7 & 80,6 & 28,3 & 190,3 & 28,2 & 71,5 & 26,8 & 164,3 & 28,5 & 71,5 & 26,9 & 158,1 & 27,9 & 75,0 & 26,8 & 190,9 & 27,6 & 77,1 & 25,8 & 201,0 \\
\hline 16:00 & 23,0 & 82,9 & 25,3 & 111,6 & 28,5 & 87,2 & 28,3 & 120,9 & 25,9 & 82,4 & 26,8 & 103,3 & 26,8 & 76,1 & 26,9 & 80,2 & 26,0 & 81,9 & 26,6 & 118,2 & 25,9 & 80,6 & 25,9 & 119,9 \\
\hline 17:00 & 22,4 & 85,7 & 24,9 & 27,7 & 26,0 & 87,4 & 28,1 & 22,0 & 23,5 & 88,0 & 26,6 & 17,1 & 24,8 & 83,6 & 26,6 & 13,6 & 23,8 & 87,8 & 26,2 & 24,7 & 24,1 & 87,0 & 25,9 & 22,5 \\
\hline 18:00 & 21,3 & 88,7 & 24,4 & 1,9 & 22,6 & 94,7 & 27,5 & 8,1 & 21,0 & 96,3 & 26,1 & 7,8 & 21,6 & 93,5 & 25,9 & 2,8 & 21,4 & 95,0 & 25,5 & 10,2 & 21,5 & 94,4 & 25,6 & 36,8 \\
\hline
\end{tabular}


DIA DE COLETA DE DADOS:

23/Abr

\begin{tabular}{|c|c|c|c|c|c|c|c|c|c|c|c|c|c|c|c|c|c|c|c|c|c|c|c|c|}
\hline \multirow[b]{2}{*}{ HORA } & \multicolumn{4}{|c|}{ TESTEMUNHA } & \multicolumn{4}{|c|}{$0 \%$} & \multicolumn{4}{|c|}{$5 \%$} & \multicolumn{4}{|c|}{$10 \%$} & \multicolumn{4}{|c|}{$15 \%$} & \multicolumn{4}{|c|}{$20 \%$} \\
\hline & $\mathrm{T}(\mathrm{C})$ & UR(\%) & Tsolo & RS & $\mathrm{T}(\mathrm{C})$ & UR(\%) & Tsolo & RS & $\mathrm{T}(\mathrm{C})$ & UR(\%) & Tsolo & RS & $\mathrm{T}(\mathrm{C})$ & UR $(\%)$ & Tsolo & RS & $\mathrm{T}(\mathrm{C})$ & UR(\%) & Tsolo & RS & $\mathrm{T}(\mathrm{C})$ & UR(\%) & Tsolo & RS \\
\hline 08:00 & 20,2 & 88,7 & 21,9 & 114,7 & 23,2 & 98,5 & 24,2 & 112,8 & 21,8 & 98,6 & 23,4 & 43,9 & 22,3 & 92,4 & 23,1 & 48,3 & 22,4 & 91,9 & 22,9 & 106,6 & 22,0 & 92,9 & 23,0 & 89,3 \\
\hline 09:00 & 22,6 & 81,7 & 22,3 & 713,0 & 29,2 & 87,0 & 24,7 & 366,7 & 27,6 & 77,4 & 23,8 & 307,4 & 26,4 & 80,4 & 23,7 & 368,4 & 27,6 & 74,8 & 23,9 & 343,5 & 25,9 & 80,8 & 23,3 & 305,9 \\
\hline 10:00 & 26,4 & 71,2 & 23,7 & 385,8 & 37,9 & 70,2 & 26,3 & 348,8 & 34,3 & 62,4 & 25,0 & 282,1 & 35,0 & 55,5 & 25,4 & 236,5 & 34,3 & 61,0 & 26,2 & 363,8 & 33,5 & 57,9 & 24,3 & 328,4 \\
\hline 11:00 & 29,0 & 59,1 & 24,8 & 834,0 & 40,0 & 66,9 & 27,5 & 660,6 & 37,6 & 62,0 & 26,0 & 590,0 & 36,7 & 54,6 & 26,7 & 590,1 & 36,9 & 52,0 & 27,4 & 713,1 & 35,1 & 57,7 & 25,2 & 731,7 \\
\hline 12:00 & 30,6 & 53,3 & 26,0 & 440,0 & 40,4 & 67,4 & 29,4 & 449,5 & 39,0 & 50,7 & 27,5 & 393,7 & 39,3 & 49,8 & 28,6 & 322,4 & 37,4 & 52,2 & 29,2 & 473,8 & 37,3 & 53,3 & 26,2 & 381,5 \\
\hline 13:00 & 31,7 & 47,5 & 27,7 & 794,3 & 42,9 & 50,9 & 30,2 & 669,3 & 40,0 & 48,3 & 28,7 & 520,3 & 40,3 & 43,6 & 29,8 & 525,9 & 38,1 & 43,8 & 30,2 & 631,7 & 38,6 & 45,9 & 27,0 & 686,7 \\
\hline 14:00 & 33,1 & 43,2 & 28,4 & 764,6 & 41,9 & 48,0 & 30,8 & 186,8 & 40,0 & 39,8 & 29,6 & 167,9 & 41,1 & 37,6 & 30,7 & 508,3 & 38,0 & 39,9 & 30,8 & 186,5 & 39,7 & 38,9 & 27,8 & 663,0 \\
\hline 15:00 & 31,3 & 44,9 & 28,2 & 371,9 & 40,6 & 52,1 & 31,1 & 271,3 & 37,3 & 43,2 & 30,2 & 218,6 & 38,9 & 41,0 & 30,8 & 242,2 & 36,4 & 43,7 & 30,8 & 242,2 & 37,3 & 43,9 & 28,3 & 314,7 \\
\hline 16:00 & 30,1 & 50,9 & 27,6 & 205,5 & 35,0 & 75,8 & 30,8 & 170,6 & 33,2 & 58,4 & 30,1 & 142,6 & 33,5 & 54,8 & 30,6 & 144,4 & 33,0 & 54,9 & 30,2 & 160,8 & 32,5 & 55,5 & 28,5 & 187,9 \\
\hline $17: 00$ & 29,6 & 54,9 & 27,2 & 29,6 & 33,6 & 76,4 & 30,6 & 35,3 & 31,3 & 63,5 & 29,8 & 25,8 & 33,9 & 57,5 & 30,2 & 21,0 & 31,4 & 62,0 & 29,7 & 34,9 & 33,0 & 55,9 & 28,5 & 51,2 \\
\hline 18:00 & 24,0 & 76,8 & 26,7 & 1,3 & 26,0 & 93,9 & 29,8 & 8,1 & 24,6 & 94,4 & 29,0 & 24,8 & 25,4 & 85,7 & 29,0 & 1,7 & 24,8 & 89,2 & 28,5 & 7,8 & 24,9 & 86,2 & 28,1 & 24,3 \\
\hline
\end{tabular}

DIA DE COLETA DE DADOS: 24/Abr

\begin{tabular}{|c|c|c|c|c|c|c|c|c|c|c|c|c|c|c|c|c|c|c|c|c|c|c|c|c|}
\hline \multirow[b]{2}{*}{ HORA } & \multicolumn{4}{|c|}{ TESTEMUNHA } & \multicolumn{4}{|c|}{$0 \%$} & \multicolumn{4}{|c|}{$5 \%$} & \multicolumn{4}{|c|}{$10 \%$} & \multicolumn{4}{|c|}{$15 \%$} & \multicolumn{3}{|c|}{$20 \%$} & \multirow[b]{2}{*}{ RS } \\
\hline & $\mathrm{T}(\mathrm{C})$ & $\mathrm{UR}(\%)$ & Tsolo & RS & $\mathrm{T}(\mathrm{C})$ & $\mathrm{UR}(\%)$ & Tsolo & RS & $\mathrm{T}(\mathrm{C})$ & UR(\%) & Tsolo & RS & $\mathrm{T}(\mathrm{C})$ & UR(\%) & Tsolo & RS & $\mathrm{T}(\mathrm{C})$ & UR(\%) & Tsolo & RS & $\mathrm{T}(\mathrm{C})$ & UR( $\%)$ & Tsolo & \\
\hline $08: 00$ & 23,0 & 80,0 & 22,7 & 140,6 & 25,8 & 95,8 & 25,0 & 114,0 & 24,2 & 97,17 & 24,3 & 84,2 & 24,8 & 84,8 & 23,9 & 71,6 & 25,7 & 76,8 & 23,9 & 108,5 & 24,5 & 85,2 & 23,8 & 109,3 \\
\hline 09:00 & 25,6 & 74,0 & 23,3 & 506,2 & 34,3 & 66,9 & 25,8 & 241,8 & 32,3 & 64,5 & 24,9 & 179,3 & 31,9 & 68,1 & 24,7 & 259,2 & 31,5 & 67,0 & 25,1 & 224,8 & 30,2 & 69,0 & 24,2 & 236,0 \\
\hline 10:00 & 28,0 & 66,0 & 24,5 & 646,1 & 41,1 & 64,1 & 27,0 & 495,7 & 38,86 & 49,56 & 26,0 & 382,3 & 37,9 & 54,6 & 26,2 & 340,5 & 36,4 & 50,2 & 26,7 & 547,9 & 35,9 & 55,9 & 25,0 & 551,9 \\
\hline 11:00 & 29,7 & 58,0 & 26,0 & 689,0 & 42,9 & 66,4 & 28,5 & 567,5 & 41,06 & 49,56 & 27,4 & 491,9 & 39,1 & 45,5 & 28,0 & 424,7 & 37,8 & 49,2 & 28,7 & 556,2 & 37,3 & 51,8 & 26,0 & 598,1 \\
\hline $12: 00$ & 30,6 & 51,3 & 27,1 & 800,6 & 45,3 & 61,6 & 30,2 & 551,3 & 42,15 & 41,38 & 28,7 & 578,2 & 40,9 & 46,0 & 29,5 & 594,1 & 39,6 & 48,8 & 30,0 & 638,0 & 38,7 & 51,9 & 26,9 & 688,6 \\
\hline 13:00 & 30,8 & 53,1 & 28,0 & 660,0 & 44,1 & 68,7 & 31,1 & 511,9 & 41,67 & 41,6 & 29,7 & 458,8 & 40,4 & 42,7 & 30,4 & 427,5 & 38,6 & 50,2 & 30,8 & 540,2 & 39,1 & 46,0 & 27,7 & 571,2 \\
\hline 14:00 & 30,9 & 53,5 & 28,9 & 499,9 & 42,8 & 68,8 & 31,6 & 411,3 & 40,3 & 42,5 & 30,4 & 354,4 & 39,8 & 41,7 & 31,0 & 327,5 & 38,0 & 42,0 & 31,1 & 421,5 & 38,5 & 44,9 & 28,3 & 425,8 \\
\hline 15:00 & 31,4 & 51,3 & 29,4 & 204,9 & 41,4 & 53,5 & 32,0 & 136,5 & 38,9 & 49,0 & 30,9 & 115,7 & 40,0 & 42,2 & 31,3 & 141,0 & 36,5 & 49,7 & 31,3 & 132,3 & 38,6 & 44,1 & 28,8 & 175,4 \\
\hline 16:00 & 29,8 & 58,8 & 28,8 & 152,6 & 35,4 & 76,5 & 31,7 & 109,9 & 33,5 & 57,7 & 30,8 & 91,5 & 34,1 & 57,7 & 30,7 & 106,9 & 32,8 & 59,2 & 30,6 & 109,0 & 33,1 & 58,7 & 28,9 & 141,1 \\
\hline $17: 00$ & 28,4 & 63,2 & 28,2 & 54,2 & 31,3 & 81,9 & 31,2 & 54,4 & 29,58 & 70,8 & 30,3 & 47,5 & 30,7 & 67,7 & 30,0 & 39,2 & 29,6 & 69,2 & 29,8 & 51,4 & 30,2 & 66,3 & 28,7 & 76,2 \\
\hline 18:00 & 24,7 & 79,1 & 27,6 & 1,3 & 26,8 & 92,0 & 30,4 & 7,5 & 25,2 & 93,6 & 29,6 & 18,6 & 26,0 & 82,8 & 29,2 & 2,3 & 25,3 & 88,6 & 28,8 & 4,4 & 25,7 & 84,5 & 28,3 & 4,4 \\
\hline
\end{tabular}


DIA DE COLETA DE DADOS:

25/Abr

\begin{tabular}{|c|c|c|c|c|c|c|c|c|c|c|c|c|c|c|c|c|c|c|c|c|c|c|c|c|}
\hline \multirow[b]{2}{*}{ HORA } & \multicolumn{4}{|c|}{ TESTEMUNHA } & \multicolumn{4}{|c|}{$0 \%$} & \multicolumn{4}{|c|}{$5 \%$} & \multicolumn{4}{|c|}{$10 \%$} & \multicolumn{4}{|c|}{$15 \%$} & \multicolumn{3}{|c|}{$20 \%$} & \multirow[b]{2}{*}{ RS } \\
\hline & $\mathrm{T}(\mathrm{C})$ & UR(\%) & Tsolo & RS & $\mathrm{T}(\mathrm{C})$ & UR(\%) & Tsolo & RS & $\mathrm{T}(\mathrm{C})$ & UR(\%) & Tsolo & RS & $\mathrm{T}(\mathrm{C})$ & UR(\%) & Tsolo & RS & $\mathrm{T}(\mathrm{C})$ & UR(\%) & Tsolo & RS & $\mathrm{T}(\mathrm{C})$ & $\mathrm{UR}(\%)$ & Tsolo & \\
\hline 08:00 & 22,3 & 83,3 & 22,7 & 224,4 & 22,9 & 84,6 & 25,2 & 272,5 & 22,99 & 80,93 & 24,6 & 296,6 & 24,2 & 78,6 & 23,9 & 239,9 & 23,2 & 80,4 & 24,2 & 279,5 & 24,7 & 76,8 & 24,0 & 249,7 \\
\hline 09:00 & 26,0 & 68,5 & 23,6 & 450,7 & 35,1 & 75,3 & 26,0 & 404,9 & 33,5 & 68,4 & 25,0 & 242,3 & 33,4 & 64,0 & 24,9 & 277,4 & 32,4 & 62,4 & 25,6 & 335,7 & 30,1 & 72,8 & 23,9 & 116,1 \\
\hline 10:00 & 27,9 & 60,8 & 24,7 & 636,7 & 41,9 & 65,3 & 27,6 & 477,8 & 38,13 & 56,03 & 26,1 & 503,2 & 37,6 & 46,8 & 26,4 & 438,3 & 35,9 & 52,5 & 27,1 & 529,5 & 34,6 & 54,4 & 24,6 & 555,6 \\
\hline 11:00 & 29,2 & 55,4 & 26,0 & 736,9 & 45,3 & 63,7 & 29,5 & 603,9 & 41,54 & 48,71 & 27,3 & 551,3 & 40,9 & 39,2 & 28,1 & 555,4 & 38,7 & 48,0 & 28,6 & 595,4 & 38,0 & 43,1 & 25,6 & 761,0 \\
\hline 12:00 & 30,2 & 52,2 & 27,2 & 773,5 & 47,5 & 60,7 & 31,2 & 648,5 & 42,3 & 48,83 & 28,5 & 522,4 & 42,9 & 42,5 & 29,4 & 615,1 & 39,5 & 42,4 & 29,6 & 628,4 & 40,1 & 48,6 & 26,4 & 737,3 \\
\hline 13:00 & 32,4 & 42,4 & 28,4 & 763,4 & 49,1 & 53,0 & 32,4 & 635,7 & 41,79 & 44,9 & 29,7 & 439,7 & 43,7 & 31,1 & 30,4 & 590,1 & 39,1 & 43,9 & 30,4 & 609,0 & 40,3 & 36,1 & 27,1 & 679,2 \\
\hline 14:00 & 32,4 & 35,4 & 28,9 & 680,8 & 48,9 & 65,9 & 33,4 & 632,3 & 42,8 & 42,1 & 30,5 & 361,2 & 43,4 & 32,2 & 31,2 & 522,5 & 40,0 & 41,5 & 31,1 & 490,3 & 40,9 & 30,9 & 27,9 & 590,6 \\
\hline 15:00 & 33,0 & 35,0 & 28,8 & 545,3 & 47,5 & 57,1 & 33,9 & 481,9 & 42,4 & 39,3 & 31,0 & 351,3 & 43,4 & 29,3 & 31,5 & 344,5 & 40,0 & 38,1 & 31,4 & 361,4 & 40,9 & 33,8 & 28,4 & 480,7 \\
\hline 16:00 & 32,0 & 33,3 & 28,6 & 311,4 & 42,4 & 68,7 & 33,8 & 191,5 & 38,9 & 44,2 & 30,9 & 132,8 & 39,8 & 39,3 & 31,1 & 149,0 & 37,1 & 44,2 & 30,8 & 199,1 & 37,9 & 37,1 & 28,5 & 243,5 \\
\hline 17:00 & 27,6 & 59,9 & 28,0 & 36,6 & 33,0 & 77,3 & 33,2 & 42,8 & 29,7 & 71,17 & 30,4 & 34,6 & 31,5 & 61,0 & 30,2 & 26,7 & 29,5 & 63,7 & 30,0 & 41,7 & 30,4 & 61,5 & 28,3 & 67,4 \\
\hline 18:00 & 23,1 & 71,8 & 27,3 & 1,3 & 26,2 & 89,5 & 31,9 & 6,4 & 23,2 & 94,2 & 29,6 & 18,6 & 24,6 & 83,5 & 29,0 & 2,3 & 23,2 & 85,9 & 28,7 & 3,9 & 23,8 & 85,8 & 27,9 & 18,7 \\
\hline
\end{tabular}

DIA DE COLETA DE DADOS: 26/Abr

\begin{tabular}{|c|c|c|c|c|c|c|c|c|c|c|c|c|c|c|c|c|c|c|c|c|c|c|c|c|}
\hline \multirow[b]{2}{*}{ HORA } & \multicolumn{4}{|c|}{ TESTEMUNHA } & \multicolumn{4}{|c|}{$0 \%$} & \multicolumn{4}{|c|}{$5 \%$} & \multicolumn{4}{|c|}{$10 \%$} & \multicolumn{4}{|c|}{$15 \%$} & \multicolumn{3}{|c|}{$20 \%$} & \multirow[b]{2}{*}{ RS } \\
\hline & $\mathrm{T}(\mathrm{C})$ & UR(\%) & Tsolo & RS & $\mathrm{T}(\mathrm{C})$ & $\mathrm{UR}(\%)$ & Tsolo & RS & $\mathrm{T}(\mathrm{C})$ & UR(\%) & Tsolo & RS & $\mathrm{T}(\mathrm{C})$ & UR(\%) & Tsolo & RS & $\mathrm{T}(\mathrm{C})$ & UR(\%) & Tsolo & RS & $\mathrm{T}(\mathrm{C})$ & UR( $\%)$ & Tsolo & \\
\hline $08: 00$ & 17,9 & 97,9 & 22,0 & 170,2 & 24,6 & 99,2 & 24,8 & 166,6 & 22,6 & 98,6 & 23,9 & 56,8 & 22,0 & 95,0 & 23,2 & 86,4 & 22,0 & 95,8 & 23,2 & 153,6 & 21,4 & 95,7 & 22,8 & 133,0 \\
\hline 09:00 & 22,5 & 78,7 & 22,6 & 486,0 & 34,1 & 72,0 & 25,8 & 341,3 & 31,0 & 70,1 & 24,5 & 261,4 & 29,8 & 64,9 & 24,1 & 204,7 & 29,3 & 68,4 & 24,7 & 291,2 & 26,7 & 76,8 & 23,1 & 173,6 \\
\hline 10:00 & 26,8 & 61,9 & 23,7 & 634,2 & 40,7 & 70,1 & 27,4 & 543,8 & 36,9 & 59,4 & 25,6 & 406,6 & 34,8 & 49,1 & 25,6 & 344,0 & 35,0 & 53,8 & 26,4 & 531,9 & 32,8 & 59,6 & 23,7 & 533,8 \\
\hline 11:00 & 29,1 & 43,8 & 25,0 & 759,0 & 40,6 & 53,3 & 29,0 & 676,2 & 36,1 & 49,4 & 26,8 & 495,5 & 36,5 & 38,8 & 27,1 & 525,9 & 34,5 & 47,7 & 27,9 & 617,2 & 34,1 & 43,3 & 24,7 & 771,0 \\
\hline 12:00 & 30,2 & 39,2 & 26,1 & 800,6 & 42,4 & 59,4 & 30,4 & 672,2 & 39,2 & 44,3 & 28,1 & 565,8 & 38,6 & 34,9 & 28,5 & 612,9 & 37,1 & 40,0 & 29,2 & 656,4 & 36,3 & 41,3 & 25,6 & 772,9 \\
\hline 13:00 & 31,3 & 35,9 & 27,0 & 774,7 & 43,7 & 64,6 & 31,3 & 669,9 & 39,3 & 39,2 & 29,2 & 494,5 & 40,9 & 30,9 & 29,5 & 594,1 & 37,6 & 42,2 & 30,1 & 625,0 & 38,2 & 34,1 & 26,4 & 688,0 \\
\hline 14:00 & 31,0 & 31,7 & 27,3 & 680,2 & 44,1 & 56,5 & 31,9 & 564,6 & 40,0 & 39,7 & 30,0 & 440,7 & 41,2 & 28,3 & 30,2 & 456,0 & 37,6 & 39,1 & 30,6 & 482,5 & 38,9 & 31,5 & 27,1 & 593,1 \\
\hline 15:00 & 32,0 & 29,2 & 27,2 & 526,4 & 43,9 & 56,8 & 32,2 & 426,9 & 39,7 & 32,8 & 30,2 & 329,6 & 40,9 & 31,0 & 30,4 & 277,4 & 37,1 & 36,7 & 30,4 & 330,4 & 38,6 & 35,4 & 27,5 & 455,1 \\
\hline 16:00 & 31,5 & 33,7 & 27,0 & 319,0 & 41,2 & 55,5 & 32,0 & 236,6 & 37,3 & 36,4 & 30,0 & 124,0 & 39,1 & 33,9 & 30,0 & 119,4 & 35,7 & 34,4 & 29,9 & 199,1 & 36,9 & 33,7 & 27,5 & 249,1 \\
\hline $17: 00$ & 27,9 & 40,8 & 26,6 & 20,2 & 32,3 & 75,1 & 31,5 & 27,2 & 29,5 & 63,7 & 29,6 & 19,6 & 31,9 & 48,3 & 29,2 & 14,2 & 28,7 & 49,1 & 29,1 & 31,0 & 30,7 & 46,1 & 27,3 & 50,6 \\
\hline 18:00 & 21,5 & 65,3 & 26,0 & 0,6 & 23,0 & 92,0 & 30,2 & 4,6 & 21,5 & 94,7 & 28,7 & 13,4 & 22,7 & 78,7 & 27,9 & 2,3 & 21,4 & 79,1 & 27,9 & 4,8 & 22,0 & 78,6 & 26,9 & 15,6 \\
\hline
\end{tabular}


DIA DE COLETA DE DADOS:

27/Abr

\begin{tabular}{|c|c|c|c|c|c|c|c|c|c|c|c|c|c|c|c|c|c|c|c|c|c|c|c|c|}
\hline \multirow[b]{2}{*}{ HORA } & \multicolumn{4}{|c|}{ TESTEMUNHA } & \multicolumn{4}{|c|}{$0^{\wedge} \%$} & \multicolumn{4}{|c|}{$5 \%$} & \multicolumn{4}{|c|}{$10 \%$} & \multicolumn{4}{|c|}{$15 \%$} & \multicolumn{3}{|c|}{$20 \%$} & \multirow[b]{2}{*}{ RS } \\
\hline & $\mathrm{T}(\mathrm{C})$ & $\mathrm{UR}(\%)$ & Tsolo & RS & $\mathrm{T}(\mathrm{C})$ & UR(\%) & Tsolo & RS & $\mathrm{T}(\mathrm{C})$ & $\mathrm{UR}(\%)$ & Tsolo & RS & $\mathrm{T}(\mathrm{C})$ & $\operatorname{UR}(\%)$ & Tsolo & RS & $\mathrm{T}(\mathrm{C})$ & $\operatorname{UR}(\%)$ & Tsolo & RS & $\mathrm{T}(\mathrm{C})$ & $\mathrm{UR}(\%)$ & Tsolo & \\
\hline $08: 00$ & 20,7 & 72,9 & 20,8 & 247,1 & 25,7 & 90,5 & 23,5 & 205,4 & 24,2 & 95,58 & 23,1 & 154,5 & 24,3 & 74,1 & 22,1 & 109,2 & 25,4 & 67,7 & 22,5 & 198,1 & 23,4 & 75,1 & 21,5 & 206,0 \\
\hline 09:00 & 23,8 & 64,0 & 21,5 & 465,8 & 34,3 & 70,7 & 24,6 & 289,8 & 32,3 & 64,2 & 23,8 & 253,2 & 31,2 & 59,1 & 23,1 & 209,8 & 31,2 & 57,3 & 24,0 & 293,6 & 27,7 & 68,8 & 21,9 & 259,7 \\
\hline $10: 00$ & 26,3 & 57,0 & 22,8 & 631,6 & 39,5 & 62,7 & 26,0 & 631,1 & 36,66 & 59,2 & 24,8 & 369,4 & 35,1 & 45,8 & 24,5 & 360,4 & 34,3 & 51,6 & 25,6 & 565,4 & 32,9 & 52,7 & 22,6 & 527,5 \\
\hline $11: 00$ & 28,8 & 47,6 & 24,2 & 730,0 & 42,9 & 63,2 & 27,6 & 628,8 & 40,08 & 53,83 & 26,0 & 478,4 & 39,8 & 38,2 & 26,2 & 418,4 & 37,8 & 45,2 & 27,3 & 590,6 & 36,8 & 41,7 & 23,6 & 761,0 \\
\hline $12: 00$ & 31,3 & 39,3 & 25,4 & 767,2 & 46,1 & 56,6 & 29,4 & 682,6 & 41,91 & 46,75 & 27,2 & 500,1 & 43,0 & 34,8 & 27,7 & 603,8 & 39,1 & 43,0 & 28,4 & 607,0 & 40,0 & 43,3 & 24,6 & 734,8 \\
\hline 13:00 & 32,4 & 35,6 & 26,4 & 431,8 & 45,9 & 51,5 & 30,8 & 330,3 & 41,06 & 33,7 & 28,2 & 283,7 & 43,5 & 34,7 & 28,9 & 365,0 & 38,4 & 32,2 & 29,2 & 309,1 & 40,1 & 39,7 & 25,4 & 403,9 \\
\hline $14: 00$ & 32,3 & 32,5 & 27,2 & 704,1 & 47,0 & 58,1 & 31,6 & 620,1 & 42,6 & 43,3 & 28,9 & 381,3 & 43,3 & 32,0 & 29,5 & 505,4 & 39,5 & 37,4 & 29,7 & 516,9 & 40,6 & 36,5 & 26,2 & 613,1 \\
\hline $15: 00$ & 32,4 & 35,6 & 27,6 & 540,9 & 45,9 & 58,5 & 32,2 & 468,0 & 41,5 & 40,9 & 29,4 & 357,0 & 42,2 & 26,9 & 30,0 & 317,2 & 39,5 & 39,2 & 30,0 & 383,2 & 40,1 & 31,5 & 26,8 & 460,1 \\
\hline $16: 00$ & 31,9 & 35,0 & 27,5 & 313,3 & 43,1 & 59,9 & 32,3 & 237,2 & 38,7 & 40,2 & 29,6 & 130,7 & 40,8 & 29,4 & 29,8 & 120,0 & 37,0 & 40,8 & 29,8 & 179,3 & 38,4 & 34,4 & 27,1 & 255,3 \\
\hline $17: 00$ & 28,6 & 48,6 & 27,0 & 27,1 & 33,2 & 68,2 & 31,8 & 31,8 & 30,31 & 65,55 & 29,4 & 22,7 & 32,8 & 45,2 & 29,0 & 18,2 & 29,6 & 55,5 & 29,2 & 33,4 & 31,4 & 49,6 & 27,1 & 51,8 \\
\hline $18: 00$ & 22,7 & 66,3 & 26,4 & 1,3 & 24,6 & 87,4 & 30,5 & 6,4 & 23,0 & 94,2 & 28,7 & 19,1 & 24,2 & 79,2 & 27,9 & 1,1 & 22,9 & 80,0 & 27,9 & 5,8 & 23,5 & 79,0 & 26,7 & 14,4 \\
\hline
\end{tabular}

DIA DE COLETA DE DADOS: 28/Abr

\begin{tabular}{|c|c|c|c|c|c|c|c|c|c|c|c|c|c|c|c|c|c|c|c|c|c|c|c|c|}
\hline \multirow[b]{2}{*}{ HORA } & \multicolumn{4}{|c|}{ TESTEMUNHA } & \multicolumn{4}{|c|}{$0 \%$} & \multicolumn{4}{|c|}{$5 \%$} & \multicolumn{4}{|c|}{$10 \%$} & \multicolumn{4}{|c|}{$15 \%$} & \multicolumn{3}{|c|}{$20 \%$} & \multirow[b]{2}{*}{ RS } \\
\hline & $\mathrm{T}(\mathrm{C})$ & UR(\%) & Tsolo & RS & $\mathrm{T}(\mathrm{C})$ & UR(\%) & Tsolo & RS & $\mathrm{T}(\mathrm{C})$ & $\mathrm{UR}(\%)$ & Tsolo & RS & $\mathrm{T}(\mathrm{C})$ & $\mathrm{UR}(\%)$ & Tsolo & RS & $\mathrm{T}(\mathrm{C})$ & UR(\%) & Tsolo & RS & $\mathrm{T}(\mathrm{C})$ & UR( $\%)$ & Tsolo & \\
\hline $08: 00$ & 20,5 & 73,2 & 21,4 & 203,0 & 25,2 & 88,6 & 24,1 & 216,9 & 23,35 & 89,23 & 23,5 & 157,1 & 23,1 & 74,3 & 22,4 & 89,8 & 24,0 & 72,1 & 22,8 & 156,0 & 22,0 & 77,3 & 22,0 & 177,9 \\
\hline 09:00 & 24,0 & 61,5 & 22,0 & 470,3 & 33,9 & 70,1 & 25,0 & 328,6 & 31,8 & 65,2 & 24,1 & 254,2 & 30,2 & 53,0 & 23,3 & 211,5 & 30,7 & 57,0 & 24,2 & 342,5 & 27,4 & 62,7 & 22,2 & 385,2 \\
\hline 10:00 & 27,4 & 51,1 & 23,1 & 620,9 & 39,5 & 61,6 & 26,3 & 495,7 & 37,03 & 56,15 & 25,0 & 409,7 & 35,9 & 43,3 & 24,6 & 358,2 & 34,7 & 47,9 & 25,7 & 504,8 & 33,4 & 46,8 & 22,8 & 561,3 \\
\hline 11:00 & 29,9 & 42,5 & 24,3 & 736,9 & 40,7 & 65,6 & 27,9 & 577,3 & 38,25 & 43,82 & 26,1 & 498,6 & 37,6 & 36,4 & 26,2 & 525,3 & 36,2 & 42,6 & 27,3 & 576,5 & 35,4 & 42,6 & 23,7 & 704,8 \\
\hline 12:00 & 31,2 & 37,7 & 25,4 & 745,1 & 43,6 & 55,3 & 29,4 & 669,9 & 40,1 & 46,27 & 27,3 & 536,3 & 40,3 & 37,2 & 27,6 & 563,4 & 37,9 & 42,0 & 28,3 & 626,9 & 37,5 & 42,7 & 24,6 & 689,2 \\
\hline 13:00 & 32,0 & 35,9 & 26,1 & 747,0 & 45,3 & 62,9 & 30,4 & 642,7 & 41,42 & 41,4 & 28,1 & 453,6 & 42,2 & 32,7 & 28,7 & 573,6 & 39,0 & 41,3 & 29,0 & 623,5 & 39,5 & 37,2 & 25,4 & 651,8 \\
\hline 14:00 & 32,6 & 32,6 & 26,7 & 648,0 & 46,4 & 48,0 & 31,2 & 551,3 & 41,5 & 41,3 & 28,8 & 394,2 & 42,8 & 26,9 & 29,4 & 437,8 & 39,1 & 37,1 & 29,4 & 468,0 & 40,3 & 35,0 & 26,0 & 566,9 \\
\hline 15:00 & 31,9 & 33,7 & 26,9 & 494,2 & 45,8 & 55,2 & 31,7 & 386,4 & 40,8 & 38,2 & 29,0 & 308,5 & 41,9 & 36,3 & 29,7 & 269,5 & 38,0 & 37,8 & 29,4 & 308,6 & 39,0 & 33,8 & 26,4 & 415,2 \\
\hline 16:00 & 31,9 & 33,4 & 26,7 & 291,9 & 42,3 & 59,6 & 31,5 & 205,9 & 38,4 & 35,0 & 29,0 & 115,7 & 39,8 & 35,8 & 29,2 & 120,0 & 36,3 & 38,6 & 29,0 & 139,0 & 37,6 & 37,0 & 26,5 & 277,8 \\
\hline $17: 00$ & 28,5 & 45,9 & 26,4 & 31,5 & 32,3 & 73,0 & 30,8 & 35,9 & 29,82 & 67,63 & 28,7 & 26,9 & 32,0 & 48,1 & 28,4 & 21,6 & 29,3 & 55,8 & 28,2 & 39,2 & 30,9 & 53,6 & 26,5 & 56,8 \\
\hline 18:00 & 22,3 & 64,8 & 25,8 & 1,3 & 23,6 & 81,5 & 29,7 & 5,8 & 22,1 & 93,0 & 27,9 & 17,6 & 23,4 & 77,8 & 27,3 & 2,8 & 22,1 & 77,3 & 27,1 & 6,3 & 22,5 & 79,6 & 26,2 & 16,9 \\
\hline
\end{tabular}


DIA DE COLETA DE DADOS:

29/Abr

\begin{tabular}{|c|c|c|c|c|c|c|c|c|c|c|c|c|c|c|c|c|c|c|c|c|c|c|c|c|}
\hline \multirow[b]{2}{*}{ HORA } & \multicolumn{4}{|c|}{ TESTEMUNHA } & \multicolumn{4}{|c|}{$0 \%$} & \multicolumn{4}{|c|}{$5 \%$} & \multicolumn{4}{|c|}{$10 \%$} & \multicolumn{4}{|c|}{$15 \%$} & \multicolumn{4}{|c|}{$20 \%$} \\
\hline & $\mathrm{T}(\mathrm{C})$ & $\mathrm{UR}(\%)$ & Tsolo & RS & $\mathrm{T}(\mathrm{C})$ & $\mathrm{UR}(\%)$ & Tsolo & RS & $\mathrm{T}(\mathrm{C})$ & $\mathrm{UR}(\%)$ & Tsolo & RS & $\mathrm{T}(\mathrm{C})$ & $\mathrm{UR}(\%)$ & Tsolo & RS & $\mathrm{T}(\mathrm{C})$ & $\operatorname{UR}(\%)$ & Tsolo & RS & $\mathrm{T}(\mathrm{C})$ & $\mathrm{UR}(\%)$ & Tsolo & RS \\
\hline $08: 00$ & 20,3 & 73,0 & 20,6 & 251,5 & 25,6 & 90,7 & 23,3 & 224,4 & 23,5 & 91,9 & 22,8 & 161,7 & 23,5 & 75,6 & 21,8 & 108,0 & 24,9 & 70,1 & 22,1 & 161,3 & 22,5 & 76,3 & 21,3 & 186,7 \\
\hline 09:00 & 23,2 & 65,6 & 21,4 & 468,4 & 33,9 & 69,7 & 24,2 & 314,7 & 31,7 & 62,9 & 23,5 & 250,6 & 30,3 & 54,7 & 22,6 & 230,8 & 30,1 & 58,0 & 23,6 & 310,5 & 27,1 & 66,4 & 21,6 & 352,7 \\
\hline $10: 00$ & 26,7 & 52,5 & 22,6 & 634,2 & 39,6 & 58,7 & 25,6 & 572,1 & 36,5 & 52,1 & 24,5 & 388,0 & 35,8 & 41,4 & 24,1 & 334,3 & 34,3 & 54,6 & 25,2 & 514,0 & 33,1 & 49,6 & 22,2 & 573,1 \\
\hline $11: 00$ & 29,9 & 46,6 & 23,8 & 738,8 & 43,3 & 57,1 & 27,1 & 616,1 & 40,2 & 46,1 & 25,6 & 552,3 & 40,1 & 43,3 & 25,7 & 448,6 & 37,3 & 40,9 & 26,7 & 569,2 & 36,9 & 46,3 & 23,1 & 711,7 \\
\hline $12: 00$ & 32,3 & 34,2 & 25,1 & 775,4 & 45,4 & 60,4 & 28,8 & 612,6 & 41,9 & 39,7 & 26,7 & 518,2 & 42,9 & 31,3 & 27,3 & 587,3 & 39,2 & 39,1 & 27,9 & 609,0 & 39,5 & 30,0 & 24,1 & 736,7 \\
\hline 13:00 & 32,6 & 31,1 & 26,0 & 729,3 & 45,6 & 59,7 & 30,0 & 676,8 & 41,4 & 40,8 & 27,6 & 429,4 & 42,2 & 35,3 & 28,3 & 571,4 & 38,7 & 37,5 & 28,6 & 613,8 & 39,1 & 40,4 & 24,7 & 646,8 \\
\hline $14: 00$ & 32,8 & 25,4 & 26,5 & 635,4 & 44,0 & 51,6 & 30,6 & 544,3 & 40,3 & 33,9 & 28,1 & 373,6 & 40,9 & 28,6 & 28,9 & 410,5 & 37,5 & 29,3 & 28,8 & 477,2 & 38,5 & 27,8 & 25,3 & 567,5 \\
\hline $15: 00$ & 32,8 & 27,1 & 26,4 & 498,6 & 43,1 & 45,3 & 30,7 & 418,8 & 39,3 & 27,1 & 28,3 & 297,1 & 40,2 & 30,3 & 29,0 & 266,1 & 36,9 & 28,2 & 28,5 & 315,9 & 38,0 & 30,5 & 25,6 & 427,0 \\
\hline $16: 00$ & 31,2 & 27,0 & 26,1 & 288,1 & 38,5 & 49,6 & 30,3 & 221,0 & 35,2 & 36,1 & 28,1 & 125,6 & 36,8 & 29,1 & 28,3 & 124,5 & 33,7 & 30,8 & 28,1 & 136,1 & 34,6 & 28,2 & 25,6 & 289,7 \\
\hline $17: 00$ & 27,9 & 32,0 & 25,5 & 30,3 & 29,1 & 49,8 & 29,3 & 33,6 & 27,0 & 43,1 & 27,7 & 29,5 & 29,5 & 37,8 & 27,4 & 18,8 & 27,1 & 39,7 & 27,2 & 35,4 & 28,1 & 39,1 & 25,5 & 59,9 \\
\hline $18: 00$ & 21,4 & 54,8 & 24,8 & 0,6 & 21,5 & 77,5 & 27,9 & 9,8 & 19,8 & 74,2 & 26,8 & 6,2 & 21,5 & 68,0 & 26,2 & 4,0 & 20,7 & 63,7 & 26,0 & 8,2 & 20,7 & 68,0 & 24,9 & 1,2 \\
\hline
\end{tabular}

DIA DE COLETA DE DADOS: 30/Abr

\begin{tabular}{|c|c|c|c|c|c|c|c|c|c|c|c|c|c|c|c|c|c|c|c|c|c|c|c|c|}
\hline \multirow[b]{2}{*}{ HORA } & \multicolumn{4}{|c|}{ TESTEMUNHA } & \multicolumn{4}{|c|}{$0 \%$} & \multicolumn{4}{|c|}{$5 \%$} & \multicolumn{4}{|c|}{$10 \%$} & \multicolumn{4}{|c|}{$15 \%$} & \multicolumn{3}{|c|}{$20 \%$} & \multirow[b]{2}{*}{ RS } \\
\hline & $\mathrm{T}(\mathrm{C})$ & $\mathrm{UR}(\%)$ & Tsolo & RS & $\mathrm{T}(\mathrm{C})$ & $\mathrm{UR}(\%)$ & Tsolo & RS & $\mathrm{T}(\mathrm{C})$ & UR(\%) & Tsolo & RS & $\mathrm{T}(\mathrm{C})$ & $\mathrm{UR}(\%)$ & Tsolo & RS & $\mathrm{T}(\mathrm{C})$ & UR(\%) & Tsolo & RS & $\mathrm{T}(\mathrm{C})$ & UR( $\%)$ & Tsolo & \\
\hline $08: 00$ & 20,4 & 81,3 & 20,8 & 244,0 & 25,1 & 91,4 & 23,1 & 212,3 & 24,2 & 87,16 & 22,6 & 156,6 & 24,0 & 80,7 & 21,8 & 101,8 & 25,3 & 74,2 & 22,2 & 158,9 & 22,7 & 83,6 & 21,3 & 196,0 \\
\hline 09:00 & 23,5 & 71,0 & 21,5 & 452,0 & 33,1 & 68,6 & 23,9 & 304,9 & 30,9 & 70,1 & 23,3 & 232,0 & 29,3 & 59,6 & 22,7 & 188,8 & 29,2 & 63,6 & 23,5 & 276,6 & 26,5 & 68,6 & 21,7 & 337,8 \\
\hline 10:00 & 25,6 & 60,2 & 22,7 & 606,4 & 38,5 & 51,4 & 25,2 & 585,4 & 34,59 & 53,96 & 24,2 & 351,3 & 34,0 & 48,8 & 24,0 & 309,3 & 32,3 & 47,5 & 25,1 & 472,8 & 31,4 & 55,5 & 22,3 & 551,9 \\
\hline 11:00 & 28,2 & 48,5 & 24,0 & 726,2 & 41,5 & 62,4 & 26,6 & 610,9 & 38,13 & 52 & 25,4 & 467,6 & 37,3 & 37,4 & 25,4 & 488,4 & 35,4 & 45,8 & 26,6 & 562,9 & 34,8 & 45,8 & 23,2 & 657,4 \\
\hline 12:00 & 29,6 & 39,7 & 25,3 & 763,4 & 44,0 & 61,4 & 27,9 & 489,4 & 39,35 & 37,96 & 26,4 & 576,6 & 40,3 & 36,3 & 26,7 & 545,8 & 37,0 & 37,2 & 27,7 & 641,9 & 37,3 & 41,0 & 24,1 & 679,9 \\
\hline 13:00 & 30,9 & 38,0 & 25,9 & 733,1 & 44,7 & 59,0 & 29,0 & 622,4 & 41,06 & 43,1 & 27,4 & 502,7 & 40,9 & 31,3 & 27,9 & 536,1 & 37,6 & 47,5 & 28,4 & 631,7 & 38,2 & 36,1 & 24,9 & 639,3 \\
\hline 14:00 & 30,8 & 35,2 & 26,4 & 622,8 & 45,1 & 47,6 & 29,7 & 451,8 & 40,3 & 46,1 & 28,0 & 361,2 & 41,8 & 33,6 & 28,6 & 357,6 & 37,1 & 43,9 & 28,7 & 455,9 & 38,9 & 39,6 & 25,5 & 543,8 \\
\hline 15:00 & 31,7 & 33,0 & 26,5 & 489,8 & 44,8 & 51,1 & 30,0 & 437,9 & 40,2 & 46,9 & 28,3 & 312,6 & 41,4 & 33,0 & 28,8 & 252,4 & 37,4 & 39,9 & 28,7 & 332,8 & 38,9 & 38,5 & 25,9 & 417,7 \\
\hline 16:00 & 30,6 & 35,0 & 26,5 & 274,2 & 40,4 & 53,0 & 30,0 & 210,6 & 36,7 & 35,6 & 28,3 & 125,0 & 38,1 & 31,7 & 28,5 & 108,6 & 34,8 & 35,2 & 28,4 & 131,3 & 35,8 & 37,6 & 26,0 & 290,9 \\
\hline $17: 00$ & 27,4 & 45,3 & 26,2 & 32,1 & 29,9 & 62,0 & 29,2 & 35,3 & 27,75 & 59,08 & 27,9 & 29,5 & 29,8 & 48,6 & 27,5 & 19,9 & 27,5 & 48,7 & 27,7 & 36,8 & 28,4 & 47,1 & 26,0 & 63,7 \\
\hline 18:00 & 21,5 & 68,0 & 25,4 & 0,6 & 22,9 & 79,2 & 28,3 & 7,5 & 21,3 & 93,1 & 27,3 & 16,5 & 22,7 & 77,4 & 26,6 & 3,4 & 21,4 & 82,3 & 26,7 & 3,9 & 21,9 & 79,7 & 25,6 & 6,2 \\
\hline
\end{tabular}


DIA DE COLETA DE DADOS:

01/Mai

\begin{tabular}{|c|c|c|c|c|c|c|c|c|c|c|c|c|c|c|c|c|c|c|c|c|c|c|c|c|}
\hline \multirow[b]{2}{*}{ HORA } & \multicolumn{4}{|c|}{ TESTEMUNHA } & \multicolumn{4}{|c|}{$0 \%$} & \multicolumn{4}{|c|}{$5 \%$} & \multicolumn{4}{|c|}{$10 \%$} & \multicolumn{4}{|c|}{$15 \%$} & \multicolumn{3}{|c|}{$20 \%$} & \multirow[b]{2}{*}{ RS } \\
\hline & $\mathrm{T}(\mathrm{C})$ & $\mathrm{UR}(\%)$ & Tsolo & RS & $\mathrm{T}(\mathrm{C})$ & $\mathrm{UR}(\%)$ & Tsolo & RS & $\mathrm{T}(\mathrm{C})$ & $\mathrm{UR}(\%)$ & Tsolo & RS & $\mathrm{T}(\mathrm{C})$ & UR $(\%)$ & Tsolo & RS & $\mathrm{T}(\mathrm{C})$ & UR(\%) & Tsolo & RS & $\mathrm{T}(\mathrm{C})$ & UR $(\%)$ & Tsolo & \\
\hline 08:00 & 19,9 & 85,9 & 20,9 & 254,7 & 25,7 & 94,2 & 23,1 & 201,3 & 24,82 & 96,44 & 22,7 & 150,9 & 23,6 & 88,5 & 21,8 & 103,5 & 25,2 & 73,4 & 22,2 & 166,2 & 22,6 & 89,6 & 21,4 & 197,9 \\
\hline 09:00 & 23,8 & 63,2 & 21,5 & 467,1 & 33,7 & 67,3 & 23,9 & 339,0 & 32,0 & 64,3 & 23,5 & 234,1 & 30,2 & 54,8 & 22,6 & 219,5 & 29,7 & 61,2 & 23,6 & 283,4 & 25,8 & 69,3 & 21,8 & 352,1 \\
\hline 10:00 & 25,6 & 60,1 & 22,7 & 623,4 & 38,4 & 60,1 & 24,9 & 542,6 & 35,56 & 59,33 & 24,3 & 355,5 & 34,0 & 47,2 & 23,9 & 314,4 & 32,6 & 54,9 & 25,0 & 482,0 & 31,7 & 56,5 & 22,3 & 596,8 \\
\hline 11:00 & 29,2 & 47,1 & 24,0 & 736,3 & 41,3 & 61,0 & 26,3 & 644,4 & 38 & 55,66 & 25,4 & 495,0 & 37,3 & 44,8 & 25,3 & 482,7 & 35,6 & 52,1 & 26,6 & 561,0 & 35,1 & 54,8 & 23,3 & 648,0 \\
\hline 12:00 & 30,2 & 41,3 & 25,3 & 783,6 & 41,1 & 62,0 & 27,5 & 671,6 & 37,1 & 48,1 & 26,4 & 586,4 & 37,9 & 44,7 & 26,6 & 560,0 & 35,3 & 39,9 & 27,8 & 657,4 & 35,6 & 47,7 & 24,1 & 683,0 \\
\hline 13:00 & 31,0 & 38,1 & 25,9 & 749,5 & 42,9 & 60,2 & 28,5 & 572,7 & 39,1 & 45,5 & 27,5 & 439,2 & 39,5 & 33,2 & 27,7 & 546,9 & 36,8 & 39,4 & 28,7 & 576,0 & 36,8 & 36,4 & 24,8 & 652,4 \\
\hline 14:00 & 30,6 & 38,5 & 26,2 & 601,4 & 41,7 & 57,7 & 28,8 & 366,7 & 38,4 & 53,2 & 28,0 & 293,5 & 37,9 & 42,2 & 28,1 & 396,3 & 36,1 & 44,8 & 28,8 & 349,3 & 35,8 & 41,9 & 25,4 & 527,5 \\
\hline 15:00 & 30,1 & 40,3 & 26,2 & 146,3 & 37,5 & 53,0 & 29,0 & 104,7 & 34,0 & 46,5 & 28,2 & 83,7 & 36,5 & 38,0 & 28,1 & 104,6 & 32,6 & 42,5 & 28,8 & 103,2 & 34,3 & 41,3 & 25,8 & 133,6 \\
\hline $16: 00$ & 31,0 & 36,9 & 25,9 & 321,5 & 39,5 & 43,2 & 28,7 & 230,2 & 36,3 & 48,3 & 28,1 & 146,2 & 36,9 & 34,9 & 27,8 & 131,9 & 34,5 & 43,3 & 28,3 & 151,2 & 35,2 & 40,0 & 25,9 & 262,8 \\
\hline $17: 00$ & 27,5 & 50,5 & 25,5 & 22,1 & 30,8 & 72,3 & 28,3 & 30,7 & 28,73 & 69,46 & 27,9 & 26,4 & 30,8 & 54,4 & 27,3 & 13,1 & 28,2 & 63,0 & 27,8 & 31,0 & 29,6 & 58,5 & 25,8 & 63,1 \\
\hline 18:00 & 22,1 & 71,2 & 25,0 & 1,3 & 23,2 & 92,4 & 27,5 & 6,4 & 21,8 & 93,4 & 27,3 & 14,5 & 23,1 & 81,4 & 26,4 & 2,8 & 22,0 & 80,2 & 26,7 & 4,8 & 22,4 & 81,8 & 25,5 & 15,0 \\
\hline
\end{tabular}

DIA DE COLETA DE DADOS: 02/Mai

\begin{tabular}{|c|c|c|c|c|c|c|c|c|c|c|c|c|c|c|c|c|c|c|c|c|c|c|c|c|}
\hline \multirow[b]{2}{*}{ HORA } & \multicolumn{4}{|c|}{ TESTEMUNHA } & \multicolumn{4}{|c|}{$0 \%$} & \multicolumn{4}{|c|}{$5 \%$} & \multicolumn{4}{|c|}{$10 \%$} & \multicolumn{4}{|c|}{$15 \%$} & \multicolumn{3}{|c|}{$20 \%$} & \multirow[b]{2}{*}{ RS } \\
\hline & $\mathrm{T}(\mathrm{C})$ & UR(\%) & Tsolo & RS & $\mathrm{T}(\mathrm{C})$ & $\mathrm{UR}(\%)$ & Tsolo & RS & $\mathrm{T}(\mathrm{C})$ & UR(\%) & Tsolo & RS & $\mathrm{T}(\mathrm{C})$ & UR(\%) & Tsolo & RS & $\mathrm{T}(\mathrm{C})$ & UR(\%) & Tsolo & RS & $\mathrm{T}(\mathrm{C})$ & UR( $\%)$ & Tsolo & \\
\hline $08: 00$ & 23,0 & 71,7 & 21,2 & 318,3 & 28,6 & 84,1 & 23,5 & 259,7 & 26,5 & 88,0 & 23,3 & 182,9 & 26,3 & 70,1 & 22,2 & 135,9 & 27,9 & 68,7 & 22,6 & 267,9 & 25,2 & 74,6 & 21,8 & 329,6 \\
\hline 09:00 & 25,6 & 63,4 & 22,1 & 455,8 & 35,2 & 60,5 & 24,3 & 385,3 & 33,7 & 63,8 & 23,9 & 300,2 & 32,1 & 52,1 & 23,1 & 207,5 & 32,3 & 57,6 & 23,9 & 369,6 & 30,1 & 59,2 & 22,2 & 442,6 \\
\hline 10:00 & 28,1 & 53,3 & 23,1 & 618,4 & 37,9 & 65,8 & 25,2 & 431,0 & 34,8 & 59,8 & 24,8 & 359,1 & 34,6 & 50,0 & 24,2 & 340,5 & 33,5 & 54,4 & 25,2 & 460,7 & 32,4 & 53,3 & 22,8 & 563,8 \\
\hline 11:00 & 30,3 & 48,2 & 24,0 & 711,7 & 40,7 & 66,7 & 26,2 & 550,7 & 37,1 & 46,6 & 25,8 & 509,4 & 38,0 & 44,1 & 25,5 & 490,1 & 35,7 & 43,3 & 26,6 & 533,9 & 35,6 & 49,4 & 23,5 & 633,0 \\
\hline $12: 00$ & 30,4 & 45,5 & 25,1 & 754,6 & 43,9 & 70,1 & 27,3 & 656,6 & 39,3 & 49,4 & 26,7 & 523,4 & 39,8 & 41,9 & 26,7 & 544,6 & 37,0 & 49,0 & 27,7 & 612,4 & 36,9 & 42,8 & 24,3 & 650,5 \\
\hline 13:00 & 32,5 & 40,2 & 26,2 & 813,8 & 46,4 & 59,9 & 28,4 & 451,2 & 42,3 & 32,6 & 27,5 & 343,6 & 41,9 & 39,9 & 27,7 & 634,5 & 38,6 & 37,6 & 28,6 & 483,0 & 39,2 & 49,4 & 25,2 & 695,5 \\
\hline 14:00 & 30,7 & 44,3 & 27,1 & 721,8 & 40,4 & 75,9 & 28,9 & 675,6 & 38,0 & 55,8 & 28,1 & 459,3 & 36,8 & 39,3 & 28,2 & 419,0 & 35,7 & 49,0 & 29,0 & 559,1 & 35,0 & 44,9 & 26,0 & 603,7 \\
\hline 15:00 & 32,1 & 40,0 & 27,2 & 613,4 & 43,0 & 53,8 & 29,4 & 192,6 & 39,3 & 46,9 & 28,5 & 160,7 & 40,3 & 38,5 & 28,4 & 375,8 & 37,0 & 46,3 & 29,3 & 182,2 & 38,2 & 43,2 & 26,4 & 508,2 \\
\hline 16:00 & 31,8 & 41,9 & 27,3 & 177,8 & 38,4 & 67,6 & 29,6 & 118,6 & 35,6 & 51,3 & 28,7 & 97,1 & 36,4 & 47,6 & 28,3 & 109,7 & 34,2 & 51,9 & 29,2 & 114,8 & 34,8 & 48,2 & 26,8 & 156,7 \\
\hline $17: 00$ & 27,1 & 63,6 & 27,0 & 15,1 & 30,2 & 84,5 & 29,2 & 28,3 & 28,2 & 82,2 & 28,5 & 32,0 & 29,8 & 70,3 & 27,8 & 10,2 & 27,9 & 72,4 & 28,5 & 27,1 & 28,7 & 75,8 & 26,7 & 53,1 \\
\hline 18:00 & 23,5 & 70,6 & 26,2 & 1,3 & 24,7 & 95,2 & 28,6 & 9,3 & 23,2 & 94,5 & 28,1 & 11,9 & 24,0 & 78,9 & 27,1 & 2,8 & 23,1 & 84,6 & 27,6 & 9,2 & 23,2 & 80,3 & 26,4 & 1,9 \\
\hline
\end{tabular}


DIA DE COLETA DE DADOS:

03/Mai

\begin{tabular}{|c|c|c|c|c|c|c|c|c|c|c|c|c|c|c|c|c|c|c|c|c|c|c|c|c|}
\hline \multirow[b]{2}{*}{ HORA } & \multicolumn{4}{|c|}{ TESTEMUNHA } & \multicolumn{2}{|c|}{$0 \%$} & \multirow[b]{2}{*}{ Tsolo } & \multirow[b]{2}{*}{ RS } & \multicolumn{3}{|c|}{$5 \%$} & \multirow[b]{2}{*}{ RS } & \multicolumn{2}{|c|}{$10 \%$} & \multirow[b]{2}{*}{ Tsolo } & \multirow[b]{2}{*}{ RS } & \multicolumn{3}{|c|}{$15 \%$} & \multirow[b]{2}{*}{ RS } & \multicolumn{2}{|c|}{$20 \%$} & \multirow[b]{2}{*}{ Tsolo } & \multirow[b]{2}{*}{ RS } \\
\hline & $\mathrm{T}(\mathrm{C})$ & $\mathrm{UR}(\%)$ & Tsolo & RS & $\mathrm{T}(\mathrm{C})$ & $\mathrm{UR}(\%)$ & & & $\mathrm{T}(\mathrm{C})$ & $\mathrm{UR}(\%)$ & Tsolo & & $\mathrm{T}(\mathrm{C})$ & UR $(\%)$ & & & $\mathrm{T}(\mathrm{C})$ & UR(\%) & Tsolo & & $\mathrm{T}(\mathrm{C})$ & UR $(\%)$ & & \\
\hline 08:00 & 21,8 & 78,1 & 22,2 & 234,5 & 26,9 & 82,3 & 24,3 & 204,2 & 25,7 & 91,31 & 24,1 & 147,8 & 24,9 & 75,2 & 23,0 & 91,5 & 26,2 & 73,4 & 23,3 & 185,1 & 23,8 & 79,7 & 22,6 & 294,1 \\
\hline 09:00 & 25,4 & 65,6 & 22,7 & 439,4 & 34,7 & 65,8 & 24,9 & 323,9 & 33,1 & 68,6 & 24,5 & 264,5 & 31,2 & 58,4 & 23,5 & 180,8 & 31,8 & 60,7 & 24,3 & 303,3 & 29,0 & 67,4 & 22,8 & 446,4 \\
\hline 10:00 & 28,2 & 57,4 & 23,6 & 593,8 & 40,2 & 68,6 & 25,8 & 497,5 & 38 & 54,69 & 25,4 & 342,0 & 36,3 & 43,6 & 24,6 & 310,4 & 35,3 & 53,6 & 25,6 & 444,3 & 34,3 & 53,2 & 23,3 & 540,0 \\
\hline 11:00 & 29,3 & 49,1 & 24,5 & 700,3 & 39,8 & 48,8 & 26,6 & 641,5 & 37,88 & 61,65 & 26,2 & 473,3 & 37,5 & 45,2 & 25,8 & 455,4 & 35,8 & 47,1 & 26,9 & 525,2 & 35,1 & 50,7 & 24,1 & 621,8 \\
\hline 12:00 & 31,4 & 42,4 & 25,4 & 733,8 & 43,9 & 59,3 & 27,7 & 624,2 & 39,71 & 44,56 & 27,1 & 524,9 & 40,4 & 43,7 & 26,8 & 540,1 & 37,5 & 44,9 & 27,8 & 598,8 & 37,5 & 49,1 & 24,7 & 639,3 \\
\hline 13:00 & 32,5 & 36,6 & 26,2 & 735,6 & 44,2 & 44,9 & 28,5 & 620,7 & 41,06 & 53,8 & 27,9 & 449,5 & 41,1 & 29,9 & 27,9 & 507,7 & 38,2 & 48,2 & 28,5 & 660,8 & 38,4 & 37,7 & 25,4 & 635,5 \\
\hline 14:00 & 32,5 & 36,3 & 26,6 & 648,7 & 44,7 & 53,0 & 29,0 & 570,4 & 40,3 & 49,9 & 28,4 & 388,0 & 41,3 & 33,0 & 28,5 & 346,8 & 37,5 & 44,9 & 28,9 & 453,9 & 38,6 & 34,8 & 25,8 & 561,9 \\
\hline 15:00 & 32,9 & 34,3 & 26,7 & 488,5 & 44,5 & 44,8 & 29,2 & 430,4 & 40,7 & 43,8 & 28,6 & 304,8 & 40,9 & 35,0 & 28,7 & 270,1 & 37,8 & 41,4 & 29,0 & 340,1 & 38,5 & 38,3 & 26,1 & 392,1 \\
\hline $16: 00$ & 31,9 & 36,3 & 26,6 & 300,1 & 41,7 & 48,1 & 29,2 & 225,0 & 37,9 & 43,2 & 28,5 & 142,6 & 39,0 & 34,8 & 28,3 & 117,7 & 35,7 & 47,0 & 28,8 & 148,2 & 36,8 & 36,4 & 26,3 & 241,6 \\
\hline $17: 00$ & 28,5 & 51,4 & 26,1 & 22,1 & 31,3 & 67,5 & 28,7 & 30,7 & 29,21 & 67,75 & 28,3 & 23,8 & 31,5 & 54,4 & 27,6 & 13,6 & 28,8 & 59,8 & 28,1 & 30,0 & 30,2 & 55,4 & 26,2 & 58,1 \\
\hline 18:00 & 22,7 & 70,4 & 25,6 & 1,3 & 23,7 & 89,0 & 28,0 & 6,9 & 22,0 & 92,5 & 27,6 & 19,1 & 23,7 & 78,4 & 26,8 & 2,3 & 22,4 & 78,6 & 27,0 & 6,8 & 22,9 & 83,1 & 25,9 & 16,9 \\
\hline
\end{tabular}

DIA DE COLETA DE DADOS: 04/Mai

\begin{tabular}{|c|c|c|c|c|c|c|c|c|c|c|c|c|c|c|c|c|c|c|c|c|c|c|c|c|}
\hline \multirow[b]{2}{*}{ HORA } & \multicolumn{4}{|c|}{ TESTEMUNHA } & \multicolumn{4}{|c|}{$0 \%$} & \multicolumn{4}{|c|}{$5 \%$} & \multicolumn{4}{|c|}{$10 \%$} & \multicolumn{4}{|c|}{$15 \%$} & \multicolumn{3}{|c|}{$20 \%$} & \multirow[b]{2}{*}{ RS } \\
\hline & $\mathrm{T}(\mathrm{C})$ & $\mathrm{UR}(\%)$ & Tsolo & RS & $\mathrm{T}(\mathrm{C})$ & $\mathrm{UR}(\%)$ & Tsolo & RS & $\mathrm{T}(\mathrm{C})$ & UR(\%) & Tsolo & RS & $\mathrm{T}(\mathrm{C})$ & $\mathrm{UR}(\%)$ & Tsolo & RS & $\mathrm{T}(\mathrm{C})$ & UR(\%) & Tsolo & RS & $\mathrm{T}(\mathrm{C})$ & UR( $\%)$ & Tsolo & \\
\hline $08: 00$ & 18,4 & 83,7 & 21,4 & 111,6 & 21,3 & 98,5 & 23,5 & 100,7 & 20,79 & 98,76 & 23,2 & 24,3 & 20,2 & 94,5 & 22,2 & 40,4 & 20,4 & 92,8 & 22,2 & 92,5 & 19,7 & 94,5 & 21,8 & 101,8 \\
\hline 09:00 & 23,4 & 68,2 & 21,9 & 254,7 & 30,1 & 83,3 & 24,0 & 346,5 & 27,3 & 88,6 & 23,5 & 260,4 & 28,8 & 68,6 & 22,6 & 135,3 & 28,6 & 65,9 & 23,1 & 287,8 & 27,3 & 74,6 & 22,1 & 213,5 \\
\hline 10:00 & 25,9 & 55,7 & 22,8 & 731,9 & 39,0 & 69,0 & 24,9 & 449,5 & 36,05 & 62,87 & 24,3 & 302,8 & 35,1 & 49,1 & 23,6 & 404,2 & 34,0 & 53,5 & 24,3 & 399,7 & 32,8 & 54,4 & 22,6 & 676,1 \\
\hline 11:00 & 28,8 & 49,6 & 23,9 & 739,4 & 42,3 & 59,1 & 26,0 & 641,5 & 38,25 & 52 & 25,1 & 504,8 & 39,3 & 46,9 & 24,8 & 435,5 & 35,6 & 47,9 & 25,6 & 527,1 & 36,5 & 54,3 & 23,3 & 644,9 \\
\hline 12:00 & 30,8 & 44,1 & 25,3 & 746,4 & 42,4 & 59,8 & 27,3 & 557,6 & 37,5 & 45,9 & 26,1 & 473,8 & 39,2 & 50,8 & 26,0 & 549,2 & 35,6 & 40,6 & 27,1 & 533,9 & 37,3 & 53,8 & 24,3 & 646,8 \\
\hline 13:00 & 31,5 & 36,4 & 25,9 & 946,8 & 36,9 & 53,1 & 27,7 & 199,0 & 34,83 & 37,2 & 26,7 & 171,0 & 35,6 & 41,5 & 26,6 & 692,5 & 33,9 & 38,0 & 27,6 & 193,8 & 34,1 & 43,8 & 25,0 & 822,8 \\
\hline 14:00 & 29,5 & 45,8 & 25,8 & 176,5 & 34,6 & 52,9 & 27,8 & 146,9 & 31,5 & 50,0 & 26,9 & 119,9 & 34,0 & 47,0 & 26,9 & 122,8 & 31,0 & 49,6 & 27,6 & 140,0 & 32,5 & 48,8 & 25,4 & 157,3 \\
\hline 15:00 & 29,1 & 47,2 & 25,6 & 566,1 & 34,7 & 76,9 & 27,8 & 465,1 & 32,5 & 51,4 & 27,0 & 279,5 & 31,8 & 56,3 & 26,8 & 314,4 & 31,5 & 47,2 & 27,3 & 385,2 & 30,8 & 56,2 & 25,6 & 496,3 \\
\hline 16:00 & 27,9 & 49,4 & 25,4 & 38,5 & 28,7 & 66,9 & 27,5 & 39,3 & 27,5 & 59,8 & 26,8 & 41,9 & 28,6 & 57,3 & 26,6 & 25,6 & 27,7 & 58,0 & 26,9 & 37,8 & 27,9 & 61,4 & 25,6 & 69,9 \\
\hline $17: 00$ & 19,9 & 94,1 & 24,4 & 3,8 & 22,1 & 96,1 & 26,8 & 6,4 & 20,91 & 96,92 & 26,3 & 4,7 & 21,5 & 97,7 & 25,9 & 4,0 & 20,7 & 96,6 & 25,9 & 12,1 & 20,9 & 98,4 & 25,2 & 18,7 \\
\hline 18:00 & 19,4 & 94,4 & 23,8 & 2,5 & 21,6 & 97,8 & 26,3 & 6,9 & 20,7 & 97,9 & 25,8 & 6,7 & 21,0 & 97,8 & 25,4 & 2,8 & 20,7 & 97,5 & 25,3 & 7,8 & 20,4 & 98,3 & 24,7 & 30,6 \\
\hline
\end{tabular}


DIA DE COLETA DE DADOS:

05/Mai

\begin{tabular}{|c|c|c|c|c|c|c|c|c|c|c|c|c|c|c|c|c|c|c|c|c|c|c|c|c|}
\hline \multirow[b]{2}{*}{ HORA } & \multicolumn{4}{|c|}{ TESTEMUNHA } & \multicolumn{2}{|c|}{$0 \%$} & \multirow[b]{2}{*}{ Tsolo } & \multirow[b]{2}{*}{ RS } & \multicolumn{3}{|c|}{$5 \%$} & \multirow[b]{2}{*}{ RS } & \multicolumn{2}{|c|}{$10 \%$} & \multirow[b]{2}{*}{ Tsolo } & \multirow[b]{2}{*}{ RS } & \multicolumn{3}{|c|}{$15 \%$} & \multirow[b]{2}{*}{ RS } & \multicolumn{2}{|c|}{$20 \%$} & \multirow[b]{2}{*}{ Tsolo } & \multirow[b]{2}{*}{ RS } \\
\hline & $\mathrm{T}(\mathrm{C})$ & $\mathrm{UR}(\%)$ & Tsolo & RS & $\mathrm{T}(\mathrm{C})$ & $\mathrm{UR}(\%)$ & & & $\mathrm{T}(\mathrm{C})$ & $\mathrm{UR}(\%)$ & Tsolo & & $\mathrm{T}(\mathrm{C})$ & UR $(\%)$ & & & $\mathrm{T}(\mathrm{C})$ & UR(\%) & Tsolo & & $\mathrm{T}(\mathrm{C})$ & UR $(\%)$ & & \\
\hline 08:00 & 13,0 & 69,2 & 19,5 & 111,0 & 16,2 & 87,3 & 21,9 & 104,1 & 15,1 & 89,7 & 22,0 & 56,3 & 14,8 & 84,5 & 21,0 & 21,6 & 15,1 & 80,3 & 21,0 & 106,6 & 15,1 & 82,8 & 20,9 & 109,9 \\
\hline 09:00 & 14,2 & 69,2 & 19,5 & 225,7 & 19,1 & 79,6 & 22,0 & 171,8 & 18,2 & 85,4 & 22,0 & 66,1 & 17,9 & 83,0 & 21,0 & 149,5 & 17,7 & 71,8 & 21,2 & 181,2 & 18,0 & 79,2 & 20,8 & 123,6 \\
\hline 10:00 & 16,3 & 57,3 & 19,9 & 666,3 & 26,5 & 67,6 & 22,3 & 588,9 & 25,8 & 65,7 & 22,4 & 355,5 & 24,1 & 64,3 & 21,4 & 333,7 & 23,2 & 57,6 & 22,2 & 513,0 & 23,7 & 57,3 & 20,9 & 709,2 \\
\hline 11:00 & 17,7 & 49,1 & 20,9 & 784,8 & 28,2 & 64,2 & 22,8 & 624,7 & 27,5 & 57,0 & 23,0 & 471,7 & 26,4 & 56,3 & 22,2 & 409,9 & 24,5 & 56,4 & 23,3 & 606,5 & 25,2 & 55,4 & 21,2 & 679,9 \\
\hline 12:00 & 18,8 & 39,9 & 21,7 & 832,1 & 29,7 & 61,4 & 23,5 & 706,3 & 27,1 & 55,1 & 23,6 & 504,3 & 27,3 & 56,4 & 22,9 & 433,2 & 24,7 & 48,8 & 24,1 & 746,1 & 26,5 & 50,7 & 21,6 & 718,0 \\
\hline 13:00 & 20,1 & 35,2 & 22,2 & 800,6 & 32,5 & 60,5 & 24,1 & 580,8 & 29,5 & 56,2 & 24,1 & 493,4 & 28,8 & 43,6 & 23,5 & 448,6 & 26,0 & 42,6 & 24,5 & 661,8 & 27,9 & 35,4 & 21,8 & 694,2 \\
\hline 14:00 & 21,0 & 26,5 & 22,6 & 698,5 & 34,1 & 52,9 & 24,4 & 466,8 & 30,1 & 61,0 & 24,4 & 337,9 & 30,1 & 45,8 & 23,9 & 349,1 & 26,7 & 48,2 & 24,7 & 519,3 & 29,3 & 35,5 & 22,1 & 714,8 \\
\hline 15:00 & 21,8 & 25,8 & 22,5 & 542,8 & 31,8 & 51,9 & 24,5 & 344,2 & 29,6 & 45,4 & 24,5 & 228,4 & 29,3 & 49,2 & 23,9 & 329,7 & 26,5 & 37,0 & 24,6 & 362,9 & 28,4 & 43,7 & 22,2 & 442,6 \\
\hline $16: 00$ & 21,5 & 27,7 & 22,2 & 327,2 & 29,7 & 40,3 & 24,2 & 206,5 & 26,9 & 40,5 & 24,3 & 153,5 & 27,9 & 38,7 & 23,7 & 145,5 & 25,3 & 30,9 & 24,1 & 188,0 & 27,1 & 31,4 & 22,2 & 274,7 \\
\hline $17: 00$ & 18,2 & 36,1 & 21,6 & 15,8 & 19,2 & 73,6 & 23,7 & 16,2 & 17,0 & 60,5 & 23,9 & 21,7 & 19,7 & 51,1 & 23,0 & 2,3 & 17,7 & 52,7 & 23,3 & 23,7 & 19,3 & 52,1 & 21,9 & 5,6 \\
\hline 18:00 & 14,0 & 59,0 & 20,9 & 1,3 & 13,5 & 92,3 & 22,9 & 3,5 & 11,5 & 87,3 & 23,1 & 6,2 & 13,2 & 79,6 & 22,1 & 5,1 & 12,5 & 73,5 & 22,2 & 2,9 & 12,5 & 76,5 & 21,4 & 14,4 \\
\hline
\end{tabular}

DIA DE COLETA DE DADOS: 06/Mai

\begin{tabular}{|c|c|c|c|c|c|c|c|c|c|c|c|c|c|c|c|c|c|c|c|c|c|c|c|c|}
\hline \multirow[b]{2}{*}{ HORA } & \multicolumn{4}{|c|}{ TESTEMUNHA } & \multicolumn{4}{|c|}{$0 \%$} & \multicolumn{4}{|c|}{$5 \%$} & \multicolumn{4}{|c|}{$10 \%$} & \multicolumn{4}{|c|}{$15 \%$} & \multicolumn{3}{|c|}{$20 \%$} & \multirow[b]{2}{*}{ RS } \\
\hline & $\mathrm{T}(\mathrm{C})$ & UR(\%) & Tsolo & RS & $\mathrm{T}(\mathrm{C})$ & UR(\%) & Tsolo & RS & $\mathrm{T}(\mathrm{C})$ & $\mathrm{UR}(\%)$ & Tsolo & RS & $\mathrm{T}(\mathrm{C})$ & UR(\%) & Tsolo & RS & $\mathrm{T}(\mathrm{C})$ & UR(\%) & Tsolo & RS & $\mathrm{T}(\mathrm{C})$ & $\mathrm{UR}(\%)$ & Tsolo & \\
\hline 08:00 & 11,3 & 83,1 & 15,7 & 247,7 & 18,6 & 97,5 & 18,4 & 219,8 & 17,3 & 95,09 & 18,6 & 103,9 & 15,7 & 92,4 & 17,4 & 85,3 & 17,4 & 85,6 & 17,7 & 167,1 & 14,8 & 92,9 & 16,7 & 285,3 \\
\hline 09:00 & 15,1 & 73,2 & 16,4 & 476,6 & 25,8 & 84,0 & 18,8 & 496,9 & 23,7 & 75,2 & 19,1 & 285,7 & 23,0 & 63,6 & 18,0 & 195,6 & 23,5 & 60,4 & 18,9 & 375,0 & 20,4 & 75,2 & 17,1 & 288,4 \\
\hline $10: 00$ & 16,9 & 60,5 & 17,6 & 506,2 & 29,3 & 54,7 & 19,7 & 453,5 & 27,99 & 65,92 & 19,9 & 331,2 & 26,3 & 58,5 & 18,9 & 217,2 & 25,3 & 56,9 & 20,3 & 487,4 & 24,8 & 60,2 & 17,6 & 492,6 \\
\hline 11:00 & 19,8 & 57,7 & 18,7 & 745,7 & 34,1 & 77,9 & 20,7 & 625,9 & 31,53 & 47,85 & 20,7 & 351,9 & 30,1 & 55,1 & 19,9 & 340,5 & 28,1 & 54,1 & 21,4 & 518,4 & 28,1 & 56,9 & 18,3 & 612,4 \\
\hline $12: 00$ & 21,5 & 49,2 & 20,0 & 801,2 & 36,4 & 63,7 & 21,8 & 627,6 & 33,98 & 50,17 & 21,7 & 487,2 & 32,4 & 49,3 & 21,2 & 403,7 & 29,8 & 52,7 & 22,6 & 756,2 & 29,6 & 56,0 & 19,1 & 701,1 \\
\hline 13:00 & 22,3 & 43,0 & 20,9 & 771,6 & 36,3 & 45,8 & 22,6 & 589,5 & 32,63 & 60,1 & 22,4 & 460,4 & 32,4 & 52,5 & 22,2 & 475,9 & 29,3 & 49,2 & 23,3 & 609,5 & 30,2 & 50,4 & 19,8 & 676,1 \\
\hline 14:00 & 23,1 & 42,0 & 21,4 & 576,2 & 37,4 & 51,9 & 23,3 & 345,9 & 32,9 & 38,8 & 23,0 & 255,8 & 33,5 & 41,1 & 22,9 & 282,6 & 29,8 & 38,9 & 23,7 & 403,1 & 32,1 & 42,6 & 20,4 & 585,0 \\
\hline 15:00 & 23,7 & 40,3 & 21,6 & 562,3 & 35,9 & 59,1 & 23,7 & 311,8 & 31,3 & 43,3 & 23,3 & 214,9 & 32,6 & 40,3 & 23,2 & 344,0 & 28,7 & 38,9 & 23,7 & 374,5 & 30,7 & 40,6 & 20,8 & 483,8 \\
\hline 16:00 & 23,0 & 40,4 & 21,5 & 335,4 & 32,6 & 57,6 & 23,7 & 231,4 & 28,7 & 45,5 & 23,3 & 150,4 & 29,1 & 46,5 & 23,0 & 165,4 & 27,1 & 40,8 & 23,3 & 215,1 & 27,6 & 40,3 & 20,9 & 279,1 \\
\hline $17: 00$ & 20,2 & 43,9 & 21,0 & 29,6 & 21,4 & 59,9 & 23,5 & 28,3 & 19,08 & 58,59 & 22,9 & 41,3 & 20,9 & 52,4 & 22,4 & 14,8 & 19,6 & 54,3 & 22,6 & 32,9 & 20,3 & 54,3 & 20,9 & 29,3 \\
\hline 18:00 & 17,5 & 57,0 & 20,4 & 0,6 & 16,0 & 85,6 & 22,7 & 2,9 & 14,8 & 76,4 & 22,2 & 5,7 & 16,3 & 71,4 & 21,6 & 4,5 & 15,8 & 69,2 & 21,6 & 3,4 & 16,0 & 69,5 & 20,5 & 25,6 \\
\hline
\end{tabular}


DIA DE COLETA DE DADOS:

07/Mai

\begin{tabular}{|c|c|c|c|c|c|c|c|c|c|c|c|c|c|c|c|c|c|c|c|c|c|c|c|c|}
\hline \multirow[b]{2}{*}{ HORA } & \multicolumn{4}{|c|}{ TESTEMUNHA } & \multicolumn{4}{|c|}{$0 \%$} & \multicolumn{4}{|c|}{$5 \%$} & \multicolumn{4}{|c|}{$10 \%$} & \multicolumn{4}{|c|}{$15 \%$} & \multicolumn{4}{|c|}{$20 \%$} \\
\hline & $\mathrm{T}(\mathrm{C})$ & UR(\%) & Tsolo & RS & $\mathrm{T}(\mathrm{C})$ & UR(\%) & Tsolo & RS & $\mathrm{T}(\mathrm{C})$ & UR(\%) & Tsolo & RS & $\mathrm{T}(\mathrm{C})$ & UR(\%) & Tsolo & RS & $\mathrm{T}(\mathrm{C})$ & UR(\%) & Tsolo & RS & $\mathrm{T}(\mathrm{C})$ & UR(\%) & Tsolo & RS \\
\hline 08:00 & 12,2 & 83,7 & 15,7 & 221,9 & 17,5 & 96,3 & 18,0 & 203,0 & 18,11 & 97,41 & 18,2 & 95,6 & 16,3 & 87,6 & 17,0 & 92,1 & 17,0 & 81,8 & 17,4 & 175,9 & 15,7 & 95,5 & 16,5 & 230,4 \\
\hline 09:00 & 16,0 & 75,6 & 16,4 & 447,6 & 26,5 & 86,7 & 18,6 & 387,0 & 24,6 & 71,9 & 18,6 & 217,0 & 23,5 & 59,1 & 17,6 & 197,8 & 23,7 & 67,0 & 18,6 & 238,8 & 21,5 & 68,6 & 16,8 & 294,7 \\
\hline 10:00 & 19,9 & 64,7 & 17,5 & 660,6 & 30,9 & 73,7 & 19,5 & 461,0 & 28,97 & 67,02 & 19,5 & 297,1 & 27,1 & 54,1 & 18,6 & 287,7 & 26,5 & 53,1 & 20,0 & 441,8 & 25,2 & 59,6 & 17,4 & 728,6 \\
\hline 11:00 & 19,9 & 60,7 & 18,8 & 581,2 & 30,7 & 78,5 & 20,4 & 284,0 & 27,75 & 63,84 & 20,3 & 218,6 & 26,7 & 54,3 & 19,7 & 318,4 & 25,9 & 71,4 & 21,0 & 276,1 & 25,1 & 58,2 & 18,2 & 544,4 \\
\hline 12:00 & 23,0 & 54,9 & 19,8 & 865,5 & 40,2 & 66,2 & 21,6 & 778,6 & 34,7 & 57,62 & 21,0 & 461,9 & 33,7 & 51,5 & 20,7 & 491,8 & 31,9 & 51,6 & 22,0 & 718,0 & 31,3 & 58,0 & 18,9 & 766,7 \\
\hline 13:00 & 23,7 & 48,8 & 20,8 & 808,1 & 36,4 & 65,6 & 22,6 & 622,4 & 32,63 & 59,3 & 21,8 & 477,4 & 30,7 & 57,6 & 21,6 & 465,1 & 29,7 & 56,8 & 22,6 & 669,5 & 28,7 & 57,6 & 19,7 & 727,9 \\
\hline 14:00 & 24,3 & 47,2 & 21,1 & 664,4 & 37,4 & 47,2 & 23,0 & 480,7 & 32,9 & 55,8 & 22,2 & 360,1 & 32,8 & 50,7 & 22,1 & 373,5 & 30,1 & 47,4 & 23,0 & 510,1 & 31,0 & 52,6 & 20,2 & 736,7 \\
\hline 15:00 & 24,6 & 46,9 & 21,4 & 489,8 & 35,6 & 68,2 & 23,3 & 388,7 & 32,4 & 49,1 & 22,4 & 321,9 & 32,4 & 48,0 & 22,5 & 300,2 & 30,1 & 49,7 & 23,3 & 334,3 & 30,8 & 49,3 & 20,5 & 423,3 \\
\hline 16:00 & 23,7 & 43,2 & 21,4 & 295,6 & 31,8 & 47,9 & 23,3 & 227,9 & 28,7 & 46,4 & 22,6 & 193,2 & 29,6 & 42,5 & 22,3 & 151,8 & 26,9 & 42,2 & 23,1 & 175,9 & 28,0 & 39,7 & 20,7 & 258,5 \\
\hline $17: 00$ & 20,9 & 50,3 & 20,9 & 27,7 & 22,0 & 65,7 & 23,1 & 31,2 & 20,18 & 65,8 & 22,4 & 44,4 & 22,1 & 57,7 & 21,9 & 15,4 & 20,7 & 55,7 & 22,5 & 34,4 & 21,5 & 58,4 & 20,7 & 32,5 \\
\hline 18:00 & 16,2 & 72,0 & 20,4 & 0,6 & 16,6 & 93,1 & 22,5 & 3,5 & 14,8 & 92,7 & 21,8 & 5,2 & 16,5 & 84,7 & 21,4 & 4,0 & 15,7 & 86,1 & 21,7 & 2,9 & 15,9 & 85,4 & 20,4 & 27,5 \\
\hline
\end{tabular}

DIA DE COLETA DE DADOS: 08/Mai

\begin{tabular}{|c|c|c|c|c|c|c|c|c|c|c|c|c|c|c|c|c|c|c|c|c|c|c|c|c|}
\hline \multirow[b]{2}{*}{ HORA } & \multicolumn{4}{|c|}{ TESTEMUNHA } & \multicolumn{4}{|c|}{$0 \%$} & \multicolumn{4}{|c|}{$5 \%$} & \multicolumn{4}{|c|}{$10 \%$} & \multicolumn{4}{|c|}{$15 \%$} & \multicolumn{3}{|c|}{$20 \%$} & \multirow[b]{2}{*}{ RS } \\
\hline & $\mathrm{T}(\mathrm{C})$ & $\mathrm{UR}(\%)$ & Tsolo & RS & $\mathrm{T}(\mathrm{C})$ & $\mathrm{UR}(\%)$ & Tsolo & RS & $\mathrm{T}(\mathrm{C})$ & UR(\%) & Tsolo & RS & $\mathrm{T}(\mathrm{C})$ & UR(\%) & Tsolo & RS & $\mathrm{T}(\mathrm{C})$ & UR(\%) & Tsolo & RS & $\mathrm{T}(\mathrm{C})$ & UR( $\%)$ & Tsolo & \\
\hline $08: 00$ & 13,8 & 92,7 & 16,1 & 226,9 & 20,5 & 98,5 & 18,5 & 197,8 & 19,4 & $\overline{95,3}$ & 18,4 & 112,1 & 18,5 & 94,5 & 17,5 & 91,0 & 20,1 & 85,6 & 17,8 & 160,8 & 17,4 & 95,9 & 16,9 & 183,6 \\
\hline 09:00 & 18,8 & 73,7 & 17,0 & 458,9 & 27,6 & 83,5 & 19,1 & 400,9 & 26,2 & 76,7 & 19,0 & 239,7 & 24,6 & 72,5 & 18,1 & 199,6 & 25,3 & 67,6 & 19,0 & 270,3 & 22,7 & 75,9 & 17,3 & 289,7 \\
\hline 10:00 & 20,8 & 63,1 & 17,9 & 666,9 & 31,7 & 71,4 & 19,8 & 576,7 & 27,9 & 78,0 & 19,7 & 388,5 & 26,5 & 68,7 & 19,0 & 311,6 & 26,5 & 65,2 & 20,1 & 461,2 & 24,7 & 63,4 & 17,8 & 693,6 \\
\hline 11:00 & 21,2 & 61,8 & 18,9 & 400,9 & 31,3 & 92,5 & 20,5 & 609,1 & 28,1 & 74,1 & 20,2 & 461,9 & 25,7 & 74,0 & 19,8 & 262,7 & 26,4 & 64,1 & 20,7 & 586,7 & 24,6 & 73,4 & 18,5 & 339,0 \\
\hline 12:00 & 22,5 & 56,4 & 19,7 & 339,1 & 35,3 & 72,1 & 21,4 & 667,5 & 32,3 & 63,6 & 20,9 & 545,1 & 30,7 & 46,3 & 20,5 & 224,6 & 29,5 & 51,5 & 21,5 & 765,5 & 29,1 & 53,7 & 19,3 & 302,2 \\
\hline 13:00 & 24,2 & 54,6 & 20,5 & 749,5 & 39,3 & 60,1 & 22,4 & 647,9 & 34,6 & 54,4 & 21,6 & 424,7 & 34,3 & 44,4 & 21,5 & 400,2 & 31,2 & 45,4 & 22,4 & 588,1 & 32,6 & 45,4 & 19,9 & 688,6 \\
\hline 14:00 & 24,9 & 48,7 & 21,2 & 624,1 & 38,9 & 51,6 & 23,1 & 511,4 & 34,5 & 50,5 & 22,2 & 288,8 & 35,1 & 36,3 & 22,4 & 327,5 & 30,9 & 40,9 & 23,0 & 464,6 & 33,1 & 37,7 & 20,4 & 692,4 \\
\hline 15:00 & 24,8 & 48,7 & 21,4 & 458,9 & 34,7 & 61,8 & 23,4 & 321,0 & 31,7 & 52,6 & 22,5 & 294,5 & 32,0 & 56,0 & 22,6 & 278,6 & 29,8 & 46,6 & 23,0 & 309,6 & 30,1 & 53,3 & 20,7 & 393,9 \\
\hline 16:00 & 24,5 & 49,1 & 21,2 & 280,5 & 32,9 & 65,4 & 23,5 & 249,9 & 29,7 & 58,7 & 22,5 & 199,4 & 30,4 & 48,8 & 22,4 & 149,0 & 28,1 & 47,5 & 22,8 & 158,4 & 29,0 & 46,9 & 20,9 & 252,2 \\
\hline $17: 00$ & 21,2 & 56,9 & 20,9 & 14,5 & 23,1 & 68,2 & 23,2 & 21,4 & 20,3 & 70,7 & 22,3 & 36,7 & 22,7 & 62,6 & 22,0 & 6,8 & 20,8 & 65,6 & 22,2 & 23,7 & 21,6 & 61,8 & 20,8 & 26,2 \\
\hline 18:00 & 16,4 & 76,8 & 20,4 & 0,6 & 17,5 & 92,8 & 22,6 & 4,0 & 15,3 & 94,7 & 21,8 & 5,7 & 16,8 & 85,2 & 21,4 & 4,5 & 15,9 & 87,4 & 21,4 & 3,4 & 16,0 & 87,9 & 20,5 & 25,6 \\
\hline
\end{tabular}


DIA DE COLETA DE DADOS:

09/Mai

\begin{tabular}{|c|c|c|c|c|c|c|c|c|c|c|c|c|c|c|c|c|c|c|c|c|c|c|c|c|}
\hline \multirow[b]{2}{*}{ HORA } & \multicolumn{4}{|c|}{ TESTEMUNHA } & \multicolumn{4}{|c|}{$0 \%$} & \multicolumn{4}{|c|}{$5 \%$} & \multicolumn{4}{|c|}{$10 \%$} & \multicolumn{4}{|c|}{$15 \%$} & \multicolumn{3}{|c|}{$20 \%$} & \multirow[b]{2}{*}{ RS } \\
\hline & $\mathrm{T}(\mathrm{C})$ & UR(\%) & Tsolo & RS & $\mathrm{T}(\mathrm{C})$ & UR(\%) & Tsolo & RS & $\mathrm{T}(\mathrm{C})$ & UR(\%) & Tsolo & RS & $\mathrm{T}(\mathrm{C})$ & UR(\%) & Tsolo & RS & $\mathrm{T}(\mathrm{C})$ & UR(\%) & Tsolo & RS & $\mathrm{T}(\mathrm{C})$ & UR(\%) & Tsolo & \\
\hline 08:00 & 12,6 & 97,8 & 16,2 & 163,3 & 19,9 & 98,0 & 18,5 & 163,7 & 17,6 & 97,53 & 18,4 & 40,8 & 17,6 & 96,4 & 17,5 & 29,0 & 17,9 & 90,8 & 17,7 & 166,2 & 16,8 & 96,6 & 16,9 & 120,5 \\
\hline 09:00 & 15,3 & 87,9 & 16,6 & 436,2 & 25,9 & 88,9 & 18,8 & 317,6 & 23,1 & 83,0 & 18,7 & 231,0 & 23,1 & 74,0 & 17,9 & 189,9 & 23,5 & 78,0 & 18,5 & 243,2 & 21,3 & 83,5 & 17,1 & 271,6 \\
\hline 10:00 & 19,6 & 72,6 & 17,7 & 603,9 & 34,7 & 72,0 & 19,7 & 544,3 & 30,19 & 64,09 & 19,4 & 310,0 & 28,5 & 61,8 & 18,8 & 261,0 & 28,4 & 62,5 & 19,9 & 407,9 & 26,9 & 67,3 & 17,7 & 613,7 \\
\hline 11:00 & 23,4 & 55,9 & 18,9 & 704,8 & 39,2 & 68,2 & 20,9 & 647,9 & 34,34 & 52,86 & 20,3 & 310,5 & 32,5 & 43,5 & 19,9 & 354,2 & 30,7 & 59,4 & 21,4 & 506,8 & 30,2 & 51,1 & 18,5 & 597,5 \\
\hline 12:00 & 24,9 & 45,0 & 20,1 & 733,1 & 43,7 & 60,3 & 22,2 & 546,1 & 36,29 & 62,74 & 21,1 & 318,8 & 37,0 & 36,6 & 20,9 & 403,1 & 32,9 & 43,6 & 22,4 & 593,5 & 33,4 & 38,2 & 19,3 & 679,9 \\
\hline 13:00 & 26,3 & 44,3 & 21,2 & 699,7 & 42,4 & 69,9 & 23,2 & 479,0 & 36,42 & 49,8 & 21,9 & 415,4 & 36,7 & 38,0 & 21,8 & 446,9 & 33,0 & 42,2 & 23,0 & 536,8 & 34,2 & 48,5 & 20,0 & 644,9 \\
\hline 14:00 & 27,4 & 40,4 & 21,9 & 603,3 & 40,8 & 63,8 & 23,9 & 511,4 & 35,9 & 37,4 & 22,5 & 291,9 & 36,8 & 45,4 & 22,6 & 286,0 & 32,5 & 37,7 & 23,5 & 534,8 & 35,0 & 50,2 & 20,7 & 700,5 \\
\hline 15:00 & 27,1 & 43,2 & 22,2 & 449,5 & 38,4 & 64,5 & 24,2 & 293,3 & 34,7 & 53,0 & 22,9 & 255,2 & 35,9 & 45,3 & 22,6 & 269,5 & 32,3 & 43,6 & 23,7 & 325,1 & 34,3 & 47,4 & 21,2 & 373,3 \\
\hline 16:00 & 27,3 & 43,9 & 22,3 & 269,2 & 34,6 & 49,3 & 24,3 & 225,6 & 32,3 & 52,5 & 23,1 & 185,0 & 33,4 & 46,6 & 22,6 & 137,6 & 30,4 & 46,0 & 23,7 & 142,9 & 32,0 & 44,7 & 21,5 & 285,3 \\
\hline $17: 00$ & 23,6 & 56,9 & 22,0 & 20,8 & 25,6 & 71,5 & 24,1 & 28,9 & 23,35 & 69,95 & 23,0 & 36,7 & 25,4 & 59,9 & 22,4 & 13,1 & 23,6 & 67,7 & 23,3 & 31,0 & 24,6 & 60,9 & 21,6 & 41,8 \\
\hline 18:00 & 19,6 & 71,0 & 21,5 & 1,3 & 19,8 & 89,4 & 23,6 & 6,9 & 18,1 & 89,4 & 22,6 & 5,2 & 19,6 & 81,3 & 22,0 & 6,8 & 19,1 & 79,0 & 22,5 & 10,7 & 19,2 & 83,0 & 21,4 & 4,4 \\
\hline
\end{tabular}

DIA DE COLETA DE DADOS: 10/Mai

\begin{tabular}{|c|c|c|c|c|c|c|c|c|c|c|c|c|c|c|c|c|c|c|c|c|c|c|c|c|}
\hline \multirow[b]{2}{*}{ HORA } & \multicolumn{4}{|c|}{ TESTEMUNHA } & \multicolumn{4}{|c|}{$0 \%$} & \multicolumn{4}{|c|}{$5 \%$} & \multicolumn{4}{|c|}{$10 \%$} & \multicolumn{4}{|c|}{$15 \%$} & \multicolumn{3}{|c|}{$20 \%$} & \multirow[b]{2}{*}{ RS } \\
\hline & $\mathrm{T}(\mathrm{C})$ & UR(\%) & Tsolo & RS & $\mathrm{T}(\mathrm{C})$ & $\mathrm{UR}(\%)$ & Tsolo & RS & $\mathrm{T}(\mathrm{C})$ & UR(\%) & Tsolo & RS & $\mathrm{T}(\mathrm{C})$ & UR(\%) & Tsolo & RS & $\mathrm{T}(\mathrm{C})$ & UR(\%) & Tsolo & RS & $\mathrm{T}(\mathrm{C})$ & UR( $\%)$ & Tsolo & \\
\hline $08: 00$ & 17,3 & 83,3 & 17,7 & 230,7 & 22,1 & 99,0 & 19,8 & 185,1 & 21,04 & 97,78 & 19,6 & 148,3 & 19,6 & 91,9 & 18,7 & 109,2 & 20,7 & 82,2 & 19,0 & 147,3 & 18,4 & 95,5 & 18,3 & 167,3 \\
\hline 09:00 & 21,4 & 70,4 & 18,2 & 429,9 & 32,1 & 81,1 & 20,3 & 309,5 & 29,1 & 68,7 & 19,9 & 229,4 & 27,5 & 65,6 & 19,3 & 186,5 & 28,0 & 68,4 & 20,0 & 242,2 & 25,3 & 74,3 & 18,6 & 294,7 \\
\hline 10:00 & 25,2 & 57,6 & 19,4 & 573,0 & 39,6 & 55,1 & 21,3 & 553,0 & 34,71 & 63,23 & 20,6 & 278,0 & 33,6 & 46,1 & 20,1 & 257,5 & 32,6 & 59,0 & 21,3 & 388,1 & 31,3 & 61,0 & 19,2 & 545,0 \\
\hline 11:00 & 27,6 & 52,2 & 20,8 & 674,5 & 41,4 & 72,6 & 22,4 & 553,0 & 37,39 & 52,73 & 21,4 & 308,5 & 36,7 & 48,3 & 21,1 & 363,3 & 34,8 & 52,5 & 22,7 & 516,0 & 34,3 & 52,9 & 19,9 & 631,8 \\
\hline 12:00 & 28,8 & 43,1 & 22,1 & 702,2 & 43,5 & 79,2 & 23,5 & 479,0 & 37,6 & 53,59 & 22,4 & 312,6 & 38,2 & 46,1 & 22,1 & 411,0 & 35,7 & 54,3 & 23,9 & 543,1 & 36,2 & 43,5 & 20,8 & 637,4 \\
\hline 13:00 & 30,1 & 41,6 & 22,9 & 718,0 & 44,7 & 42,2 & 24,5 & 511,9 & 38,86 & 50,7 & 23,3 & 399,9 & 39,2 & 50,0 & 23,0 & 434,4 & 36,3 & 39,7 & 24,6 & 530,5 & 37,1 & 54,4 & 21,6 & 643,0 \\
\hline 14:00 & 30,3 & 42,4 & 23,3 & 598,9 & 42,5 & 46,0 & 25,1 & 495,2 & 37,5 & 54,9 & 23,7 & 309,0 & 37,1 & 44,6 & 23,6 & 279,7 & 33,9 & 44,3 & 24,7 & 555,7 & 35,0 & 42,5 & 22,2 & 651,8 \\
\hline 15:00 & 30,7 & 38,2 & 23,3 & 456,4 & 42,2 & 49,7 & 25,6 & 379,5 & 37,9 & 53,0 & 24,0 & 275,4 & 38,9 & 37,8 & 23,9 & 271,8 & 35,4 & 44,9 & 25,0 & 334,8 & 37,1 & 41,4 & 22,6 & 376,5 \\
\hline 16:00 & 29,9 & 40,6 & 23,2 & 223,8 & 36,7 & 71,7 & 25,7 & 207,1 & 33,7 & 48,2 & 24,1 & 158,6 & 35,1 & 40,9 & 23,9 & 129,1 & 32,8 & 41,1 & 24,8 & 141,5 & 33,2 & 42,7 & 22,8 & 259,7 \\
\hline $17: 00$ & 27,3 & 47,0 & 22,8 & 44,1 & 28,4 & 82,6 & 25,5 & 42,2 & 26,53 & 63,72 & 23,9 & 38,8 & 28,2 & 57,1 & 23,7 & 31,8 & 26,9 & 59,9 & 24,3 & 45,1 & 27,3 & 59,0 & 22,8 & 71,8 \\
\hline 18:00 & 23,1 & 66,3 & 22,5 & 1,3 & 23,5 & 82,5 & 25,1 & 5,8 & 22,0 & 83,9 & 23,5 & 14,0 & 23,4 & 76,2 & 23,4 & 3,4 & 22,6 & 76,5 & 23,7 & 3,9 & 22,9 & 75,0 & 22,6 & 13,7 \\
\hline
\end{tabular}


DIA DE COLETA DE DADOS:

11/Mai

\begin{tabular}{|c|c|c|c|c|c|c|c|c|c|c|c|c|c|c|c|c|c|c|c|c|c|c|c|c|}
\hline \multirow[b]{2}{*}{ HORA } & \multicolumn{4}{|c|}{ TESTEMUNHA } & \multicolumn{4}{|c|}{$0 \%$} & \multicolumn{4}{|c|}{$5 \%$} & \multicolumn{4}{|c|}{$10 \%$} & \multicolumn{4}{|c|}{$15 \%$} & \multicolumn{3}{|c|}{$20 \%$} & \multirow[b]{2}{*}{ RS } \\
\hline & $\mathrm{T}(\mathrm{C})$ & $\mathrm{UR}(\%)$ & Tsolo & RS & $\mathrm{T}(\mathrm{C})$ & $\mathrm{UR}(\%)$ & Tsolo & RS & $\mathrm{T}(\mathrm{C})$ & $\mathrm{UR}(\%)$ & Tsolo & RS & $\mathrm{T}(\mathrm{C})$ & $\mathrm{UR}(\%)$ & Tsolo & RS & $\mathrm{T}(\mathrm{C})$ & $\mathrm{UR}(\%)$ & Tsolo & RS & $\mathrm{T}(\mathrm{C})$ & $\mathrm{UR}(\%)$ & Tsolo & \\
\hline $08: 00$ & 19,6 & 84,5 & 19,8 & 110,3 & 23,0 & 99,0 & 21,7 & 85,6 & 21,0 & 98,6 & 21,0 & 26,9 & 21,3 & 97,8 & 20,5 & 43,8 & 21,0 & 97,2 & 20,5 & 79,9 & 20,7 & 98,1 & 20,2 & 91,8 \\
\hline 09:00 & 23,4 & 69,0 & 20,3 & 437,5 & 33,4 & 80,8 & 22,2 & 308,9 & 31,0 & 66,8 & 21,4 & 311,0 & 29,7 & 66,8 & 21,0 & 221,7 & 29,7 & 63,7 & 21,4 & 393,9 & 27,3 & 68,4 & 20,5 & 336,5 \\
\hline $10: 00$ & 23,8 & 62,4 & 21,1 & 155,7 & 33,6 & 60,1 & 22,9 & 152,1 & 30,9 & 53,5 & 22,0 & 121,9 & 32,4 & 56,2 & 21,7 & 109,2 & 29,1 & 57,4 & 22,3 & 153,1 & 31,2 & 54,0 & 20,9 & 156,1 \\
\hline $11: 00$ & 26,7 & 54,7 & 21,7 & 795,5 & 41,2 & 68,5 & 23,5 & 715,6 & 38,1 & 43,3 & 22,4 & 569,4 & 36,4 & 50,4 & 22,2 & 474,7 & 34,5 & 45,5 & 23,0 & 675,8 & 34,2 & 65,3 & 21,4 & 713,0 \\
\hline 12:00 & 25,1 & 59,7 & 22,3 & 188,5 & 33,4 & 75,4 & 24,1 & 179,9 & 30,6 & 57,4 & 23,0 & 161,7 & 31,4 & 65,7 & 22,9 & 135,3 & 29,2 & 59,1 & 23,5 & 181,2 & 30,3 & 62,1 & 22,0 & 172,9 \\
\hline 13:00 & 24,1 & 65,1 & 22,5 & 37,2 & 27,3 & 83,4 & 24,1 & 58,4 & 25,4 & 75,2 & 23,1 & 69,8 & 26,5 & 71,9 & 23,1 & 28,4 & 25,2 & 71,8 & 23,3 & 58,1 & 25,6 & 72,9 & 22,4 & 44,3 \\
\hline 14:00 & 23,5 & 69,0 & 22,3 & 10,1 & 26,0 & 82,0 & 24,1 & 17,4 & 24,3 & 78,0 & 23,1 & 21,7 & 25,4 & 69,9 & 23,0 & 8,0 & 24,3 & 75,4 & 23,1 & 18,9 & 24,9 & 72,5 & 22,5 & 21,9 \\
\hline $15: 00$ & 19,6 & 95,2 & 22,1 & 116,6 & 22,6 & 97,3 & 23,9 & 78,1 & 21,5 & 97,2 & 22,9 & 27,9 & 21,4 & 96,9 & 22,8 & 79,0 & 21,3 & 97,4 & 22,7 & 83,8 & 21,0 & 97,5 & 22,4 & 36,8 \\
\hline $16: 00$ & 20,1 & 94,2 & 21,9 & 64,3 & 24,7 & 92,3 & 23,9 & 66,5 & 22,5 & 93,5 & 22,8 & 62,0 & 23,0 & 93,9 & 22,7 & 40,4 & 22,5 & 94,6 & 22,6 & 67,8 & 22,7 & 95,3 & 22,3 & 51,2 \\
\hline $17: 00$ & 19,7 & 94,6 & 21,9 & 12,0 & 22,5 & 94,8 & 23,8 & 35,3 & 21,2 & 96,1 & 22,8 & 14,5 & 21,4 & 95,5 & 22,6 & 3,4 & 20,9 & 95,7 & 22,6 & 34,9 & 21,3 & 95,9 & 22,3 & 41,2 \\
\hline 18:00 & 19,7 & 95,0 & 21,7 & 2,5 & 21,5 & 96,7 & 23,7 & 7,5 & 20,7 & 97,0 & 22,6 & 5,7 & 21,0 & 96,7 & 22,5 & 4,5 & 20,7 & 96,8 & 22,4 & 6,8 & 20,8 & 97,3 & 22,2 & 21,2 \\
\hline
\end{tabular}

DIA DE COLETA DE DADOS: 12/Mai

\begin{tabular}{|c|c|c|c|c|c|c|c|c|c|c|c|c|c|c|c|c|c|c|c|c|c|c|c|c|}
\hline \multirow[b]{2}{*}{ HORA } & \multicolumn{4}{|c|}{ TESTEMUNHA } & \multicolumn{4}{|c|}{$0 \%$} & \multicolumn{4}{|c|}{$5 \%$} & \multicolumn{4}{|c|}{$10 \%$} & \multicolumn{4}{|c|}{$15 \%$} & \multicolumn{3}{|c|}{$20 \%$} & \multirow[b]{2}{*}{ RS } \\
\hline & $\mathrm{T}(\mathrm{C})$ & UR(\%) & Tsolo & RS & $\mathrm{T}(\mathrm{C})$ & UR(\%) & Tsolo & RS & $\mathrm{T}(\mathrm{C})$ & $\mathrm{UR}(\%)$ & Tsolo & RS & $\mathrm{T}(\mathrm{C})$ & UR(\%) & Tsolo & RS & $\mathrm{T}(\mathrm{C})$ & UR(\%) & Tsolo & RS & $\mathrm{T}(\mathrm{C})$ & $\mathrm{UR}(\%)$ & Tsolo & \\
\hline 08:00 & 17,9 & 94,6 & 20,5 & 52,3 & 21,0 & 98,0 & 22,1 & 51,5 & 19,6 & 98,51 & 21,5 & 19,1 & 19,9 & 97,7 & 21,2 & 4,0 & 19,3 & 95,3 & 20,9 & 44,6 & 19,6 & 97,7 & 20,9 & 55,6 \\
\hline 09:00 & 19,4 & 88,3 & 20,6 & 260,3 & 27,0 & 99,6 & 22,2 & 264,9 & 23,6 & 93,5 & 21,6 & 226,8 & 23,4 & 89,4 & 21,3 & 175,1 & 23,6 & 86,4 & 21,2 & 242,7 & 23,2 & 91,8 & 21,0 & 201,0 \\
\hline $10: 00$ & 19,9 & 88,7 & 21,0 & 134,9 & 27,0 & 88,5 & 22,6 & 135,4 & 24,09 & 83,01 & 21,8 & 97,1 & 24,1 & 84,4 & 21,6 & 93,8 & 23,5 & 88,3 & 21,6 & 133,2 & 23,7 & 87,8 & 21,2 & 82,4 \\
\hline 11:00 & 22,4 & 81,7 & 21,4 & 432,4 & 36,1 & 78,9 & 23,1 & 286,3 & 31,29 & 74,22 & 22,1 & 252,7 & 29,6 & 65,4 & 22,0 & 305,9 & 29,7 & 72,6 & 22,2 & 279,1 & 29,1 & 73,7 & 21,6 & 355,9 \\
\hline $12: 00$ & 23,5 & 72,9 & 21,9 & 834,6 & 38,6 & 69,1 & 23,8 & 443,7 & 34,46 & 64,21 & 22,6 & 327,6 & 32,6 & 62,0 & 22,7 & 512,8 & 31,0 & 64,5 & 22,9 & 448,6 & 31,7 & 66,3 & 22,0 & 796,6 \\
\hline 13:00 & 24,6 & 67,3 & 22,5 & 704,8 & 43,3 & 59,4 & 24,5 & 564,0 & 35,81 & 60,7 & 23,1 & 426,8 & 35,7 & 59,8 & 23,3 & 482,7 & 33,2 & 62,4 & 23,6 & 580,4 & 34,6 & 61,4 & 22,5 & 719,2 \\
\hline 14:00 & 24,9 & 65,8 & 22,9 & 421,1 & 38,5 & 62,5 & 25,2 & 352,9 & 33,1 & 65,9 & 23,5 & 267,6 & 34,8 & 53,6 & 23,9 & 289,4 & 30,8 & 58,7 & 24,1 & 372,1 & 33,5 & 59,8 & 22,9 & 383,3 \\
\hline 15:00 & 25,2 & 61,6 & 23,1 & 405,3 & 34,7 & 88,0 & 25,4 & 229,7 & 31,0 & 71,5 & 23,8 & 188,1 & 30,9 & 61,2 & 24,1 & 280,9 & 29,6 & 58,8 & 24,1 & 251,0 & 30,1 & 67,6 & 23,3 & 365,2 \\
\hline 16:00 & 25,4 & 59,0 & 23,1 & 279,9 & 33,5 & 79,2 & 25,4 & 247,6 & 30,7 & 64,5 & 23,9 & 164,3 & 31,3 & 58,0 & 24,1 & 149,5 & 29,9 & 56,8 & 24,0 & 197,7 & 30,4 & 68,7 & 23,4 & 294,1 \\
\hline $17: 00$ & 23,2 & 66,5 & 22,8 & 37,8 & 26,3 & 84,4 & 25,2 & 49,2 & 24,09 & 86,06 & 23,7 & 60,5 & 25,2 & 76,9 & 23,9 & 25,6 & 24,0 & 77,9 & 23,7 & 51,4 & 24,6 & 77,5 & 23,4 & 41,2 \\
\hline 18:00 & 20,2 & 83,7 & 22,6 & 1,3 & 22,4 & 93,9 & 24,9 & 8,7 & 20,7 & 94,8 & 23,5 & 3,6 & 21,3 & 92,7 & 23,6 & 5,1 & 20,4 & 90,6 & 23,2 & 10,7 & 21,0 & 93,4 & 23,2 & 14,4 \\
\hline
\end{tabular}


DIA DE COLETA DE DADOS:

13/Mai

\begin{tabular}{|c|c|c|c|c|c|c|c|c|c|c|c|c|c|c|c|c|c|c|c|c|c|c|c|c|}
\hline \multirow[b]{2}{*}{ HORA } & \multicolumn{4}{|c|}{ TESTEMUNHA } & \multicolumn{4}{|c|}{$0 \%$} & \multicolumn{4}{|c|}{$5 \%$} & \multicolumn{4}{|c|}{$10 \%$} & \multicolumn{4}{|c|}{$15 \%$} & \multicolumn{4}{|c|}{$20 \%$} \\
\hline & $\mathrm{T}(\mathrm{C})$ & UR(\%) & Tsolo & RS & $\mathrm{T}(\mathrm{C})$ & UR(\%) & Tsolo & RS & $\mathrm{T}(\mathrm{C})$ & UR(\%) & Tsolo & RS & $\mathrm{T}(\mathrm{C})$ & $\mathrm{UR}(\%)$ & Tsolo & RS & $\mathrm{T}(\mathrm{C})$ & UR(\%) & Tsolo & RS & $\mathrm{T}(\mathrm{C})$ & $\mathrm{UR}(\%)$ & Tsolo & RS \\
\hline 08:00 & 16,6 & 96,8 & 19,7 & 11,3 & 19,0 & 98,4 & 21,5 & 24,9 & 18,35 & 98,63 & 21,4 & 8,8 & 18,2 & 98,0 & 20,5 & 4,0 & 18,4 & 98,0 & 20,7 & 22,3 & 18,1 & 98,5 & 20,1 & 22,5 \\
\hline 09:00 & 17,7 & 97,0 & 19,8 & 166,4 & 22,1 & 99,5 & 21,5 & 141,7 & 20,9 & 98,8 & 21,4 & 37,7 & 20,2 & 98,6 & 20,5 & 78,5 & 20,3 & 98,1 & 20,8 & 131,3 & 20,1 & 98,8 & 20,1 & 132,4 \\
\hline 10:00 & 18,2 & 94,5 & 20,0 & 139,3 & 23,2 & 92,4 & 21,7 & 145,2 & 20,91 & 94,97 & 21,5 & 54,8 & 21,0 & 95,9 & 20,8 & 65,9 & 20,5 & 92,7 & 21,2 & 136,6 & 20,7 & 95,7 & 20,3 & 125,5 \\
\hline 11:00 & 19,3 & 86,5 & 20,4 & 202,4 & 28,1 & 78,1 & 22,1 & 227,3 & 24,7 & 83,25 & 21,8 & 202,0 & 24,5 & 85,4 & 21,2 & 142,7 & 23,6 & 86,5 & 21,6 & 231,1 & 24,1 & 84,1 & 20,5 & 190,4 \\
\hline 12:00 & 20,8 & 79,8 & 20,8 & 515,0 & 31,9 & 85,0 & 22,5 & 256,3 & 29,9 & 81,79 & 22,1 & 216,5 & 26,5 & 79,7 & 21,6 & 325,8 & 27,4 & 76,8 & 22,0 & 251,0 & 26,7 & 73,4 & 20,9 & 498,8 \\
\hline 13:00 & 22,9 & 67,4 & 21,2 & 766,5 & 38,0 & 67,9 & 23,0 & 323,4 & 33,24 & 61,3 & 22,4 & 273,3 & 31,2 & 67,7 & 22,0 & 525,9 & 29,8 & 57,9 & 22,6 & 337,2 & 30,7 & 57,9 & 21,2 & 746,7 \\
\hline 14:00 & 23,5 & 66,0 & 21,6 & 395,9 & 39,7 & 59,0 & 23,8 & 667,0 & 34,1 & 66,5 & 23,0 & 411,8 & 34,0 & 66,3 & 22,7 & 228,5 & 30,1 & 67,9 & 23,3 & 728,6 & 33,1 & 53,2 & 21,6 & 392,1 \\
\hline 15:00 & 23,8 & 59,2 & 21,9 & 495,5 & 37,5 & 76,9 & 24,2 & 352,3 & 31,2 & 62,9 & 23,3 & 263,5 & 32,5 & 62,7 & 22,9 & 274,6 & 29,3 & 54,9 & 23,5 & 412,3 & 31,7 & 58,6 & 22,0 & 430,2 \\
\hline 16:00 & 23,8 & 54,7 & 21,9 & 110,3 & 32,6 & 72,5 & 24,3 & 240,1 & 28,7 & 60,9 & 23,3 & 173,6 & 30,3 & 54,1 & 22,8 & 54,6 & 27,3 & 55,2 & 23,3 & 200,1 & 29,6 & 53,6 & 22,0 & 111,8 \\
\hline $17: 00$ & 21,3 & 64,8 & 21,5 & 60,5 & 23,8 & 80,0 & 24,1 & 46,9 & 21,28 & 79,71 & 23,1 & 54,8 & 23,1 & 73,9 & 22,6 & 38,1 & 21,8 & 73,7 & 22,9 & 54,3 & 22,4 & 76,9 & 22,0 & 79,3 \\
\hline 18:00 & 19,0 & 74,1 & 21,2 & 1,3 & 19,0 & 95,8 & 23,7 & 4,0 & 17,1 & 93,3 & 22,8 & 5,7 & 18,1 & 89,2 & 22,2 & 4,0 & 17,7 & 88,7 & 22,2 & 5,3 & 17,7 & 88,6 & 21,8 & 20,0 \\
\hline
\end{tabular}

DIA DE COLETA DE DADOS: 14/Mai

\begin{tabular}{|c|c|c|c|c|c|c|c|c|c|c|c|c|c|c|c|c|c|c|c|c|c|c|c|c|}
\hline \multirow[b]{2}{*}{ HORA } & \multicolumn{4}{|c|}{ TESTEMUNHA } & \multicolumn{4}{|c|}{$0 \%$} & \multicolumn{4}{|c|}{$5 \%$} & \multicolumn{4}{|c|}{$10 \%$} & \multicolumn{4}{|c|}{$15 \%$} & \multicolumn{3}{|c|}{$20 \%$} & \multirow[b]{2}{*}{ RS } \\
\hline & $\mathrm{T}(\mathrm{C})$ & $\mathrm{UR}(\%)$ & Tsolo & RS & $\mathrm{T}(\mathrm{C})$ & $\mathrm{UR}(\%)$ & Tsolo & RS & $\mathrm{T}(\mathrm{C})$ & UR(\%) & Tsolo & RS & $\mathrm{T}(\mathrm{C})$ & $\mathrm{UR}(\%)$ & Tsolo & RS & $\mathrm{T}(\mathrm{C})$ & UR(\%) & Tsolo & RS & $\mathrm{T}(\mathrm{C})$ & UR( $\%)$ & Tsolo & \\
\hline $08: 00$ & 15,7 & 80,3 & 18,2 & 238,3 & 19,3 & 95,9 & 20,0 & 170,1 & 18,1 & 94,7 & 19,8 & 141,6 & 17,6 & 92,3 & 18,8 & 87,0 & 19,0 & 75,3 & 19,1 & 141,5 & 16,8 & 88,5 & 18,6 & 150,5 \\
\hline 09:00 & 17,5 & 72,3 & 18,4 & 436,2 & 27,5 & 77,4 & 20,3 & 345,3 & 24,5 & 77,4 & 20,0 & 297,1 & 23,1 & 68,4 & 19,1 & 193,3 & 23,2 & 75,1 & 19,7 & 390,5 & 21,4 & 71,7 & 18,7 & 282,8 \\
\hline 10:00 & 17,1 & 73,9 & 18,8 & 223,2 & 23,7 & 87,9 & 20,7 & 190,9 & 20,9 & 76,7 & 20,3 & 175,2 & 20,7 & 80,0 & 19,5 & 150,7 & 20,2 & 79,1 & 20,0 & 186,0 & 19,8 & 80,2 & 18,9 & 179,2 \\
\hline 11:00 & 19,7 & 70,9 & 19,0 & 832,7 & 30,7 & 82,5 & 21,2 & 293,9 & 27,3 & 74,7 & 20,6 & 245,9 & 25,7 & 73,9 & 19,9 & 502,0 & 25,7 & 68,0 & 20,5 & 279,5 & 24,8 & 80,0 & 19,3 & 729,8 \\
\hline 12:00 & 21,6 & 62,6 & 19,7 & 890,1 & 35,9 & 77,6 & 22,0 & 711,5 & 31,5 & 62,5 & 21,2 & 514,6 & 29,5 & 59,4 & 20,6 & 527,6 & 29,2 & 54,7 & 21,5 & 731,1 & 27,7 & 70,2 & 19,7 & 822,8 \\
\hline 13:00 & 21,0 & 58,4 & 20,1 & 280,5 & 30,8 & 68,1 & 22,4 & 154,5 & 26,5 & 70,1 & 21,6 & 142,1 & 27,1 & 61,5 & 21,1 & 209,2 & 24,8 & 64,3 & 21,8 & 164,7 & 25,8 & 58,0 & 20,1 & 245,4 \\
\hline 14:00 & 20,8 & 59,9 & 20,1 & 351,1 & 28,2 & 76,7 & 22,6 & 160,2 & 24,7 & 64,3 & 21,6 & 157,1 & 24,7 & 72,8 & 21,2 & 260,4 & 24,0 & 64,5 & 21,6 & 161,3 & 23,8 & 68,8 & 20,3 & 314,0 \\
\hline 15:00 & 20,7 & 60,2 & 20,3 & 298,2 & 28,1 & 88,6 & 22,8 & 244,7 & 24,6 & 66,4 & 21,7 & 230,4 & 24,9 & 64,7 & 21,4 & 212,6 & 23,7 & 65,1 & 21,7 & 249,5 & 23,8 & 64,6 & 20,5 & 264,7 \\
\hline 16:00 & 19,9 & 65,9 & 20,1 & 172,1 & 25,6 & 86,2 & 23,0 & 108,8 & 22,5 & 73,6 & 21,8 & 100,2 & 23,4 & 70,9 & 21,4 & 118,8 & 22,1 & 69,5 & 21,7 & 113,4 & 22,3 & 77,4 & 20,7 & 161,1 \\
\hline $17: 00$ & 18,6 & 67,7 & 20,0 & 46,6 & 20,4 & 89,7 & 22,8 & 49,7 & 18,4 & 81,9 & 21,6 & 34,1 & 19,3 & 76,4 & 21,3 & 27,3 & 18,6 & 80,3 & 21,3 & 57,7 & 18,8 & 80,4 & 20,6 & 36,8 \\
\hline 18:00 & 16,9 & 74,5 & 19,8 & 1,3 & 17,6 & 95,7 & 22,5 & 5,2 & 15,9 & 88,9 & 21,4 & 5,7 & 16,8 & 85,8 & 20,9 & 5,1 & 16,4 & 86,8 & 20,8 & 4,8 & 16,4 & 86,8 & 20,4 & 16,9 \\
\hline
\end{tabular}


DIA DE COLETA DE DADOS:

15/Mai

\begin{tabular}{|c|c|c|c|c|c|c|c|c|c|c|c|c|c|c|c|c|c|c|c|c|c|c|c|c|}
\hline \multirow[b]{2}{*}{ HORA } & \multicolumn{4}{|c|}{ TESTEMUNHA } & \multicolumn{4}{|c|}{$0 \%$} & \multicolumn{4}{|c|}{$5 \%$} & \multicolumn{4}{|c|}{$10 \%$} & \multicolumn{4}{|c|}{$15 \%$} & \multicolumn{4}{|c|}{$20 \%$} \\
\hline & $\mathrm{T}(\mathrm{C})$ & UR(\%) & Tsolo & RS & $\mathrm{T}(\mathrm{C})$ & UR(\%) & Tsolo & RS & $\mathrm{T}(\mathrm{C})$ & UR(\%) & Tsolo & RS & $\mathrm{T}(\mathrm{C})$ & UR(\%) & Tsolo & RS & $\mathrm{T}(\mathrm{C})$ & UR(\%) & Tsolo & RS & $\mathrm{T}(\mathrm{C})$ & UR(\%) & Tsolo & RS \\
\hline 08:00 & 13,6 & 87,6 & 17,0 & 145,0 & 18,2 & 99,2 & 18,9 & 163,1 & 17,0 & 98,76 & 18,7 & 55,3 & 16,0 & 97,8 & 17,8 & 26,7 & 16,4 & 98,0 & 17,9 & 147,8 & 15,8 & 98,1 & 17,4 & 122,4 \\
\hline 09:00 & 15,7 & 77,1 & 17,3 & 240,8 & 21,5 & 91,6 & 19,3 & 245,3 & 19,0 & 93,8 & 18,9 & 232,5 & 19,1 & 84,2 & 18,1 & 146,1 & 19,4 & 80,8 & 18,4 & 232,5 & 18,4 & 86,7 & 17,6 & 171,1 \\
\hline 10:00 & 18,5 & 66,9 & 17,8 & 556,0 & 31,0 & 72,3 & 19,8 & 387,0 & 26,9 & 68,6 & 19,3 & 344,1 & 25,4 & 60,7 & 18,6 & 282,0 & 24,6 & 65,3 & 19,1 & 429,7 & 23,7 & 61,4 & 17,9 & 526,3 \\
\hline 11:00 & 20,3 & 64,7 & 18,4 & 804,4 & 35,8 & 65,7 & 20,5 & 650,2 & 31,53 & 74,59 & 19,8 & 420,1 & 28,4 & 58,8 & 19,2 & 456,0 & 28,8 & 63,5 & 19,9 & 589,6 & 27,0 & 69,6 & 18,3 & 733,6 \\
\hline 12:00 & 21,8 & 60,7 & 19,2 & 276,7 & 37,6 & 60,7 & 21,4 & 219,8 & 30,8 & 52,98 & 20,4 & 189,1 & 31,8 & 57,5 & 19,9 & 186,5 & 28,2 & 60,2 & 20,8 & 236,4 & 29,7 & 57,7 & 18,8 & 239,1 \\
\hline 13:00 & 21,5 & 61,2 & 19,7 & 617,1 & 37,0 & 81,1 & 22,0 & 603,9 & 31,17 & 71,4 & 20,9 & 477,4 & 29,6 & 59,2 & 20,6 & 353,1 & 28,0 & 69,8 & 21,2 & 671,5 & 27,5 & 61,3 & 19,3 & 612,4 \\
\hline 14:00 & 23,5 & 59,0 & 20,1 & 377,6 & 37,9 & 65,3 & 22,5 & 207,1 & 31,7 & 58,4 & 21,4 & 176,7 & 32,8 & 60,3 & 21,1 & 267,2 & 29,5 & 63,2 & 21,6 & 211,2 & 31,4 & 57,7 & 19,7 & 339,6 \\
\hline 15:00 & 22,3 & 60,4 & 20,3 & 180,3 & 29,5 & 74,0 & 22,8 & 107,0 & 26,0 & 74,5 & 21,5 & 96,1 & 26,7 & 73,1 & 21,3 & 133,0 & 24,9 & 67,0 & 21,6 & 112,9 & 25,4 & 62,7 & 20,2 & 176,7 \\
\hline 16:00 & 22,1 & 61,9 & 20,1 & 226,3 & 27,3 & 89,0 & 22,8 & 145,8 & 24,6 & 76,1 & 21,5 & 120,4 & 24,9 & 66,9 & 21,2 & 134,2 & 24,1 & 61,5 & 21,4 & 126,9 & 24,0 & 70,6 & 20,3 & 207,3 \\
\hline $17: 00$ & 20,4 & 65,1 & 20,0 & 36,6 & 22,5 & 90,1 & 22,6 & 27,2 & 20,18 & 79,71 & 21,4 & 28,4 & 21,2 & 75,1 & 21,1 & 21,0 & 20,4 & 79,0 & 21,0 & 30,0 & 20,7 & 75,6 & 20,3 & 32,5 \\
\hline 18:00 & 18,7 & 70,4 & 19,8 & 1,3 & 18,6 & 96,2 & 22,4 & 4,0 & 17,0 & 87,8 & 21,2 & 4,1 & 17,9 & 82,4 & 20,7 & 4,0 & 17,6 & 84,5 & 20,6 & 4,8 & 17,6 & 84,0 & 20,2 & 27,5 \\
\hline
\end{tabular}

DIA DE COLETA DE DADOS:

16/Mai

\begin{tabular}{|c|c|c|c|c|c|c|c|c|c|c|c|c|c|c|c|c|c|c|c|c|c|c|c|c|}
\hline \multirow[b]{2}{*}{ HORA } & \multicolumn{4}{|c|}{ TESTEMUNHA } & \multicolumn{4}{|c|}{$0 \%$} & \multicolumn{4}{|c|}{$5 \%$} & \multicolumn{4}{|c|}{$10 \%$} & \multicolumn{4}{|c|}{$15 \%$} & \multicolumn{3}{|c|}{$20 \%$} & \multirow[b]{2}{*}{ RS } \\
\hline & $\mathrm{T}(\mathrm{C})$ & UR(\%) & Tsolo & RS & $\mathrm{T}(\mathrm{C})$ & UR(\%) & Tsolo & RS & $\mathrm{T}(\mathrm{C})$ & UR(\%) & Tsolo & RS & $\mathrm{T}(\mathrm{C})$ & $\operatorname{UR}(\%)$ & Tsolo & RS & $\mathrm{T}(\mathrm{C})$ & UR(\%) & Tsolo & RS & $\mathrm{T}(\mathrm{C})$ & UR(\%) & Tsolo & \\
\hline $08: 00$ & 15,3 & 96,3 & 18,3 & 49,8 & 18,2 & 98,6 & 20,1 & 43,4 & 17,25 & 98,39 & $\overline{19,6}$ & 12,9 & 17,4 & 97,8 & 18,9 & 2,8 & 17,0 & 97,2 & 18,9 & 39,2 & 16,9 & 98,1 & 18,6 & 51,8 \\
\hline 09:00 & 15,7 & 95,0 & 18,3 & 69,3 & 18,2 & 98,3 & 20,1 & 33,0 & 17,1 & 98,1 & 19,6 & 10,3 & 17,4 & 97,5 & 19,0 & 4,5 & 17,0 & 96,8 & 19,0 & 30,5 & 17,0 & 97,8 & 18,6 & 68,0 \\
\hline 10:00 & 14,8 & 93,0 & 18,3 & 7,6 & 16,6 & 97,5 & 20,1 & 11,0 & 15,54 & 97,53 & 19,6 & 12,9 & 16,0 & 96,8 & 18,9 & 3,4 & 15,8 & 96,6 & 18,9 & 10,7 & 15,8 & 97,3 & 18,6 & 19,4 \\
\hline 11:00 & 15,3 & 93,4 & 18,2 & 158,2 & 20,2 & 92,7 & 20,1 & 139,4 & 18,84 & 97,9 & 19,6 & 54,8 & 18,6 & 96,8 & 18,9 & 81,9 & 18,2 & 92,8 & 18,9 & 132,7 & 18,2 & 96,1 & 18,6 & 86,8 \\
\hline 12:00 & 16,3 & 90,0 & 18,3 & 176,5 & 21,8 & 94,4 & 20,2 & 181,6 & 19,8 & 90,45 & 19,7 & 108,0 & 19,6 & 91,1 & 19,0 & 89,8 & 19,0 & 87,8 & 19,1 & 180,2 & 19,0 & 90,8 & 18,7 & 154,2 \\
\hline 13:00 & 17,1 & 87,8 & 18,4 & 254,7 & 24,1 & 87,3 & 20,4 & 195,5 & 22,38 & 85,0 & 19,9 & 165,3 & 21,6 & 86,1 & 19,3 & 181,4 & 20,7 & 83,0 & 19,3 & 198,6 & 20,7 & 88,0 & 18,9 & 201,0 \\
\hline 14:00 & 16,5 & 89,8 & 18,7 & 53,0 & 20,4 & 91,6 & 20,6 & 73,5 & 19,0 & 92,7 & 20,0 & 26,4 & 19,1 & 90,5 & 19,5 & 7,4 & 18,4 & 91,7 & 19,4 & 73,2 & 18,5 & 92,4 & 19,0 & 68,7 \\
\hline 15:00 & 16,9 & 93,0 & 18,7 & 128,0 & 22,0 & 94,0 & 20,7 & 92,6 & 20,7 & 91,8 & 20,0 & 33,6 & 20,2 & 92,4 & 19,6 & 75,6 & 19,9 & 92,9 & 19,5 & 94,0 & 20,1 & 95,0 & 19,1 & 114,3 \\
\hline 16:00 & 16,3 & 94,5 & 18,8 & 35,3 & 19,4 & 93,9 & 20,7 & 33,0 & 17,9 & 94,4 & 20,1 & 16,0 & 18,2 & 94,5 & 19,7 & 6,3 & 18,1 & 95,5 & 19,6 & 31,0 & 18,1 & 96,2 & 19,3 & 41,2 \\
\hline 17:00 & 15,8 & 95,8 & 18,7 & 3,8 & 18,2 & 96,6 & 20,7 & 7,5 & 17,25 & 96,68 & 20,0 & 9,3 & 17,7 & 96,2 & 19,6 & 5,7 & 17,3 & 96,1 & 19,5 & 8,2 & 17,5 & 96,6 & 19,3 & 15,6 \\
\hline 18:00 & 15,7 & 96,3 & 18,6 & 1,9 & 17,5 & 97,2 & 20,6 & 5,8 & 16,5 & 97,4 & 19,9 & 6,7 & 17,0 & 97,0 & 19,5 & 5,1 & 16,9 & 97,2 & 19,4 & 6,8 & 16,9 & 97,9 & 19,2 & 12,5 \\
\hline
\end{tabular}


DIA DE COLETA DE DADOS:

17/Mai

\begin{tabular}{|c|c|c|c|c|c|c|c|c|c|c|c|c|c|c|c|c|c|c|c|c|c|c|c|c|}
\hline \multirow[b]{2}{*}{ HORA } & \multicolumn{4}{|c|}{ TESTEMUNHA } & \multicolumn{4}{|c|}{$0 \%$} & \multicolumn{4}{|c|}{$5 \%$} & \multicolumn{4}{|c|}{$10 \%$} & \multicolumn{4}{|c|}{$15 \%$} & \multicolumn{4}{|c|}{$20 \%$} \\
\hline & $\mathrm{T}(\mathrm{C})$ & UR(\%) & Tsolo & RS & $\mathrm{T}(\mathrm{C})$ & UR $(\%)$ & Tsolo & RS & $\mathrm{T}(\mathrm{C})$ & UR $(\%)$ & Tsolo & RS & $\mathrm{T}(\mathrm{C})$ & UR $(\%)$ & Tsolo & RS & $\mathrm{T}(\mathrm{C})$ & UR $(\%)$ & Tsolo & RS & $\mathrm{T}(\mathrm{C})$ & UR $(\%)$ & Tsolo & RS \\
\hline 08:00 & 16,0 & 96,1 & 17,8 & 105,3 & 22,7 & 99,5 & 19,4 & 178,7 & 21,9 & 98,6 & 19,0 & 111,6 & 19,9 & 97,7 & 18,4 & 21,6 & 21,3 & 93,9 & 18,6 & 153,1 & 19,4 & 98,0 & 18,3 & 95,5 \\
\hline 09:00 & 16,6 & 94,0 & 18,1 & 68,1 & 21,5 & 96,2 & 19,6 & 67,7 & 19,3 & 95,6 & 19,3 & 13,4 & 19,7 & 95,2 & 18,7 & 5,1 & 19,4 & 92,9 & 18,8 & 63,0 & 19,7 & 95,6 & 18,4 & 77,4 \\
\hline 10:00 & 17,4 & 91,8 & 18,3 & 54,8 & 21,6 & 93,0 & 19,9 & 56,1 & 20,1 & 91,7 & 19,4 & 14,0 & 20,4 & 92,0 & 19,0 & 4,5 & 20,1 & 90,8 & 19,1 & 52,8 & 20,3 & 90,5 & 18,6 & 64,3 \\
\hline 11:00 & 18,5 & 91,8 & 18,6 & 124,8 & 23,5 & 91,4 & 20,1 & 119,2 & 21,3 & 93,0 & 19,5 & 72,9 & 21,3 & 92,5 & 19,3 & 70,5 & 21,2 & 91,7 & 19,3 & 120,6 & 21,2 & 93,6 & 18,8 & 87,4 \\
\hline 12:00 & 19,1 & 86,5 & 18,9 & 153,2 & 24,5 & 89,6 & 20,5 & 229,7 & 22,1 & 89,4 & 19,8 & 213,9 & 22,0 & 90,3 & 19,7 & 105,2 & 21,8 & 89,1 & 19,8 & 226,2 & 21,8 & 89,7 & 19,2 & 99,3 \\
\hline 13:00 & 18,2 & 92,9 & 19,0 & 233,2 & 23,5 & 94,2 & 20,7 & 367,3 & 21,6 & 93,9 & 20,0 & 337,4 & 21,3 & 94,1 & 19,9 & 164,3 & 21,0 & 92,9 & 20,0 & 396,3 & 21,0 & 94,2 & 19,5 & 211,0 \\
\hline 14:00 & 21,6 & 74,5 & 19,4 & 837,8 & 31,4 & 68,0 & 21,2 & 208,8 & 26,8 & 70,2 & 20,3 & 201,5 & 26,8 & 80,2 & 20,3 & 514,5 & 25,7 & 69,9 & 20,4 & 212,2 & 26,4 & 72,9 & 19,8 & 699,2 \\
\hline 15:00 & 20,4 & 69,0 & 19,5 & 440,0 & 28,5 & 71,5 & 21,5 & 301,4 & 24,7 & 69,7 & 20,5 & 291,4 & 25,3 & 69,9 & 20,5 & 204,1 & 24,0 & 70,3 & 20,6 & 252,9 & 25,1 & 69,1 & 20,0 & 388,9 \\
\hline 16:00 & 21,2 & 62,7 & 19,4 & 286,8 & 27,5 & 71,2 & 21,6 & 205,9 & 23,4 & 71,7 & 20,6 & 175,7 & 24,9 & 70,9 & 20,5 & 136,4 & 23,2 & 65,6 & 20,5 & 143,4 & 24,3 & 68,0 & 20,1 & 241,0 \\
\hline 17:00 & 19,1 & 64,7 & 19,2 & 22,7 & 18,5 & 89,8 & 21,4 & 17,9 & 17,3 & 82,4 & 20,4 & 11,4 & 18,2 & 80,6 & 20,3 & 7,4 & 17,9 & 77,8 & 20,2 & 24,2 & 18,0 & 80,4 & 20,0 & 16,2 \\
\hline 18:00 & 17,5 & 65,8 & 18,9 & 1,3 & 15,3 & 93,0 & 21,0 & 4,0 & 14,9 & 85,8 & 20,1 & 5,7 & 15,7 & 82,8 & 19,9 & 5,7 & 15,8 & 80,8 & 19,7 & 3,9 & 15,4 & 83,6 & 19,8 & 20,0 \\
\hline
\end{tabular}




\section{APÊNDICE III}

Dados obtidos no Experimento II - cultivo do rabanete no inverno 
DIA DE COLETA DE DADOS:

22/Ago

\begin{tabular}{|c|c|c|c|c|c|c|c|c|c|c|c|c|c|c|c|c|c|c|c|c|c|c|c|c|}
\hline \multirow[b]{2}{*}{ HORA } & \multicolumn{4}{|c|}{ TESTE MUNHA } & \multicolumn{2}{|c|}{$0 \%$} & \multirow[b]{2}{*}{ Tsolo } & \multirow[b]{2}{*}{ RS } & \multicolumn{3}{|c|}{$5 \%$} & \multirow[b]{2}{*}{ RS } & \multicolumn{2}{|c|}{$10 \%$} & \multirow[b]{2}{*}{ Tsolo } & \multirow[b]{2}{*}{ RS } & \multicolumn{3}{|c|}{$15 \%$} & \multirow[b]{2}{*}{ RS } & \multicolumn{2}{|c|}{$20 \%$} & \multirow[b]{2}{*}{ Tsolo } & \multirow[b]{2}{*}{ RS } \\
\hline & $\mathrm{T}(\mathrm{C})$ & $\mathrm{UR}(\%)$ & Tsolo & RS & $\mathrm{T}(\mathrm{C})$ & $\mathrm{UR}(\%)$ & & & $\mathrm{T}(\mathrm{C})$ & $\mathrm{UR}(\%)$ & Tsolo & & $\mathrm{T}(\mathrm{C})$ & $\mathrm{UR}(\%)$ & & & $\mathrm{T}(\mathrm{C})$ & $\mathrm{UR}(\%)$ & Tsolo & & $\mathrm{T}(\mathrm{C})$ & UR(\%) & & \\
\hline $08: 00$ & 16,6 & 86,2 & 18,3 & 155,7 & 21,4 & 89,1 & 20,1 & 179,3 & 20,3 & 87,6 & 19,6 & 145,7 &, 7 & 88,9 & 19,7 & 96,6 & 19,3 & 87,6 & 19,6 & 178,2 & 19,1 & 87,4 & 19,2 & 00,5 \\
\hline 09:00 & 19,1 & 76,9 & 18,7 & 427,4 & 29,8 & 76,7 & 20,7 & 210,7 & 28,0 & 69,1 & 20,3 & 196,9 & 25,6 & 74,6 & 20,1 & 289,4 & 24,9 & 72,5 & 20,1 & 226,8 & 24,6 & 77,9 & 19,7 & 318,4 \\
\hline $10: 00$ & 18,8 & 79,3 & 19,4 & 706,0 & 29,1 & 85,9 & 21,7 & 457,3 & 26,7 & 76,1 & 21,3 & 406,6 & 24,5 & 81,3 & 20,8 & 487,8 & 24,3 & 72,9 & 20,7 & 502,1 & 23,2 & 73,7 & 20,5 & 586,9 \\
\hline $11: 00$ & 22,7 & 65,6 & 20,3 & 900,2 & 38,6 & 65,2 & 23,0 & 316,8 & 34,7 & 49,3 & 22,7 & 301,7 & 32,1 & 56,6 & 21,8 & 676,5 & 30,4 & 57,4 & 21,7 & 367,9 & 30,4 & 55,2 & 21,7 & 830,3 \\
\hline $12: 00$ & 22,3 & 65,8 & 21,4 & 272,3 & 37,4 & 75,0 & 24,7 & 755,3 & 32,1 & 61,8 & 24,3 & 518,2 & 31,5 & 61,5 & 23,2 & 200,1 & 28,8 & 63,7 & 23,0 & 654,2 & 29,2 & 56,5 & 23,2 & 239,1 \\
\hline 13:00 & 24,9 & 58,4 & 22,3 & 755,8 & 41,2 & 70,1 & 26,4 & 649,2 & 37,0 & 56,8 & 25,7 & 486,2 & 34,5 & 52,5 & 24,5 & 639,0 & 32,6 & 61,4 & 24,2 & 653,7 & 32,0 & 50,3 & 24,5 & 726,1 \\
\hline $14: 00$ & 24,0 & 61,3 & 22,8 & 682,7 & 36,5 & 75,6 & 27,6 & 578,9 & 32,8 & 60,2 & 26,5 & 388,0 & 30,9 & 59,0 & 25 & 564,0 & 29,5 & 56,6 & 25,0 & 579,0 & 28,8 & 56,5 & 25,4 & 669,9 \\
\hline $15: 00$ & 23,8 & 59,6 & 22,9 & 504,3 & 34,5 & 72,9 & 28,1 & 306,2 & 31,0 & 56,6 & 26,7 & 304,8 & 30,4 & 56,2 & 25,8 & 347,4 & 28,8 & 54,8 & 25,4 & 427,5 & 28,5 & 53,7 & 25,6 & 401,4 \\
\hline $16: 00$ & 23,2 & 61,5 & 22,8 & 323,4 & 32,8 & 74,6 & 28,1 & 143,9 & 29,8 & 58,7 & 26,4 & 141,1 & 29,3 & 63,6 & 25,9 & 238,2 & 28,0 & 58,0 & 25,5 & 187,4 & 27,7 & 58,0 & 25,6 & 312,2 \\
\hline $17: 00$ & 21,5 & 66,3 & 22,6 & 53,6 & 27,7 & 83,9 & 27,9 & 51,8 & 24,2 & 69,5 & 25,9 & 39,8 & 25,3 & 67,4 & 25,7 & 68,2 & 23,8 & 67,3 & 25,3 & 60,2 & 24,3 & 66,5 & 25,3 & 93,0 \\
\hline $18: 00$ & 18,8 & 73,5 & 22,0 & 1,3 & 21,4 & 95,8 & 27,0 & 3,4 & 18,7 & 84,8 & 25,1 & 5,7 & 19,6 & 80,7 & 24,9 & 2,3 & 19,1 & 83,0 & 24,5 & 6,9 & 19,1 & 79,8 & 24,5 & 28,1 \\
\hline
\end{tabular}

DIA DE COLETA DE DADOS:

23/Ago

\begin{tabular}{|c|c|c|c|c|c|c|c|c|c|c|c|c|c|c|c|c|c|c|c|c|c|c|c|c|}
\hline \multirow[b]{2}{*}{ HORA } & \multicolumn{4}{|c|}{ TESTE MUNHA } & \multicolumn{4}{|c|}{$0 \%$} & \multicolumn{3}{|c|}{$5 \%$} & \multirow[b]{2}{*}{ RS } & \multicolumn{3}{|c|}{$10 \%$} & \multirow[b]{2}{*}{$\mathrm{RS}$} & \multicolumn{3}{|c|}{$15 \%$} & & \multicolumn{3}{|c|}{$20 \%$} & \multirow[b]{2}{*}{ RS } \\
\hline & $\mathrm{T}(\mathrm{C})$ & $\mathrm{UR}(\%)$ & Tsolo & RS & $\mathrm{T}(\mathrm{C})$ & $\mathrm{UR}(\%)$ & Tsolo & RS & $\mathrm{T}(\mathrm{C})$ & $\mathrm{UR}(\%)$ & Tsolo & & $\mathrm{T}(\mathrm{C})$ & $\mathrm{UR}(\%)$ & Tsolo & & $\mathrm{T}(\mathrm{C})$ & $\mathrm{UR}(\%)$ & Tsolo & RS & $\mathrm{T}(\mathrm{C})$ & $\mathrm{UR}(\%)$ & Tsolo & \\
\hline $08: 00$ & 15,1 & 94,6 & 17,2 & 4,4 & 17,4 & 97,9 & 19,9 & 8,2 & 15,9 & 97,8 & 18,9 & 11,4 & 16,2 & 96,9 & 19,0 & 2,8 & 16,0 & 97,5 & 18,8 & 9,8 & 15,8 & 97,0 & 18,4 & 18,1 \\
\hline 09:00 & 16,3 & 89,6 & 17,3 & 176,5 & 19,1 & 98,9 & 20,0 & 85,7 & 17,6 & 97,4 & 19,0 & 37,7 & 17,4 & 96,6 & 19,1 & 73,9 & 17,5 & 94,2 & 18,9 & 87,9 & 17,1 & 95,6 & 18,5 & 110,5 \\
\hline $10: 00$ & 15,5 & 91,2 & 17,6 & 6,3 & 17,5 & 97,0 & 20,2 & 10,2 & 16,3 & 96,1 & 19,3 & 7,8 & 16,4 & 96,1 & 19,3 & 4,5 & 16,3 & 96,9 & 19,1 & 13,3 & 16,2 & 96,4 & 18,7 & 19,4 \\
\hline $11: 00$ & 15,9 & 92,9 & 17,6 & 175,9 & 19,6 & 98,6 & 20,2 & 121,6 & 17,6 & 96,4 & 19,3 & 28,9 & 17,1 & 96,6 & 19,3 & 43,2 & 17,4 & 96,6 & 19,2 & 125,5 & 17,0 & 96,1 & 18,8 & 141,7 \\
\hline 12:00 & 15,7 & 91,3 & 17,6 & 13,9 & 18,1 & 97,4 & 20,3 & 17,9 & 16,4 & 96,2 & 19,5 & 11,9 & 16,5 & 96,2 & 19,4 & 5,7 & 16,4 & 96,7 & 19,3 & 20,8 & 16,2 & 95,9 & 18,9 & 25,6 \\
\hline $13: 00$ & 16,0 & 89,6 & 17,6 & 56,1 & 18,7 & 98,0 & 20,3 & 46,0 & 16,9 & 94,8 & 19,4 & 13,4 & 17,0 & 95,1 & 19,4 & 3,4 & 16,8 & 94,5 & 19,3 & 50,9 & 16,6 & 94,5 & 19,0 & 59,9 \\
\hline $14: 00$ & 17,9 & 80,4 & 17,7 & 54,2 & 21,6 & 91,2 & 20,5 & 19,4 & 19,6 & 87,4 & 19,6 & 8,3 & 19,6 & 90,8 & 19,5 & 3,4 & 19,2 & 89,4 & 19,4 & 22,6 & 19,1 & 88,6 & 19,0 & 60,6 \\
\hline 15:00 & 16,6 & 90,3 & 17,9 & 237,7 & 20,3 & 98,1 & 20,7 & 188,9 & 18,4 & 95,5 & 19,8 & 83,7 & 17,9 & 96,7 & 19,7 & 123,9 & 18,1 & 94,7 & 19,6 & 204,8 & 17,5 & 96,2 & 19,3 & 199,8 \\
\hline $16: 00$ & 16,9 & 89,7 & 18,1 & 40,3 & 20,7 & 92,7 & 20,9 & 57,7 & 18,0 & 93,1 & 20,0 & 16,5 & 18,2 & 94,5 & 19,9 & 2,8 & 17,9 & 93,5 & 19,8 & 65,9 & 18,0 & 95,5 & 19,5 & 47,4 \\
\hline $17: 00$ & 17,0 & 88,4 & 18,2 & 23,3 & 19,4 & 96,7 & 21,1 & 21,3 & 17,5 & 95,3 & 20,1 & 14,5 & 17,6 & 95,6 & 19,9 & 4,5 & 17,5 & 95,9 & 19,9 & 26,0 & 17,4 & 94,7 & 19,6 & 32,5 \\
\hline 18:00 & 16,8 & 89,6 & 18,2 & 1,3 & 18,4 & 97,7 & 21,0 & 5,8 & 17,1 & 97,0 & 19,9 & 9,3 & 17,3 & 97,2 & 19,9 & 4,5 & 17,1 & 97,7 & 19,8 & 8,7 & 16,9 & 97,3 & 19,5 & 13,1 \\
\hline
\end{tabular}


DIA DE COLETA DE DADOS:

24/Ago

\begin{tabular}{|c|c|c|c|c|c|c|c|c|c|c|c|c|c|c|c|c|c|c|c|c|c|c|c|c|}
\hline \multirow[b]{2}{*}{ HORA } & \multicolumn{4}{|c|}{ TESTE MUNHA } & \multicolumn{4}{|c|}{$0 \%$} & \multicolumn{3}{|c|}{$5 \%$} & \multirow[b]{2}{*}{ RS } & \multicolumn{4}{|c|}{$10 \%$} & \multicolumn{4}{|c|}{$15 \%$} & \multicolumn{3}{|c|}{$20 \%$} & \multirow[b]{2}{*}{ RS } \\
\hline & $\mathrm{T}(\mathrm{C})$ & $\mathrm{UR}(\%)$ & Tsolo & RS & $\mathrm{T}(\mathrm{C})$ & $\mathrm{UR}(\%)$ & Tsolo & RS & $\mathrm{T}(\mathrm{C})$ & $\mathrm{UR}(\%)$ & Tsolo & & $\mathrm{T}(\mathrm{C})$ & $\mathrm{UR}(\%)$ & Tsolo & RS & $\mathrm{T}(\mathrm{C})$ & $\mathrm{UR}(\%)$ & Tsolo & RS & $\mathrm{T}(\mathrm{C})$ & $\mathrm{UR}(\%)$ & Tsolo & \\
\hline $08: 00$ & $\overline{18,0}$ & 80,7 & 17,0 & 336,0 & 20,5 & 99,2 & 18,8 & 152,6 & 19,3 & 93,1 & 18,1 & 63,0 & 18,4 & $\overline{95,2}$ & 18,2 & 237,1 & 19,1 & 89,1 & $\overline{18,2}$ & 155,0 & 18,6 & $\overline{90,5}$ & 17,8 & $\overline{217,3}$ \\
\hline 09:00 & 20,7 & 73,6 & 17,6 & 480,3 & 28,7 & 85,7 & 19,4 & 348,8 & 25,2 & 78,5 & 18,9 & 303,8 & 23,6 & 86,2 & 18,7 & 331,5 & 23,8 & 77,9 & 18,8 & 361,0 & 23,4 & 77,9 & 18,4 & 379,6 \\
\hline 10:00 & 22,4 & 66,3 & 18,4 & 658,1 & 33,1 & 78,4 & 20,6 & 522,7 & 27,4 & 75,0 & 20,3 & 424,2 & 26,2 & 72,4 & 19,7 & 507,7 & 25,9 & 69,3 & 19,7 & 559,9 & 25,8 & 67,7 & 19,5 & 637,4 \\
\hline 11:00 & 23,4 & 61,9 & 19,3 & 688,4 & 33,9 & 80,7 & 22,2 & 622,5 & 30,1 & 69,1 & 22,0 & 459,8 & 27,9 & 59,8 & 20,9 & 562,3 & 28,2 & 68,6 & 20,9 & 577,9 & 27,1 & 61,8 & 20,8 & 587,5 \\
\hline 12:00 & 23,8 & 60,1 & 20,3 & 226,9 & 34,6 & 75,6 & 23,7 & 277,1 & 29,6 & 62,9 & 23,3 & 216,0 & 29,1 & 63,7 & 22,2 & 176,2 & 27,9 & 66,2 & 22,2 & 281,7 & 28,2 & 62,3 & 22,2 & 207,9 \\
\hline 13:00 & 21,6 & 72,3 & 20,6 & 24,0 & 27,1 & 87,0 & 24,5 & 27,6 & 24,1 & 84,6 & 23,8 & 22,7 & 24,6 & 81,3 & 22,8 & 9, & 23,4 & 84,1 & 22,8 & 29,5 & 23,6 & 81,2 & 22,8 & 23,1 \\
\hline 14:00 & 18,2 & 92,3 & 20,5 & 34,0 & 22,5 & 96,2 & 24,3 & 37,8 & 20,2 & 95,5 & 23,3 & 14,0 & 20,3 & 95,7 & 22,7 & 7,4 & 19,8 & 97,2 & 22,7 & 38,2 & 19,7 & 95,6 & 22,6 & 64,3 \\
\hline 15:00 & 18,0 & 91,4 & 20,3 & 146,9 & 23,1 & 95,7 & 23,9 & 130,3 & 20,9 & 94,8 & 22,8 & 123,5 & 20,4 & 97,0 & 22,3 & 101,8 & 20,1 & 95,5 & 22,4 & 144,0 & 19,8 & 95,1 & 22,2 & 135,5 \\
\hline $16: 00$ & 19,0 & 90,0 & 20,1 & 58,0 & 24,1 & 92,4 & 23,7 & 30,5 & 22,1 & 91,2 & 22,6 & 15,0 & 21,9 & 94,8 & 22,1 & 31,3 & 21,3 & 92,0 & 22,2 & 33,0 & 21,2 & 91,9 & 22,0 & 61,2 \\
\hline $17: 00$ & 18,1 & 95,7 & 20,0 & 21,4 & 21,9 & 96,7 & 23,4 & 20,8 & 20,4 & 95,6 & 22,3 & 12,9 & 20,7 & 97,4 & 22,0 & 2,3 & 20,1 & 97,0 & 22,0 & 24,3 & 19,8 & 97,3 & 21,8 & 35,0 \\
\hline 18:00 & 17,4 & 96,6 & 19,9 & 1,9 & 20,3 & 97,8 & 23,1 & 5,3 & 19,0 & 96,6 & 22,0 & 8,8 & 19,3 & 97,5 & 21,8 & 4,5 & 19,0 & 97,7 & 21,8 & 8,1 & 18,6 & 97,8 & 21,5 & 13,7 \\
\hline
\end{tabular}

DIA DE COLETA DE DADOS:

25/Ago

\begin{tabular}{|c|c|c|c|c|c|c|c|c|c|c|c|c|c|c|c|c|c|c|c|c|c|c|c|c|}
\hline \multirow[b]{2}{*}{ HORA } & \multicolumn{4}{|c|}{ TESTE MUNHA } & \multicolumn{4}{|c|}{$0 \%$} & \multicolumn{3}{|c|}{$5 \%$} & \multirow[b]{2}{*}{ RS } & \multicolumn{3}{|c|}{$10 \%$} & \multirow[b]{2}{*}{ RS } & \multicolumn{3}{|c|}{$15 \%$} & \multirow[b]{2}{*}{ RS } & \multicolumn{3}{|c|}{$20 \%$} & \multirow[b]{2}{*}{ RS } \\
\hline & $\mathrm{T}(\mathrm{C})$ & $\mathrm{UR}(\%)$ & Tsolo & RS & $\mathrm{T}(\mathrm{C})$ & $\mathrm{UR}(\%)$ & Tsolo & RS & $\mathrm{T}(\mathrm{C})$ & $\mathrm{UR}(\%)$ & Tsolo & & $\mathrm{T}(\mathrm{C})$ & $\mathrm{UR}(\%)$ & Tsolo & & $\mathrm{T}(\mathrm{C})$ & UR(\%) & Tsolo & & $\mathrm{T}(\mathrm{C})$ & $\mathrm{UR}(\%)$ & Tsolo & \\
\hline $08: 00$ & 16,9 & 88,6 & 16,8 & 264,8 & 21,8 & 92,8 & 18,9 & 158,9 & 19,9 & 96,9 & 18,4 & 119,4 & 19,3 & 91,6 & 18,5 & 130,8 & 19,9 & 89,0 & 18,5 & 131,9 & 19,3 & 88,7 & 18,0 & $\overline{174,2}$ \\
\hline 09:00 & 20,3 & 78,9 & 17,5 & 477,2 & 29,0 & 82,0 & 19,5 & 272,8 & 26,5 & 77,3 & 19,3 & 272,3 & 23,8 & 84,4 & 19,0 & 326,3 & 24,0 & 83,9 & 19,0 & 249,3 & 23,4 & 83,0 & 18,6 & 304,0 \\
\hline 10:00 & 23,5 & 68,0 & 18,7 & 643,6 & 34,5 & 76,4 & 20,7 & 407,9 & 31,0 & 66,3 & 20,7 & 354,4 & 27,7 & 78,4 & 19,9 & 590,7 & 28,0 & 74,1 & 20,0 & 383,5 & 27,3 & 77,9 & 19,7 & 475,7 \\
\hline 11:00 & 24,9 & 59,2 & 20,3 & 752,7 & 37,6 & 80,8 & 22,5 & 485,4 & 33,5 & 63,0 & 22,8 & 456,2 & 30,8 & 67,5 & 21,5 & 442,3 & 30,3 & 66,5 & 21,5 & 613,2 & 29,9 & 67,5 & 21,3 & 654,9 \\
\hline 12:00 & 27,4 & 50,7 & 22,0 & 789,2 & 41,1 & 73,7 & 24,4 & 754,3 & 35,1 & 63,6 & 24,9 & 469,7 & 33,1 & 56,4 & 23,5 & 542,4 & 32,4 & 62,7 & 23,4 & 642,7 & 32,9 & 56,0 & 23,1 & 675,5 \\
\hline 13:00 & 28,7 & 44,8 & 23,3 & 758,3 & 42,5 & 71,4 & 26,4 & 624,0 & 36,4 & 58,0 & 26,8 & 449,0 & 34,7 & 60,4 & 25,4 & 537,3 & 34,1 & 53,8 & 25,3 & 671,0 & 33,9 & 56,6 & 24,9 & 711,7 \\
\hline $14: 00$ & 29,0 & 41,6 & 23,9 & 667,6 & 43,1 & 71,5 & 28,1 & 534,8 & 37,4 & 55,2 & 27,9 & 382,3 & 35,4 & 53,5 & 26,4 & 541,8 & 35,2 & 51,5 & 26,5 & 536,2 & 34,2 & 45,7 & 26,2 & 648,0 \\
\hline 15:00 & 29,6 & 40,3 & 24,0 & 502,4 & 42,8 & 74,0 & 29,4 & 364,8 & 37,5 & 59,2 & 28,3 & 281,6 & 35,7 & 54,1 & 26,9 & 349,1 & 35,0 & 54,7 & 27,1 & 396,8 & 34,5 & 48,1 & 27,0 & 398,9 \\
\hline $16: 00$ & 29,6 & 38,1 & 24,0 & 310,8 & 39,5 & 79,7 & 30,2 & 135,2 & 36,1 & 55,8 & 28,3 & 151,4 & 34,1 & 59,9 & 27,2 & 282,0 & 34,0 & 50,9 & 27,3 & 216,3 & 32,9 & 52,0 & 27,3 & 325,9 \\
\hline 17:00 & 28,6 & 46,5 & 23,8 & 44,8 & 33,9 & 84,4 & 30,4 & 51,4 & 30,7 & 70,1 & 27,7 & 30,5 & 30,9 & 66,9 & 26,9 & 64,2 & 30,1 & 65,3 & 27,1 & 68,3 & 30,1 & 60,3 & 27,1 & 101,1 \\
\hline 18:00 & 21,9 & 69,7 & 23,3 & 1,3 & 26,9 & 96,3 & 29,7 & 3,4 & 22,3 & 95,2 & 26,9 & 15,0 & 22,9 & 88,3 & 26,2 & 3,4 & 22,1 & 92,2 & 26,4 & 6,9 & 22,1 & 87,8 & 26,4 & 12,5 \\
\hline
\end{tabular}


DIA DE COLETA DE DADOS:

26/Ago

\begin{tabular}{|c|c|c|c|c|c|c|c|c|c|c|c|c|c|c|c|c|c|c|c|c|c|c|c|c|}
\hline \multirow[b]{2}{*}{ HORA } & \multicolumn{4}{|c|}{ TESTE MUNHA } & \multicolumn{4}{|c|}{$0 \%$} & \multicolumn{3}{|c|}{$5 \%$} & \multirow[b]{2}{*}{ RS } & \multicolumn{4}{|c|}{$10 \%$} & \multicolumn{4}{|c|}{$15 \%$} & \multicolumn{4}{|c|}{$20 \%$} \\
\hline & $\mathrm{T}(\mathrm{C})$ & UR(\%) & Tsolo & RS & $\mathrm{T}(\mathrm{C})$ & $\mathrm{UR}(\%)$ & Tsolo & RS & $\mathrm{T}(\mathrm{C})$ & $\mathrm{UR}(\%)$ & Tsolo & & $\mathrm{T}(\mathrm{C})$ & $\mathrm{UR}(\%)$ & Tsolo & RS & $\mathrm{T}(\mathrm{C})$ & $\mathrm{UR}(\%)$ & Tsolo & RS & $\mathrm{T}(\mathrm{C})$ & $\mathrm{UR}(\%)$ & Tsolo & RS \\
\hline 08:00 & 16,9 & 85,2 & 18,4 & 132,4 & 19,7 & 99,0 & 21,4 & 115,3 & 17,9 & $\overline{92,3}$ & 20,2 & 57,9 & 18,0 & $\overline{89,2}$ & 20,1 & 25,0 & $\overline{17,9}$ & $\overline{90,0}$ & 20,0 & 121,5 & 17,7 & $\overline{90,2}$ & 19,7 & $\overline{125,5}$ \\
\hline 09:00 & 19,6 & 74,6 & 18,7 & 273,0 & 25,8 & 90,6 & 21,7 & 164,7 & 22,5 & 78,2 & 20,6 & 139,0 & 23,2 & 75,6 & 20,3 & 209,2 & 22,1 & 76,4 & 20,3 & 171,8 & 22,6 & 77,0 & 19,9 & 247,9 \\
\hline 10:00 & 20,8 & 70,1 & 18,9 & 291,2 & 25,9 & 91,9 & 22,2 & 234,0 & 24,0 & 77,0 & 21,2 & 210,3 & 23,8 & 77,3 & 20,8 & 234,2 & 23,4 & 72,6 & 20,7 & 244,7 & 23,1 & 78,9 & 20,5 & 262,8 \\
\hline 11:00 & 24,5 & 58,2 & 19,5 & 736,9 & 36,1 & 82,0 & 23,1 & 620,6 & 33,6 & 62,9 & 22,0 & 453,6 & 31,9 & 56,6 & 21,4 & 614,6 & 30,8 & 61,9 & 21,4 & 590,0 & 30,6 & 58,4 & 21,2 & 658,0 \\
\hline $12: 00$ & 24,3 & 57, & 20,9 & 332,8 & 35,1 & 75,3 & 24,5 & 18 , & 31,0 & 61, & 23,7 & 257 & 30,6 & 58,0 & 22,6 & 253,0 & 29,3 & 63,5 & 22,6 & 316,4 & 29,2 & 54,9 & 22,6 & 295,3 \\
\hline 13:00 & 26,3 & 54,0 & 21,6 & 399,7 & 40,2 & 73,1 & 26,0 & 272,3 & 36,3 & 53,5 & 24,9 & 210,8 & 34,7 & 54,7 & 23,7 & 318,4 & 32,6 & 57,3 & 23,7 & 275,9 & 32,8 & 52,2 & 23,7 & 362,1 \\
\hline 14:00 & 26,2 & 52,5 & 22,2 & 412,3 & 34,8 & 85,2 & 26,8 & 452,5 & 31,8 & 70,8 & 25,4 & 331,7 & 30,3 & 62,6 & 24,3 & 325,2 & 30,1 & 60,9 & 24,3 & 437,9 & 29,2 & 61,9 & 24,3 & 367,1 \\
\hline $15: 00$ & 26,5 & 53,8 & 22,5 & 313,9 & 36,7 & 66,9 & 27,5 & 299,9 & 32,9 & 53,2 & 25,8 & 232,5 & 32,0 & 63,0 & 24,7 & 242,2 & 30,4 & 52,7 & 24,8 & 316,4 & 30,4 & 53,3 & 24,7 & 279,7 \\
\hline $16: 00$ & 25,8 & 54,4 & 22,6 & 220,0 & 32,3 & 84,7 & 27,8 & 181,7 & 29,1 & 69,9 & 25,9 & 144,7 & 28,6 & 64,2 & 25,1 & 170,0 & 28,2 & 65,7 & 25,0 & 192,6 & 27,6 & 56,6 & 24,9 & 209,1 \\
\hline $17: 00$ & 24,9 & 57,1 & 22,5 & 86,4 & 28,7 & 85,4 & 27,7 & 80,9 & 25,7 & 72,0 & 25,6 & 64,1 & 26,2 & 69,7 & 24,9 & 65,4 & 25,4 & 68,0 & 24,9 & 85,6 & 25,4 & 65,4 & 24,8 & 104,9 \\
\hline $18: 00$ & 21,5 & 73,1 & 22,1 & 1,3 & 24,8 & 96,3 & 27,1 & 8,7 & 21,5 & 94,1 & 25,1 & 6,2 & 22,5 & 89,0 & 24,5 & 6,3 & 21,9 & 89,5 & 24,5 & 9,8 & 21,8 & 88,5 & 24,4 & 16,9 \\
\hline
\end{tabular}

DIA DE COLETA DE DADOS:

$27 / \mathrm{Ago}$

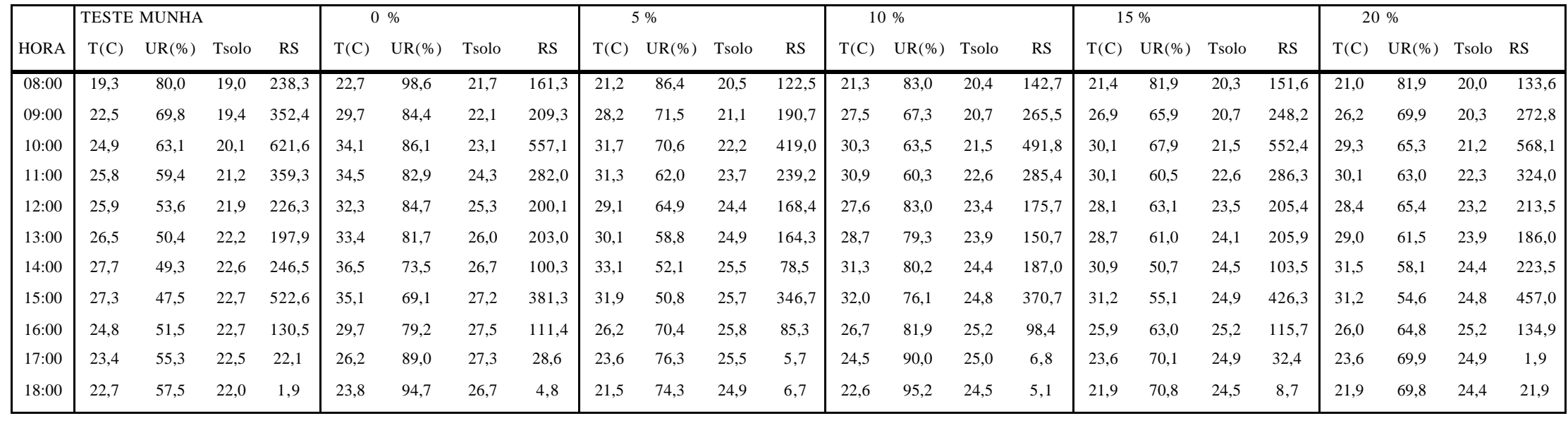


DIA DE COLETA DE DADOS:

28/Ago

\begin{tabular}{|c|c|c|c|c|c|c|c|c|c|c|c|c|c|c|c|c|c|c|c|c|c|c|c|c|}
\hline \multirow[b]{2}{*}{ HORA } & \multicolumn{4}{|c|}{ TESTE MUNHA } & \multicolumn{4}{|c|}{$0 \%$} & \multicolumn{3}{|c|}{$5 \%$} & \multirow[b]{2}{*}{ RS } & \multicolumn{4}{|c|}{$10 \%$} & \multicolumn{4}{|c|}{$15 \%$} & \multicolumn{3}{|c|}{$20 \%$} & \multirow[b]{2}{*}{ RS } \\
\hline & $\mathrm{T}(\mathrm{C})$ & UR(\%) & Tsolc & RS & $\mathrm{T}(\mathrm{C})$ & UR $(\%)$ & Tsolo & RS & $\mathrm{T}(\mathrm{C})$ & $\mathrm{UR}(\%)$ & Tsolo & & $\mathrm{T}(\mathrm{C})$ & $\mathrm{UR}(\%)$ & Tsolo & RS & $\mathrm{T}(\mathrm{C})$ & UR $(\%)$ & Tsolo & RS & $\mathrm{T}(\mathrm{C})$ & $\mathrm{UR}(\%)$ & Tsolo & \\
\hline$\overline{08: 00}$ & 18, & 89,7 & $\overline{19,2}$ & 56,7 & $\overline{, 2}$ & 98,8 & 21,7 & 56,7 & 18,8 & 95,0 & 2 & 22,7 & $\overline{16}$ & $\overline{7,8}$ & 20,6 & 3,4 & $\overline{19,0}$ & $\overline{3,3}$ & 20,5 & $\overline{3,1}$ & 18,7 & $\overline{93,1}$ & 20,2 & $\overline{62,4}$ \\
\hline 09:00 & 19,3 & 83,1 & 19,3 & 247,1 & 23,5 & 97,8 & 21,8 & 197,7 & 22,4 & 90,1 & 20, & 144,2 & 22,1 & 91,9 & 20,7 & 192,7 & 22,1 & 86,1 & 20,6 & 207 & 21,5 & 85,4 & 20,3 & 188,5 \\
\hline 10:00 & 21,6 & 76,5 & 19,7 & 677,0 & 29,9 & 92,4 & 22,2 & 535,3 & 27,5 & 79,8 & 21,2 & 499,1 & 23,7 & 90,0 & 21,0 & 519,6 & 26,0 & 75,0 & 21,0 & 572 & 24,9 & 78,6 & 20,7 & 577,5 \\
\hline $11: 00$ & 24,7 & 65,7 & 20,5 & 706,7 & 38,6 & 79,1 & 23,4 & 618,7 & 32,1 & 70,7 & 22,5 & 500,1 & 29,3 & 81,4 & 21,9 & 555,4 & 30,7 & 70,9 & 22,0 & 646 , & 31,0 & 64,7 & 21,7 & 614,9 \\
\hline $12: 00$ & 25,8 & 63,1 & 21,6 & 455,8 & 37,8 & 76,3 & 25,0 & 374,0 & 31,9 & 60,9 & 24,0 & 295,0 & 31,2 & 76,4 & 23,1 & 354,2 & 30,4 & 60,4 & 23,1 & 367, & 30,6 & 66,8 & 23,1 & 400,8 \\
\hline 13:00 & 27,1 & 53,3 & 22,3 & 562,9 & 40,1 & 70,3 & 26,4 & 464,6 & 35,4 & 49,3 & 25,0 & 361,2 & 32,5 & 73,9 & 24,0 & 440,6 & 32,9 & 52,7 & 24,1 & 452 & 32,5 & 59,8 & 24,0 & 490,1 \\
\hline $14: 00$ & 27,5 & 54,7 & 22,8 & 442,5 & 38,7 & 79,3 & 27,5 & 316 , & 34,6 & 61,0 & 25,7 & 247,0 & 30,9 & 82,4 & 24,7 & 320,6 & 32,4 & 52,5 & 24,8 & 328, & 31,7 & 63,1 & 24,7 & 371,5 \\
\hline $15: 00$ & 27,9 & 48,2 & 23,2 & 520,7 & 36,8 & 79,7 & 28,3 & 391,0 & 33,2 & 57,5 & 26,1 & 296,1 & 31,5 & 60,5 & 25,3 & 342,8 & 31,9 & 51,9 & 25,2 & 45 & 30,4 & 62,6 & 25,2 & 495,1 \\
\hline 16:00 & 29,1 & 39,7 & 23,4 & 450,1 & 38,1 & 73,4 & 28, & 297,0 & 35,2 & 45,7 & 26,4 & 249,6 & 34,0 & 57,4 & 25 & 312,7 & 33 , & 42,8 & 2 & 36 & 32,3 & 50,3 & 25,5 & 360,2 \\
\hline $17: 00$ & 27,6 & 48,2 & 23,6 & 73,1 & 33,0 & 77,5 & 29,1 & 52,8 & 29,9 & 57,3 & 26,5 & 34,6 & 30,9 & 50,7 & 26,0 & 57,4 & 28,7 & 57,9 & 26,0 & 59 & 29,7 & 53,0 & 25,7 & 88,0 \\
\hline 18:00 & 24,6 & 62,7 & 23,3 & 1,9 & 26,0 & 91,7 & 28,6 & 10,7 & 24,2 & 72,0 & 26,1 & 8,8 & 24,7 & 71,5 & 25,8 & 4,0 & 24,3 & 73,7 & 25,6 & 16,2 & 24,2 & 71,8 & 25,5 & 1,9 \\
\hline
\end{tabular}

DIA DE COLETA DE DADOS:

29/Ago

\begin{tabular}{|c|c|c|c|c|c|c|c|c|c|c|c|c|c|c|c|c|c|c|c|c|c|c|c|c|}
\hline \multirow[b]{2}{*}{ HORA } & \multicolumn{4}{|c|}{ TESTE MUNHA } & \multicolumn{4}{|c|}{$0 \%$} & \multicolumn{3}{|c|}{$5 \%$} & \multirow[b]{2}{*}{ RS } & \multicolumn{3}{|c|}{$10 \%$} & \multirow[b]{2}{*}{ RS } & \multicolumn{3}{|c|}{$15 \%$} & \multirow[b]{2}{*}{ RS } & \multicolumn{3}{|c|}{$20 \%$} & \multirow[b]{2}{*}{ RS } \\
\hline & $\mathrm{T}(\mathrm{C})$ & UR(\%) & Tsolo & RS & $\mathrm{T}(\mathrm{C})$ & $\mathrm{UR}(\%)$ & Tsolo & RS & $\mathrm{T}(\mathrm{C})$ & $\mathrm{UR}(\%)$ & Tsolo & & $\mathrm{T}(\mathrm{C})$ & $\mathrm{UR}(\%)$ & Tsolo & & $\mathrm{T}(\mathrm{C})$ & $\mathrm{UR}(\%)$ & Tsolo & & $\mathrm{T}(\mathrm{C})$ & $\mathrm{UR}(\%)$ & Tsolo & \\
\hline 08:00 & 18,1 & 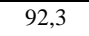 & 19,4 & 108,4 & , & ול, & $2, \pi$ & 0,1 & 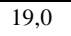 & 98,4 & 21,1 & 30,0 & 19,0 & 98,8 & 20,9 & 10,8 & 19,1 & 97,7 & 20,7 & 93,1 & ro, & 97,9 & 20,7 & 96,1 \\
\hline 09:00 & 18,7 & 91,1 & 19,5 & 66,2 & 22,0 & 97,8 & 22,5 & 46,0 & 19,7 & 97,0 & 21,3 & 6,7 & 20,2 & 97,4 & 20,9 & 3,4 & 19,7 & 96,8 & 20,9 & 50,3 & 19,7 & 97,2 & 20,8 & 69,9 \\
\hline 10:00 & 19,6 & 87,8 & 19,7 & 122,9 & 22,5 & 98,4 & 22,6 & 100,3 & 20,5 & 95,9 & 21,4 & 36,7 & 20,7 & 97,5 & 21,0 & 33,5 & 20,4 & 94,4 & 21,0 & 104,7 & 20,3 & 97,0 & 20,9 & 118,6 \\
\hline $11: 00$ & 20,4 & 83,9 & 19,9 & 245,8 & 25,3 & 96,7 & 22,8 & 263,6 & 22,7 & 93,5 & 21,6 & 236,1 & 22,1 & 93,5 & 21,2 & 166,0 & 22,0 & 89,8 & 21,2 & 279,4 & 21,5 & 94,5 & 21,1 & 177,3 \\
\hline $12: 00$ & 22,1 & 78,6 & 20,4 & 341,7 & 31,3 & 85,0 & 23,5 & 274,7 & 24,9 & 84,0 & 22,2 & 261,4 & 26,3 & 83,7 & 21,6 & 250,2 & 24,7 & 82,8 & 21,7 & 311,2 & 24,7 & 89,1 & 21,5 & 297,8 \\
\hline 13:00 & 23,6 & 71,3 & 21,1 & 477,2 & 34,1 & 85,9 & 24,4 & 516,0 & 28,7 & 79,5 & 23,0 & 420,6 & 28,5 & 77,9 & 22,2 & 357,0 & 28,1 & 73,2 & 22,4 & 537,4 & 26,9 & 76,8 & 22,2 & 427,7 \\
\hline 14:00 & 24,6 & 63,1 & 21,7 & 455,1 & 38,0 & 75,4 & 25,6 & 443,8 & 31,3 & 70,8 & 23,9 & 334,3 & 30,9 & 61,5 & 23,0 & 343,4 & 29,6 & 66,3 & 23,3 & 427,5 & 29,3 & 66,3 & 23,1 & 406,4 \\
\hline $15: 00$ & 23,8 & 70,6 & 22,3 & 189,1 & 32,5 & 82,8 & 26,6 & 153,1 & 26,7 & 83,1 & 24,7 & 123,0 & 27,1 & 75,0 & 23,7 & 143,3 & 26,3 & 74,7 & 23,9 & 157,9 & 26,4 & 73,0 & 23,8 & 182,3 \\
\hline $16: 00$ & 23,5 & 71,9 & 22,3 & 167,1 & 29,9 & 83,4 & 27,0 & 127,9 & 24,9 & 83,0 & 24,8 & 104,9 & 25,6 & 76,3 & 23,9 & 126,2 & 24,7 & 78,4 & 24,1 & 130,7 & 25,1 & 78,0 & 24,0 & 169,2 \\
\hline 17:00 & 22,7 & 72,0 & 22,1 & 58,6 & 26,5 & 91,3 & 26,8 & 52,3 & 23,0 & 85,6 & 24,6 & 58,9 & 23,7 & 77,8 & 23,8 & 44,9 & 23,1 & 81,5 & 23,9 & 55,5 & 23,2 & 79,6 & 23,9 & 79,9 \\
\hline 18:00 & 21,3 & 80,9 & 21,9 & 3,2 & 24,0 & 96,3 & 26,4 & 6,8 & 21,4 & 93,9 & 24,2 & 5,7 & 22,0 & 90,5 & 23,5 & 4,5 & 21,5 & 90,9 & 23,6 & 10,4 & 21,5 & 89,8 & 23,6 & 26,8 \\
\hline
\end{tabular}


DIA DE COLETA DE DADOS:

30/Ago

\begin{tabular}{|c|c|c|c|c|c|c|c|c|c|c|c|c|c|c|c|c|c|c|c|c|c|c|c|c|}
\hline \multirow[b]{2}{*}{ HORA } & \multicolumn{4}{|c|}{ TESTE MUNHA } & \multicolumn{4}{|c|}{$0 \%$} & \multicolumn{4}{|c|}{$5 \%$} & \multicolumn{4}{|c|}{$10 \%$} & \multicolumn{4}{|c|}{$15 \%$} & \multicolumn{4}{|c|}{$20 \%$} \\
\hline & $\mathrm{T}(\mathrm{C})$ & UR(\%) & Tsolo & RS & $\mathrm{T}(\mathrm{C})$ & $\mathrm{UR}(\%)$ & Tsolo & RS & $\mathrm{T}(\mathrm{C})$ & $\mathrm{UR}(\%)$ & Tsolo & RS & $\mathrm{T}(\mathrm{C})$ & $\mathrm{UR}(\%)$ & Tsolo & RS & $\mathrm{T}(\mathrm{C})$ & $\mathrm{UR}(\%)$ & Tsolo & RS & $\mathrm{T}(\mathrm{C}$ & $\mathrm{UR}(\%)$ & Tsolo & RS \\
\hline$\overline{08: 00}$ & 19, & 82,3 & 18,4 & 299,4 & 8.8 & 95,6 & 21,2 & 164,2 & 20,8 & 95,6 & 20,1 & 170,5 & 20,7 & $\overline{6,4}$ & 19,9 & 193,9 & $\overline{, 7}$ & $\overline{87,2}$ & 19,9 & 175, & 20,8 & 36,4 & 19,7 & $\overline{174,2}$ \\
\hline 09:00 & 21,8 & 74,7 & 18,8 & 483,5 & 32,0 & 87,2 & 21,7 & 284,4 & 28,7 & 77,4 & 20,7 & 304,3 & 27,4 & 75,1 & 20,2 & 253,6 & 26,9 & 78,5 & 20,3 & 256, & 26,2 & 74,5 & 20,0 & 272,2 \\
\hline 10:00 & 24,5 & 61,8 & 19,8 & 700,3 & 36,3 & 70,8 & 22,7 & 477,2 & 31,4 & 62,3 & 21,8 & 431,9 & 30,2 & 64,9 & 20,9 & 432,6 & 29,6 & 61,9 & 21,1 & 461, & 29,5 & 64,8 & 20,8 & 568,7 \\
\hline 11:00 & 26,8 & 56,8 & 21,2 & 769,1 & 40,0 & 73,7 & 24,2 & 613,3 & 33,1 & 65,9 & 23,3 & 481,5 & 32,6 & 63,6 & 22,2 & 614,6 & 31,3 & 64,8 & 22,4 & 616, & 32,1 & 61,9 & 22,1 & 664,9 \\
\hline 12:00 & 27,7 & 56,2 & 22,5 & 806,2 & 41,9 & 75,4 & 25,8 & 631,7 & 35,6 & 63,2 & 24,8 & 483,1 & 34,1 & 63,7 & 23,5 & 629,9 & 32,9 & 61,5 & 23,8 & 631, & 33,6 & 55,5 & 23,5 & 724,8 \\
\hline 13:00 & 29,7 & 49,1 & 23,4 & 788,0 & 44,0 & 76,8 & 27 & 536 & 37,1 & 62,1 & 26,0 & 548, & 35,3 & 59,4 & 24 & 615 & 34 & 56 & 25 & 62 & 34,6 & 61,3 & 24,8 & 688,6 \\
\hline $14: 00$ & 30,7 & 45,9 & 24,0 & 675,8 & 44,0 & 79,3 & 28,7 & 546,0 & 37,4 & 54,3 & 27,0 & 418,0 & 35,8 & 58,6 & 25,4 & 471,9 & 35,3 & 54,1 & 26,0 & 565, & 35,0 & 55,4 & 25,8 & 593,1 \\
\hline $15: 00$ & 30,9 & 42,0 & 24,3 & 528,3 & 42,2 & 75,9 & 29,8 & 31 & 36,2 & 56,5 & 27,4 & 215,5 & 34,8 & 55,8 & 26,1 & 344,0 & 34,2 & 51,9 & 26,4 & 333 & 34,0 & 55,3 & 26,5 & 505,7 \\
\hline 16:00 & 31,0 & 41,9 & 24,3 & 356,8 & 39,8 & 80 , & 30 , & 209 & 35,3 & 64,5 & 27,5 & 177, & 34,2 & 56,8 & 26 & 253,6 & 33 & 5 & 2 & 28 & 3 & 54,4 &, 7 & 296,5 \\
\hline $17: 00$ & 28,5 & 49,0 & 24,2 & 42,2 & 32,6 & 86,3 & 30,4 & 38,8 & 29,1 & 64,6 & 27,3 & 27,4 & 30,3 & 52,9 & 26,3 & 52,3 & 28,6 & 61,6 & 26,4 & 44,0 & 29,0 & 58,8 & 26,6 & 93,6 \\
\hline $18: 00$ & 25,7 & 58,6 & 23,7 & 2,5 & 27,3 & 96,4 & 29,8 & 13,6 & 24,0 & 79,7 & 26,6 & 17,1 & 24,9 & 71,8 & 25,9 & 3,4 & 24,3 & 73,4 & 25,9 & 17,4 & 24,5 & 70,7 & 26,1 & 5,0 \\
\hline
\end{tabular}

DIA DE COLETA DE DADOS:

31/Ago

\begin{tabular}{|c|c|c|c|c|c|c|c|c|c|c|c|c|c|c|c|c|c|c|c|c|c|c|c|c|}
\hline \multirow[b]{2}{*}{ HORA } & \multicolumn{4}{|c|}{ TESTE MUNHA } & \multicolumn{4}{|c|}{$0 \%$} & \multicolumn{3}{|c|}{$5 \%$} & \multirow[b]{2}{*}{ RS } & \multicolumn{3}{|c|}{$10 \%$} & \multirow[b]{2}{*}{ RS } & \multicolumn{3}{|c|}{$15 \%$} & \multirow[b]{2}{*}{ RS } & \multicolumn{3}{|c|}{$20 \%$} & \multirow[b]{2}{*}{ RS } \\
\hline & $\mathrm{T}(\mathrm{C})$ & $\mathrm{UR}(\%)$ & Tsolo & RS & $\mathrm{T}(\mathrm{C})$ & $\mathrm{UR}(\%)$ & Tsolo & RS & $\mathrm{T}(\mathrm{C})$ & $\mathrm{UR}(\%)$ & Tsolo & & $\mathrm{T}(\mathrm{C})$ & $\mathrm{UR}(\%)$ & Tsolo & & $\mathrm{T}(\mathrm{C})$ & $\mathrm{UR}(\%)$ & Tsolo & & $\mathrm{T}(\mathrm{C})$ & $\mathrm{UR}(\%)$ & Tsolo & \\
\hline $08: 00$ & 20,8 & 78,2 & 19,2 & 292,5 & 25,8 & 98,4 & 22,4 & 157,0 & 22,7 & 92,3 & 20,7 & 169,0 & 22,6 & 85,3 & 20,5 & 163,7 & 22,9 & 81,7 & 20,5 & 166,0 & 20,2 & 83,6 & 20,5 & 161,7 \\
\hline 09:00 & 23,2 & 63,6 & 19,5 & 495,5 & 32,5 & 85,7 & 22,9 & 285,4 & 29,0 & 69,9 & 21,2 & 300,7 & 28,1 & 66,9 & 20,9 & 427,0 & 27,9 & 65,6 & 20,9 & 321,0 & 20,6 & 65,6 & 20,9 & 390,2 \\
\hline 10:00 & 26,4 & 52,2 & 20,5 & 668,8 & 37,4 & 83,1 & 23,9 & 503,4 & 33,1 & 64,6 & 22,4 & 401,5 & 31,9 & 61,9 & 21,7 & 475,9 & 31,0 & 61,2 & 21,8 & 526,4 & 21,4 & 63,4 & 21,7 & 594,3 \\
\hline $11: 00$ & 28,1 & 49,0 & 21,6 & 773,5 & 41,5 & 77,0 & 25,2 & 590,6 & 35,9 & 59,7 & 23,9 & 499,1 & 34,2 & 56,3 & 22,7 & 574,2 & 32,6 & 54,2 & 22,8 & 646,7 & 22,4 & 54,2 & 22,7 & 678,6 \\
\hline 12:00 & 30,3 & 44,7 & 22,8 & 794,3 & 45,3 & 73,9 & 26,8 & 610,9 & 38,7 & 54,4 & 25,2 & 497,0 & 36,4 & 48,0 & 23,8 & 621,4 & 35,4 & 54,8 & 24,0 & 632,3 & 23,7 & 48,6 & 23,8 & 734,8 \\
\hline 13:00 & 31,0 & 43,3 & 24,3 & 781,0 & 46,4 & 78,2 & 28,5 & 628,8 & 40,4 & 61,6 & 27,0 & 473,8 & 38,1 & 51,5 & 25,2 & 617,4 & 37,0 & 58,1 & 25,6 & 624,2 & 25,0 & 46,3 & 25,2 & 677,4 \\
\hline $14: 00$ & 32,0 & 39,6 & 25,5 & 719,3 & 47,3 & 71,4 & 30,0 & 163,3 & 39,6 & 49,6 & 28,3 & 138,5 & 38,9 & 52,4 & 26,5 & 536,1 & 37,1 & 46,0 & 26,9 & 170,6 & 26,3 & 48,2 & 26,5 & 618,7 \\
\hline $15: 00$ & 31,5 & 37,1 & 25,8 & 498,6 & 42,2 & 85,0 & 31,1 & 408,4 & 37,9 & 61,0 & 28,5 & 315,2 & 35,1 & 47,6 & 27,1 & 345,7 & 35,2 & 46,3 & 27,4 & 406,1 & 27,0 & 44,3 & 27,1 & 510,1 \\
\hline $16: 00$ & 30,8 & 39,2 & 25,5 & 304,5 & 39,3 & 81,3 & 31,5 & 194,8 & 36,2 & 43,6 & 28,3 & 158,1 & 34,6 & 56,6 & 27,1 & 205,2 & 34,0 & 54,6 & 27,3 & 236,0 & 27,1 & 49,0 & 27,1 & 246,6 \\
\hline $17: 00$ & 30,9 & 35,4 & 25,1 & 55,5 & 35,7 & 86,8 & 31,5 & 60,1 & 33,1 & 65,8 & 27,9 & 35,1 & 33,1 & 58,2 & 26,9 & 73,3 & 31,4 & 46,5 & 27,1 & 74,0 & 26,8 & 52,2 & 26,9 & 113,0 \\
\hline 18:00 & 25,1 & 60,7 & 24,8 & 1,9 & 28,6 & 95,9 & 31,1 & 7,8 & 23,7 & 91,8 & 27,3 & 23,3 & 24,8 & 76,9 & 26,5 & 2,3 & 23,8 & 76,4 & 26,6 & 11,6 & 26,4 & 73,9 & 26,5 & 18,7 \\
\hline
\end{tabular}


DIA DE COLETA DE DADOS:

$01 /$ Set

\begin{tabular}{|c|c|c|c|c|c|c|c|c|c|c|c|c|c|c|c|c|c|c|c|c|c|c|c|c|}
\hline \multirow[b]{2}{*}{ HORA } & \multicolumn{4}{|c|}{ TESTE MUNHA } & \multicolumn{4}{|c|}{$0 \%$} & \multicolumn{3}{|c|}{$5 \%$} & \multirow[b]{2}{*}{ RS } & \multicolumn{3}{|c|}{$10 \%$} & \multirow[b]{2}{*}{ RS } & \multicolumn{3}{|c|}{$15 \%$} & \multirow[b]{2}{*}{ RS } & \multicolumn{3}{|c|}{$20 \%$} & \multirow[b]{2}{*}{ RS } \\
\hline & $\mathrm{T}(\mathrm{C})$ & UR(\%) & Tsolo & RS & $\mathrm{T}(\mathrm{C})$ & UR(\%) & Tsolo & RS & $\mathrm{T}(\mathrm{C})$ & $\mathrm{UR}(\%)$ & Tsolo & & $\mathrm{T}(\mathrm{C})$ & $\mathrm{UR}(\%)$ & Tsolo & & $\mathrm{T}(\mathrm{C})$ & $\mathrm{UR}(\%)$ & Tsolo & & $\mathrm{T}(\mathrm{C})$ & $\mathrm{UR}(\%)$ & Tsolo & \\
\hline $08: 00$ & 20 & $\overline{79,1}$ & 19,7 & 297,5 & 25,7 & 97,8 & 23,1 & 185, & 22,1 & $\overline{95,3}$ & $\overline{21,4}$ & 162,2 & 2 & 88,0 & 21,2 & 166,0 & 22,0 & 87,5 & 21,0 & 154,5 & 21,8 & $\overline{87,4}$ & 0,7 & 279,7 \\
\hline 09:00 & 23,7 & 65,1 & 20,0 & 508,1 & 33,9 & 86,7 & 23,6 & 235,0 & 31,5 & 70,4 & 21,9 & 295,5 & 28,6 & 73,1 & 21,4 & 261,5 & 28,4 & 62,7 & 21,4 & 311,2 & 27,6 & 68,5 & 21,0 & 305,9 \\
\hline $10: 00$ & 27,4 & 56,2 & 20,9 & 665,0 & 39,5 & 85,2 & 24,7 & 385,6 & 36,1 & 66,3 & 22,9 & 403,0 & 33,5 & 65,4 & 22,0 & 376,4 & 33,0 & 63,5 & 22,1 & 494,0 & 32,5 & 66,7 & 21,8 & 577,5 \\
\hline $11: 00$ & 28,7 & 48,6 & 22,1 & 781,7 & 42,3 & 84,5 & 26,2 & 596,9 & 36,7 & 64,1 & 24,3 & 507,9 & 34,8 & 59,6 & 23,2 & 575,3 & 34,0 & 57,0 & 23,3 & 624,7 & 34,2 & 56,8 & 22,8 & 686,1 \\
\hline $12: 00$ & 30,6 & 43,2 & 23,4 & 817,6 & 46,1 & 71,8 & 27,8 & 678,2 & 38,4 & 49,2 & 25,8 & 519,3 & 37,5 & 58,5 & 24,5 & 646,4 & 35,3 & 47,4 & 24,6 & 639,2 & 36,3 & 52,5 & 24,1 & 714,2 \\
\hline $13: 00$ & 31 , & 39,8 & 24,4 & 852,9 & 46,9 & 80,6 & 29,4 & 22 & 40,9 & 53,3 & 26,8 & 557,0 & 37 , & 45, & 25 & 676,0 & 36,9 & 45,4 & 7 & 699,4 & 36,4 & 55,8 & 25,2 & 754,2 \\
\hline $14: 00$ & 31,8 & 36,3 & 25,0 & 714,2 & 48,1 & 73,0 & 30,6 & 483,0 & 41,4 & 43,9 & 27,7 & 422,1 & 39,5 & 53,3 & 26,2 & 533,3 & 38,0 & 36,0 & 26,5 & 570,9 & 37,1 & 50,5 & 26,2 & 609,3 \\
\hline $15: 00$ & 32,3 & 32,7 & 25,4 & 572,4 & 47,2 & 73,2 & 31,7 & 446,7 & 40,9 & 47,2 & 28,1 & 334,3 & 39,2 & 45,7 & 26,7 & 367,8 & 37,6 & 41,3 & 27,0 & 446,0 & 36,9 & 38,5 & 26,8 & 498,2 \\
\hline $16: 00$ & 31,5 & 34 , & 25,3 & 329,7 & 38,7 & 86 , & 32,0 & 215, & 35,4 & 50,7 & 28,0 & 169,0 & 33 & 50,8 & 26 & 21 & 33,5 & 47,9 & 2 & 277,7 & 32,4 & 46,0 & 9 & 285,3 \\
\hline $17: 00$ & 30,2 & 37,6 & 24,9 & 46,0 & 35,1 & 83,9 & 31,9 & 52,3 & 32,1 & 48,6 & 27,6 & 28,4 & 32,1 & 53,5 & 26,7 & 63,1 & 30,6 & 45,0 & 26,8 & 70,0 & 30,4 & 45,4 & 26,6 & 90,5 \\
\hline $18: 00$ & 24,7 & 55,5 & 24,4 & 1,9 & 27,9 & 96,8 & 31,3 & 7,3 & 23,0 & 89,2 & 26,9 & 21,7 & 24,2 & 74,8 & 26,2 & 2,3 & 23,4 & 67,4 & 26,2 & 11,0 & 23,5 & 72,0 & 26,1 & 19,4 \\
\hline
\end{tabular}

DIA DE COLETA DE DADOS:

02/Set

\begin{tabular}{|c|c|c|c|c|c|c|c|c|c|c|c|c|c|c|c|c|c|c|c|c|c|c|c|c|}
\hline \multirow[b]{2}{*}{ HORA } & \multicolumn{4}{|c|}{ TESTE MUNHA } & \multicolumn{4}{|c|}{$0 \%$} & \multicolumn{3}{|c|}{$5 \%$} & \multirow[b]{2}{*}{ RS } & \multicolumn{3}{|c|}{$10 \%$} & \multirow[b]{2}{*}{ RS } & \multicolumn{3}{|c|}{$15 \%$} & \multirow[b]{2}{*}{ RS } & \multicolumn{3}{|c|}{$20 \%$} & \multirow[b]{2}{*}{ RS } \\
\hline & $\mathrm{T}(\mathrm{C})$ & UR(\%) & Tsolo & RS & $\mathrm{T}(\mathrm{C})$ & $\mathrm{UR}(\%)$ & Tsolo & RS & $\mathrm{T}(\mathrm{C})$ & UR(\%) & Tsolo & & $\mathrm{T}(\mathrm{C})$ & $\mathrm{UR}(\%)$ & Tsolo & & $\mathrm{T}(\mathrm{C})$ & $\mathrm{UR}(\%)$ & Tsolo & & $\mathrm{T}(\mathrm{C})$ & $\mathrm{UR}(\%)$ & Tsolo & \\
\hline 08:00 & 21,5 & 73,6 & $1, r$ & 146,9 & 3 & (2, & 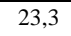 & 161,3 & 23,6 & 98,1 & 21,2 & 168,4 & 23,1 & 86,5 & 21,0 & 60,3 & 23,2 & 82,0 & 20,8 & 162,6 & 2,0 & 84,0 & 20,5 & 26,0 \\
\hline 09:00 & 24,0 & 63,6 & 20,0 & 486,0 & 32,5 & 90,6 & 23,7 & 275,2 & 29,1 & 76,1 & 21,7 & 291,4 & 27,5 & 69,2 & 21,4 & 336,0 & 27,4 & 69,6 & 21,2 & 326,3 & 27,1 & 72,0 & 20,9 & 349,6 \\
\hline $10: 00$ & 26,9 & 47,5 & 21,0 & 666,9 & 38,1 & 85,6 & 24,7 & 532,4 & 33,7 & 69,2 & 22,8 & 421,6 & 31,9 & 56,2 & 22,1 & 472,4 & 31,2 & 61,8 & 22,1 & 505,0 & 30,9 & 57,7 & 21,7 & 579,4 \\
\hline 11:00 & 28,5 & 43,2 & 22,0 & 779,1 & 41,3 & 78,4 & 26,0 & 608,5 & 35,3 & 61,5 & 24,2 & 511,5 & 33,4 & 47,7 & 23,1 & 583,9 & 32,4 & 57,5 & 23,3 & 655,4 & 32,8 & 50,0 & 22,8 & 682,4 \\
\hline 12:00 & 29,5 & 41,4 & 23,1 & 813,2 & 44,1 & 81,8 & 27,5 & 672,0 & 37,3 & 67,7 & 25,4 & 510,5 & 35,8 & 61,9 & 24,1 & 628,2 & 34,3 & 53,3 & 24,3 & 636,3 & 34,7 & 57,6 & 23,9 & 713,6 \\
\hline 13:00 & 30,8 & 38,2 & 23,8 & 769,7 & 47,2 & 75,9 & 29,0 & 631,7 & 40,0 & 58,1 & 26,4 & 489,3 & 38,1 & 57,9 & 25,0 & 610,0 & 36,1 & 42,5 & 25,3 & 610,3 & 36,4 & 42,2 & 25,0 & 671,1 \\
\hline 14:00 & 30,9 & 38,5 & 24,4 & 600,1 & 44,5 & 80,9 & 30,4 & 557,6 & 37,5 & 60,1 & 27,3 & 406,6 & 36,1 & 58,0 & 25,9 & 381,5 & 34,5 & 39,4 & 26,0 & 550,7 & 34,0 & 51,5 & 25,8 & 485,7 \\
\hline 15:00 & 32,0 & 32,2 & 24,7 & 557,3 & 45,2 & 78,4 & 31,4 & 114,3 & 40,0 & 47,5 & 27,5 & 92, & 37,3 & 48,6 & 26,4 & 365,0 & 36,3 & 45,7 & 26,4 & 123,2 & 35,8 & 45,5 & 26,3 & 535,7 \\
\hline 16:00 & 31,0 & 34,1 & 24,7 & 339,8 & 41,8 & 79,8 & 31,9 & 223,3 & 37,3 & 50,4 & 27,5 & 173,6 & 36,2 & 56,8 & 26,6 & 211,5 & 34,1 & 39,6 & 26,5 & 221,6 & 33,6 & 54,9 & 26,5 & 294,7 \\
\hline 17:00 & 30,2 & 38,2 & 24,4 & 67,5 & 36,2 & 82,9 & 31,9 & 62,5 & 32,8 & 45,8 & 27,3 & 38,8 & 32,8 & 53,7 & 26,6 & 74 & 30,7 & 48,2 & 26,4 & 81,6 & 30,9 & 52,4 & 26,4 & 103,0 \\
\hline 18:00 & 26,9 & 44,3 & 24,2 & 2,5 & 28,0 & 95,9 & 31,3 & 9,2 & 24,1 & 67,1 & 26,6 & 26,4 & 25,3 & 58,7 & 26,2 & 2,3 & 24,5 & 58,6 & 25,9 & 13,3 & 24,3 & 60,4 & 26,0 & 20,0 \\
\hline
\end{tabular}


DIA DE COLETA DE DADOS:

$03 /$ Set

\begin{tabular}{|c|c|c|c|c|c|c|c|c|c|c|c|c|c|c|c|c|c|c|c|c|c|c|c|c|}
\hline \multirow[b]{2}{*}{ HORA } & \multicolumn{4}{|c|}{ TESTE MUNHA } & \multicolumn{4}{|c|}{$0 \%$} & \multicolumn{3}{|c|}{$5 \%$} & \multirow[b]{2}{*}{ RS } & \multicolumn{3}{|c|}{$10 \%$} & \multirow[b]{2}{*}{ RS } & \multicolumn{3}{|c|}{$15 \%$} & \multirow[b]{2}{*}{ RS } & \multicolumn{3}{|c|}{$20 \%$} & \multirow[b]{2}{*}{ RS } \\
\hline & $\mathrm{T}(\mathrm{C})$ & UR(\%) & Tsolo & RS & $\mathrm{T}(\mathrm{C})$ & $\mathrm{UR}(\%)$ & Tsolo & RS & $\mathrm{T}(\mathrm{C})$ & $\mathrm{UR}(\%)$ & Tsolo & & $\mathrm{T}(\mathrm{C})$ & $\mathrm{UR}(\%)$ & Tsolo & & $\mathrm{T}(\mathrm{C})$ & $\mathrm{UR}(\%)$ & Tsolo & & $\mathrm{T}(\mathrm{C})$ & $\mathrm{UR}(\%)$ & Tsolo & \\
\hline $08: 00$ & 20 & 65,3 & 19,5 & 70,0 & 26,0 & $\overline{96,2}$ & $\overline{23,3}$ & 155, & 21,9 & $\overline{87,8}$ & 21 & 174,1 & 21,8 & 76,9 & 20 & 191,6 & 22,3 & 76,5 & 20,7 & 177,6 & 22,0 & $\overline{72,8}$ & 20,4 & 231,6 \\
\hline 09:00 & 23,6 & 59,4 & 19,9 & 517,5 & 33,2 & 87,8 & 23,7 & 299,9 & 28,6 & 75,6 & 21,6 & 329,6 & 28,4 & 53,8 & 21,2 & 415,0 & 27,1 & 65,1 & 20,9 & 366,2 & 27,3 & 68,5 & 20,7 & 403,9 \\
\hline $10: 00$ & 27,5 & 44,2 & 20,6 & 692,2 & 39,1 & 81,4 & 24,7 & 562,0 & 33,7 & 62,1 & 22,5 & 410,2 & 32,5 & 52,4 & 21,8 & 483,2 & 31,2 & 57,3 & 21,6 & 514,8 & 30,8 & 52,6 & 21,4 & 618,7 \\
\hline $11: 00$ & 29,6 & 39,7 & 21,6 & 784,8 & 43,4 & 74,8 & 26,1 & 635,6 & 36,7 & 56,3 & 23,6 & 505,3 & 34,7 & 47,9 & 22,7 & 589,6 & 33,1 & 58,5 & 22,6 & 662,9 & 33,9 & 56,4 & 22,4 & 684,9 \\
\hline $12: 00$ & 30,3 & 33,9 & 22,6 & 828,3 & 46,8 & 75,8 & 27,7 & 677,3 & 38,9 & 45,4 & 24,9 & 518,7 & 36,4 & 46,5 & 23,7 & 646,4 & 35,2 & 48,7 & 23,7 & 627,0 & 35,3 & 46,9 & 23,6 & 729,2 \\
\hline $13: 00$ & 31 , & 35,0 & 23,6 & 801,8 & 47,6 & 76,9 & 29,4 & 636,1 & 40,3 & 46,6 & 26 , & 528,0 & 38 & 51,5 & 24 & 522 & 36,4 & 43,3 & 24,9 & 636,9 & 36,7 & 49,3 &, 7 & 692,4 \\
\hline $14: 00$ & 31,7 & 30,9 & 24,2 & 702,9 & 46,8 & 78,5 & 30,7 & 560,5 & 40,1 & 51,4 & 27,0 & 431,4 & 37,6 & 49,8 & 25,5 & 516,8 & 35,7 & 36,1 & 25,7 & 579,6 & 35,6 & 40,3 & 25,7 & 599,3 \\
\hline $15: 00$ & 30,1 & 36,9 & 24,3 & 97,7 & 38,6 & 77,6 & 31,5 & 86,7 & 33,2 & 45,9 & 27,3 & 59,9 & 33,1 & 49,7 & 25 & 67, & 30,9 & 44,3 & 26,0 & 92,6 & 31,3 & 47,1 & 26,1 & 95,5 \\
\hline $16: 00$ & 32,0 & 28,6 & 24,2 & 336,6 & 41,1 & 76,4 & 31 & 212,7 & 37,3 & 47,4 & 27, & 176,2 & 36,3 & 45,2 & 26 & 209,8 & 34,5 & 40,6 & 26,0 & 271,3 & 3 & 46,4 & 0 & 288,4 \\
\hline $17: 00$ & 30,1 & 31,0 & 24,3 & 49,8 & 35,0 & 81,8 & 31,5 & 55,2 & 32,6 & 58,5 & 26,9 & 30,0 & 32,4 & 45,4 & 26,0 & 75,6 & 30,4 & 40,5 & 26,0 & 87,3 & 30,8 & 43,1 & 26,0 & 94,9 \\
\hline $18: 00$ & 24,6 & 56,2 & 24,2 & 2,5 & 28,0 & 95,9 & 30,9 & 8,2 & 23,0 & 87,3 & 26,5 & 24,8 & 24,3 & 72,3 & 25,8 & 2,3 & 23,6 & 67,7 & 25,6 & 11,0 & 23,4 & 72,1 & 25,6 & 17,5 \\
\hline
\end{tabular}

DIA DE COLETA DE DADOS:

04/Set

\begin{tabular}{|c|c|c|c|c|c|c|c|c|c|c|c|c|c|c|c|c|c|c|c|c|c|c|c|c|}
\hline \multirow[b]{2}{*}{ HORA } & \multicolumn{4}{|c|}{ TESTE MUNHA } & \multicolumn{4}{|c|}{$0 \%$} & \multicolumn{3}{|c|}{$5 \%$} & \multirow[b]{2}{*}{ RS } & \multicolumn{3}{|c|}{$10 \%$} & \multirow[b]{2}{*}{ RS } & \multicolumn{3}{|c|}{$15 \%$} & \multirow[b]{2}{*}{ RS } & \multicolumn{3}{|c|}{$20 \%$} & \multirow[b]{2}{*}{ RS } \\
\hline & $\mathrm{T}(\mathrm{C})$ & UR(\%) & Tsolo & RS & $\mathrm{T}(\mathrm{C})$ & $\mathrm{UR}(\%)$ & Tsolo & RS & $\mathrm{T}(\mathrm{C})$ & $\mathrm{UR}(\%)$ & Tsolo & & $\mathrm{T}(\mathrm{C})$ & $\mathrm{UR}(\%)$ & Tsolo & & $\mathrm{T}(\mathrm{C})$ & $\mathrm{UR}(\%)$ & Tsolo & & $\mathrm{T}(\mathrm{C})$ & $\mathrm{UR}(\%)$ & Tsolo & \\
\hline 08:00 & 21,0 & 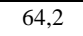 & 1,7 & 126,1 & , & 97,8 & 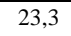 & 56,0 & 22,4 & 96,1 & 21,1 & 162,2 & 22,4 & 75,7 & 20,7 & 99,0 & 22,6 & 70,6 & 20,5 & 64,9 & 2,3 & 69,9 & 20,2 & 189,8 \\
\hline 09:00 & 24,5 & 55,4 & 19,8 & 503,7 & 34,0 & 90,7 & 23,8 & 276,1 & 30,2 & 74,5 & 21,6 & 288,3 & 29,7 & 53,2 & 21,0 & 318,4 & 28,4 & 56,6 & 20,7 & 356,3 & 28,1 & 57,7 & 20,5 & 392,1 \\
\hline $10: 00$ & 27,4 & 49,6 & 20,5 & 657,5 & 40,2 & 86,5 & 24,8 & 519,8 & 36,5 & 65,4 & 22,4 & 396,3 & 34,6 & 61,2 & 21,6 & 465,6 & 32,6 & 62,0 & 21,5 & 498,1 & 32,5 & 55,9 & 21,2 & 595,0 \\
\hline 11:00 & 29,9 & 39,9 & 21,6 & 766,5 & 44,8 & 83,6 & 26,2 & 665,7 & 39,2 & 62,7 & 23,5 & 485,7 & 37,6 & 55,8 & 22,4 & 573,6 & 35,0 & 60,1 & 22,4 & 588,3 & 35,3 & 50,8 & 22,2 & 671,1 \\
\hline 12:00 & 30,7 & 34,2 & 22,7 & 792,4 & 46,7 & 75,3 & 27,9 & 623,5 & 39,3 & 37,4 & 24,7 & 524,4 & 38,6 & 50,3 & 23,4 & 612,9 & 34,7 & 41,0 & 23,5 & 623,6 & 36,3 & 38,3 & 23,3 & 721,1 \\
\hline 13:00 & 31,9 & 33,3 & 23,6 & 737,5 & 47,6 & 74,5 & 29,4 & 618,7 & 39,8 & 47,0 & 25,7 & 474,8 & 38,2 & 50,9 & 24,3 & 573,6 & 35,6 & 49,3 & 24,5 & 616,1 & 36,4 & 51,3 & 24,3 & 673,6 \\
\hline 14:00 & 31,4 & 32,5 & 24,2 & 686,5 & 45,2 & 83,9 & 30,7 & 599,3 & 38,9 & 60,1 & 26,5 & 490,3 & 37,1 & 41,0 & 25,2 & 523,6 & 35,3 & 56,2 & 25,3 & 631,7 & 34,7 & 38,9 & 25,1 & 600,0 \\
\hline 15:00 & 32,1 & 28,7 & 24,3 & 547,2 & 45,2 & 70,2 & 31,5 & 388,5 & 38,6 & 39,1 & 26,8 & 306,9 & 37,4 & 38,6 & 25,8 & 348,5 & 34,5 & 34,2 & 25,6 & 410,1 & 35,2 & 35,2 & 25,6 & 408,9 \\
\hline 16:00 & 32,1 & 28,1 & 24,3 & 331,6 & 40,6 & 78,0 & 31,9 & 241,8 & 36,5 & 44,2 & 27,1 & 162,8 & 35,4 & 39,1 & 26,2 & 195,0 & 32,5 & 39,4 & 25,9 & 214,6 & 33,1 & 39,7 & 25,8 & 271,6 \\
\hline 17:00 & 30,8 & 31,4 & 24,3 & 48,5 & 34,2 & 82,9 & 31,7 & 51,4 & 31,8 & 51,0 & 26,9 & 27,4 & 32,0 & 41,1 & 26,3 & 62 & 29,5 & 37,8 & 26,0 & 74,0 & 30,1 & 44,4 & 25,8 & 93,6 \\
\hline 18:00 & 24,5 & 53,7 & 24,2 & 1,9 & 27,3 & 97,0 & 31,0 & 9,2 & 22,1 & 88,1 & 26,3 & 24,8 & 23,7 & 73,5 & 25,9 & 2,3 & 23,0 & 63,0 & 25,6 & 12,1 & 22,6 & 67,1 & 25,4 & 18,1 \\
\hline
\end{tabular}


DIA DE COLETA DE DADOS:

$05 /$ Set

\begin{tabular}{|c|c|c|c|c|c|c|c|c|c|c|c|c|c|c|c|c|c|c|c|c|c|c|c|c|}
\hline \multirow[b]{2}{*}{ HORA } & \multicolumn{4}{|c|}{ TESTE MUNHA } & \multicolumn{4}{|c|}{$0 \%$} & \multicolumn{3}{|c|}{$5 \%$} & \multirow[b]{2}{*}{ RS } & \multicolumn{3}{|c|}{$10 \%$} & \multirow[b]{2}{*}{ S } & \multicolumn{3}{|c|}{$15 \%$} & \multirow[b]{2}{*}{ S } & \multicolumn{3}{|c|}{$20 \%$} & \multirow[b]{2}{*}{ RS } \\
\hline & $\mathrm{T}(\mathrm{C})$ & UR(\%) & Tsolo & RS & $\mathrm{T}(\mathrm{C})$ & UR $(\%)$ & Tsolo & RS & $\mathrm{T}(\mathrm{C})$ & UR(\%) & Tsolo & & $\mathrm{T}(\mathrm{C})$ & UR $(\%)$ & Tsolo & & $\mathrm{T}(\mathrm{C})$ & $\mathrm{UR}(\%)$ & Tsolo & & $\mathrm{T}(\mathrm{C})$ & UR(\%) & Tsolo & \\
\hline $08: 00$ & 19,4 & 72,9 & 19,7 & 298,8 & 25,3 & 95,9 & 23,4 & 168,6 & 22,4 & 81,4 & 20,9 & 169,0 & 22,0 & 80,0 & 20,9 & 245,6 & 21,8 & 76,4 & 20,6 & 172,4 & 21,5 & 74,3 & 20,5 & $\overline{231,0}$ \\
\hline 09:00 & 21 , & 63,2 & 19,8 & 5 & 32,1 & 88,9 & 23,7 & $J 1$ & 28,5 & 70,8 & 21,2 & 283,1 & 27,6 & 66,7 & 21,1 & 380,3 & 5,6 & 64,7 & 8 & 82,9 & 25,6 & 67,1 & 20,6 & 412,7 \\
\hline 10:00 & 23,7 & 55,8 & 20,4 & 709,2 & 37,5 & 86,5 & 24,5 & 585,2 & 1,9 & 67,3 & 21,8 & 405,1 & 30 & 62,9 & 21,6 & 486,7 & 28,2 & 57, & 21,4 & 519,5 & 27,9 & 55,2 & 21,2 & 661,8 \\
\hline 11:00 & 26,2 & 51,6 & 21,1 & 787,3 & 41,9 & 75,9 & 25,6 & 644,3 & 34,5 & 57,0 & 22,7 & 491,4 & 33,7 & 59,3 & 22,2 & 574,8 & 30,1 & 57,4 & 22,1 & 596,4 & 31,4 & 49,4 & 21,9 & 688,6 \\
\hline 12:00 & 27,6 & 44,7 & 22,0 & 800,6 & 44,2 & 76,3 & 27,1 & 670,0 & 36,4 & 56,8 & 23,9 & 515,1 & 34,6 & 53,1 & 23,0 & 618,0 & 31,9 & 54,8 & 23,0 & 615,5 & 32,5 & 45,8 & 22,8 & 787,3 \\
\hline 13:00 & 28,1 & 46,1 & 22,7 & 735,6 & 43,1 & 75,7 & 28,5 & 601,2 & 35,9 & 55,9 & 24,9 & 428,8 & 34,6 & 58,5 & 23,7 & 571,4 & 32,0 & 59,2 & 23,8 & 569,8 & 32,4 & 47,9 & 23,5 & 668,0 \\
\hline $14: 00$ & 29,1 & 40 & 23,1 & 643 & 44,6 & 68 & 29 & 517 & 37,8 & 45,8 &, 5 & 373,0 & 36,4 & 60 & 2 & 474,7 & 32,8 & 47 & 24,5 & 507,3 & 33,7 & 41 & 13 & 559,4 \\
\hline 15:00 & 29,8 & 40,0 & 23,3 & 493,6 & 42,8 & 73,0 & 30,5 & 429,2 & 36,4 & 48,2 & 25,9 & 288,8 & 35,0 & 48,8 & 24,9 & 320,1 & 32,3 & 45,2 & 24,9 & 361,0 & 33,0 & 47,5 & 24,7 & 385,8 \\
\hline $16: 00$ & 28,8 & 42,7 & 23,3 & 269,2 & 36,5 & 77,6 & 30,8 & 200,1 & 32,1 & 50,5 & 26,0 & 153,5 & 31,8 & 51,1 & 25,4 & 171,7 & 29,0 & 50,3 & 25,1 & 211,7 & 29,9 & 50,0 & 4,9 & 241,0 \\
\hline $17: 00$ & 27,3 & 43,1 & 23,4 & 66,2 & 30,2 & 85,2 & 30,5 & 65,4 & 27,5 & 54,4 & 25,9 & 42,4 & 28,0 & 55,9 & 25,6 & 67,1 & 26,0 & 56,5 & 25,2 & 86,8 & 26,7 & 57,1 & 24,9 & 115,5 \\
\hline 18:00 & 23,6 & 56,3 & 23,1 & 2,5 & 23,7 & 95,6 & 29,7 & 11,6 & 21,9 & 73,4 & 25,4 & 5,7 & 22,7 & 68,1 & 25,3 & 2,8 & 22,1 & 70,7 & 24,8 & 15,6 & 22,1 & 67,9 & 24,7 & 2,5 \\
\hline
\end{tabular}




\section{APÊNDICE IV}

Dados obtidos no Experimento II - cultivo do rabanete na primavera 
DIA DE COLETA DE DADOS:

$22 / 11$

\begin{tabular}{|c|c|c|c|c|c|c|c|c|c|c|c|c|c|c|c|c|c|c|c|c|c|c|c|c|}
\hline \multirow[b]{2}{*}{ HORA } & \multicolumn{4}{|c|}{ TESTE MUNHA } & \multicolumn{2}{|c|}{$0 \%$} & \multirow[b]{2}{*}{ Tsolo } & \multirow[b]{2}{*}{ RS } & \multicolumn{3}{|c|}{$5 \%$} & \multirow[b]{2}{*}{ RS } & \multicolumn{2}{|c|}{$10 \%$} & \multirow[b]{2}{*}{ Tsolo } & \multirow[b]{2}{*}{ RS } & \multicolumn{3}{|c|}{$15 \%$} & \multirow[b]{2}{*}{ RS } & \multicolumn{2}{|c|}{$20 \%$} & \multirow[b]{2}{*}{ Tsolo } & \multirow[b]{2}{*}{ RS } \\
\hline & $\mathrm{T}(\mathrm{C})$ & UR $(\%)$ & Tsolo & RS & $\mathrm{T}(\mathrm{C})$ & UR(\%) & & & $\mathrm{T}(\mathrm{C})$ & UR $(\%)$ & Tsolo & & $\mathrm{T}(\mathrm{C})$ & UR $(\%)$ & & & $\mathrm{T}(\mathrm{C})$ & UR $(\%)$ & Tsolo & & $\mathrm{T}(\mathrm{C})$ & UR $(\%)$ & & \\
\hline 08:00 & 25,3 & 72,8 & 23,9 & 441,3 & 34,6 & 78,6 & 27,3 & 418,1 & 32,1 & 66,7 & 25,9 & 409,2 & 30,1 & 78,2 & 25,6 & 311,6 & 29,9 & 71,2 & 25,6 & 448,9 & 28,6 & 76,9 & 25,2 & 247,9 \\
\hline 09:00 & 26,3 & 67,6 & 24,0 & 559,8 & 40,4 & 67,3 & 28,6 & 766,9 & 37,5 & 56,6 & 26,8 & 609,2 & 32,1 & 70,2 & 25,8 & 407,1 & 34,2 & 61,8 & 27,3 & 639,2 & 30,1 & 72,1 & 25,4 & 433,9 \\
\hline 10:00 & 29,0 & 55,5 & 26,4 & 527,0 & 45,4 & 68,6 & 31,0 & 787,3 & 40,7 & 55,4 & 28,3 & 735,7 & 40,9 & 51,3 & 28,5 & 406,5 & 36,8 & 48,5 & 29,5 & 857,9 & 38,7 & 53,7 & 28,5 & 422,0 \\
\hline 11:00 & 29,9 & 58,7 & 27,1 & 979,0 & 45,2 & 62,5 & 33,0 & 208,3 & 40,3 & 51,1 & 29,8 & 186,0 & 40,0 & 48,6 & 29,5 & 806,2 & 36,9 & 55,2 & 30,7 & 217,5 & 37,5 & 47,1 & 29,4 & 845,3 \\
\hline 12:00 & 30,7 & 53,7 & 27,8 & 1090,5 & 48,3 & 65,8 & 34,4 & 862,8 & 42,8 & 44,7 & 30,9 & 847,9 & 40,7 & 59,2 & 30,6 & 889,7 & 39,5 & 55,3 & 31,5 & 902,4 & 38,6 & 56,5 & 30,4 & 872,2 \\
\hline 13:00 & 29,8 & 53,1 & 28,7 & 182,2 & 40,8 & 68,5 & 35,7 & 138,6 & 35,4 & 58,6 & 31,9 & 109,0 & 35,2 & 63,4 & 31,5 & 121,1 & 33,7 & 62,6 & 31,9 & 148,1 & 33,5 & 57,3 & 31,1 & 141,1 \\
\hline 14:00 & 33,5 & 40,2 & 28,9 & 905,8 & 49,6 & 64,2 & 36,0 & 644,8 & 44,2 & 45,8 & 32,2 & 597,8 & 42,2 & 46,6 & 31,9 & 711,8 & 40,9 & 49,7 & 32,4 & 645,0 & 39,8 & 40,9 & 31,3 & 713,6 \\
\hline 15:00 & 33,0 & 44,4 & 29,2 & 540,9 & 45,2 & 66,2 & 36,4 & 454,4 & 41,4 & 46,4 & 32,5 & 413,9 & 40,0 & 49,9 & 32,1 & 414,5 & 38,5 & 49,4 & 32,5 & 459,3 & 37,9 & 50,8 & 31,6 & 430,2 \\
\hline $16: 00$ & 31,0 & 49,1 & 29,2 & 295,0 & 39,1 & 75,9 & 36,1 & 232,1 & 36,1 & 57,5 & 32,3 & 212,4 & 35,3 & 60,3 & 32,0 & 219,5 & 34,3 & 52,6 & 32,3 & 249,3 & 33,7 & 53,5 & 31,4 & 234,1 \\
\hline 17:00 & 30,1 & 49,2 & 28,8 & 160,7 & 34,2 & 79,7 & 35,1 & 124,0 & 31,9 & 61,3 & 31,7 & 108,5 & 32,0 & 66,0 & 31,6 & 121,7 & 31,3 & 65,2 & 31,7 & 133,0 & 30,8 & 55,8 & 31,0 & 139,8 \\
\hline 18:00 & 26,7 & 57,4 & 28,1 & 39,7 & 28,2 & 82,6 & 33,8 & 36,3 & 26,5 & 70,3 & 31,0 & 47,5 & 27,1 & 69,3 & 30,9 & 31,3 & 26,7 & 72,5 & 30,8 & 39,3 & 26,5 & 65,4 & 30,3 & 52,4 \\
\hline
\end{tabular}

DIA DE COLETA DE DADOS:

$24 / 11$

\begin{tabular}{|c|c|c|c|c|c|c|c|c|c|c|c|c|c|c|c|c|c|c|c|c|c|c|c|c|}
\hline \multirow[b]{2}{*}{ HORA } & \multicolumn{4}{|c|}{ TESTE MUNHA } & \multicolumn{4}{|c|}{$0 \%$} & \multicolumn{3}{|c|}{$5 \%$} & \multirow[b]{2}{*}{ RS } & \multicolumn{3}{|c|}{$10 \%$} & \multirow[b]{2}{*}{ RS } & \multicolumn{3}{|c|}{$15 \%$} & \multirow[b]{2}{*}{ RS } & \multicolumn{3}{|c|}{$20 \%$} & \multirow[b]{2}{*}{ RS } \\
\hline & $\mathrm{T}(\mathrm{C})$ & $\mathrm{UR}(\%)$ & Tsolo & RS & $\mathrm{T}(\mathrm{C})$ & $\mathrm{UR}(\%)$ & Tsolo & RS & $\mathrm{T}(\mathrm{C})$ & $\mathrm{UR}(\%)$ & Tsolo & & $\mathrm{T}(\mathrm{C})$ & $\mathrm{UR}(\%)$ & Tsolo & & $\mathrm{T}(\mathrm{C})$ & $\mathrm{UR}(\%)$ & Tsolo & & $\mathrm{T}(\mathrm{C})$ & $\mathrm{UR}(\%)$ & Tsolo & \\
\hline 08:00 & 25,3 & 72,8 & 23,9 & 441,3 & 37,4 & 79,5 & 27,5 & 427,8 & 32,3 & 73,5 & 26,1 & 310,0 & 30,1 & 78,2 & 25,6 & 311,6 & 29,8 & 75,3 & 25,9 & 422,9 & 28,6 & 76,9 & 25,2 & 247,9 \\
\hline 09:00 & 26,3 & 67,6 & 24,0 & 559,8 & 40,6 & 69,7 & 28,8 & 611,9 & 35,6 & 58,0 & 26,9 & 487,7 & 32,1 & 70,2 & 25,8 & 407,1 & 33,0 & 65,8 & 27,0 & 619,5 & 30,1 & 72,1 & 25,4 & 433,9 \\
\hline $10: 00$ & 27,5 & 62,4 & 24,4 & 759,0 & 45,1 & 69,2 & 30,5 & 765,9 & 39,2 & 59,0 & 27,9 & 716,6 & 35,7 & 61,9 & 26,5 & 586,1 & 36,3 & 63,1 & 28,2 & 866,0 & 34,1 & 62,0 & 26,2 & 593,1 \\
\hline 11:00 & 29,0 & 60,9 & 25,0 & 11,5 & 48,5 & 74 & 32,4 & 009,1 & 40,8 & 59 & 29 & 57,5 & 38 & 60,3 & 27 & 22 & 38 & 67,7 & 29,4 & 941,7 & 36,8 & 59,0 &, 5 & 56,7 \\
\hline $12: 00$ & 30,3 & 56,4 & 25,9 & 1035,7 & 48,3 & 79,8 & 34,2 & 874,5 & 41,2 & 65,9 & 30,5 & 816,4 & 39,8 & 58,8 & 28,9 & 838,6 & 39,0 & 54,6 & 30,6 & 912,8 & 38,0 & 57,4 & 29,0 & 885,3 \\
\hline 13:00 & 30,4 & 51,8 & 27,1 & 1074,8 & 50,5 & 70,2 & 35,7 & 887,1 & 43,5 & 47,9 & 31,5 & 836,5 & 39,8 & 64,3 & 30,2 & 890,3 & 40,3 & 52,1 & 31,7 & 898,9 & 37,8 & 53,1 & 30,3 & 879,0 \\
\hline 14:00 & 31,3 & 47,7 & 28,2 & 1025,6 & 49,7 & 68,5 & 36,8 & 361,4 & 42,5 & 55,3 & 32,3 & 322,4 & 41,2 & 58,1 & 31,4 & 835,2 & 39,7 & 57,5 & 32,6 & 375,4 & 39,1 & 53,6 & 31,3 & 897,1 \\
\hline 15:00 & 32,4 & 45,0 & 29,1 & 189,7 & 47,6 & 75,1 & 36,8 & 601,2 & 42,5 & 55,5 & 32,3 & 612,3 & 42,0 & 52,0 & 32,2 & 124,5 & 40,1 & 57,0 & 32,5 & 642,1 & 39,5 & 52,0 & 32,1 & 139,8 \\
\hline 16:00 & 33,2 & 43,7 & 29,4 & 757,7 & 42,5 & 75,6 & 36,2 & 137,6 & 38,4 & 62,5 & 32,0 & 115,7 & 39,0 & 65,4 & 32,3 & 593,5 & 36,5 & 48,5 & 31,9 & 147,5 & 37,3 & 57,4 & 31,9 & 623,7 \\
\hline 17:00 & 32,6 & 44,7 & 29,4 & 131,8 & 39,6 & 74,1 & 35,5 & 168,6 & 35,9 & 57,1 & 31,6 & 151,4 & 37,1 & 50,4 & 32,0 & 96,6 & 35,1 & 64,8 & 31,5 & 173,5 & 35,7 & 50,8 & 31,5 & 109,9 \\
\hline 18:00 & 32,0 & 45,3 & 29,4 & 208,7 & 33,6 & 90,0 & 34,8 & 41,2 & 29,6 & 76,3 & 31,1 & 41,3 & 35,4 & 55,2 & 31,6 & 152,9 & 29,9 & 76,1 & 30,9 & 41,6 & 34,0 & 62,5 & 31,1 & 159,2 \\
\hline
\end{tabular}


DIA DE COLETA DE DADOS:

$25 / 11$

\begin{tabular}{|c|c|c|c|c|c|c|c|c|c|c|c|c|c|c|c|c|c|c|c|c|c|c|c|c|}
\hline \multirow[b]{2}{*}{ HORA } & \multicolumn{4}{|c|}{ TESTE MUNHA } & \multicolumn{4}{|c|}{$0 \%$} & \multicolumn{3}{|c|}{$5 \%$} & \multirow[b]{2}{*}{ RS } & \multicolumn{4}{|c|}{$10 \%$} & \multicolumn{4}{|c|}{$15 \%$} & \multicolumn{4}{|c|}{$20 \%$} \\
\hline & $\mathrm{T}(\mathrm{C})$ & $\mathrm{UR}(\%)$ & Tsolo & RS & $\mathrm{T}(\mathrm{C})$ & $\mathrm{UR}(\%)$ & Tsolo & RS & $\mathrm{T}(\mathrm{C})$ & UR(\%) & Tsolo & & $\mathrm{T}(\mathrm{C})$ & $\mathrm{UR}(\%)$ & Tsolo & RS & $\mathrm{T}(\mathrm{C})$ & $\mathrm{UR}(\%)$ & Tsolo & RS & $\mathrm{T}(\mathrm{C})$ & $\mathrm{UR}(\%)$ & Tsolo & RS \\
\hline $08: 00$ & 24,1 & 69,1 & 23,4 & 462,1 & 37,1 & 75,6 & 27,7 & 392,4 & 35,2 & $\overline{5,2}$ & 26,4 & 338,4 & 29,2 & 66,7 & 25,0 & 316,1 & 1,9 & $\overline{70,6}$ & 26,2 & 436,2 & 28,2 & 76,9 & 24,5 & $\overline{316,5}$ \\
\hline 09:00 & 28,2 & 59,9 & 24,9 & 624,7 & 40,8 & 71,0 & 29,0 & 673,9 & 38,1 & 57,9 & 27,1 & 483,1 & 35,8 & 62,3 & 26,6 & 456,5 & 35,0 & 64,0 & 27,5 & 611,4 & 34,0 & 57,4 & 26,2 & 538,8 \\
\hline 10:00 & 29,2 & 59,6 & 25,3 & 733,8 & 45,0 & 71,7 & 30,4 & 794,0 & 40,9 & 58,0 & 28,1 & 516,2 & 37,1 & 60,1 & 27,0 & 575,9 & 37,0 & 51,5 & 28,4 & 885,6 & 35,1 & 58,2 & 26,6 & 574,4 \\
\hline 11:00 & 29,9 & 52,5 & 25,9 & 895,8 & 46,1 & 79,8 & 31,9 & 819,2 & 41,1 & 64,1 & 29,2 & 626,2 & 39,7 & 60,3 & 28,0 & 717,5 & 38,6 & 70,4 & 29,4 & 856,7 & 37,3 & 47,1 & 27,7 & 767,3 \\
\hline 12:00 & 31, & 45,8 & 26,7 & 973,9 & 46,3 & 77,5 & 33 & 864, & 41,2 & 50,9 & 30,4 & 885 & 40,1 & 54,7 & 29,2 & 799 & 38,4 & 49,0 & 30,4 & 905,3 & 38,2 & 52,5 & 29,0 & 873,4 \\
\hline 13:00 & 32,4 & 38,8 & 27,7 & 1038,9 & 45,4 & 71,0 & 34 & 779,5 & 41,4 & 53,8 & 31,4 & 748,2 & 40,1 & 49,6 & 30,2 & 863,0 & 39,2 & 37,2 & 31,2 & 843,4 & 37,9 & 59,8 & 30,2 & 841,6 \\
\hline 14:00 & 33,4 & 33,1 & 28,6 & 998,5 & 48,0 & 72,5 & 35,0 & 681,2 & 43,3 & 47,9 & 31,9 & 688,7 & 40,3 & 48,5 & 31,3 & 817,0 & 40,2 & 58,7 & 31,8 & 738,1 & 38,0 & 43,2 & 31,1 & 957,7 \\
\hline 15:00 & 34,5 & 32,1 & 29,2 & 578,7 & 44,5 & 56,2 & 35,5 & 453,0 & 39,5 & 42,2 & 32,0 & 461,9 & 40,8 & 54,1 & 32,0 & 444,6 & 37,5 & 41,0 & 32,1 & 488,2 & 38,5 & 49,4 & 31,5 & 485,7 \\
\hline $16: 00$ & 34,0 & 33,9 & 29,5 & 168,9 & 40,9 & 59,4 & 35,3 & 338,2 & 37,9 & 51,9 & 31,7 & 344,1 & 39,7 & 45,4 & 32,4 & 120,0 & 36,5 & 48,5 & 31,8 & 444,8 & 37,1 & 37,2 & 31,7 & 128,6 \\
\hline $17: 00$ & 33,4 & 36,1 & 29,4 & 464,0 & 37,5 & 58,7 & 34,6 & 179,7 & 34,5 & 49,2 & 31,3 & 161,7 & 37,1 & 43,0 & 32,1 & 353,1 & 33,7 & 48,7 & 31,3 & 185,1 & 34,8 & 44,8 & 31,5 & 344,0 \\
\hline 18:00 & 32,9 & 35,6 & 28,9 & 262,2 & 28,8 & 79,2 & 33,5 & 36,8 & 27,4 & 67,3 & 30,6 & 54,3 & 34,7 & 48,0 & 31,8 & 197,3 & 27,5 & 65,3 & 30,4 & 42,8 & 33,0 & 48,2 & 30,9 & 187,9 \\
\hline
\end{tabular}

DIA DE COLETA DE DADOS:

$26 / 11$

\begin{tabular}{|c|c|c|c|c|c|c|c|c|c|c|c|c|c|c|c|c|c|c|c|c|c|c|c|c|}
\hline \multirow[b]{2}{*}{ HORA } & \multicolumn{4}{|c|}{ TESTE MUNHA } & \multicolumn{4}{|c|}{$0 \%$} & \multicolumn{3}{|c|}{$5 \%$} & \multirow[b]{2}{*}{ RS } & \multicolumn{3}{|c|}{$10 \%$} & \multirow[b]{2}{*}{ RS } & \multicolumn{3}{|c|}{$15 \%$} & \multirow[b]{2}{*}{ RS } & \multicolumn{3}{|c|}{$20 \%$} & \multirow[b]{2}{*}{ RS } \\
\hline & $\mathrm{T}(\mathrm{C})$ & $\mathrm{UR}(\%)$ & Tsolo & RS & $\mathrm{T}(\mathrm{C})$ & UR(\%) & Tsolo & RS & $\mathrm{T}(\mathrm{C})$ & $\mathrm{UR}(\%)$ & Tsolo & & $\mathrm{T}(\mathrm{C})$ & $\mathrm{UR}(\%)$ & Tsolo & & $\mathrm{T}(\mathrm{C})$ & $\mathrm{UR}(\%)$ & Tsolo & & $\mathrm{T}(\mathrm{C})$ & $\mathrm{UR}(\%)$ & Tsolo & \\
\hline $08: 00$ & 24,1 & 69,1 & 23,4 & 462,1 & 34,2 & 72,6 & 26,0 & 479,1 & 31,0 & 66,4 & 25,2 & 360,6 & 29,2 & 66,7 & 25,0 & 316,1 & 28,8 & 67,4 & 25,1 & 449,5 & 28,2 & 76,9 & 24,5 & 316,5 \\
\hline 09:00 & 25,1 & 66,8 & 23,6 & 570,5 & 40,1 & 68,8 & 27,5 & 767,9 & 36,5 & 60,2 & 25,9 & 600,4 & 30,9 & 63,6 & 25,2 & 398,5 & 33,7 & 63,2 & 26,2 & 621,8 & 29,6 & 71,0 & 24,8 & 430,8 \\
\hline 10:00 & 27,9 & 54,9 & 24,2 & 788,6 & 44,0 & 69,6 & 28,8 & 786,8 & 38,1 & 56,5 & 27,0 & 751,3 & 35,8 & 56,4 & 25,9 & 604,3 & 36,1 & 63,8 & 27,2 & 762,4 & 33,7 & 62,3 & 25,6 & 621,2 \\
\hline 11:00 & 29,2 & 51,0 & 24,8 & 926,0 & 49,0 & 61,4 & 30,5 & 957,3 & 42,2 & 54,3 & 28,3 & 800,9 & 37,3 & 52,1 & 26,8 & 736,8 & 38,7 & 44,7 & 28,2 & 830,1 & 35,6 & 51,9 & 26,6 & 801,6 \\
\hline 12:00 & 30,9 & 48,2 & 25,6 & 997,9 & 48,9 & 60,2 & 32,1 & 843,9 & 42,2 & 46,1 & 29,5 & 814,3 & 40,6 & 54,7 & 28,0 & 811,3 & 39,5 & 58,7 & 29,3 & 864,8 & 38,6 & 52,5 & 27,9 & 866,5 \\
\hline 13:00 & 31,8 & 42,8 & 26,9 & 1020,6 & 49,4 & 60,3 & 33,6 & 824,6 & 43,0 & 47,9 & 30,4 & 824,1 & 41,5 & 54,3 & 29,2 & 844,8 & 40,3 & 47,9 & 30,2 & 879,3 & 39,2 & 40,5 & 28,9 & 829,7 \\
\hline $14: 00$ & 33,6 & 36,1 & 27,8 & 1022,5 & 45,2 & 64,1 & 34,4 & 179,7 & 39,6 & 39,4 & 30,8 & 165,9 & 41,8 & 58,1 & 30,3 & 831,7 & 37,4 & 53,2 & 30,8 & 192,6 & 39,5 & 57,6 & 29,8 & 957,1 \\
\hline 15:00 & 33,9 & 34,8 & 28,6 & 658,1 & 41,4 & 86,2 & 34,5 & 541,6 & 38,6 & 65,2 & 30,8 & 534,2 & 38,9 & 60,9 & 31,1 & 492,3 & 36,4 & 67,4 & 30,7 & 586,0 & 37,1 & 57,6 & 30,4 & 511,9 \\
\hline $16: 00$ & 33,2 & 36,5 & 28,7 & 714,8 & 42,8 & 68,5 & 34,4 & 326,0 & 40,2 & 54,3 & 30,6 & 335,3 & 35,3 & 47,6 & 31,1 & 561,7 & 37,5 & 56,3 & 30,6 & 426,3 & 33,6 & 51,6 & 30,3 & 558,8 \\
\hline 17:00 & 33,6 & 32,7 & 28,7 & 486,7 & 37,5 & 68,4 & 34,0 & 177,8 & 35,4 & 52,9 & 30,4 & 167,9 & 38,1 & 46,8 & 31,1 & 387,2 & 33,7 & 52,2 & 30,2 & 182,2 & 35,7 & 50,3 & 30,2 & 361,5 \\
\hline 18:00 & 32,8 & 32,5 & 28,4 & 249,0 & 29,9 & 88,0 & 33,2 & 32,0 & 27,3 & 61,6 & 29,9 & 39,8 & 35,2 & 42,0 & 30,8 & 183,6 & 27,6 & 61,0 & 29,5 & 34,7 & 32,9 & 41,6 & 30,0 & 175,4 \\
\hline
\end{tabular}


DIA DE COLETA DE DADOS:

$27 / 11$

\begin{tabular}{|c|c|c|c|c|c|c|c|c|c|c|c|c|c|c|c|c|c|c|c|c|c|c|c|c|}
\hline \multirow[b]{2}{*}{ HORA } & \multicolumn{4}{|c|}{ TESTE MUNHA } & \multicolumn{4}{|c|}{$0 \%$} & \multicolumn{3}{|c|}{$5 \%$} & \multirow[b]{2}{*}{ RS } & \multicolumn{4}{|c|}{$10 \%$} & \multicolumn{4}{|c|}{$15 \%$} & \multicolumn{4}{|c|}{$20 \%$} \\
\hline & $\mathrm{T}(\mathrm{C})$ & UR(\%) & Tsolo & RS & $\mathrm{T}(\mathrm{C})$ & $\mathrm{UR}(\%)$ & Tsolo & RS & $\mathrm{T}(\mathrm{C})$ & $\mathrm{UR}(\%)$ & Tsolo & & $\mathrm{T}(\mathrm{C})$ & $\mathrm{UR}(\%)$ & Tsolo & RS & $\mathrm{T}(\mathrm{C})$ & $\mathrm{UR}(\%)$ & Tsolo & RS & $\mathrm{T}(\mathrm{C})$ & $\mathrm{UR}(\%)$ & Tsolo & RS \\
\hline 08:00 & $\overline{24,}$ & 69,1 & 23,4 & 462,1 & 37,0 & 74,6 & 26,4 & 406,0 & 33,4 & 67,1 & 25,3 & 329,6 & 29,2 & 66,7 & 25,0 & 316,1 & 1,2 & $\overline{71,4}$ & 24,9 & 441,4 & 37,1 & 76,9 & 30,4 & $\overline{511,9}$ \\
\hline 09:00 & 25,9 & 75,1 & 24,5 & 539,0 & 41,1 & 67,5 & 27,6 & 713,1 & 37,5 & 46,9 & 25,9 & 566,3 & 32,5 & 77,4 & 25,9 & 419,0 & 35,1 & 60,9 & 25,8 & 601,6 & 33,6 & 51,6 & 30,3 & 558,8 \\
\hline 10:00 & 28,0 & 60,2 & 25,0 & 723,7 & 42,4 & 69,9 & 29,1 & 822,6 & 38,6 & 57,4 & 26,9 & 773,5 & 36,8 & 68,1 & 26,4 & 599,2 & 37,1 & 68,8 & 26,9 & 809,8 & 34,2 & 61,0 & 26,0 & 566,9 \\
\hline 11:00 & 30,8 & 44,1 & 24,9 & 931,1 & 43,5 & 61,2 & 30,6 & 431,2 & 39,0 & 54,6 & 28,0 & 381,8 & 38,6 & 60,3 & 26,7 & 733,4 & 37,4 & 65,6 & 28,7 & 417,6 & 36,9 & 52,4 & 26,6 & 761,7 \\
\hline $12: 00$ & 31, & 46,1 & 26,2 & 627,9 & 45,2 & 54,7 & 32 & 274 & 40,2 & 45,2 & 28,9 & 255 & 39 , & 54,8 & 27 & 488,9 & 38,9 & 62,5 & 30,2 & 282,9 & 38,0 & 56,2 & 27,9 & 505,7 \\
\hline 13:00 & 33,2 & 43,2 & 27,7 & 427,4 & 46,1 & 69,2 & 33,1 & 708,3 & 41,4 & 47,4 & 29,7 & 672,7 & 41,8 & 49,8 & 29,0 & 325,2 & 39,6 & 49,9 & 30,6 & 730,0 & 40,1 & 46,0 & 29,0 & 331,5 \\
\hline 14:00 & 33,6 & 39,2 & 28,2 & 834,6 & 45,1 & 76,5 & 33,8 & 183,6 & 40,6 & 58,4 & 30,2 & 169,0 & 40,7 & 57,3 & 30,0 & 682,8 & 38,9 & 49,2 & 30,8 & 197,8 & 39,0 & 51,8 & 29,8 & 697,4 \\
\hline $15: 00$ & 33,4 & 41,7 & 28,6 & 752,7 & 39,7 & 75,6 & 33,7 & 175,9 & 36,1 & 55,2 & 30,2 & 159,1 & 39,7 & 63,0 & 30,6 & 606,0 & 34,1 & 49,4 & 30,6 & 186,8 & 37,8 & 57,3 & 30,1 & 611,2 \\
\hline $16: 00$ & 32,0 & 41,9 & 28,8 & 215,0 & 34,7 & 83,5 & 33,2 & 93,5 & 32,0 & 58,0 & 30,0 & 80,1 & 35,7 & 59,1 & 30,6 & 165,4 & 30,9 & 61,9 & 30,1 & 101,2 & 34,2 & 53,3 & 30,1 & 174,8 \\
\hline $17: 00$ & 31,3 & 41,3 & 28,6 & 116,0 & 33,0 & 88,7 & 32,4 & 83,3 & 30,1 & 68,4 & 29,5 & 70,8 & 31,8 & 55,7 & 30,4 & 87,6 & 29,6 & 64,0 & 29,6 & 87,3 & 30,4 & 56,4 & 29,7 & 106,1 \\
\hline $18: 00$ & 29,1 & 54,0 & 28,3 & 87,0 & 29,3 & 86,8 & 31,7 & 32,9 & 27,5 & 68,2 & 29,2 & 43,9 & 30,4 & 80,8 & 30,0 & 69,9 & 27,4 & 71,4 & 29,1 & 37,0 & 29,5 & 69,1 & 29,3 & 94,9 \\
\hline
\end{tabular}

DIA DE COLETA DE DADOS:

$28 / 11$

\begin{tabular}{|c|c|c|c|c|c|c|c|c|c|c|c|c|c|c|c|c|c|c|c|c|c|c|c|c|}
\hline \multirow[b]{2}{*}{ HORA } & \multicolumn{4}{|c|}{ TESTE MUNHA } & \multicolumn{4}{|c|}{$0 \%$} & \multicolumn{3}{|c|}{$5 \%$} & \multirow[b]{2}{*}{ RS } & \multicolumn{3}{|c|}{$10 \%$} & \multirow[b]{2}{*}{ RS } & \multicolumn{3}{|c|}{$15 \%$} & \multirow[b]{2}{*}{ RS } & \multicolumn{3}{|c|}{$20 \%$} & \multirow[b]{2}{*}{ RS } \\
\hline & $\mathrm{T}(\mathrm{C})$ & UR(\%) & Tsolo & RS & $\mathrm{T}(\mathrm{C})$ & $\mathrm{UR}(\%)$ & Tsolo & RS & $\mathrm{T}(\mathrm{C})$ & UR(\%) & Tsolo & & $\mathrm{T}(\mathrm{C})$ & $\mathrm{UR}(\%)$ & Tsolo & & $\mathrm{T}(\mathrm{C})$ & UR(\%) & Tsolo & & $\mathrm{T}(\mathrm{C})$ & UR(\%) & Tsolo & \\
\hline $08: 00$ & 24, & 69,1 & 23,4 & 462,1 &, 5 & 78,5 & 26 & 450,6 & 34,0 & 65,6 & 25,8 & 317,2 & 29,2 & 66,7 & 25,0 & 316,1 & 30,8 & 70,3 & 25,8 & 420,0 & 7,1 & 76,9 & 30,4 & 11,9 \\
\hline 09:00 & 25,9 & 75,1 & 24,5 & 539,0 & 42,4 & 71,7 & 28,1 & 632,7 & 38,2 & 55,4 & 26,3 & 448,5 & 32,5 & 77,4 & 25,9 & 419,0 & 35,0 & 67,3 & 26,6 & 593,5 & 30,3 & 74,5 & 25,5 & 437,6 \\
\hline $10: 00$ & 28,0 & 60,2 & 25,0 & 723,7 & 45,4 & 73,1 & 30,0 & 721,9 & 39,6 & 55,2 & 27,1 & 531,1 & 36,8 & 68,1 & 26,4 & 599,2 & 36,8 & 53,7 & 28,1 & 723,7 & 34,2 & 61,0 & 26,0 & 566,9 \\
\hline $11: 00$ & 29,3 & 60,2 & 26,2 & 872,4 & 47,4 & 66,4 & 31,8 & 414,7 & 41,1 & 50,2 & 27,9 & 322,4 & 38,5 & 69,1 & 27,1 & 705,5 & 37,6 & 61,5 & 29,5 & 406,1 & 36,3 & 66,7 & 27,2 & 689,9 \\
\hline $12: 00$ & 30,4 & 55,2 & 27,6 & 879,4 & 49,2 & 70,8 & 32,7 & 778,0 & 43,1 & 53,0 & 28,7 & 655,7 & 40,4 & 66,8 & 28,1 & 704,4 & 40,0 & 54,2 & 29,7 & 793,1 & 37,3 & 63,8 & 28,4 & 751,0 \\
\hline 13:00 & 32,5 & 50,8 & 28,2 & 886,3 & 36,5 & 73,0 & 33,7 & 357, & 32,3 & 64,3 & 29,2 & 320,3 & 42,6 & 59,1 & 28 & 717,5 & 32,6 & 74,1 & 30,1 & 363,3 & 39,0 & 48,5 & 29,0 & 721,7 \\
\hline $14: 00$ & 27,9 & 59,7 & 28,7 & 452,0 & 33,2 & 85,1 & 33,1 & 282,9 & 30,2 & 67,3 & 29,1 & 266,6 & 33,9 & 68,7 & 29 , & 339,4 & 29,7 & 80,4 & 29,6 & 296,2 & 32,6 & 69,5 & 29,5 & 353,4 \\
\hline $15: 00$ & 26,3 & 64,6 & 28,4 & 368,1 & 32,6 & 84,2 & 32,3 & 112,9 & 29,3 & 79,0 & 28,9 & 97,7 & 29,9 & 80,1 & 29,7 & 280,9 & 28,8 & 75,7 & 29,3 & 119,7 & 29,1 & 77,3 & 29,3 & 302,8 \\
\hline $16: 00$ & 26,9 & 59,8 & 28,0 & 134,3 & 25,6 & 88, & 31 & 7, & 23,7 & 85,0 & 28,5 & 7,2 & 29,9 & 76,1 & 29 & 98, & 24,0 & 89,1 & 28,7 & 9, & 28,7 & 70,6 & 28,9 & 123,6 \\
\hline $17: 00$ & 24,1 & 70,6 & 27,5 & 3,2 & 24,0 & 96,6 & 30,3 & 20,8 & 22,4 & 96,3 & 27,9 & 7,2 & 24,7 & 84,5 & 29,0 & 8,0 & 22,7 & 98,5 & 28,0 & 22,0 & 24,1 & 78,1 & 28,4 & 10,6 \\
\hline $18: 00$ & 20,5 & 93,9 & 26,7 & 15,8 & 24,2 & 96,8 & 29,5 & 14,0 & 22,3 & 96,8 & 27,5 & 6,2 & 22,9 & 97,2 & 28,4 & 3,4 & 22,5 & 98,9 & 27,5 & 13,9 & 21,8 & 96,7 & 27,8 & 31,2 \\
\hline
\end{tabular}


DIA DE COLETA DE DADOS:

$29 / 11$

\begin{tabular}{|c|c|c|c|c|c|c|c|c|c|c|c|c|c|c|c|c|c|c|c|c|c|c|c|c|}
\hline \multirow[b]{2}{*}{ HORA } & \multicolumn{4}{|c|}{ TESTE MUNHA } & \multicolumn{4}{|c|}{$0 \%$} & \multicolumn{3}{|c|}{$5 \%$} & \multirow[b]{2}{*}{ RS } & \multicolumn{3}{|c|}{$10 \%$} & \multirow[b]{2}{*}{ RS } & \multicolumn{3}{|c|}{$15 \%$} & \multirow[b]{2}{*}{ RS } & \multicolumn{3}{|c|}{$20 \%$} & \multirow[b]{2}{*}{ RS } \\
\hline & $\mathrm{T}(\mathrm{C})$ & UR(\%) & Tsolo & RS & $\mathrm{T}(\mathrm{C})$ & $\mathrm{UR}(\%)$ & Tsolo & RS & $\mathrm{T}(\mathrm{C})$ & $\mathrm{UR}(\%)$ & Tsolo & & $\mathrm{T}(\mathrm{C})$ & $\mathrm{UR}(\%)$ & Tsolo & & $\mathrm{T}(\mathrm{C})$ & $\mathrm{UR}(\%)$ & Tsolo & & $\mathrm{T}(\mathrm{C})$ & $\mathrm{UR}(\%)$ & Tsolo & \\
\hline $08: 00$ & 24 & 69,1 & 23,4 & 462,1 & 35,6 & 78,9 & $\overline{25}$ & 457, & 29,9 & 77,9 & 24,8 & $\overline{385,4}$ & 29,2 & 66,7 & $\overline{2}$ & 316,1 & $\overline{7,3}$ & $\overline{88,4}$ & 24,6 & $\overline{53,5}$ & 1 & 76,9 & 30,4 & 11,9 \\
\hline 09:00 & 25,2 & 71,9 & 23,1 & 701,0 & 42,5 & 70,9 & 27,1 & 758,2 & 35,9 & 59,7 & 25,3 & 517,7 & 32,9 & 66,8 & 24,9 & 487,8 & 32,4 & 73,1 & 25,2 & 635,7 & 31,0 & 72,4 & 24,6 & 671,8 \\
\hline $10: 00$ & 25,4 & 71,5 & 23,3 & 778,5 & 48,6 & 65,7 & 28,6 & 822,6 & 40,0 & 53,3 & 26,0 & 622,6 & 35,4 & 66,9 & 25,2 & 600,4 & 36,3 & 68,7 & 26,0 & 823,1 & 33,1 & 67,3 & 24,9 & 609,3 \\
\hline $11: 00$ & 26,8 & 66,9 & 24,2 & 1028,8 & 50,5 & 70,9 & 30,4 & 213,2 & 41,2 & 62,3 & 27,1 & 182,9 & 38,4 & 65,1 & 26,0 & 848,2 & 37,8 & 56,8 & 27,6 & 242,4 & 36,3 & 57,4 & 26,0 & 893,4 \\
\hline $12: 00$ & 27,9 & 63,7 & 25,5 & 1132,1 & 44,0 & 70,2 & 31,5 & 185,6 & 35,9 & 64,3 & 27,8 & 157,1 & 39,8 & 62,3 & 27,0 & 902,2 & 33,5 & 60,3 & 28,1 & 204,8 & 38,4 & 46,4 & 27,2 & 934,0 \\
\hline $13: 00$ & 28,1 & 62,6 & 26,6 & 319,6 & 47,4 & 68,4 & 32 & 22 & 39,1 & 56,0 & 28 & 686,1 & 35 & 76,3 & 27 & 25 & 35,6 & 56, & 28 & 839,9 & 34,1 & 58,1 & 27,8 & 264,7 \\
\hline $14: 00$ & 29,2 & 54,2 & 27,1 & 307,6 & 44,6 & 73,5 & 33,0 & 495,1 & 37,4 & 62,9 & 28,7 & 409,2 & 37,8 & 61,8 & 28,3 & 224,6 & 34,5 & 58,2 & 28,7 & 502,1 & 36,1 & 50,5 & 28,2 & 241,0 \\
\hline $15: 00$ & 28,8 & 56,6 & 27,5 & 673,2 & 43,6 & 70,6 & 33,2 & 404,0 & 37,1 & 57,9 & 28,8 & 316,2 & 35,9 & 56,6 & 28,8 & 523,0 & 34,5 & 57,7 & 28,9 & 395,1 & 34,7 & 52,6 & 28,5 & 545,0 \\
\hline $16: 00$ & 29,0 & 56,2 & 27,6 & 643,0 & 43,9 & 71, & 33 & 31 & 38,4 & 61 & 28 & 25 & 35, & 69,1 & 29 & 507,7 & 35,2 & 62,6 & 29,0 & 330,9 & 33,7 & 62,4 & 6 & 513,8 \\
\hline $17: 00$ & 29,6 & 56,3 & 27,6 & 419,8 & 35,1 & 84,2 & 33,2 & 188,0 & 30,3 & 73,2 & 28,9 & 143,6 & 36,2 & 63,1 & 29,2 & 324,6 & 29,0 & 72,3 & 28,7 & 200,7 & 34,2 & 63,5 & 28,7 & 320,3 \\
\hline $18: 00$ & 28,4 & 58,1 & 27,5 & 197,9 & 31,0 & 90,2 & 32,4 & 38,8 & 26,2 & 86,2 & 28,5 & 42,9 & 29,7 & 73,4 & 29,1 & 150,7 & 26,2 & 86,4 & 28,3 & 45,1 & 28,6 & 69,5 & 28,5 & 167,9 \\
\hline
\end{tabular}

DIA DE COLETA DE DADOS:

$30 / 11$

\begin{tabular}{|c|c|c|c|c|c|c|c|c|c|c|c|c|c|c|c|c|c|c|c|c|c|c|c|c|}
\hline \multirow[b]{2}{*}{ HORA } & \multicolumn{4}{|c|}{ TESTE MUNHA } & \multicolumn{4}{|c|}{$0 \%$} & \multicolumn{3}{|c|}{$5 \%$} & \multirow[b]{2}{*}{ RS } & \multicolumn{3}{|c|}{$10 \%$} & \multirow[b]{2}{*}{ RS } & \multicolumn{4}{|c|}{$15 \%$} & \multicolumn{3}{|c|}{$20 \%$} & \multirow[b]{2}{*}{ RS } \\
\hline & $\mathrm{T}(\mathrm{C})$ & $\mathrm{UR}(\%)$ & Tsolo & RS & $\mathrm{T}(\mathrm{C})$ & UR(\%) & Tsolo & RS & $\mathrm{T}(\mathrm{C})$ & UR(\%) & Tsolo & & $\mathrm{T}(\mathrm{C})$ & UR(\%) & Tsolo & & $\mathrm{T}(\mathrm{C})$ & $\mathrm{UR}(\%)$ & Tsolo & RS & $\mathrm{T}(\mathrm{C})$ & UR(\%) & Tsolo & \\
\hline 08:00 & 1 & 69,1 & 23,4 & 462,1 & 26,2 & 99,1 & 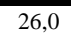 & 0,7 & , & 97,8 & $\overline{4,9}$ & 96,6 &, 2 & 5,7 & 25,0 & 16,1 & 6 & 98,3 & 4,6 & 69,5 & 1 & $\overline{6,9}$ & $\overline{0,4}$ & 11,9 \\
\hline 09:00 & 20,5 & 92, & 23,6 & 211, & 28 & 94, & 26 & 13,2 & 25 , & 89 & 25,2 & 226,3 & 23,8 & 98,1 & 24 & 42 & 24,3 & 92,9 & 24,7 & 256,8 & 23,1 & 97,9 & .5 & 114,9 \\
\hline 10:00 & 21,4 & 86,1 & 23,7 & 242,1 & 37,8 & 80,9 & 27,1 & 383,2 & 32,4 & 68,7 & 25,4 & 343,6 & 24,5 & 90,3 & 25,0 & 178,5 & 29,5 & 77,9 & 25,2 & 422,9 & 23,8 & 91,7 & 24,7 & 209,1 \\
\hline 11:00 & 23,7 & 75,0 & 23,9 & 383,9 & 34,1 & 77,0 & 27,7 & 216,1 & 28,2 & 77,1 & 25,8 & 201,0 & 30,9 & 74,7 & 25,3 & 284,8 & 26,8 & 82,4 & 25,5 & 239,5 & 29,6 & 73,6 & 25,0 & 327,1 \\
\hline $12: 00$ & 23,2 & 75,0 & 24,3 & 255,3 & 36,9 & 75,9 & 28,2 & 344,5 & 30,3 & 71,2 & 26,0 & 291,9 & 28,2 & 79,2 & 25,6 & 181,9 & 28,1 & 81,5 & 25,7 & 361,5 & 27,5 & 78,0 & 25,4 & 225,4 \\
\hline 13:00 & 23,8 & 72,8 & 24,4 & 339,1 & 42,9 & 72,9 & 29,0 & 518,4 & 34,8 & 68,0 & 26,4 & 425,2 & 29,8 & 75,6 & 25,8 & 246,7 & 31,7 & 79,5 & 26,2 & 514,8 & 29,1 & 75,2 & 25,6 & 287,2 \\
\hline 14:00 & 25,7 & 68,0 & 24,8 & 643,0 & 42,0 & 77,1 & 30,0 & 729,1 & 34,0 & 69,8 & 26,8 & 644,8 & 32,6 & 69,0 & 26,2 & 485,0 & 31,7 & 79,3 & 26,6 & 706,9 & 32,0 & 63,8 & 25,9 & 525,0 \\
\hline 15:00 & 26,5 & 63,8 & 25,4 & 592,6 & 38,7 & (1), & $30, J$ & 220,9 & 30,9 & 72,6 & 27,2 & 183,4 & 32,3 & 75,7 & 26,7 & 456,5 & 29,3 & 79,6 & 27,0 & 237,2 & 31,7 & 75,9 & 26,4 & 486,3 \\
\hline $16: 00$ & 26,4 & 63,4 & 25,6 & 252,2 & 36,7 & 82,3 & 30,7 & 213,2 & 30,2 & 81,2 & 27,3 & 180,3 & 31,0 & 72,9 & 27,1 & 183,6 & 28,4 & 81,8 & 27,0 & 232,5 & 30,2 & 75,3 & 26,7 & 209,1 \\
\hline $17: 00$ & 25,9 & 65,2 & 25,8 & 215,6 & 35,7 & 80,3 & 30,6 & 217,5 & 29,3 & 79,5 & 27,3 & 184,5 & 29,1 & 77,5 & 27,2 & 158,6 & 28,1 & 81,5 & 26,9 & 233,7 & 28,5 & 78,2 & 26,8 & 188,5 \\
\hline 18:00 & 25,7 & 64,8 & 25,6 & 223,2 & 28,7 & 90,8 & 30,2 & 46,5 & 23,8 & 87,9 & 27,1 & 54,8 & 28,7 & 73,7 & 27,2 & 163,2 & 24,0 & 85,9 & 26,6 & 56,7 & 28,0 & 76,7 & 26,7 & 184,8 \\
\hline
\end{tabular}

